\title{
EVALUATION OF THE PERFORMANCE CHARACTERISTICS OF THE NORTH AMERICAN LIGHTNING DETECTION NETWORK BASED ON EXTENSIVE CN TOWER LIGHTNING DATA
}

by

Savdulla Kazazi

M. Eng., Ryerson University, Toronto, ON, Canada, 2011

B. Sc., University of Tirana, Tirana, Albania, 1987

\author{
A dissertation \\ presented to Ryerson University \\ in partial fulfillment of the \\ requirements for the degree of \\ Doctor of Philosophy \\ in the program of \\ Electrical and Computer Engineering
}

Toronto, Ontario, Canada, 2016

(C) Savdulla Kazazi 2016 


\section{Author's Declaration}

I hereby declare that I am the sole author of this dissertation. This is a true copy of the dissertation, including any required final revisions, as accepted by my examiners.

I authorize Ryerson University to lend this dissertation to other institutions or individuals for the purpose of scholarly research.

I further authorize Ryerson University to reproduce this dissertation by photocopying or by other means, in total or in part, at the request of other institutions or individuals for the purpose of scholarly research.

I understand that my dissertation may be made electronically available to the public. 


\begin{abstract}
Evaluation of the Performance Characteristics of the North American Lightning Detection Network Based on Extensive CN Tower Lightning Data
\end{abstract}

Savdulla Kazazi

Doctor of Philosophy, Department of Electrical and Computer Engineering, Ryerson University, Toronto, 2016

The North American Lightning Detection Network (NALDN) has been providing lightning data since 1998. Important applications, such as detection of lightning-caused forest fires, power line fault locations and aviation safety procedures, have triggered a number of hardware and software upgrades for improving the network performance characteristics, including its detection efficiency and location accuracy. The NALDN performance characteristics are here evaluated based on the lightning currents measured at the CN Tower during three major storms (2005, 2011 and 2014). Each of these three storms followed one of the network's substantial upgrades that took place in 2003-2004, 2010-2011 and 2013-2014. The major contribution of this extensive investigation is the determination of the network's performance characteristics following each of the three major upgrades, which is expected to lead to additional upgrades. Since 1990, the lightning current derivatives of return strokes have been measured at the $\mathrm{CN}$ Tower. Its 553-m height has allowed the recording of the current derivative signals of many hundreds of return strokes. Also, imaging systems have been used to record trajectories of flashes to the tower. The evaluated performance characteristics of the network include returnstroke detection efficiency, location accuracy, and return-stroke polarity and peak current 
estimation. The 2013 NALDN deployment of LS7002 digital sensors with enhanced embedded software has substantially improved the sensitivity of the sensors leading to a greater returnstroke detection efficiency. Furthermore, the 2014 total lightning processor (TLP100) designed with new algorithm - provides smaller time-of-arrival errors, leading to better location accuracy. Based on the 2014 storm evaluation, the numbers and polarities of NALDN-detected return strokes were perfectly matched with those recorded at the tower. Furthermore, based on the 2014 storm evaluation, the NALDN is found, as expected, to overestimate the current peak measured at the tower by a factor of 3.89 , which is due to the field enhancement effect resulting from the high-speed of propagation of the current within the tall tower. The presented analysis shows that the latest NALDN upgrades (2013-2014), following the 2003-2004 and 2010-2011 upgrades, have substantially improved the NALDN performance characteristics, especially in terms of stroke-detection efficiency and location accuracy.

Keywords: Tall-structure lightning; lightning detection; detection efficiency; location accuracy; peak current estimation. 


\section{ACKNOWLEDGMENTS}

I would like to express my special appreciation and thanks to my advisor Professor Dr. Ali M. Hussein; you have been a remarkable mentor for me. I would like to thank you for encouraging and motivating me to grow as a research scientist. Your advice and criticism on my research have been invaluable.

I would like to thank Environment Canada for providing lightning data from the Canadian Lightning Detection Network. Ryerson University continuous research/financial support is thankfully acknowledged. Also, the financial support of the Natural Sciences and Engineering Research Council (NSERC) of Canada is gratefully acknowledged.

I would like to thank Mr. Petros Liatos for the high-speed and regular-speed optical recordings of CN Tower flash trajectories during 2013-2014. I would also like to thank students, with whom I had the opportunity to work with, for their help in the success of the measurement campaign, namely, M.S. Rahimian, M. Anwar, M. Yusouf, H. Hajihassen, M. Morelli and J. MacPherson. The provision of lightning images for the 2011 storm, by video amateurs P. Weiss and W. S. Tho, is much appreciated. I would like to acknowledge the contribution of G. Arias and F. Roman, from National Instruments, for their technical support. Also, I would like to thank M. Milewski, D. Pavanello, E. Petrache, I. Boev, S. Faisal, and F. Jabar for their help in acquiring the $2005 \mathrm{CN}$ Tower lightning data.

I would like to thank my employer, Humber Institute of Technology and Advanced Learning, for helping me during these years with the workload, time schedule and financial support.

A special thank you goes to my family. Words cannot express how grateful I am to my parents, my wife and my daughters for all the sacrifices they have made, for spending sleepless nights with and were always my support in the moments when there was no one to answer my queries. Your prayers were what sustained me thus far. I would also like to thank all of my friends, especially M. Cassidy, who supported me to strive towards my goal. 
Table of Contents

List of Tables ............................................................................................................................................................ ix

List of Figures............................................................................................................................................................. ix

Table of Abbreviations .................................................................................................................. xii

1. Introduction - Importance of Lightning Locating Systems ...................................................... 1

1.1 Problem - Evaluation of Lightning Locating Systems ……..................................................................

1.2 Motivation - Use of CN Tower Lightning Data for Evaluating NALDN Performance Characteristics ......4

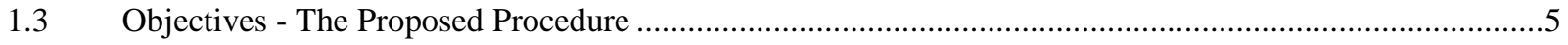

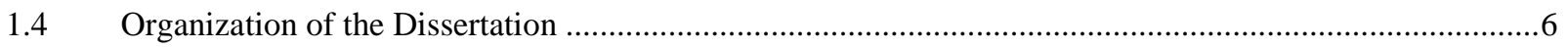

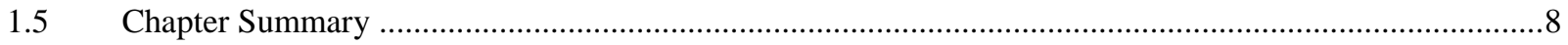

2. Lightning Phenomenon......................................................................................................................... 10

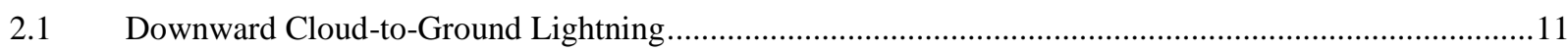

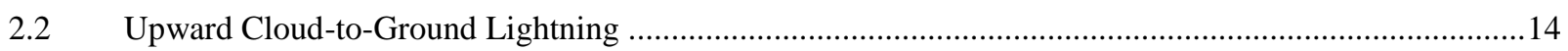

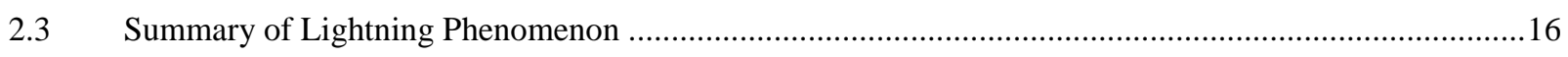

3. Lightning Locating Systems ................................................................................................... 17

3.1 Magnetic Direction Finding (MDF) ............................................................................................

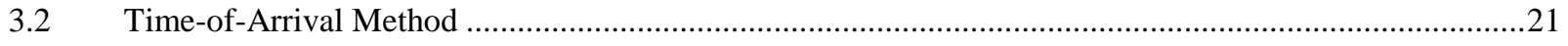

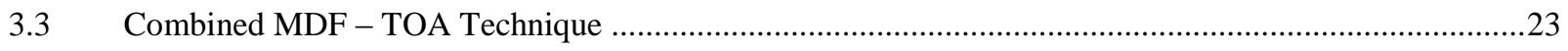

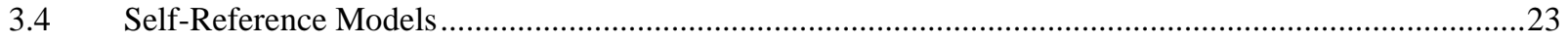

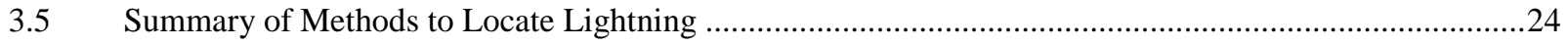

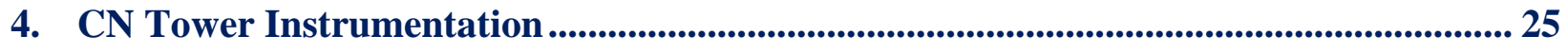

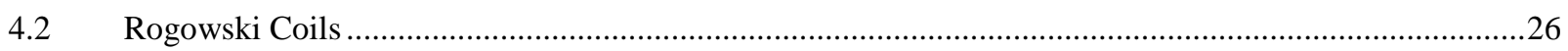

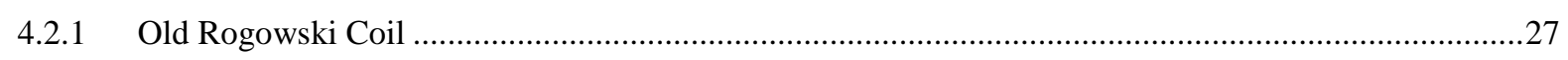

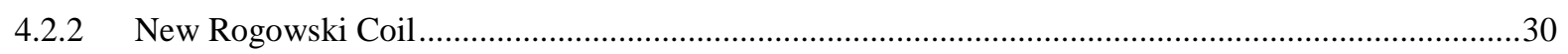

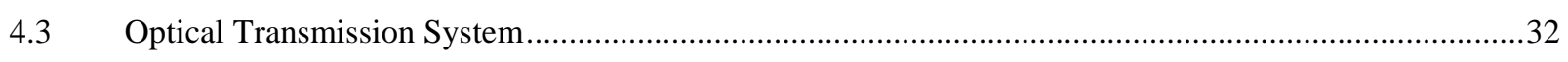

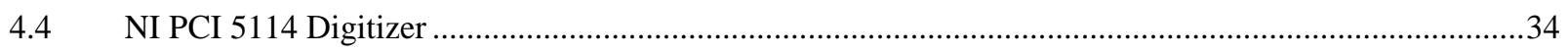

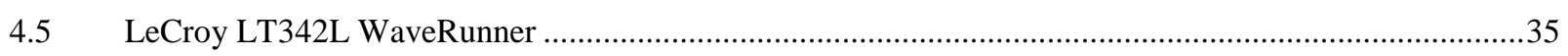

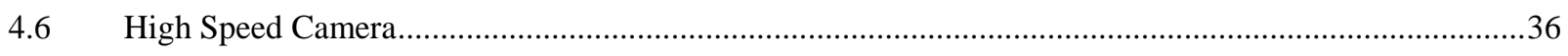

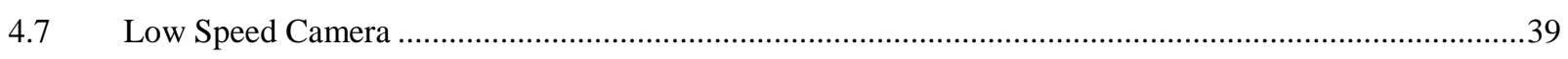

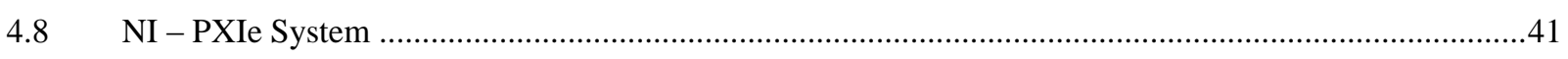

4.8.1 PXIe-1082, 8-Slot 3U PXI Express Chassis .................................................................................

4.8.2 NI PXIe-8135 Core i7-3610QE 2.3GHz Controller ......................................................................42 
4.8.3 NI PXIe-5160, 2 CH, 2.5GS/S, 500MHz Digitizer with 2GB Onboard Memory ……….....................42

4.8.4 NI PXI-6683H GPS, IRIG-B, IEEE 1588 Sync and Time Module with TCXO .................................43

4.9 Summary of Complimentary Nature of the Instruments ........................................................................45

5. Performance Characteristics of NALDN based on CN Tower Lightning Data .............. 46

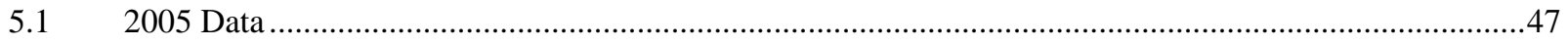

5.1.1 Network Upgrades before the 2005 Storm .......................................................................................51

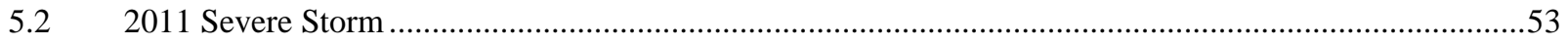

5.2.1 Network Upgrades before the August 24, 2011 Storm ........................................................................56

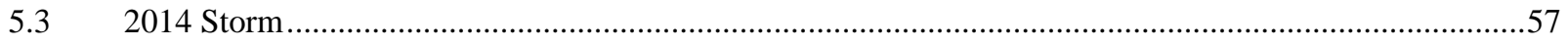

5.3.1 Network Upgrades before the September 05, 2014 Storm.................................................................61

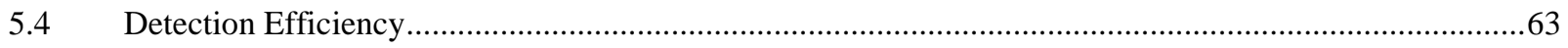

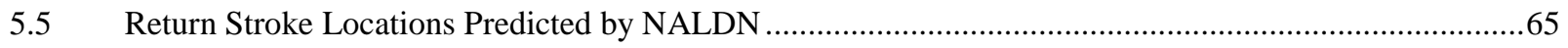

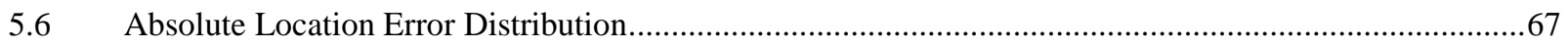

5.7 Absolute Location Error vs NALDN and CNT Peak Currents ...............................................................72

5.7.1 Absolute Location Error vs Estimated NALDN Peak Current .............................................................72

5.7.2 Absolute Location Error vs CN Tower Peak Current ........................................................................74

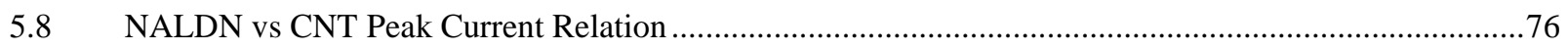

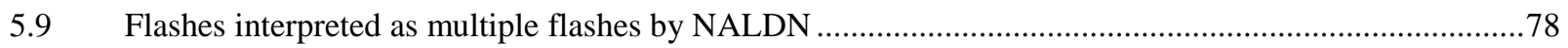

5.10 Flash Recorded by NI PXIe Current Measuring System in December 2015 ............................................80

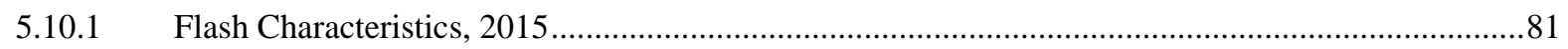

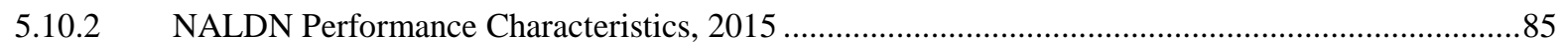

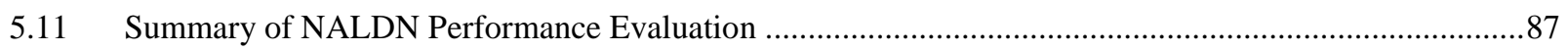

6. Major Contributions ................................................................................................................................ 93

Conclusions and Recommendations .......................................................................................................... 95

Appendix A. Lightning Electromagnetic Pulse ..................................................................................... 98

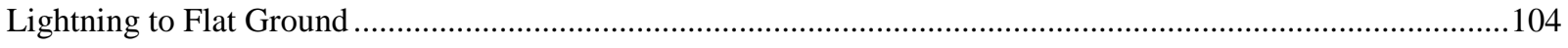

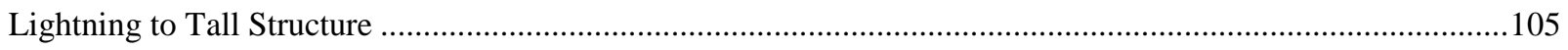

Lightning Electromagnetic Fields Used to Locate Lightning Strokes .............................................................109

Appendix B. Interferometric Method ..................................................................................................... 113

Appendix C. Models of Lightning Locating Systems .................................................................... 115

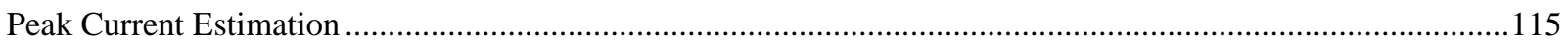

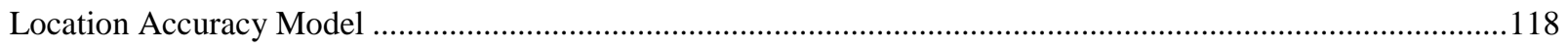

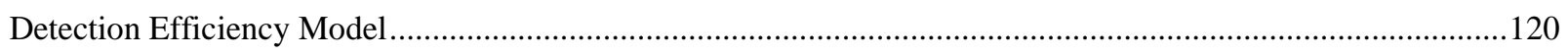


Flash Multiplicity and Misinterpretation of Noise.

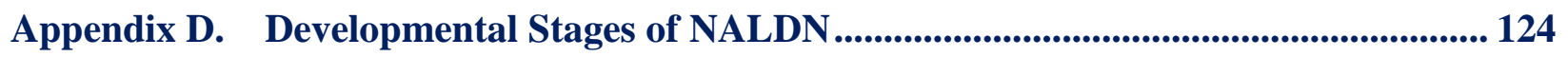

Appendix E. The Universal Transverse Mercator Coordinates.......................................... 128

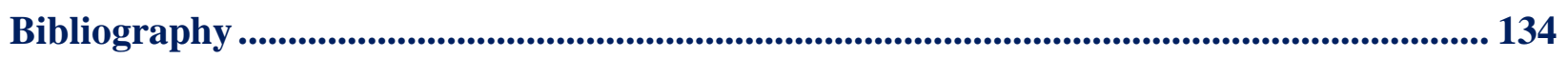




\section{List of Tables}

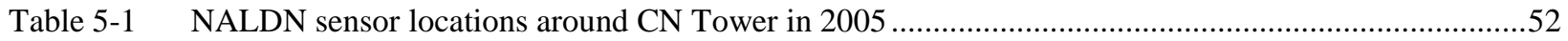

Table 5-2 Average and median location errors in 2005, 2011 and 2014 ..........................................................67

Table 5-3 NALDN absolute location errors, statistics 2005, 2011 and 2014 ….................................................71

Table 5-4 NALDN vs CNT peak current relation in 2005 and 2014 .............................................................77

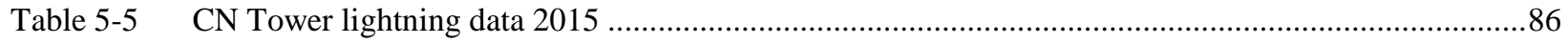

Table 5-6 Important characteristics of the three storms; 2005, 2011 and 2014...................................................8

Table 5-7 Network evaluation based on CN Tower and rocket-triggered (RT) lightning data.............................92

\section{List of Figures}

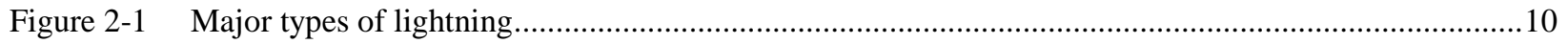

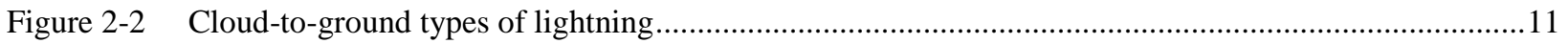

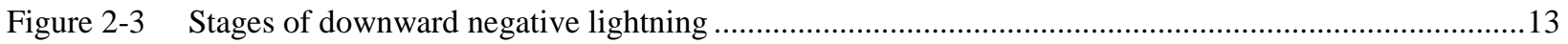

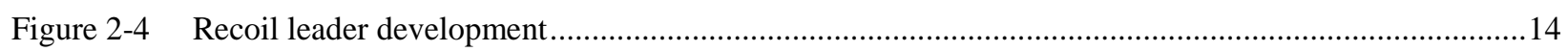

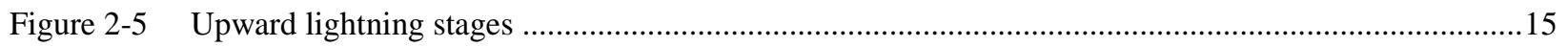

Figure 2-6 A schematic of tall-structure current components......................................................................

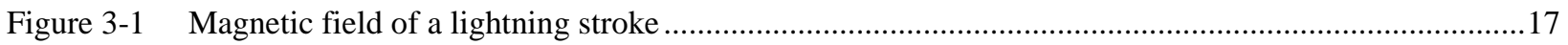

Figure 3-2 Two perpendicular loops used for determining the direction and the magnitude of the magnetic

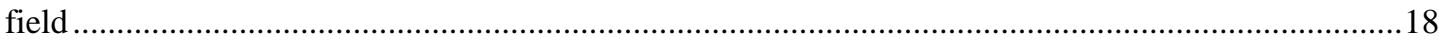

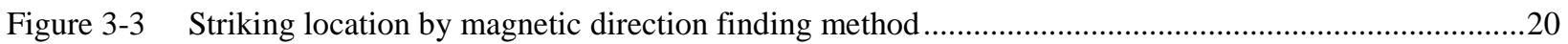

Figure 3-4 Striking location using time-of-arrival method ................................................................................21

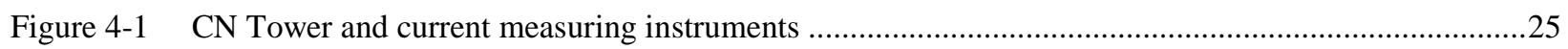

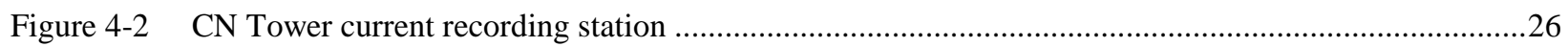

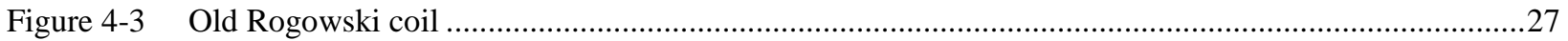

Figure 4-4 Current derivative of a CN Tower flash recorded on July 4, 2013 via the old coil............................28

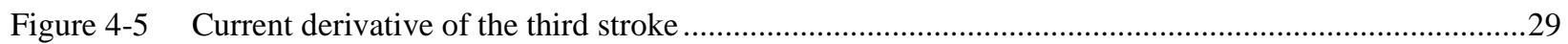

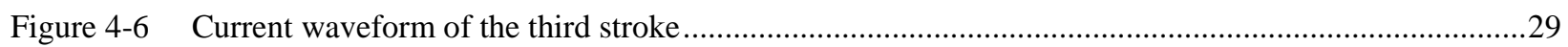

Figure 4-7 New Rogowski coil..........................................................................................................

Figure 4-8 Current derivative of a flash recorded at the tower by the new coil, July 19, 2013 ...........................31

Figure 4-9 Current derivative of the second return stroke .........................................................................................31

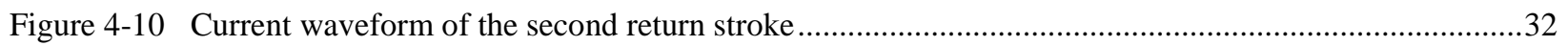

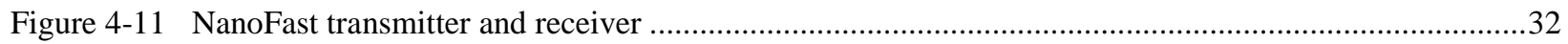

Figure 4-12 A return-stroke raw signal recorded by LeCroy digitizer via the new coil and fiber link on June 12,2014

Figure 4-13 Raw signal of the same return stroke, simultaneously recorded by NI PCI 5114 digitizer via the

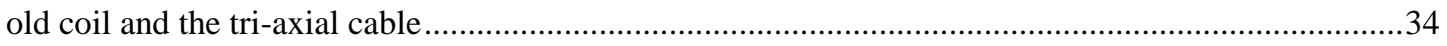

Figure 4-14 NI PCI 5114 digitizer connected to the new Rogowski coil ............................................................35 
Figure 4-15 LeCroy LT342L Waverunner connected to the old Rogowski coil .....................................................36

Figure 4-16 Phantom v5.0 high speed camera, present location ...........................................................................37

Figure 4-17 CN Tower lightning image recorded by the high speed camera on July 19, 2013 .............................38

Figure 4-18 Current derivative vs luminosity of a CN Tower flash on July 19, 2013 ............................................38

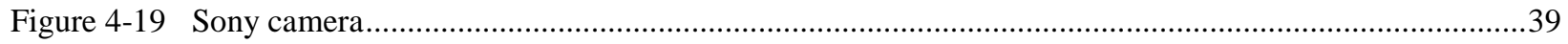

Figure 4-20 Image recorded by Sony camera, third CN Tower flash on September 5, 2014 ..................................40

Figure 4-21 Current derivative vs luminosity of flash 19, September 5, 2014 .....................................................40

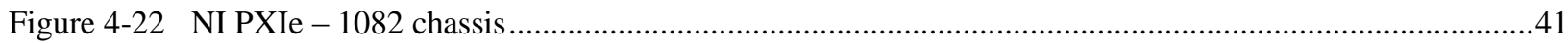

Figure 4-23 NI PXIe - 8135 controller with 500GB in SATA hard drive ........................................................42

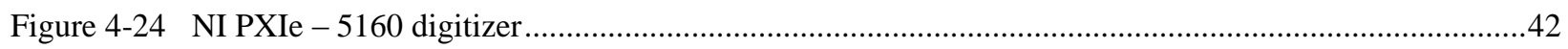

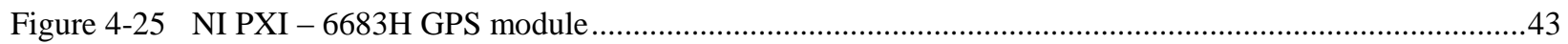

Figure 4-26 First CN Tower flash recorded by PXIe system, December 29, 2015 ..............................................44

Figure 4-27 CN Tower flash, simultaneously recorded by NI-PCI-5114, December 29, 2015 .............................44

Figure 5-1 Relative times of occurrence of CN Tower flashes, 2005 selected storm ...........................................48

Figure 5-2 Current and channel luminosity of second flash, 2005 selected storm ..............................................49

Figure 5-3 HSC video frames of the second flash, 2005 selected storm ...........................................................50

Figure 5-4 Locations of NLDN and CLDN sensors around the CN Tower .....................................................52

Figure 5-5 Locations of the CN Tower and two video cameras, August 24, 2011 Storm .......................................53

Figure 5-6 Relative times of occurrence of CN Tower flashes, August 24, 2011 .................................................54

Figure 5-7 Current derivative of return-strokes time matched with channel luminosity, first flash .......................55

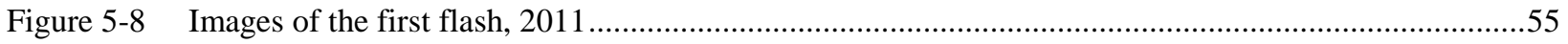

Figure 5-9 NALDN sensor types and locations, November 2008 .................................................................56

Figure 5-10 Luminosity, current derivative and current for flash 22, 2014 ...........................................................58

Figure 5-11 Relative times of occurrence of CN Tower flashes during the 2014 storm .......................................59

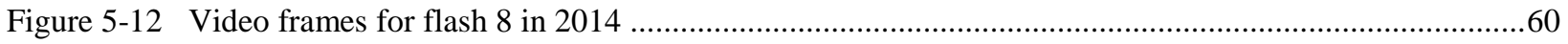

Figure 5-13 Current derivative of return-strokes time matched with channel luminosity, flash 8 .........................61

Figure 5-14 Network median location accuracy, 2014 …...............................................................................62

Figure 5-15 Cloud-to-ground flash detection efficiency, 2014 ......................................................................62

Figure 5-16 NALDN stroke detection efficiency versus CN Tower lightning current peak, 2005 ........................64

Figure 5-17 NALDN stroke detection efficiency versus CN Tower lightning current peak, 2014 ........................64

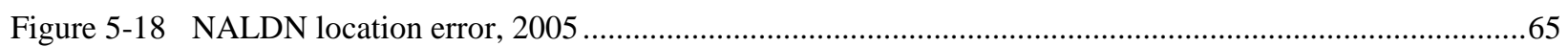

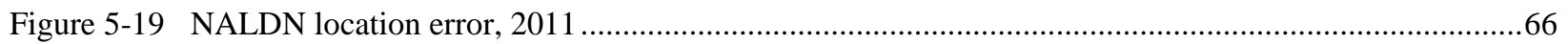

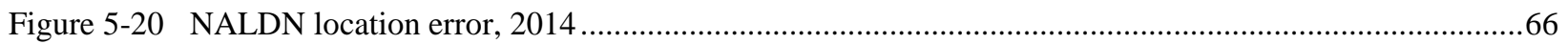

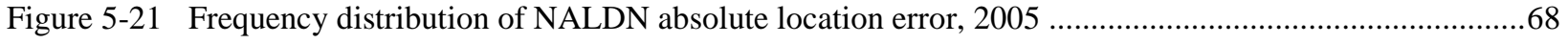

Figure 5-22 Frequency distribution of NALDN absolute location error, 2011 ....................................................68

Figure 5-23 Frequency distribution of NALDN absolute location error, 2014 .....................................................69

Figure 5-24 Cumulative probability distribution of absolute location error, 2005 ...............................................70 
Figure 5-25 Cumulative probability distribution of absolute location error, 2011 .................................................70

Figure 5-26 Cumulative probability distribution of absolute location error, 2014 ....................................................71

Figure 5-27 NALDN absolute location error versus NALDN peak current, 2005 .................................................72

Figure 5-28 NALDN absolute location error versus NALDN peak current, 2011 .................................................73

Figure 5-29 NALDN absolute location error versus NALDN peak current, 2014 .................................................73

Figure 5-30 NALDN absolute location error versus measured peak current, 2005 ...................................................75

Figure 5-31 NALDN absolute location error versus measured peak current, 2014 ................................................75

Figure 5-32 NALDN versus CN Tower peak current, 2005 ...........................................................................

Figure 5-33 NALDN versus CN Tower peak current 2014 ...............................................................................77

Figure 5-34 Trajectories of three return strokes of flash 8, 2014 .........................................................................79

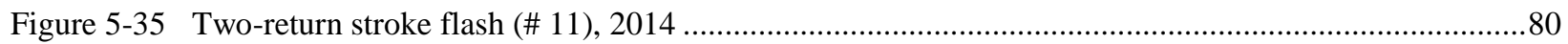

Figure 5-36 Current derivative of the $2015 \mathrm{CN}$ Tower flash recorded by two independent current

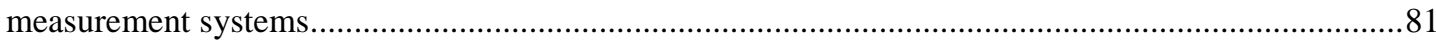

Figure 5-37 Current derivative of 2015 CN Tower flash recorded by NI PXIe system .........................................82

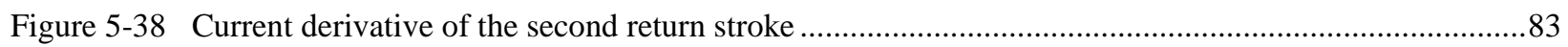

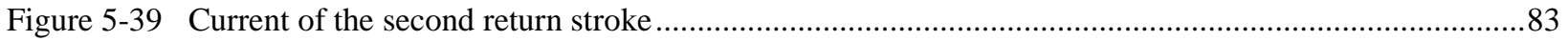

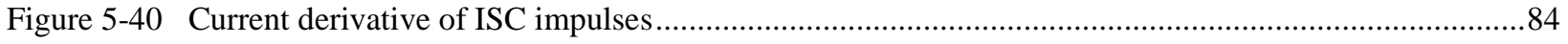

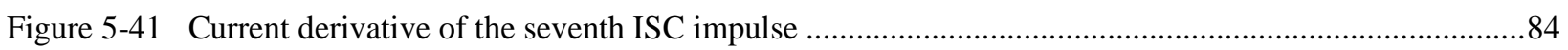

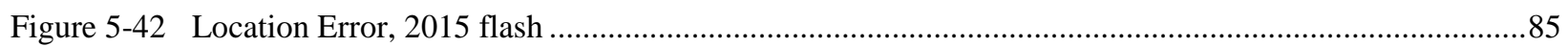

Figure 5-43 Absolute location error versus peak current estimate, 2015 flash......................................................87

Figure 5-44 Cumulative probability distribution of absolute location error; 2005, 2011 and 2014 ......................88

Figure 5-45 Absolute location error versus estimated peak current; 2005, 2011 and 2014 …..............................90

Figure 5-46 Absolute location versus estimated peak current curves; 2005, 2011 and 2014 ................................90

Figure 5-47 NALDN estimated peak current versus measured peak current, 2005 and 2014 ...............................91

Figure A-1 The differential current element and the point of observation ...........................................................100

Figure A-2 Representation of a vertical lightning channel ............................................................................100

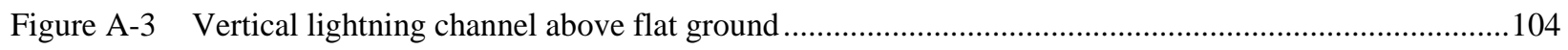

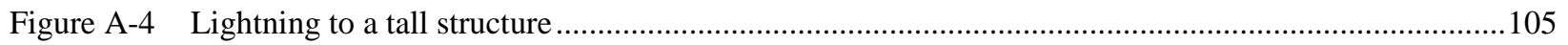

Figure A-5 Lightning current waveforms to flat ground and to a tower.........................................................108

Figure A-6 Radiated magnetic field waveforms for flat-ground and tall-structure lightning ................................109

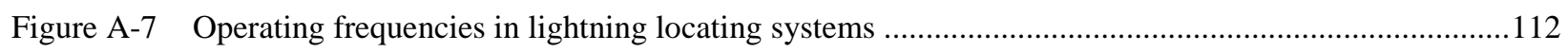

Figure B-1 Direction of arrival at two stations by interferometric method .........................................................114

Figure C-1 Two-dimensional Gaussian distributions of location accuracy .......................................................120

Figure C-2 Sensor detection efficiency versus signal strength relationship .....................................................122

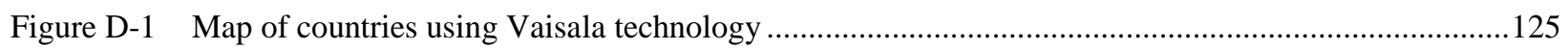

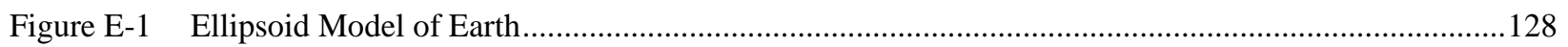

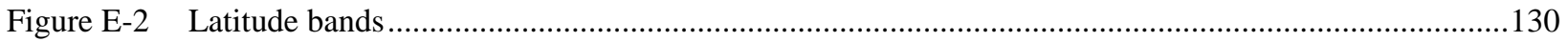




\section{Table of Abbreviations}

$\begin{array}{ll}\text { CC } & \text { Continuing Current } \\ \text { CLDN } & \text { Canadian Lightning Detection Network } \\ \text { CNT } & \text { Canadian National Tower } \\ \text { HSC } & \text { High Speed Camera } \\ \text { IMPACT-ESP } & \text { Improved Accuracy from Combined Technology - Enhanced Sensitivity } \\ \text { ISC } & \text { and Performance } \\ \text { VLF-LF-VHF } & \text { Very Low Frequency-Low Frequency-Very High Frequency } \\ \text { LLS } & \text { Lightning Locating System } \\ \text { LMA } & \text { Lightning Mapping Array } \\ \text { LPATS } & \text { Lightning Position and Tracking System } \\ \text { LSC } & \text { Low Speed Camera } \\ \text { TLP } & \text { Time of Arrival } \\ \text { NLDN } & \text { Lightning Sensor series 7000X } \\ \text { MDF } & \text { Magnetic Direction Finder } \\ \text { NALDN } & \text { North American Lightning Detection Network } \\ & \end{array}$




\section{Introduction - Importance of Lightning Locating Systems}

Lightning is a natural phenomenon. As such, it has a designated role in sustaining the natural climatic order of the planet. Lightning is beneficial to humanity by contributing to the generation of organic compounds vital for stabilizing life on Earth, to the creation of fixed nitrogen and to the provision in sustaining the balance of ozone in the atmosphere [1]. Also, it helps in maintaining the global electric circuit around the globe [2].

Lightning can also be fatal and destructive. It is the second most dangerous storm-related killer, floods being the first [2]. Lightning can injure or kill by way of direct hits, side flashes, and step and touch voltages. Also, lightning strikes trees, airplanes and wind turbines. Lightning is assessed to cause about 24,000 fatalities and 240,000 injuries per year in the world [3] - [7]. Cloud-to-ground flashes are the main cause of damages and aberrations in power transmission and distribution systems [8], [9]. Over voltages due to direct lightning hits, as well as those induced by nearby lightning, present challenging problems for transmission and distribution lines. Financial losses from lightning include multi-billions of dollars related to forest fires [5], [10], residential or industrial constructions, and equipment [5], [11], [12]. A lightning discharge is a transient that generates an electromagnetic pulse (LEMP) that represents a major issue in protection and electromagnetic compatibility (EMC) of buildings, electrical equipment and installations on ground.

The lightning protection system, invented in 1752 by Benjamin Franklin, is still in use to protect ground objects from lightning. Maxwell in 1876 suggested a completely enclosed metallic cage known as Faraday cage to protect objects from lightning, which is used nowadays for cars, airplanes and modern buildings. Since Franklin, many scientists have been studying and investigating lightning events to provide efficient protection methods against lightning.

Lightning locating systems (LLSs) are worldwide established to save lives and to increase operational efficiency of weather-critical facilities. The performance characteristics of lightning locating systems are determined by their ability to accurately locate lightning events with high detection efficiency and to report the details of various features of lightning. The major advantage of a lightning locating system include the advance warning of lightning occurrences to 
help in allocating crews and resources to avoid or recover from lightning damages, and to accurately determine points of lightning strikes for insurance claims and conducting lightning risk assessments of transmission lines infrastructure [9], [13].

At present, lightning locating systems provide the services below [14]:

- Weather forecasting: detect, record and predict severe weather for public warning.

- Electric power: organize maintenance crews to minimize damages or losses from upcoming storms. Statistical analysis of lightning data helps in improving the design and performance of electric power transmission and distribution lines.

- $\quad$ Air traffic control: change flying routes to avoid lightning thunderstorms.

- $\quad$ Airports: suspend high-risk activities, such as ramp services during lightning occurrences.

- Insurance and arson: investigate lightning data to define the cause of damage or fire on properties.

- Power-sensitive operations: take preventive actions for thunderstorm-caused power outages by switching to back-up power before thunderstorm affects the power grid.

- Hazardous materials management: advise personnel to evacuate areas nearby explosives and flammable supplies.

- Forestry: distribute firefighting squads to apprehensive areas of fire for efficient and successful extinction strategies, reducing the search for zones stuck by lightning.

- Golf and outdoor recreation: advise players and bystanders to follow safety procedures before and during lightning events.

- Aerospace: observe weather for safest conditions to launch satellites.

Distinctive users of lightning evidence include meteorological organizations and air traffic dispatchers, space launch facilities, land administration objects, forest facilities, electric power transmission and distribution operators, wind farm operators and other public services [15]. 


\subsection{Problem - Evaluation of Lightning Locating Systems}

Lightning can be observed using ground-based lightning locating systems and satellite-based systems. The ground based systems include electric and magnetic field sensors connected to a processor that computes the lightning location with an accuracy determined by the features of the hardware and software of the locating system. Details about ground-based lightning locating systems are provided in Chapter 3. Satellite-based systems use orbiting satellites equipped with electromagnetic and optical sensors to locate lightning. The latest satellite based system "Geostationary Operational Environmental Satellite (GOES-R)" is expected to be launched in 2016 [15]. Satellite-based LLSs use either optical imaging [16] or very high frequency (VHF) observations by digital interferometry to locate lightning [17], [18]. The accuracy of a satellitebased system is not less than $10 \mathrm{~km}$, it cannot distinguish in-cloud flashes from cloud-to-ground flashes [9]. Even though ground-based lightning locating systems provide more accurate lightning information than satellite-based systems, they are far from being perfect. Groundbased lightning locating systems measure the lightning-generated electric and magnetic fields in order to detect return strokes, determine their locations, polarities and peak currents. The lightning flash density (number of flashes per square kilometer per year) $\mathrm{N}_{\mathrm{g}}$, obtained by a lightning locating system, is essential in lightning protection standards for risk assessment designs [19]. NALDN uses an algorithm to estimate the lightning current peak based on the measured magnetic field peak. An important step towards reaching the goal of solving the inverse source problem is the establishment of an accurate field-current relationship that is based on experimental data. The high detection efficiency of return strokes, location accuracy, polarity and current peak estimation are fundamental for saving lives and protecting ground objects. Moreover, the peak current distribution provided by the networks is valuable to lightning statistical analysis used in lightning protection standards [20].

Even though, different methods may be used to assess lightning locating system data, the key performance characteristics of the networks must be validated with lightning ground-truth data [20]. 


\subsection{Motivation - Use of CN Tower Lightning Data for Evaluating NALDN Performance Characteristics}

The North American Lightning Detection Network (NALDN) is a lightning locating system (LLS), which is composed of the U.S. National Lightning Detection Network (NLDN) and the Canadian Lightning Detection Network (CLDN). The CLDN and NLDN are completely interconnected, with all data processing being performed at Vaisala Network Control Center, Tucson, AZ [21]. Vaisala, a commercial company, operates lightning detection networks in more than 50 countries, including North America. The NALDN has been developed to mainly provide lightning information by accurately detecting and locating cloud-to-ground lightning return strokes. It allows lightning activity to be monitored in real time for use in weather services, aviation management, protection of the North American forests, electrical power utilities, and for a range of applications in forestry, insurance and arson. Utility companies and airports in North America are dependent on the accuracy and the consistency of this network. Since 1998, the NALDN has contributed 18 years of lightning data that have helped advance meteorological and scientific understanding of lightning. Since 2013-2014, the newest Vaisala digital technology sensors with upgraded software have been used to improve the differentiation between cloud and cloud-to-ground lightning [22]. The latest low frequency (LF) LS7002 sensors replaced the LS7001 and IMPACT sensors [23].

The Toronto Canadian National $(\mathrm{CN})$ Tower is considered to be one of the best sites in the world to study tall-structure lightning. Since this instrumented tower lies on the border of CLDN and NLDN, it provides an excellent opportunity to evaluate the performance characteristics of the NALDN in Toronto and its surrounding areas. Although theoretical models can help in assessing the performance characteristics of lightning locating systems, the ground-truth data are necessary to determine the true performance of the network. Lightning return strokes to tall object and rocket-triggered lightning are presently the only direct ways to evaluate the peak current estimation accuracy of lightning locating systems [24]. Instrumented towers have been providing lightning truth data for evaluating the performance characteristics of lightning locating systems [20], [25]. The CN Tower is well-equipped with instrumentation that allows the measurement of the lightning current derivative with high resolutions. Moreover, a new current measurement system was acquired in 2015 to continuously record CN Tower flashes at much 
higher resolutions [26]. Also, high resolution imaging systems are placed $4.73 \mathrm{~km}$ north-east of the tower for recording CN Tower lightning trajectory images.

The $\mathrm{CN}$ Tower lightning data constitute the basis for evaluating the performance characteristics of NALDN, with the aim of improving the network's operation.

In this dissertation, for the first time, an extensive evaluation of NALDN performance characteristics has been accomplished following each of the most recent three major upgrades that took place in 2002-2003, 2010-2011 and 2013-2014. Also, the first peak, not the absolute peak, of the measured current waveform is used for correlation with the network estimated current peak [27]. Furthermore, only CN Tower lightning current waveforms, exhibiting clear first peaks, are used in the network evaluation process [25].

\subsection{Objectives - The Proposed Procedure}

The CN Tower lightning data acquired over the three storms of 2005, 2011 and 2014 have been used to evaluate NALDN performance characteristics, namely: return-stroke detection efficiency, stroke polarity, location error and peak current estimation [28]. For the best outcome, the procedure included a review of the hardware and software systems for recording CN Tower lightning current derivative signals and flash trajectory images. The following approach was used to define the important parameters of the recorded data.

The time recorded by the tower's current derivative measurement systems is matched with that of the NALDN, as well as that of the video recording cameras. The inter-stroke time is determined from the return-stroke current derivative signals, recorded at $125 \mathrm{MS} / \mathrm{s}$ (Mega Samples per second), 4.55MS/s and 250MS/s in 2005, 2011 and 2014, respectively. Time synchronizations of the current signals with those of the corresponding trajectory images were accomplished for the three storms.

The recorded current derivative signals, by identifying individual return strokes, authenticate the location of each stroke, which is the location of the tower. Also, the high-speed camera (HSC)

and the continuously recording low-speed camera (LSC) video records optically confirm the 
stroke occurrence at the tower. The HSC images are utilized to distinguish between return strokes and initial stage current (ISC) pulses.

Each current derivative recorded signal verifies the polarity of the return stroke.

The current derivative measurement system provides the current derivative waveform of each return stroke, which is numerically integrated to obtain the current waveform. The first peak of the current waveform has been used in this study (Appendix A).

After determining the number of $\mathrm{CN}$ Tower strokes detected by NALDN, the stroke detection efficiency is calculated. The absolute location error of each detected stroke is the distance between the NALDN estimated stroke location and that of the tower. The NALDN estimated polarity and current peak for a detected stroke are also compared with those measured at the tower. Only one stroke within a flash has to be detected by the network for that flash to be considered detected.

\subsection{Organization of the Dissertation}

This study presents a comprehensive evaluation of NALDN performance characteristics, based on CN Tower lightning data recorded during three major storms in 2005, 2011 and 2014. Each of the three storms occurred after one of the major network upgrades in 2003-2004, 2010-2011 and 2013-2014. The performance characteristics of a lightning detection network consist of its ability to detect and report various aspects of lightning discharges, namely detection efficiency (DE) for cloud-to-ground return strokes (RS), location accuracy (LA), polarity and peak current estimation [25].

The data of the first storm, which occurred on August 19, 2005, was previously used to evaluate the network performance [25]. Recently, it was possible to acquire the 2005 NALDN location data with 10-m resolution rather than the previously-obtained data based on 100-m resolution. Also, a detailed investigation of $2005 \mathrm{CN}$ Tower current records proved the existence of one extra return stroke, which has been perfectly time matched with a return stroke reported by the network. Furthermore, in this work, NALDN predicted lightning current has been correlated 
with the first peak of the CN Tower measured current [27], rather than its absolute peak, which was used in previous evaluations [25]. In 2005, the return-stroke current derivative signals were recorded by two-channel LeCroy LT362 digitizer, operating at 125MS/s. The lightning trajectory images were recorded by HSC and LSC. The $2005 \mathrm{CN}$ Tower storm data comprise six flashes containing 38 return strokes; 21 of them were reported by NALDN.

In the second storm, which took place on August 24, 2011, the current derivative of each flash was continuously recorded for 2s by National Instruments (NI) PCI 5114 digitizer at 4.55 MS/s. Also, the CN Tower lightning trajectory images were recorded by two LSCs. The 2011 storm data comprise 52 flashes, 32 of them contain return strokes [29]. The current measurement system recorded a total of 156 return strokes, 84 of them were reported by NALDN [30]. Because of time resolution problem (220ns), the initial peak current was established with acceptable accuracy. Thus, a correlation between the CN Tower recorded peak current and that reported by the network was not feasible.

The CN Tower current derivative data of the third storm, which occurred on September 5, 2014, were recorded by two independent current measurement systems. The corresponding lightning trajectory images were simultaneously recorded by HSC and LSC [21], [31]. The programs for the LeCroy LT342L WaveRunner and NI PCI 5114 digitizers were updated to record all return strokes with optimal resolutions. The current derivative signal was recorded at the highest resolution, 250MS/s. The storm comprises 24 video-recorded flashes containing nine currentrecorded flashes. These nine flashes contain a total of 30 strokes, all detected by NALDN.

The new current measurement system recorded a single flash at the tower on December 29, 2015. The flash contains eight impulses superimposed on an initial stage current as well as three return strokes. All these return strokes were reported by the network. These three return-stroke current derivative signals were recorded by NI PCI 5114 digitizer (operating at 8bit, 10MS/s) and by NI PXIe system (operating at 10bit, 250MS/s).

The evaluation outcomes of this study are compared with those of similar studies (during the same years) based on rocket-triggered lightning [32]. The last rocket-triggered evaluation of the network was performed in 2013, during the network upgrades, while the latest CN Tower 
lightning-based evaluation was accomplished after the completion of the last major upgrades of 2013-2014 (completed in spring 2014).

This work is organized as follows. Chapter 2 provides the main processes for downward and upward lightning flashes. In Chapter 3, the methods used by lightning location systems to geolocate lightning flashes are provided. Chapter 4 presents the instruments, with their specifications, used to capture $\mathrm{CN}$ Tower lightning flashes. In Chapter 5, the direct lightning data recorded at the tower during 2005, 2011 and 2014 storms are used to evaluate the performance characteristics of NALDN in terms of detection efficiency, location accuracy, polarity and peak current estimation. In addition, a CN Tower flash recorded by the new highresolution current recording system on December 29, 2015, and reported by NALDN is investigated. Chapter 6 includes the major contributions of this work in evaluating the NALDN performance characteristics. Finally, conclusions and recommendations are provided.

\subsection{Chapter Summary}

A cloud-to-ground lightning is an electric discharge between a thundercloud and ground or objects on it. Lightning flashes can cause death or injuries to people and animals. The lightning current can directly or indirectly damage equipment and installations on ground.

Lightning locating system real-time data are used to help in predicting lightning events based on the progress of thunderstorms. They also reduce the recovering time from lightning damages, validate insurance claims and enable lightning risk assessments.

Lightning locating systems are upgraded continually, in terms of hardware and software, to best satisfy industry trends and requests. These upgrades require continual evaluation of the performance characteristics of LLSs.

The CN Tower represents one of the best sites in the world for NALDN performance characteristics evaluation because it gets struck by dozens of flashes every year. It is equipped with the state-of-the-art instrumentation to record return-stroke lightning current and trajectory images with high resolutions. 
The evaluation of the network in this study includes the determination of the detection efficiency, location accuracy, polarity and peak current estimation, based on CN Tower lightning truth data. What distinguishes this work from previous evaluations is a focus on the first current peak, rather than the maximum that occurs at some later time. Since 2015, for the first time, the lightning current derivative of each $\mathrm{CN}$ Tower flash has been continuously recorded for two seconds with $4 \mathrm{~ns}$ time resolution and 10bit signal-level resolution. 


\section{Lightning Phenomenon}

Lightning is a natural, short-lived, high current electrical discharge between electrically charged regions. Lightning can occur between adjacent clouds (inter-cloud lightning), inside a cloud (intra-cloud lightning), between a cloud and the air above it, or between a cloud and the ground. Cloud-to-ground (CG) lightning is of major practical interest because of the presence of humans and their ground installations (Figure 2-1). A lightning discharge is called a lightning flash. When it hits the ground or an object on it, it is called a lightning strike. A lightning strike to ground starts with a downward leader that is followed by at least one upward-propagated return stroke (RS). A return stroke may be followed by a slow time-varying current (continuing current). Transient processes (pulses) within a lightning channel during the continuing current phase are called M-components. The first return stroke is initiated by a downward stepped leader, whereas subsequent strokes are initiated by dart leaders.

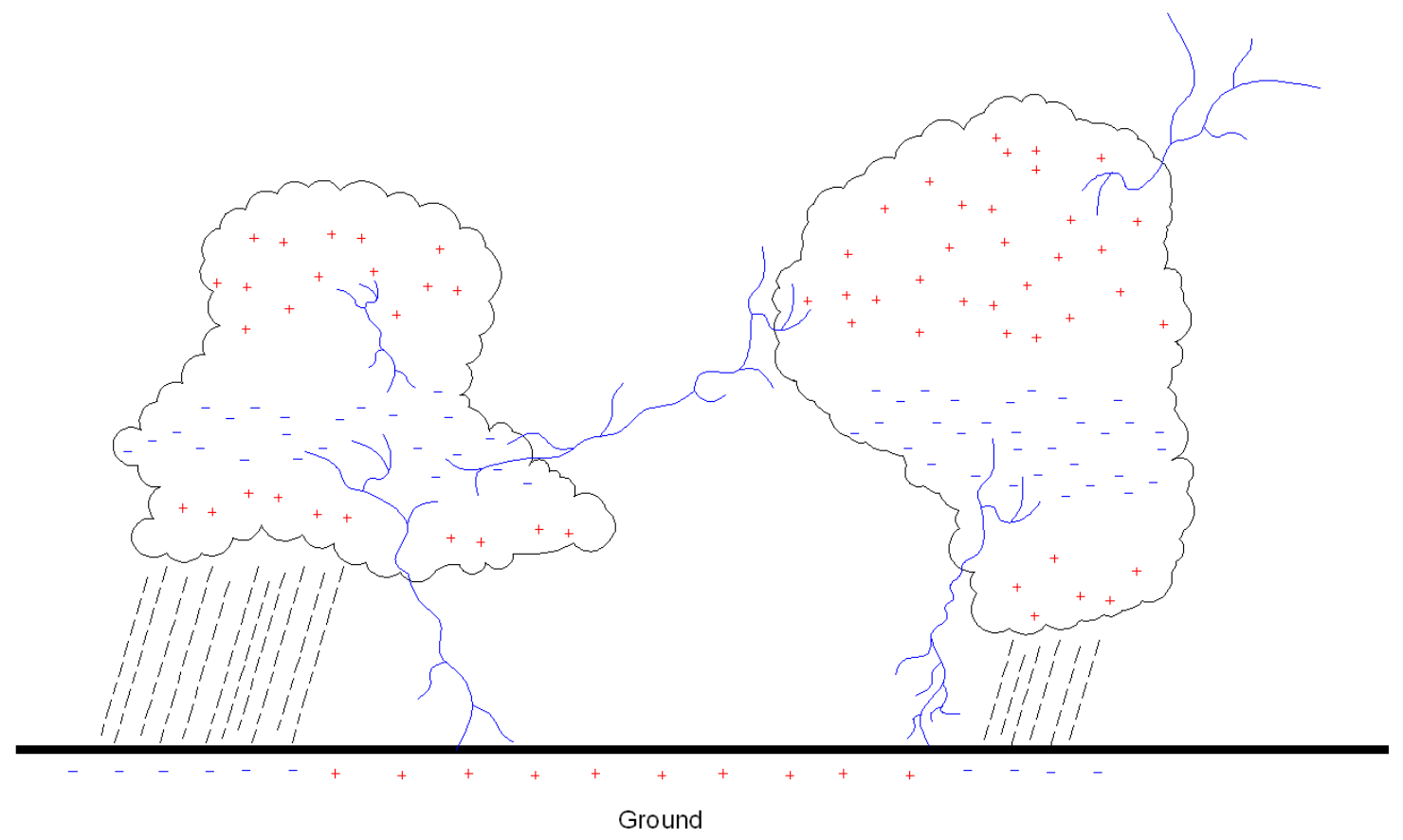

Figure 2-1 Major types of lightning

There are four types of lightning discharges between cloud and ground, based on the polarity of the charge deposited to ground and the direction of propagation of the leader [33]. These four types are displayed in Figure 2-2: (a) downward negative, (b) downward positive, (c) upward negative and (d) upward positive. Downward negative lightning makes about $90 \%$ of all cloud- 
to-ground lightning discharges. However, downward positive lightning makes almost the rest [34]. Upward lightning discharges, which are relatively quite rare, occur at structures normally higher than $100 \mathrm{~m}[2]$. It is worth mentioning that the flash polarity is defined based on the sign of the charge lowered to ground and the direction is defined by leader-propagation direction.
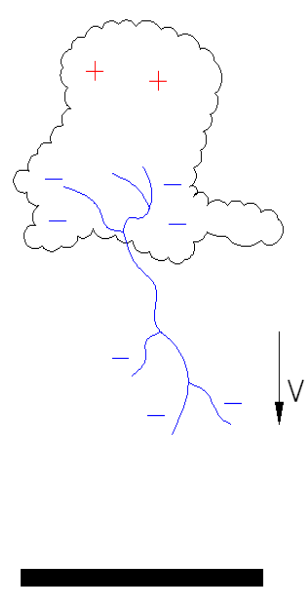

Ground

a)

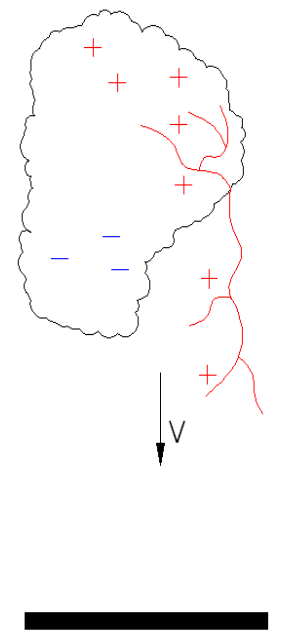

Ground

b)

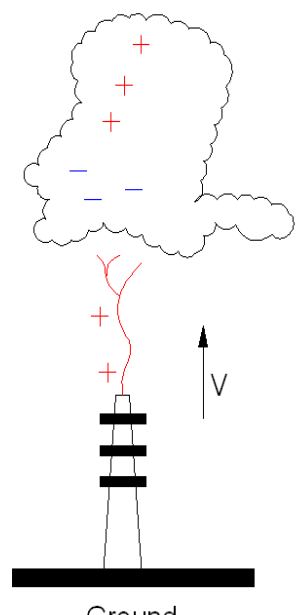

Ground

c)

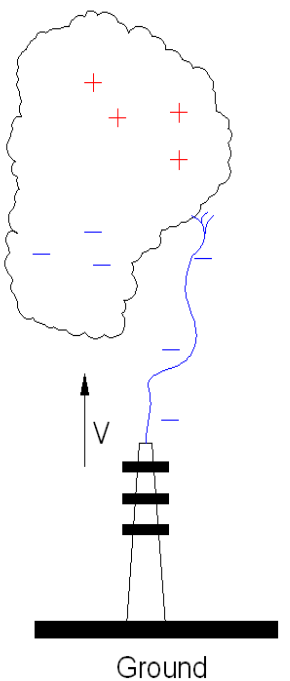

d)

Figure 2-2 Cloud-to-ground types of lightning

\subsection{Downward Cloud-to-Ground Lightning}

The cloud-to-ground lightning is of major importance for lightning protection studies because humans and most of their installations are at ground level. Downward ground flashes are initiated by stepped leaders that originate in thunderclouds. As the downward extending leader (usually negatively charged) approaches the ground, the enhanced electric field intensity at irregularities on the ground surface or at protruding grounded objects increases and eventually exceeds the electric field breakdown strength of air. As a result, one of the upward moving streamers from ground contacts a branch of the downward moving stepped leader, initiating an upward-propagating return stroke. The main processes during cloud-to-ground lightning are presented below [1]. These processes specifically refer to negative lightning because about $90 \%$ of cloud-to-ground flashes are negative. Figure 2-3 illustrates the sequence of events involved in a negative downward lightning flash. 
1. The charge distribution in a thundercloud is mostly - from top to bottom - positive, negative and positive, as shown in Figure 2-3.

2. Preliminary breakdowns lead to generation of downward-propagating stepped leaders.

3. When a stepped leader approaches ground, the enhanced electric field creates upward-connecting leaders from ground, especially from sharp or tall conducting objects.

4. The connection of the stepped leader with an upward connecting leader initiates a return stroke.

5. A wave of ground potential moving from the connecting point towards the cloud is called a return-stroke wave.

a. The change of potential in the cloud, at the point where the return stroke channel is connected to, may lead to the generation of a positive discharge away from that point as shown in Figure 2-4.d.

b. Negative recoil streamers may start propagating from the far end of the positive discharge toward the point where the return stroke channel is connected to the cloud (Figure 2-4.e).

c. Electric discharges may be initiated at any point in the thundercloud and move toward the point where the return stroke channel is connected to the cloud.

6. In addition to the powerful return stroke with its strong radiated field, other discharge activity can also be observed as follows:

a. The electric discharges that do not reach the point, where the return stroke channel is connected to the cloud, are called K-changes.

b. The electric discharges that do reach the point, where the return stroke channel is connected to the cloud, are called M-components if there is a continuing current flowing through the channel discharge.

c. The electric discharges that do reach the point, where the return stroke channel is connected to the cloud, will initiate a dart leader process if there is no current flowing through the channel discharge.

i. If the dart leader reaches the ground, through a partially conducting channel, a subsequent return stroke is generated.

ii. If the dart leader does not reach the ground because of the very low channel conductivity (almost zero), it is called attempted leader. 
iii. If the dart leader moves through the partially conducting channel and reaches a channel section with very low conductivity, it becomes a stepped leader followed by a subsequent return stroke.
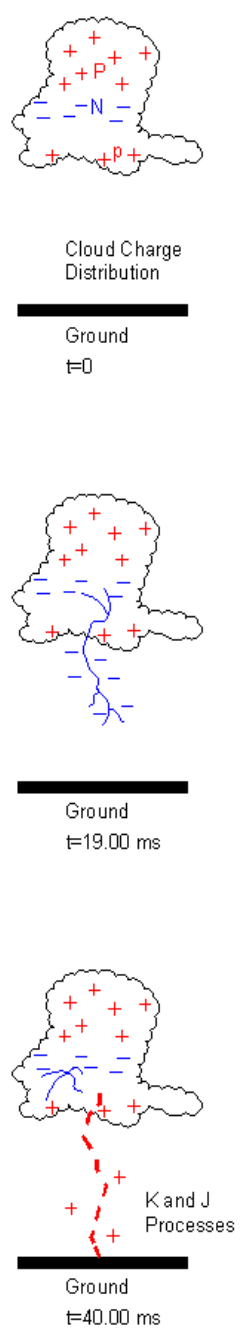
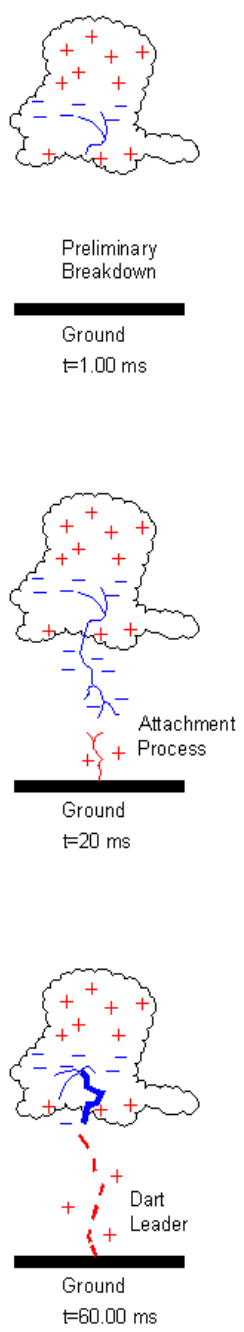

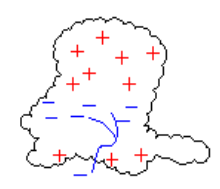

Stepped Leader
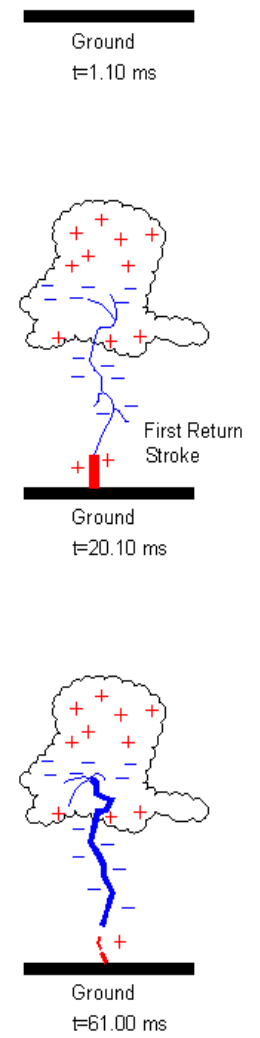

Figure 2-3 Stages of downward negative lightning
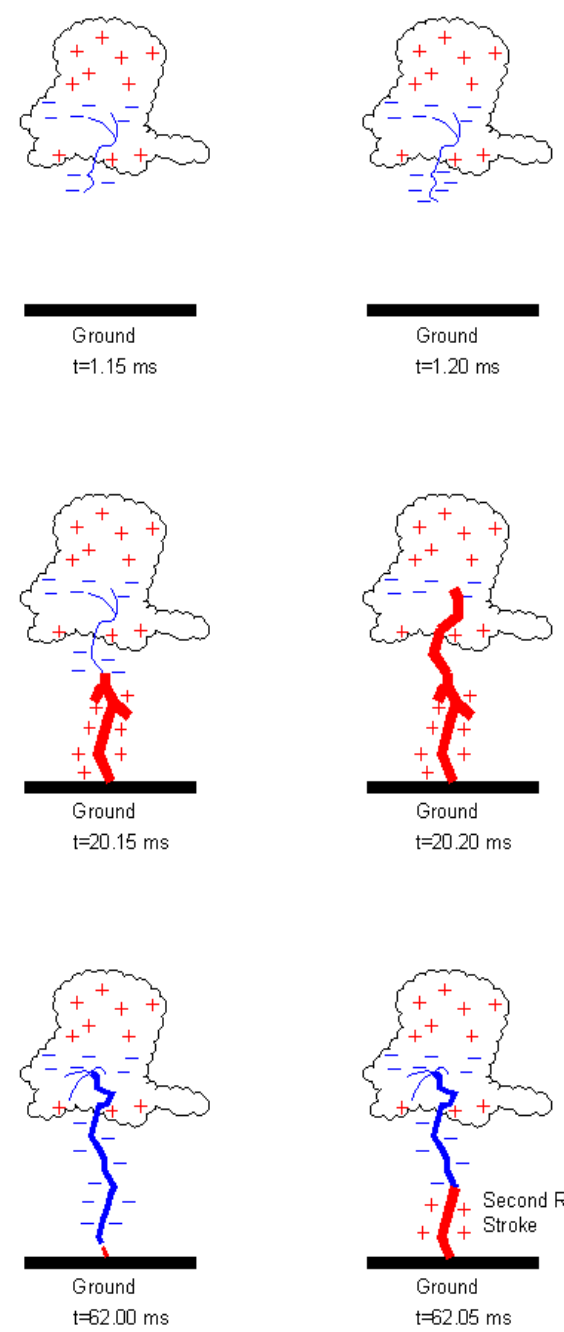

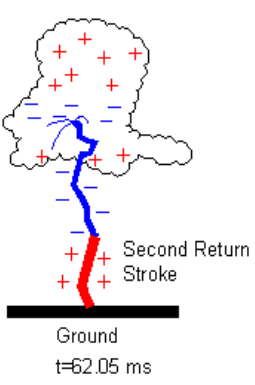

7. When the return stroke wave comes across a branch, an increase in the channel luminosity occurs. These are called branch components.

8. Any return stroke may be followed by a slow time-varying current named continuing current (CC).

9. Branches on the discharge channel and branch components are observed commonly on the first return stroke.

10. Junction or J processes include electrical activities that occur in the cloud between 
consecutive return strokes.
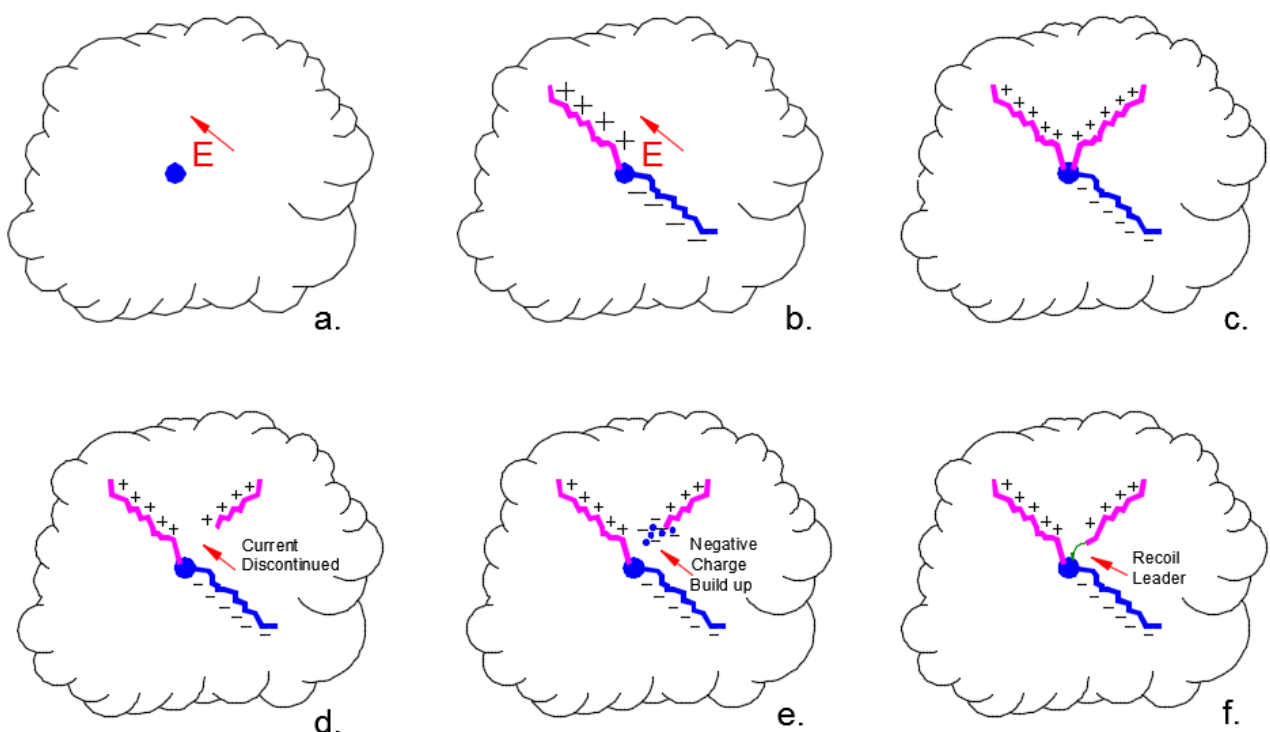

Figure 2-4 Recoil leader development

\subsection{Upward Cloud-to-Ground Lightning}

Upward lightning is usually initiated by the object because it would not occur if the object was not present, Figure 2-5. Objects with heights in the range of $100-500 \mathrm{~m}$ experience both downward and upward flashes; the percentage of upward flashes increases as the height of the object increases. Structures having heights less than $100 \mathrm{~m}$ or so are assumed to be mostly struck by downward lightning, and structures with heights greater than 500m or so are usually assumed to be struck by upward flashes [2]. Upward lightning can be artificially triggered by launching rockets from ground towards the thundercloud. Upward lightning flashes, rocket-triggered or from tall structures, can deposit negative or positive charges to ground. The current features of triggered lightning are comparable to those of tall-structure lightning [2].

When a thundercloud is built up near a tall structure, the electric field at its top reaches its highest level. As a result, an upward leader starts rising from the top of the structure. Under a negatively-charged cloud, the leader is positively charged. 
As the leader develops towards the main negative charge in the cloud, a slow time-varying current flows from the cloud towards the tall structure. This lightning event (flash) may end with this slow-time varying current, which is referred to as the initial-stage current (ISC), or after the ISC ends, a dart leader-return stroke sequence, similar to subsequent strokes in cloud-to-ground lightning, may begin. If the flash only contains ISC, it is called initial-stage flash. Soft or sharp impulses may be superimposed on ISC, which are called M-component type or return-stroke type pulses, respectively. A schematic diagram of the current stages of upward-initiated lightning is presented in Figure 2-6.
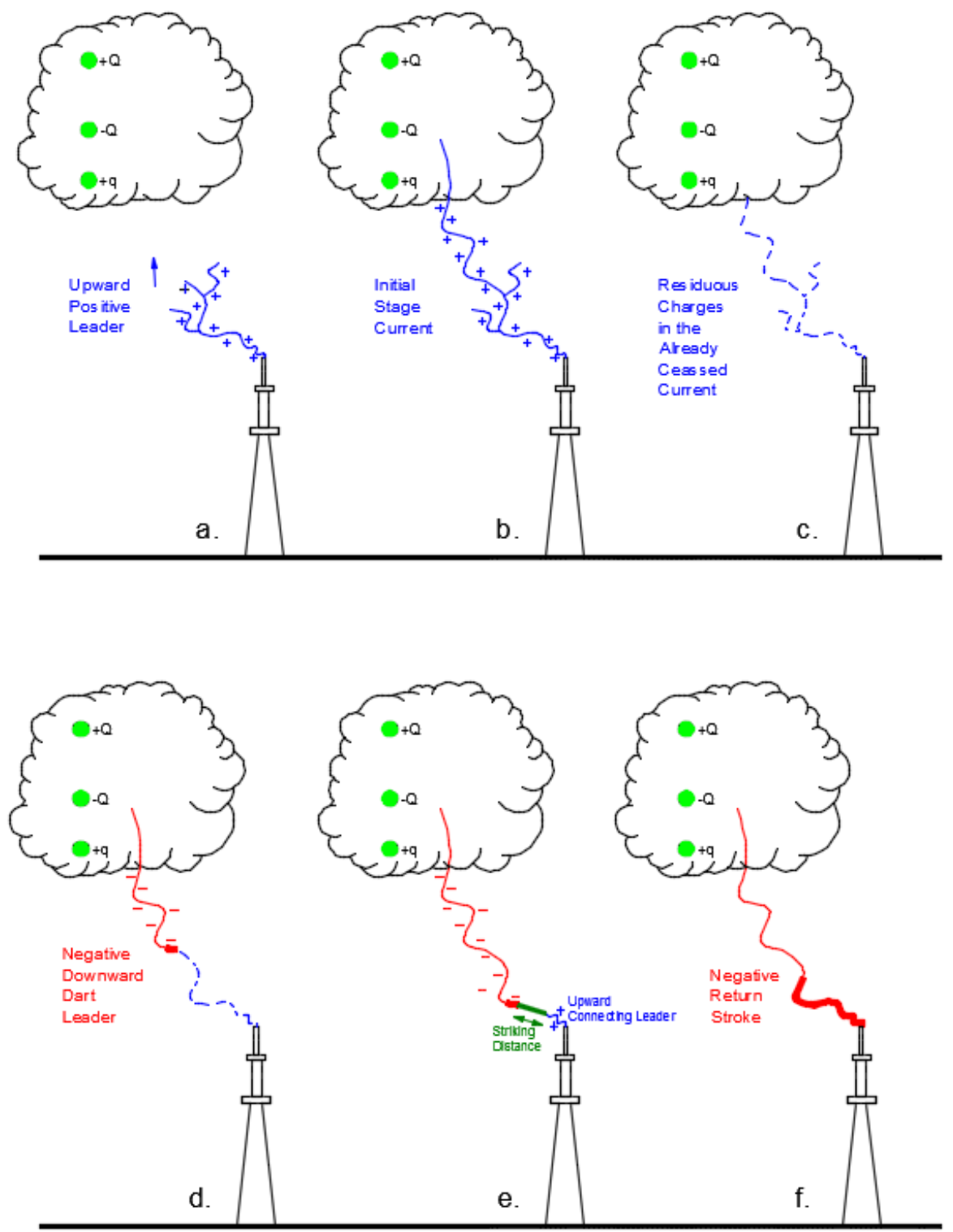

Figure 2-5 Upward lightning stages 


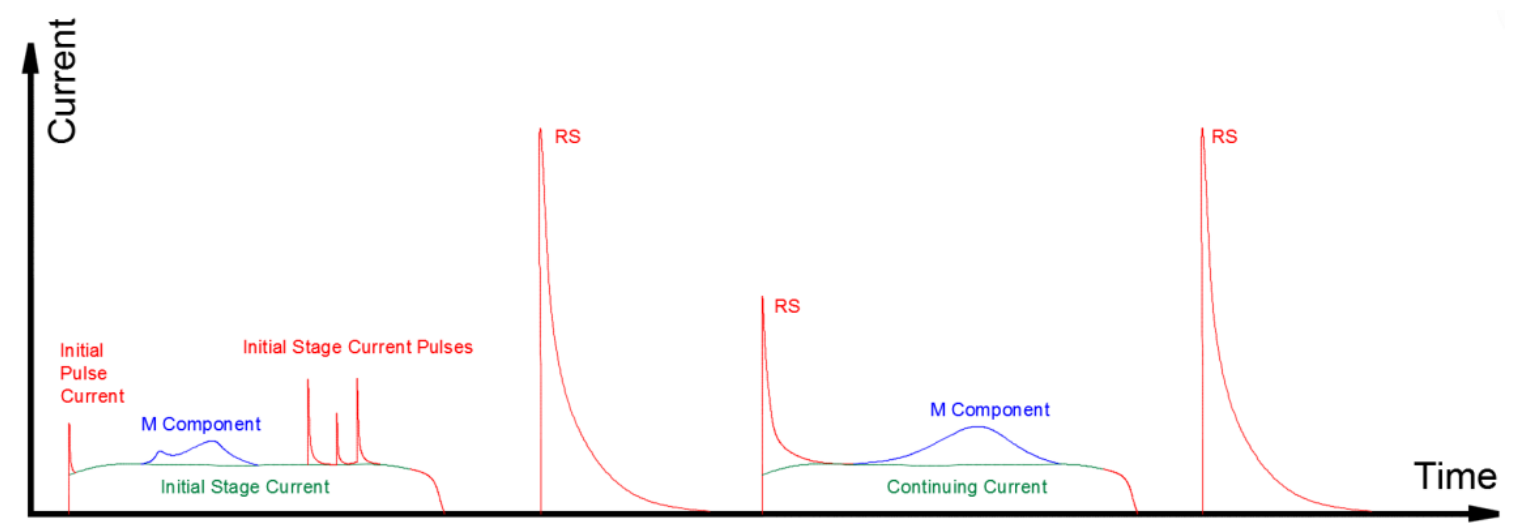

Figure 2-6 A schematic of tall-structure current components

\subsection{Summary of Lightning Phenomenon}

Lightning is a natural phenomenon of transient electric discharges between electrically charged regions within clouds or between clouds and ground. The lightning channel, which is in kilometers, carries currents of several kiloamperes $(\mathrm{kA})$ and represents a direct and indirect risk to humans and installations.

The total time duration of a flash is typically in hundreds of milliseconds with time intervals between successive return strokes in the range from few milliseconds to several tens of milliseconds. The downward negative lightning discharge to ground is the most common type of cloud to ground lightning. Upward lightning is usually initiated by objects with heights beyond $100 \mathrm{~m}$. The most problematic component of both types of lightning, upward or downward, is the return stroke. The return stroke in a flash carries the highest peak current and represents the optically brightest phase of the flash. Its effect can be easily detected hundreds of kilometers away from its strong electromagnetic radiation. 


\section{Lightning Locating Systems}

This chapter comprises information about different methods used by lightning location systems (LLSs) to accurately geo-locate striking points. A lightning locating system provides the coordinates of the most probable location of a lightning stroke based on the information obtained from field sensors. The magnetic direction finding and the time-of-arrival methods are the most commonly used for determining the stroke location [35], [36].

\subsection{Magnetic Direction Finding (MDF)}

One of the earliest methods used to find the point of stroke of a return stroke is the "magnetic direction finding." According to Ampere's law, the return stroke current produces an electromagnetic field. At any time, the radiated electric field is vertical and the radiated magnetic field is horizontal with respect to Earth's surface; both perpendicular to the direction of propagation (assuming the stroke is perpendicular to a perfectly conducting ground). The generated magnetic flux of a vertical lightning discharge has the shape of cylinders with radius increasing from the stroke point (Figure 3-1).

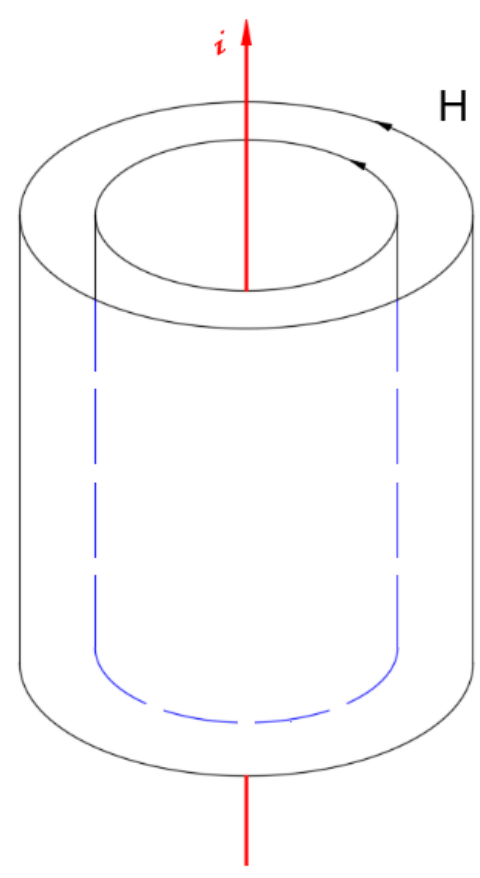

Figure 3-1 Magnetic field of a lightning stroke

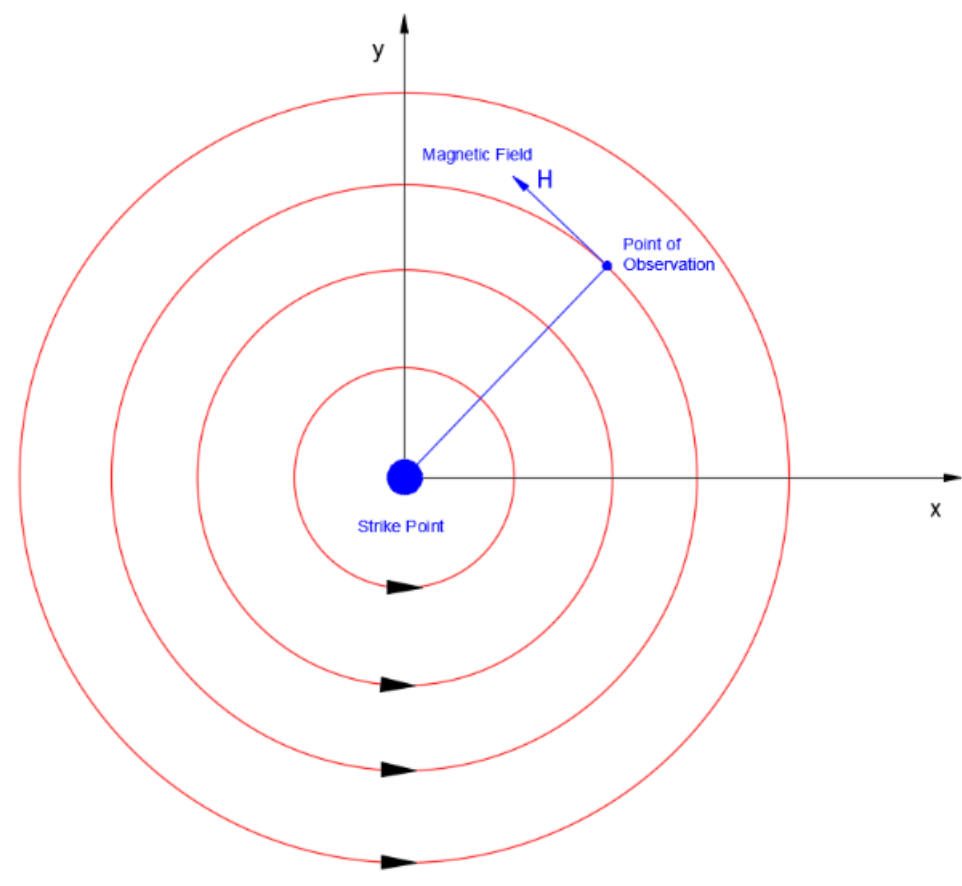


At the ground level, the magnetic field is represented by concentric circles with respect to the ground stroke point. At any location, the magnetic field is tangential to the circle (Figure 3-1). Therefore, it is possible to determine the direction from the point of observation towards the stroke point.

Based on Faraday's law, the output voltage of a coil in the path of the magnetic field is proportional to the cosine of the angle between the magnetic field vector and the axis of the coil (in addition to the magnetic field strength and the cross-section area of the coil). A locating station, consisting of two vertical and orthogonal coils with planes oriented NS and EW, each measuring the magnetic field resulting from a vertical lightning current channel, can be used to obtain the direction towards the striking point. There is an ambiguity of $180^{\circ}$ in determining the direction towards the lightning stroke point depending on the polarity of the discharge (Figure 3-2). For this reason, the electric field is also measured to determine the polarity of the charge transferred to ground [37], [38].

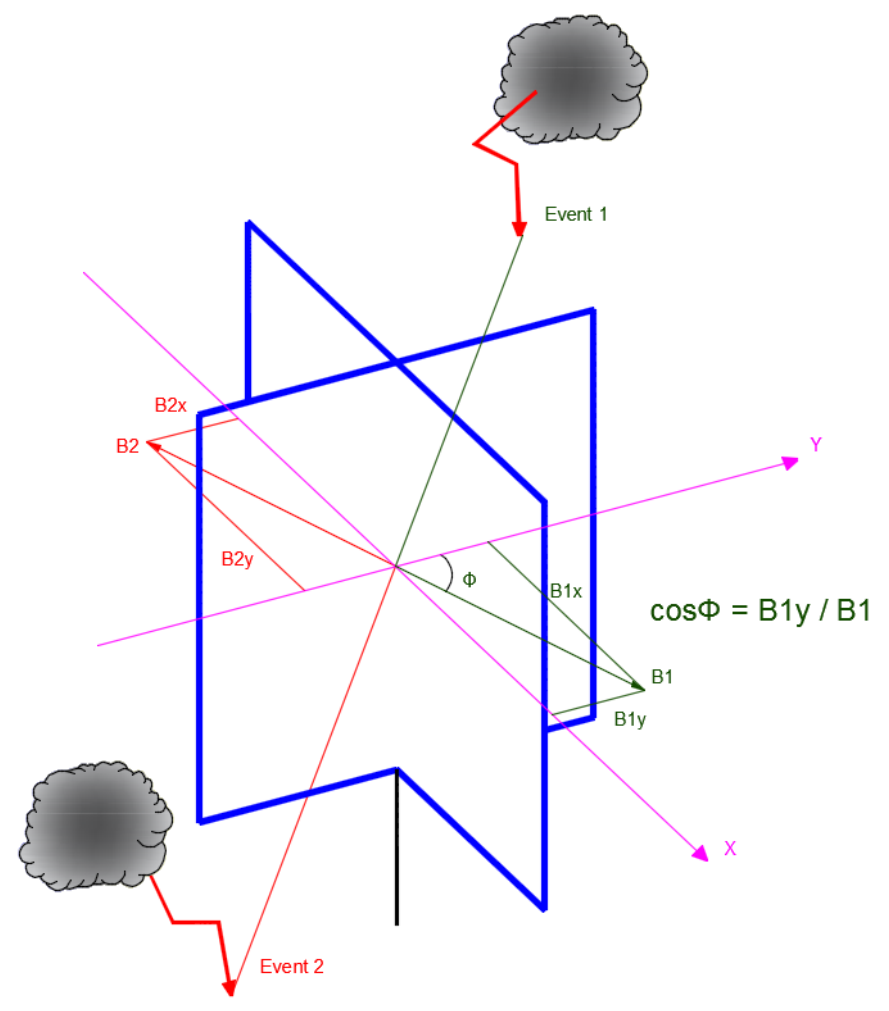

Figure 3-2 Two perpendicular loops used for determining the direction and the magnitude of the magnetic field 
In order to find the location of the stroke point, two locating stations must each provide one direction towards the stroke point. The intersection of these two directions determines the stroke location point. If the stroke point happens to be along the line connecting the two locating stations, the stroke location would be indeterminate, Figure 3-3 a. Therefore, the minimum number of locating stations has to be three [39], Figure 3-3 b. In most cases, the three determined directions from the three locating stations do not intersect at one point. In these cases, an optimization technique is used to minimize the angle of disagreement between the reporting sensors in order to define the stroke location, Figure 3-3 c. The lightning event's time, latitude and longitude can be determined using the described method [40].

There are two general types of MDFs: narrow band direction finders and gated wideband direction finders. The narrow band direction finder operates in a small frequency range with a midpoint between $5 \mathrm{kHz}$ and $10 \mathrm{kHz}$, within which the return-stroke radiated field is strong and the attenuation within the ground-ionosphere waveguide, is low [35]. One of the assumptions made, using the magnetic direction finding technique, is that the flash trajectory is perpendicular to the ground surface. There is a significant angle error in narrow band MDFs, especially at small distances, when the flash is not perpendicular to ground and the reflections from the ionosphere interfere in the sensor input signal. The angle error, which is related to the location error, is proportional to the distance between the sensors and the striking point [14].

The use of gated wideband MDFs has decreased the angle error by sampling the peak of the magnetic field from the lower hundreds of meters of the lightning channel, which is assumed to be vertical. The method is based on the first few microseconds of the magnetic field produced by the return stroke, which is the most powerful feature of the flash that can be detected at longer distances. The first few microseconds of the magnetic field are produced by the lower part of the return-stroke channel that can be considered perpendicular to ground. In addition, by considering the first few microseconds, the reflected electromagnetic waves from the ionosphere are avoided as they arrive later, after the sampling of the initial magnetic field peak is made. Moreover, the magnetic field of the return stroke, measured by this method, provides a better correlation with the return-stroke peak current. 
Both types of direction finders are susceptible to site errors related to metallic objects on ground, which may distort the detected magnetic field. It is possible to determine the systematic site errors from historical records based on validation events and implement that for correcting the location algorithm [41]. Lightning locating systems using MDF, corrected for site errors in addition to applied optimization based location algorithm, were able to locate strokes with accuracy better than $500 \mathrm{~m}$ for sensor baseline distances of less than $50 \mathrm{~km}$. For sensor baseline distances of $200-300 \mathrm{~km}$, the location accuracy drops to $2-4 \mathrm{~km}$ [36], [42], [43].

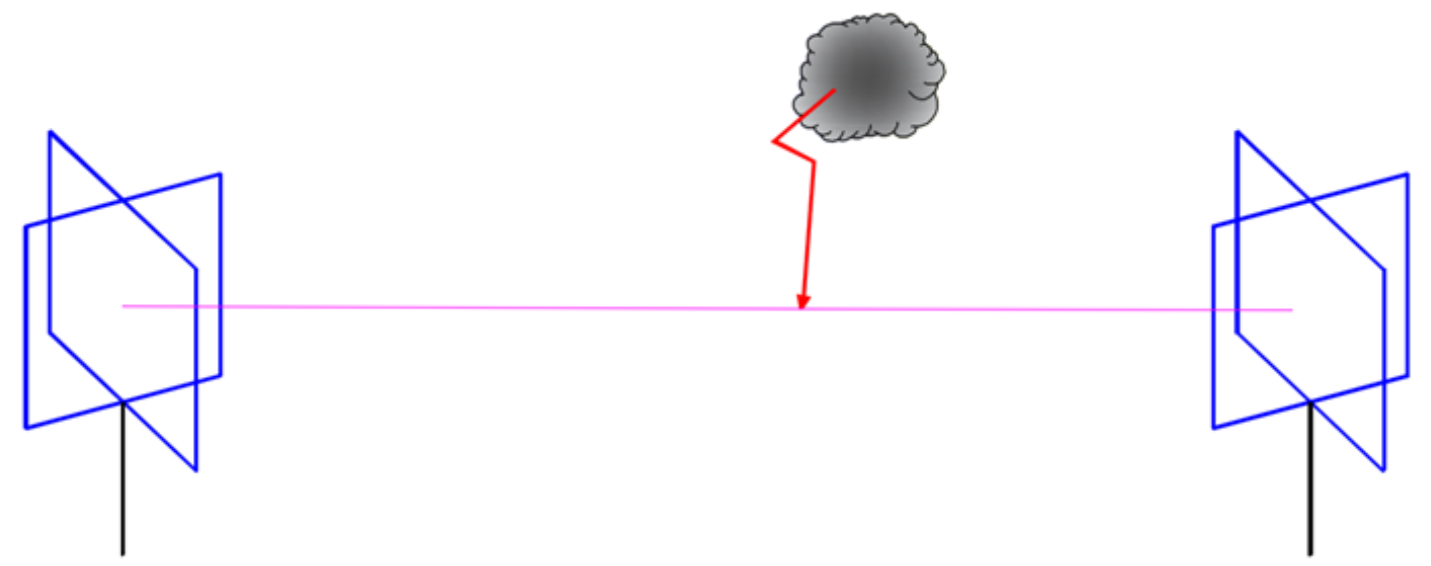

a.
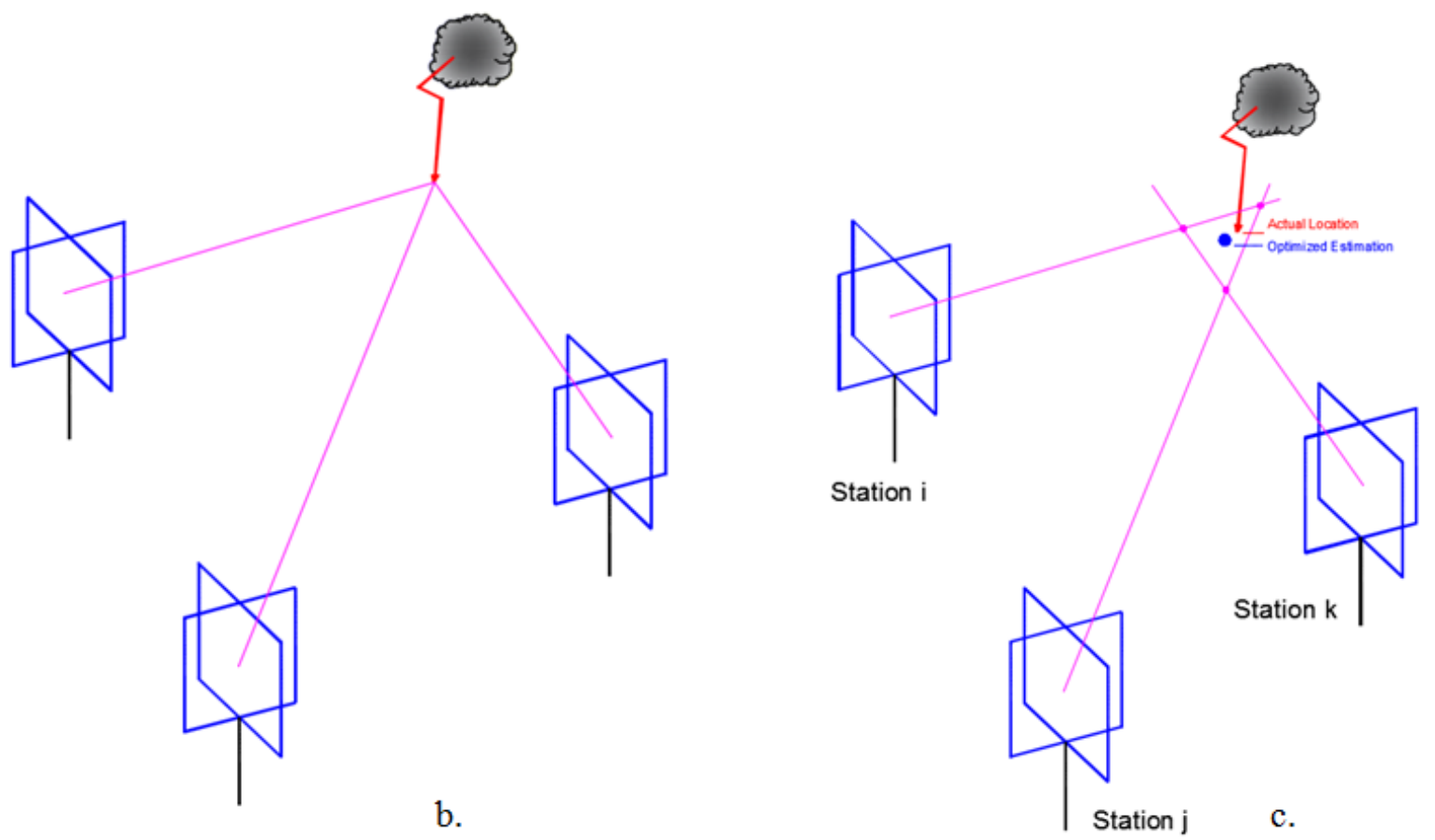

Figure 3-3 Striking location by magnetic direction finding method 


\subsection{Time-of-Arrival Method}

The time-of-arrival method (TOA) is another way to find the location of the stroke point. It provides better accuracy than the direction finding technique for longer sensor baseline distances (it is independent on the distance between sensors). TOA technique is based on the exact time measurement of particular features of the lightning radiated field by different sensors [9].

The distance from the point of stroke to one of the stations is found as the product of the speed of propagation (speed of light, c) and the time difference between the time measured by that station and the unknown time of occurrence of the stroke. On a flat surface, the distance between the stroke point and the three stations $i, j$ and $k$ (Figure 3-4) are respectively given by:

$c *\left(t_{i}-t_{p}\right)=d_{i p}=\sqrt{\left(x_{i}-x_{p}\right)^{2}+\left(y_{i}-y_{p}\right)^{2}}$

$c *\left(t_{j}-t_{p}\right)=d_{j p}=\sqrt{\left(x_{j}-x_{p}\right)^{2}+\left(y_{j}-y_{p}\right)^{2}}$
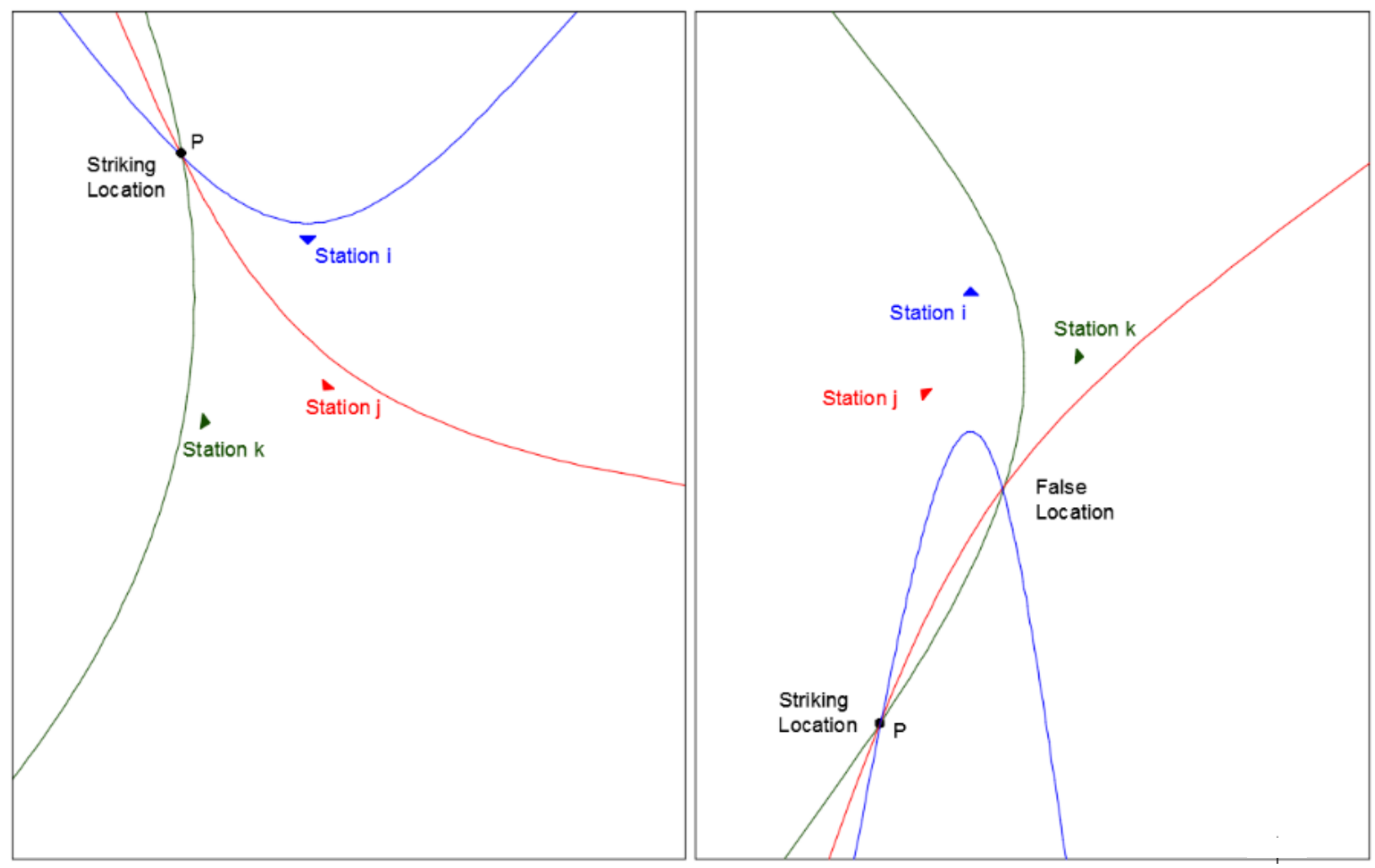

Figure 3-4 Striking location using time-of-arrival method 
$c *\left(t_{k}-t_{p}\right)=d_{k p}=\sqrt{\left(x_{k}-x_{p}\right)^{2}+\left(y_{k}-y_{p}\right)^{2}}$

Subtracting Equation 3.2 from 3.1 and Equation 3.3 from 3.1 result in:

$c *\left(t_{i}-t_{j}\right)=d_{i j}=\sqrt{\left(x_{i}-x_{p}\right)^{2}+\left(y_{i}-y_{p}\right)^{2}}-\sqrt{\left(x_{j}-x_{p}\right)^{2}+\left(y_{j}-y_{p}\right)^{2}}$
$c *\left(t_{i}-t_{k}\right)=d_{i k}=\sqrt{\left(x_{i}-x_{p}\right)^{2}+\left(y_{i}-y_{p}\right)^{2}}-\sqrt{\left(x_{k}-x_{p}\right)^{2}+\left(y_{k}-y_{p}\right)^{2}}$

Each of Equations 3.4 and 3.5 represents a hyperbolic equation. Equation 3.1 is not suitable for long-range detection [40]. The introduction of spherical geometry using radius of earth adds some further complications [44]. Solving these equations produces the stroke point location $\left(x_{p}\right.$ and $y_{p}$ ). The source time $t_{p}$ can then be determined from Equation 3.1. Three stations could be used to localize the striking point within the area covered by the sensors. In some situations, for strokes outside the area comprised by the sensors, hyperbolas generated from only three stations will lead to uncertain locations (resulting in two intersections) as shown in Figure 3-4. In this case, at least four sensors must be used. This method requires GPS timing for precise synchronization between the sensors [41]. Lightning Position and Tracking System (LPATS) sensors have been used for locating lightning sources using TOA method with long range sensor baseline distances [45] - [47].

There is a random error in the time measurements when this method is used to determine the striking point. This error is directly proportional to the timing error and does not depend on the sensor baseline distances [9]. The factors affecting timing error are terrain landscape, ground conductivity, GPS timing error, channel tortuosity and details of lightning radiated field [15]. Timing error by terrain landscape and ground conductivity can be corrected by implementing location-specific adjustments to the times measured by the sensors [48], [49].

TOA technique can be used with very low frequency (VLF), low frequency (LF) and very high frequency (VHF) lightning radiated fields. VHF radiation is related to the physics of air breakdown processes. VHF waves are associated to the spatial and temporal development of discharges used for three-dimensional mapping of lightning channels, known as lightning 
mapping arrays (LMA). VLF signals are related to return-stroke currents in conducting lightning channels used to identify the ground striking point by lightning locating systems [35].

\subsection{Combined MDF - TOA Technique}

Atmospheric Research Systems, Inc. (ARSI) and Lightning Location and Protection (LLP) designed Improved Accuracy from Combined Technology (IMPACT) sensors, Improved Accuracy from Combined Technology - Enhanced Sensitivity and Performance (IMPACT-ESP) sensors and IMPACT algorithm that allow the processing of the information received by both MDF (only time information from LPATS sensors) and MDF-TOA (angle and time information from IMPACT sensors) [2], [14], [50] - [52]. The combined (MDF and TOA) algorithm offers better results over either MDF or TOA method taken separately [53]. As few as two sensors are required to provide redundant information for an optimized estimation of the location of the striking point [41]. IMPACT system can be used based on calibrated magnetic field measurements for peak current estimation [54]. These measurements generate four estimated parameters: latitude, longitude, peak magnitudes and discharge time. Another method, used by LLSs, to determine the source location of discharges for noise-like bursts of electromagnetic radiation is presented in Appendix B.

\subsection{Self-Reference Models}

Lightning locating systems determine the current peak estimate, location accuracy and detection efficiency based on the MDF and TOA technique (or a combination of the two). The accuracy of the lightning data provided by LLSs is evaluated based on self-reference models, integrated in the networks. These models designate the confidence level of the lightning data as described in Appendix C. The NALDN uses an empirical factor of 0.185 to determine the lightning current peak from the sensor range normalization signal strength. LLSs calculate location confidence ellipses (with median 50\%, 90\%, 95\%) based on the number and the relative positions of the sensors contributing to stroke location, as well as the time and angle of incidence information obtained by the sensors contributing to the detected stroke. The optimized stroke location is determined by minimizing the unconstrained error function $\chi^{2}$ in Equation C.9. The detection 
efficiency model finds the detection efficiency for a stroke by using a grid with a simulated peak current at any point of the network. Even though the networks use their models to self-evaluate their performance characteristics, it is fundamentally important to validate their results based on lightning ground-truth data. The methods developed to evaluate the performance characteristics of a network, based on the lightning ground-truth data, include rocket-triggered lightning, lightning flashes to tall objects and video camera recordings [55]. The ground-truth data should comprise the exact location and peak current of the lightning event. Because of continuous improvements in lightning locating systems, it is important to continually validate their performance characteristics.

\subsection{Summary of Methods to Locate Lightning}

Lightning locating systems (LLSs) have lightning sensors to determine the strength, polarity, angle of incidence and time of each lightning stroke. All these parameters are obtained from the measured electric and magnetic fields that a return stroke produces. LLSs employ the returnstroke radiated magnetic field for determining the return-stroke location.

LLSs use different methods or a combination of methods to detect and accurately locate lightning strokes to ground. The main methods used to geo-locate lightning are the magnetic direction finding (MDF), the time-of-arrival (TOA) or a combination of the two. These three methods are mostly used to detect the striking points of return strokes to ground. The minimum number of sensors required to locate lightning strokes is three with MDF method, four with TOA method and two with the combined MDF-TOA technique. Each method requires specifically designed sensors, which include sensitivity range and frequency. The location accuracy greatly depends on sensors' detection efficiencies, number of sensors contributing to the stroke location and sensors' baselines. Also, the landscape of the terrain from the stroke location to the sensor, ground conductivity and lightning channel tortuosity affect the location accuracy.

Theoretical models, designed by LLSs, are used to evaluate the accuracy of the current peak estimates, location errors, and detection efficiency. However, lightning ground-truth data is required to verify the true performance characteristics of a lightning locating system. 


\section{CN Tower Instrumentation}

The Toronto 553-m high Canadian National (CN) Tower, located at $43.6426^{\circ} \mathrm{N}$ and $79.3871^{\circ} \mathrm{W}$, has provided a unique site for the measurements of lightning parameters and for studies of tallstructure lightning. While the local lightning flash density in Toronto is about two flashes per square kilometer per year, the tower is usually struck by several dozens of lightning flashes yearly; making it very valuable for Lightning Locating System (LLS) assessment. Lightning flashes to the tower have been optically observed since 1978, two years after its construction. Since 1990, the CN Tower has been equipped to measure the lightning current derivative signals [56], [57]. Its extreme height has allowed the recording of many hundreds of current derivative signals, mostly resulting from return strokes. Also, optical recording systems have been used to record CN Tower channel trajectories images. The details of the presently used instrumentations for recording the current derivative signals and the corresponding channel trajectory images are discussed in this chapter.

Figure 4-1 shows the CN Tower and the locations of the current measurement instruments, which include two Rogowski coils and a current derivative recording station, containing three independently-operating digitizers. The details of the current derivative recording station are shown in Figure 4-2.

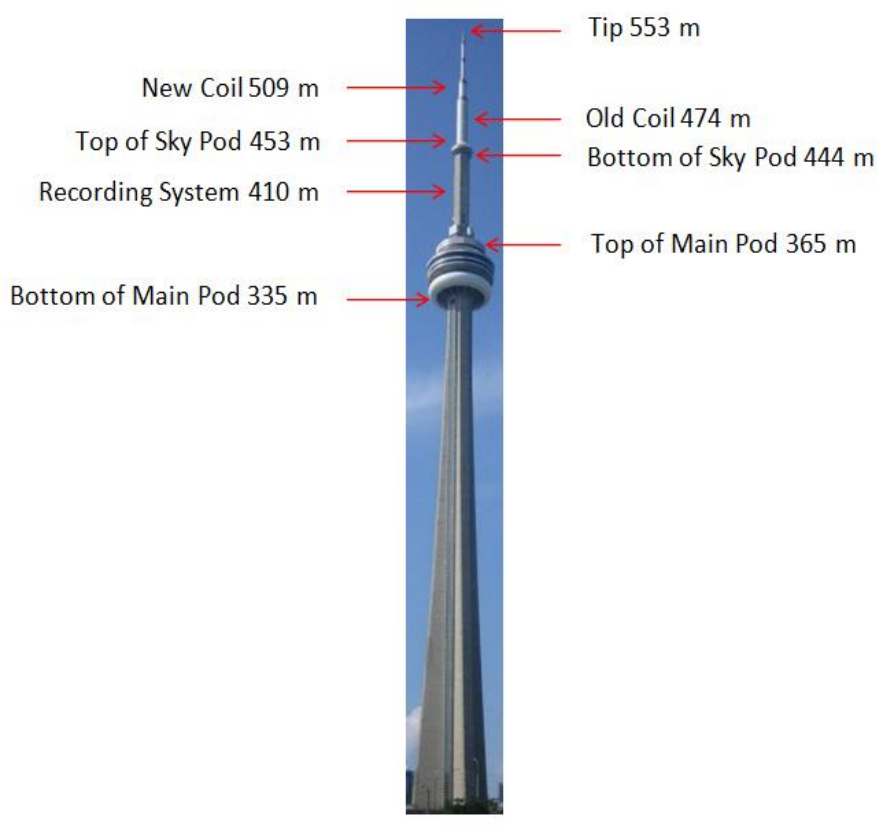

Figure 4-1 CN Tower and current measuring instruments 


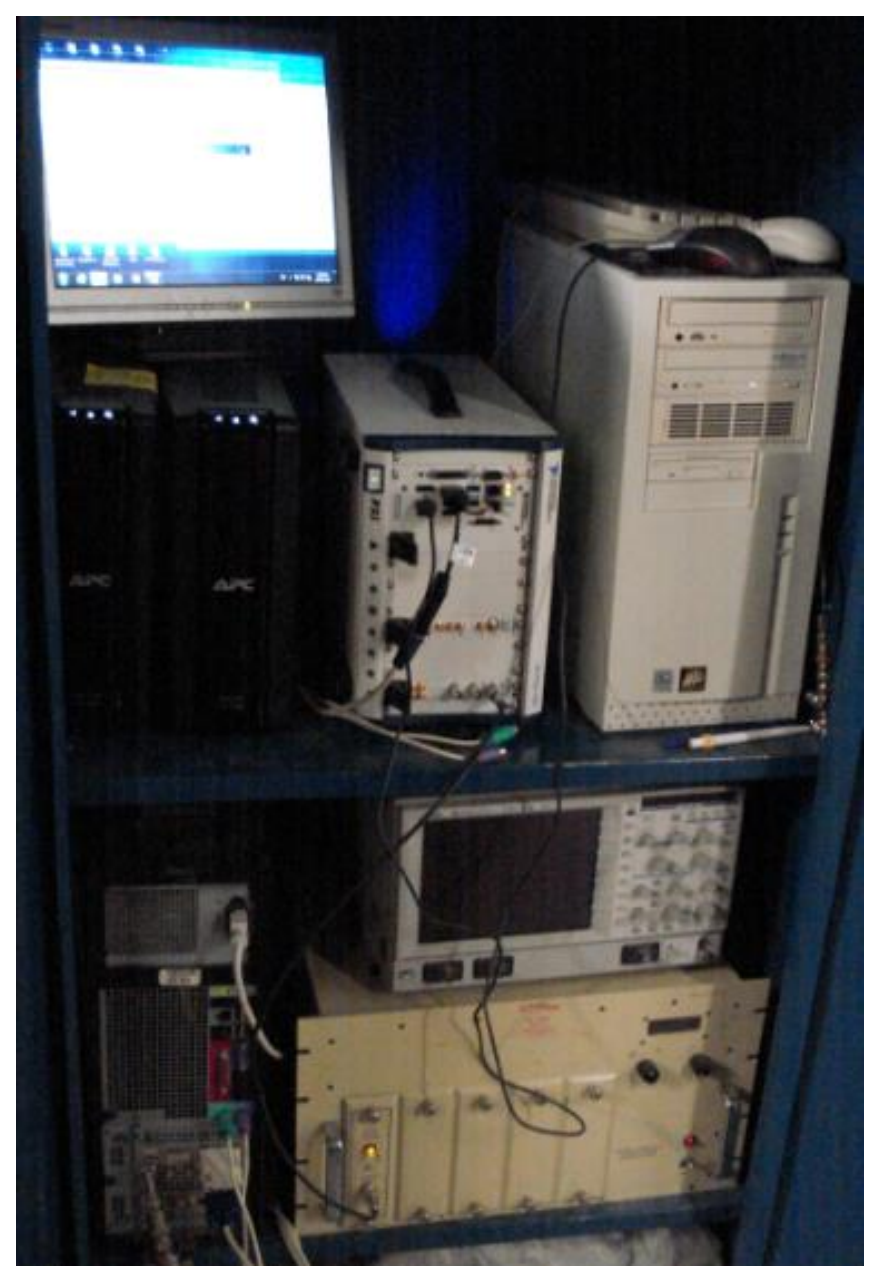

Figure 4-2 CN Tower current recording station

\subsection{Rogowski Coils}

The time derivative of the lightning current flowing through the tower's structure is measured using two Rogowski coils. The first 40MHz-bandwidth Rogowski coil, was installed at the $474 \mathrm{~m}$ above ground level (AGL) in 1989. A second Rogowski coil, with a 20MHz bandwidth, was installed at the 509m AGL in 1997.

Toroidal, nonferrous Rogowski coils have many turns arranged on an insulating core. The voltage induced at the output of a Rogowski coil is proportional to the rate of change of the total current flowing through it. The current is then obtained by numerically integrating the current derivative signal. 


\subsubsection{Old Rogowski Coil}

The old Rogowski is shown in Figure 4-3 encircling one-fifth of the CN Tower's pentagonal steel structure at 474-m AGL. Because of the apparent cross-sectional symmetry, the measured current is assumed to be $20 \%$ of the total current flowing within the tower's structure. The 3-m long coil consists of two-identical segments $1.5 \mathrm{~m}$ each. Each of the two segments is terminated with a resistor at one end in order to absorb reflections. The other ends of the two segments are connected to a $50 \Omega$ impedance matching box. This impedance matching box is presently connected to a National Instrument (NI) PCI 5114 digitizer via a $50-\Omega$ 165-m tri-axial cable (Belden RG-8/U) [58].

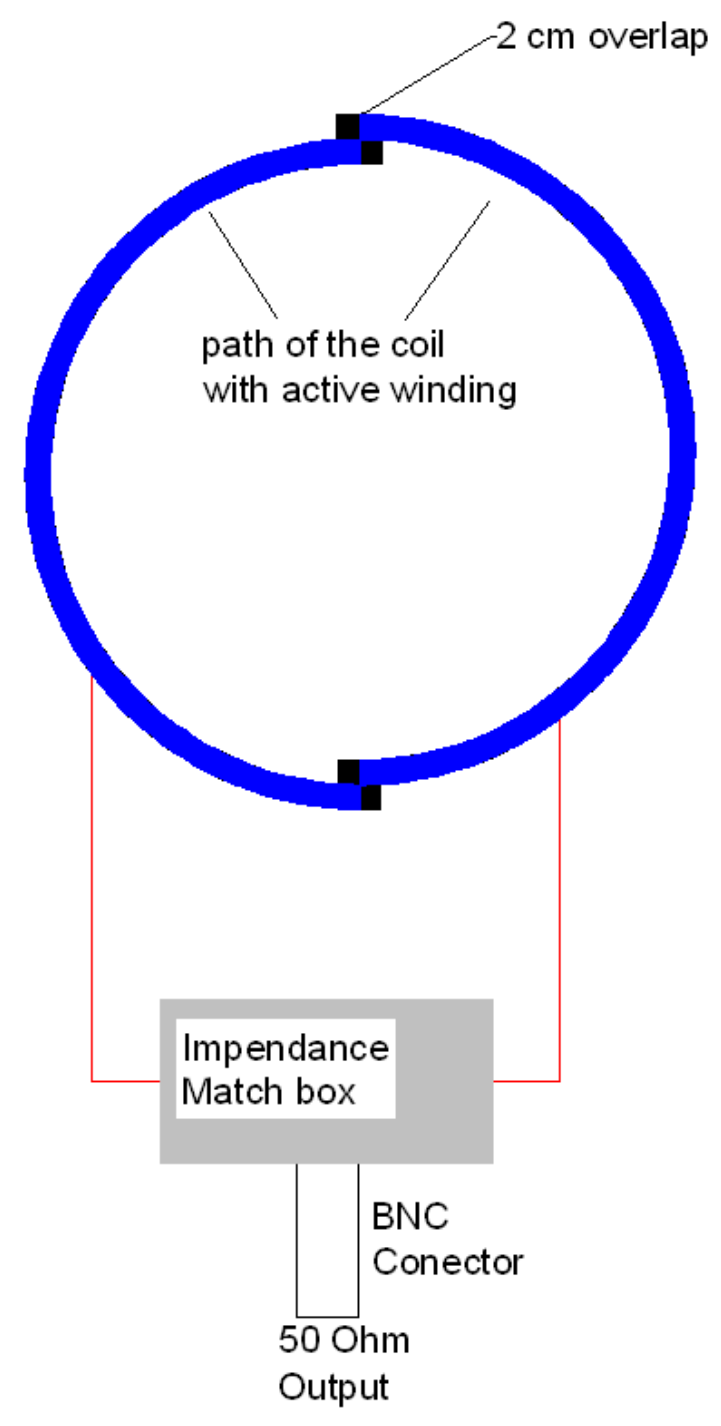

Figure 4-3 Old Rogowski coil

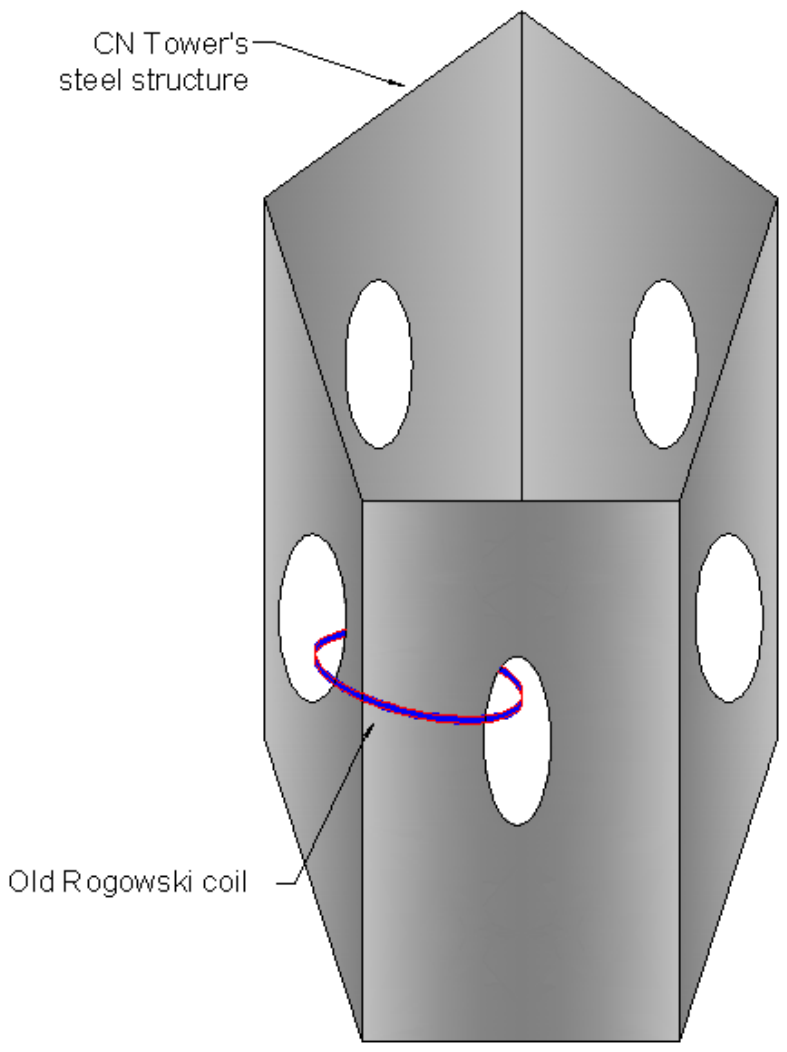


The current derivative of a three-stroke CN Tower flash, recorded on July 4, 2013 via the old coil, is shown in Figure 4-4. Although this flash is negative, it is displayed in Figure 4-4, and the following two figures, as positive for convenience. A time expansion of the third return stroke is shown in Figure 4-5. The current waveform of the third stroke, obtained by numerically integrating the current derivative signal of Figure 4-5, is shown in Figure 4-6.

The old Rogowski coil was calibrated at the CN Tower in May 1997 [59], resulting in a sensitivity of $0.359 \mathrm{~V} /(\mathrm{A} / \mathrm{ns})$, which was close to that quoted by the manufacturer; 0.350 $\mathrm{V} /(\mathrm{A} / \mathrm{ns})$. Figure 4-4 shows that the current recorded via the old Rogowski coil and the tri-axial cable is noisy and is also affected by LORAN-C, a radio navigation signal [60], especially for low-level current derivative signals. Although this fact was the main motivation for acquiring a new Rogowski coil with an optical fiber link, LORAN-C signal level has been recently weakened in the vicinity of the tower, perhaps because of the expanded dependence of global positioning systems for navigation.

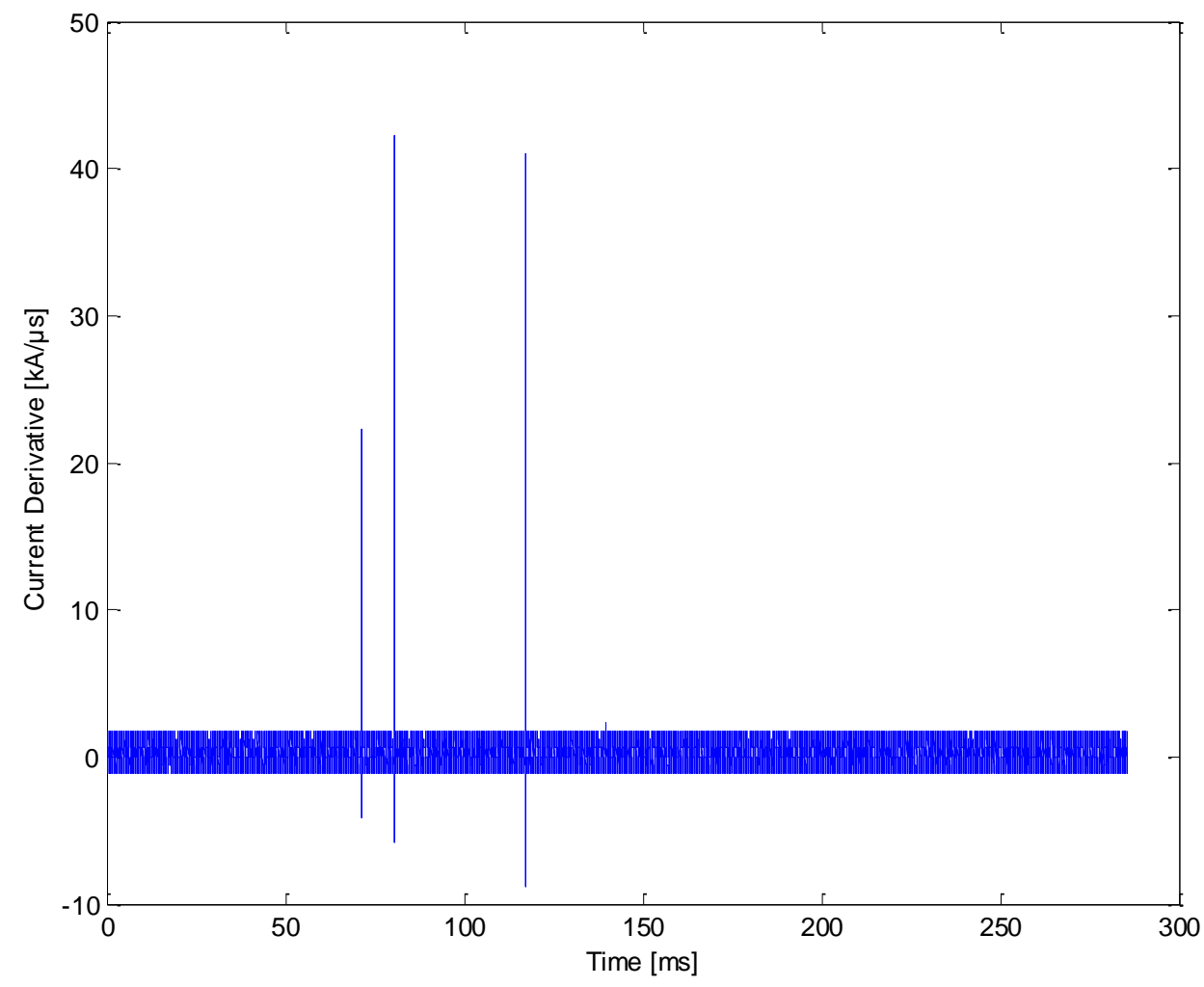

Figure 4-4 Current derivative of a CN Tower flash recorded on July 4, 2013 via the old coil 


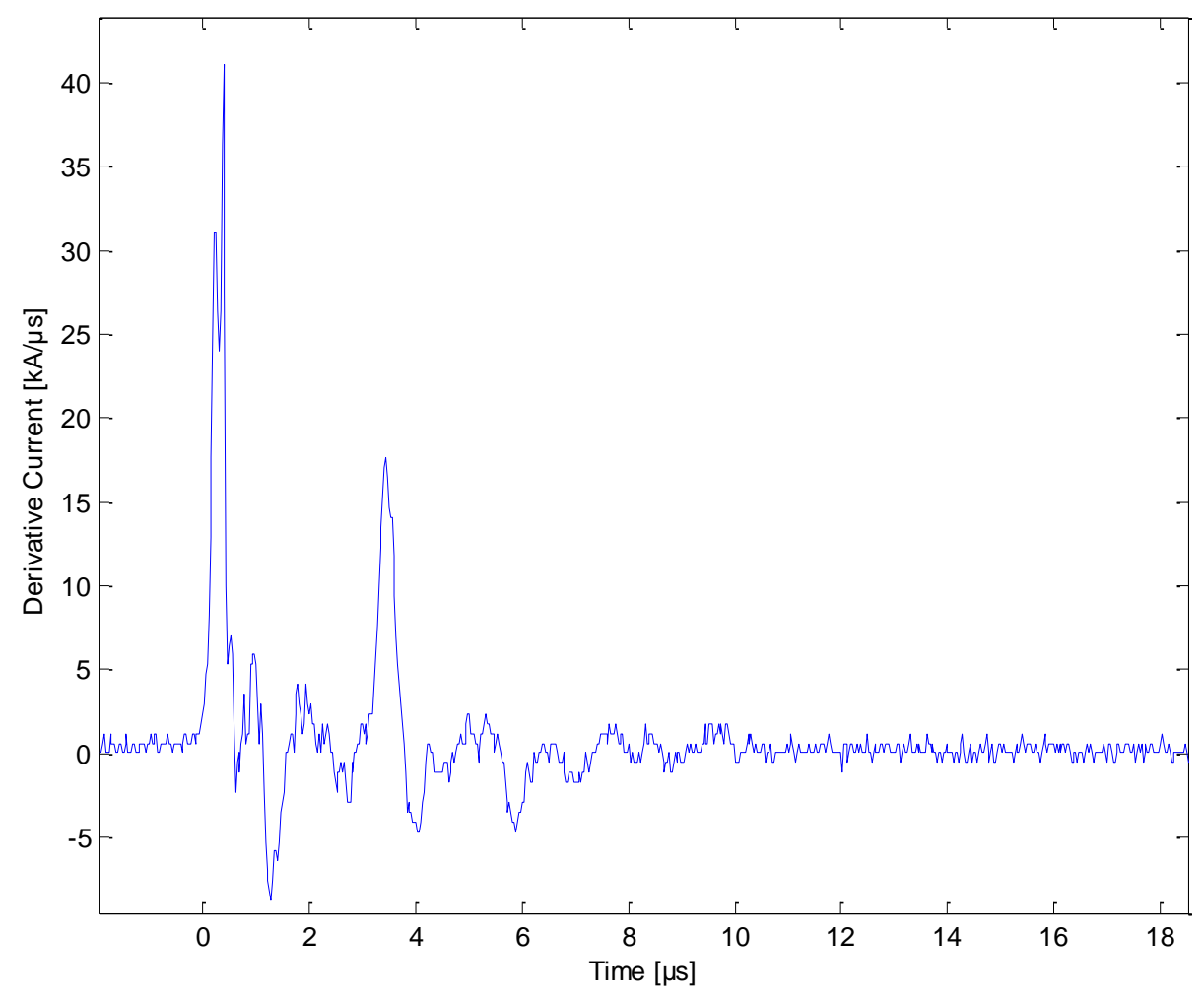

Figure 4-5 Current derivative of the third stroke

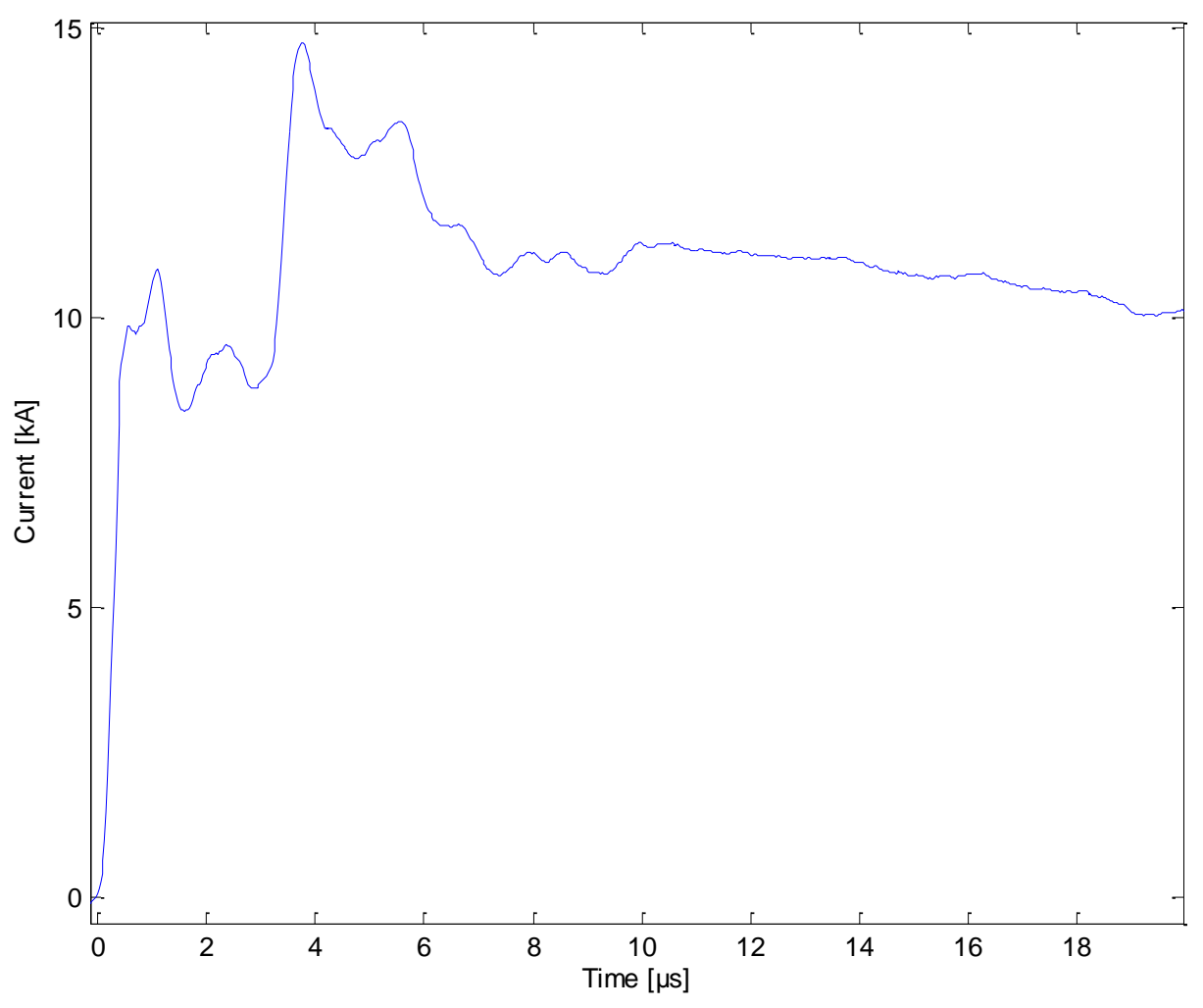

Figure 4-6 Current waveform of the third stroke 


\subsubsection{New Rogowski Coil}

A new 20MHz-bandwidth Rogowski coil with an optical fiber link were installed at the tower in 1997. The new Rogowski coil encircles the tower's pentagonal steel structure at 509-m AGL. The new coil consists of four 1.5-m long segments for a total length of $6 \mathrm{~m}$, Figure 4-7. In this case three matching boxes were necessary. The impedance seen at the output of the third matching box is $50 \Omega$. A $25 \mathrm{~dB}$ attenuator is used between the third matching box and the fiber optic transmitter to ensure that the output of the new Rogowski coil, which can reach a maximum of 16 volts, does not saturate the optical fiber link operating at $\pm 1 \mathrm{~V}$ [61]. The new Rogowski coil was calibrated at the CN Tower in May 1997 [59], resulting in a sensitivity of $1.2642 \mathrm{~V} /(\mathrm{A} / \mathrm{ns})$, which was close to that quoted by the manufacturer; $1.2862 \mathrm{~V} /(\mathrm{A} / \mathrm{ns})$. The current derivative signals measured via the new Rogowski coil proved to have markedly better signal-to-noise ratio than those previously measured by the old Rogowski coil, mainly because of the optical fiber link [60].
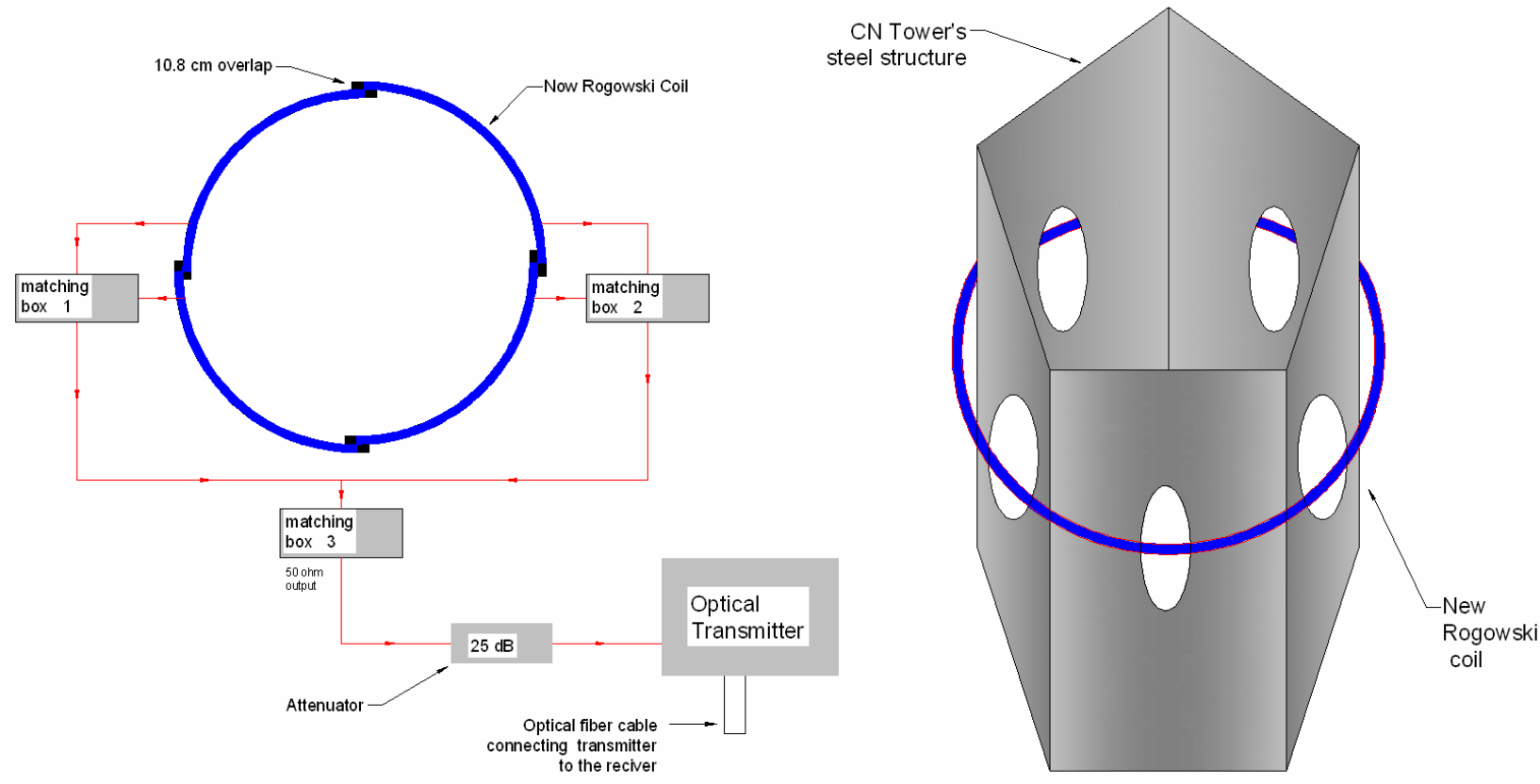

Figure 4-7 New Rogowski coil

The current derivative of a two-stroke CN Tower flash, recorded by a LeCroy LT342L digitizer on July 19, 2013 via the new coil and the fiber link is shown in Figure 4-8. This is a negative 
flash, but it is displayed in the figure as positive for convenience. A time expansion of the second stroke of the considered flash is shown in Figure 4-9. The current waveform of the second stroke, obtained by numerically integrating the current derivative signal of Figure 4-9, is shown in Figure 4-10.

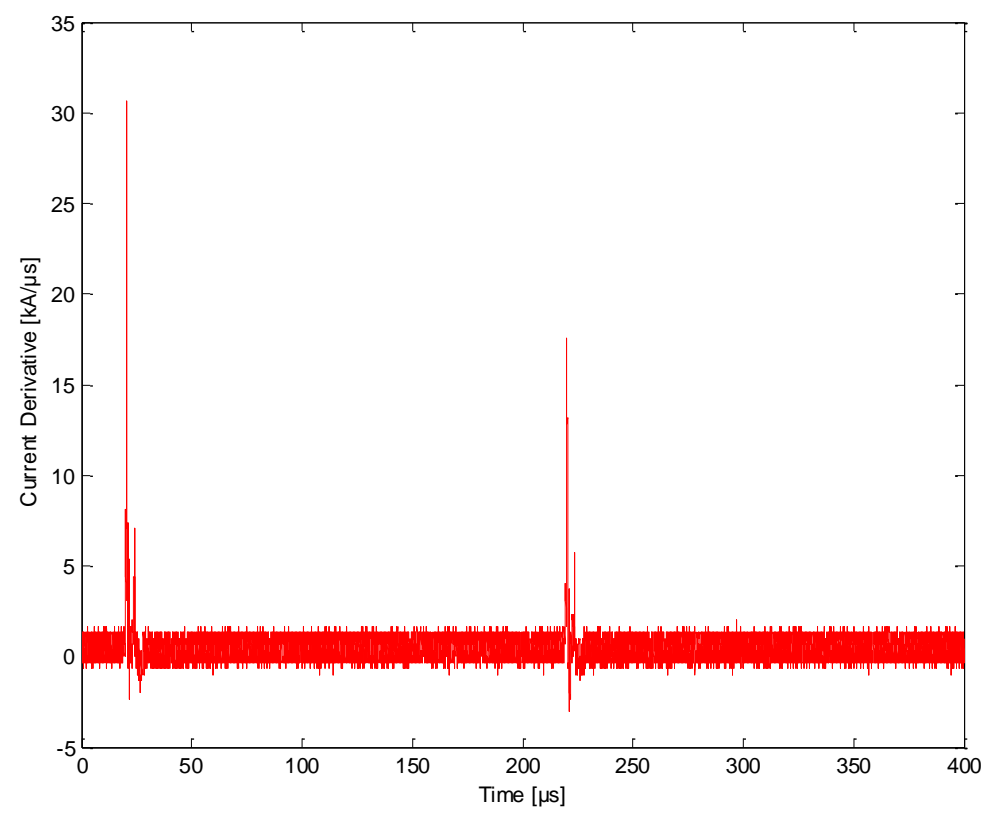

Figure 4-8 Current derivative of a flash recorded at the tower by the new coil, July 19, 2013

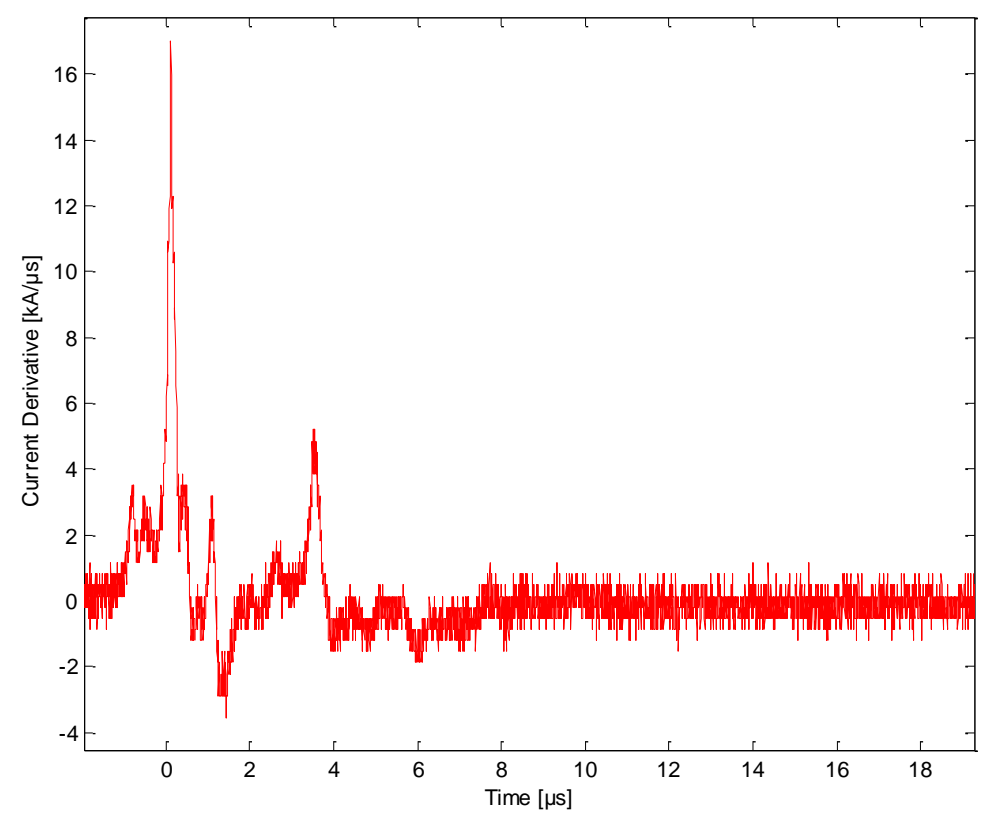

Figure 4-9 Current derivative of the second return stroke 


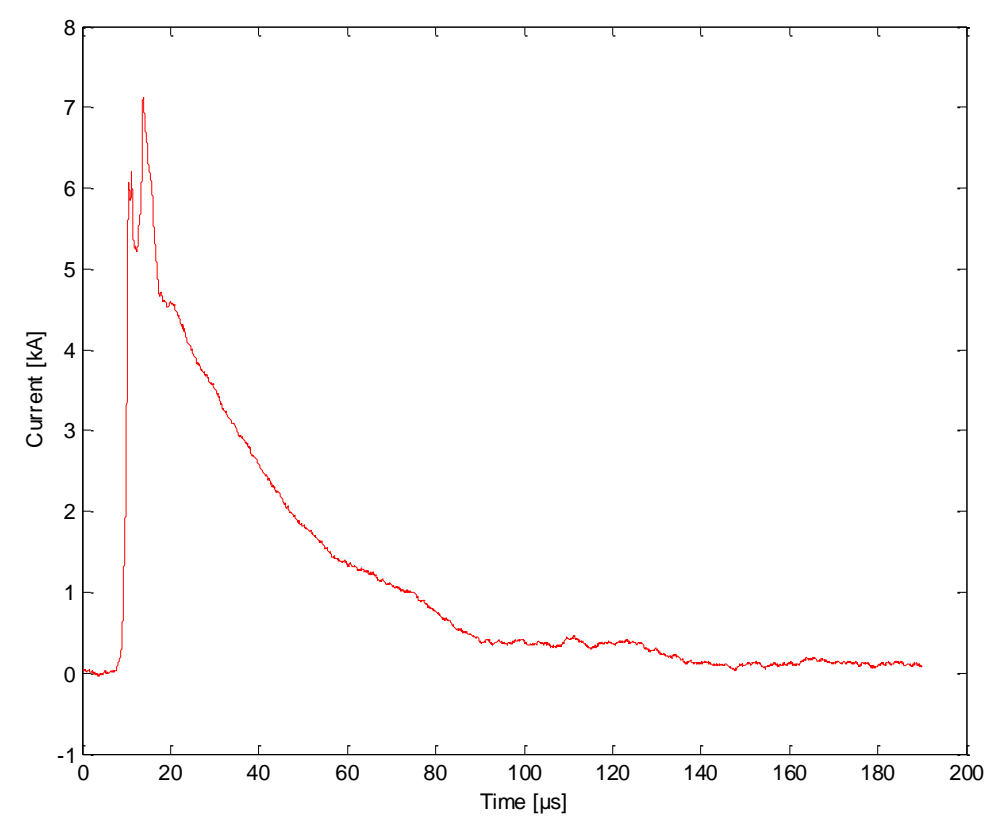

Figure 4-10 Current waveform of the second return stroke

\subsection{Optical Transmission System}

The NanoFast Optical Transmission System (Figure 4-11) consists of Radio Frequency Interference (RFI) protected transmitter chassis with OA-1 Optical Analog Transmitter Plug In board and a 10-1/2" RFI protected receiver chassis with one OA-1 Optical Analog Receiver Plug In board.

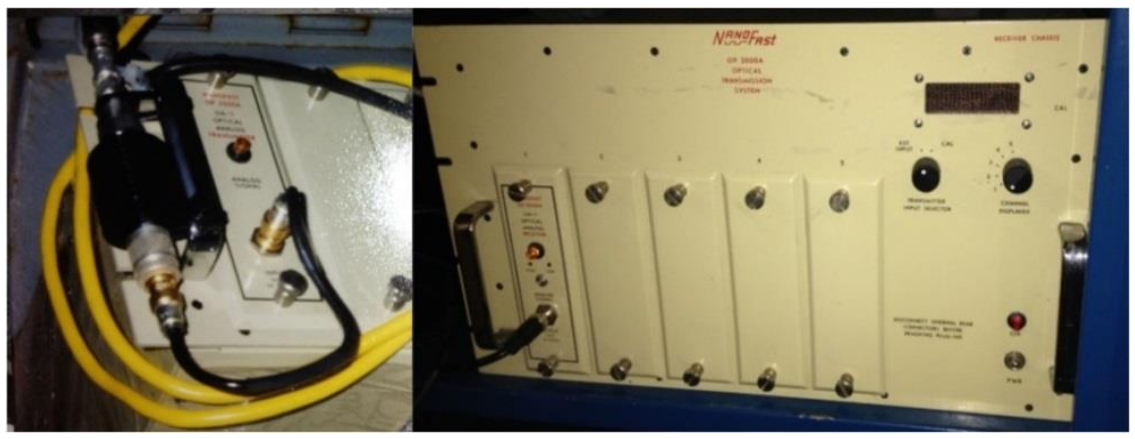

Figure 4-11 NanoFast transmitter and receiver

The transmitter and the receiver are connected with a $150 \mathrm{~m}$ long fiber optic cable. The OA-1 Optical Analog Transmitter provides $\pm 1 \mathrm{~V}$ out full scale into $50 \Omega$ output and the OA-1 Optical 
Analog Receiver accepts $\pm 1 \mathrm{~V}$ in into $50 \Omega$ input. The $3 \mathrm{~dB}$ points are at $35 \mathrm{~Hz}$ and $100 \mathrm{MHz}$. The chassis of the transmitter and the receiver reduce external electromagnetic noise by more than $120 \mathrm{~dB}$ or greater than one million to one. The system is also designed to attenuate any voltage spikes on the AC line, for example a $5 \mathrm{kV}$ spike creates less than $100 \mu \mathrm{V}$ signal into the input of the transmitter and the receiver [62]. The optical fiber link greatly reduces the interfering noise, which is the main problem noticed in current derivative signals captured by the old Rogowski coil via the tri-axial cable.

The current derivative signal recorded via the new Rogowski coil and the Optical NanoFast Transmission System (Figure 4-12) have a markedly better signal-to-noise ratio than that for the signal that was simultaneously recorded by the old Rogowski coil via the tri-axial cable, Figure 4-13.

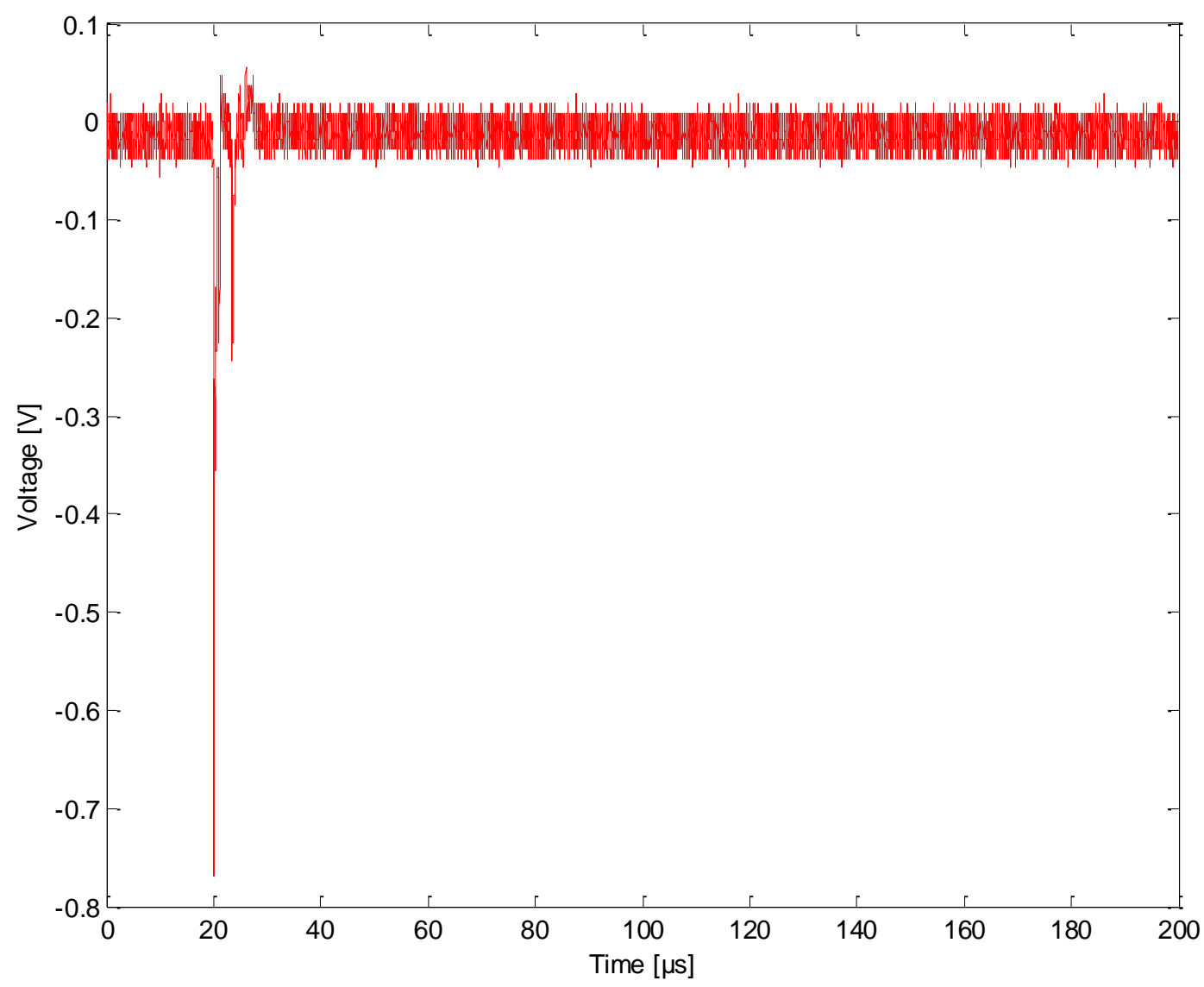

Figure 4-12 A return-stroke raw signal recorded by LeCroy digitizer via the new coil and fiber link on June 12, 2014 


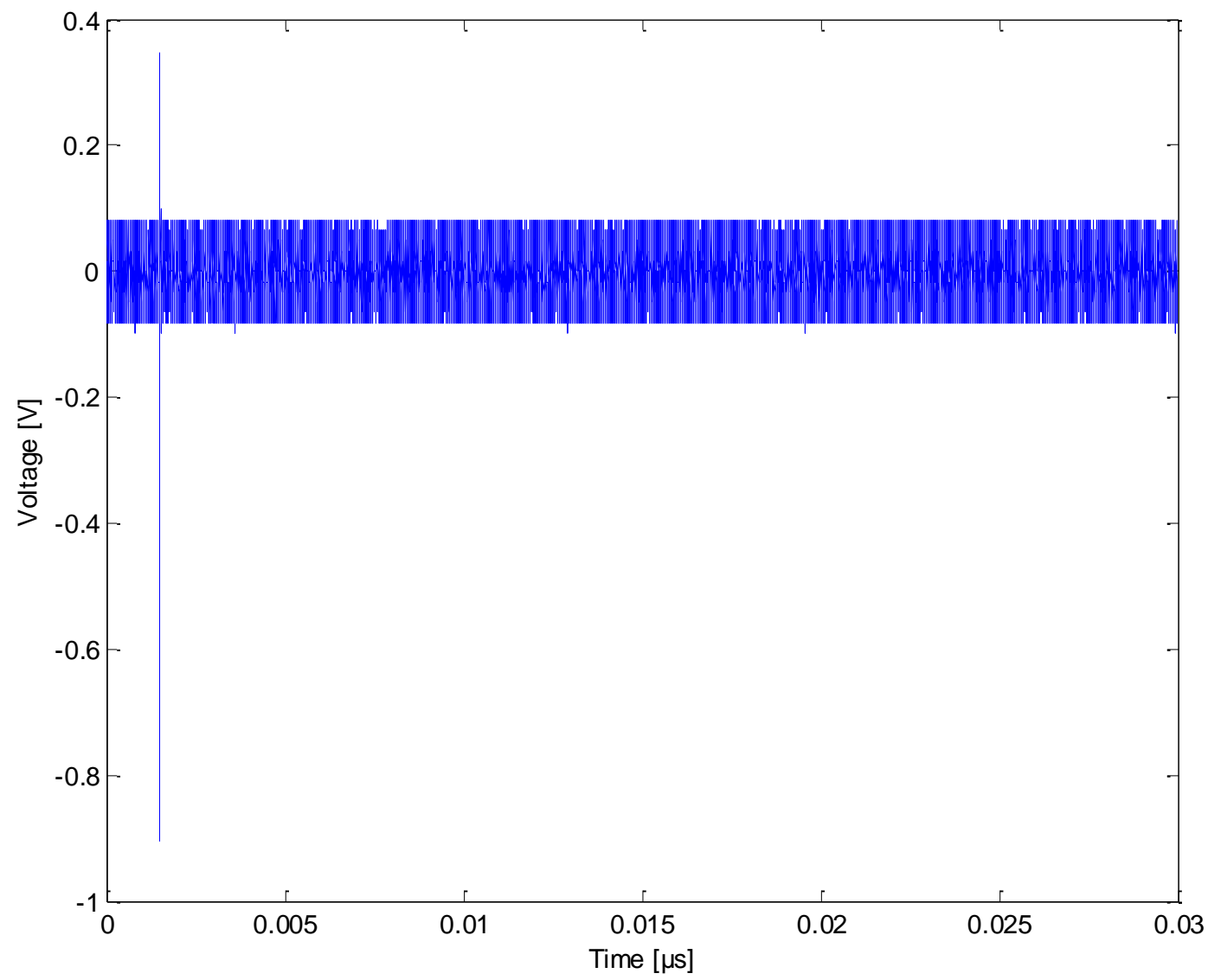

Figure 4-13 Raw signal of the same return stroke, simultaneously recorded by NI PCI 5114 digitizer via the old coil and the tri-axial cable

\subsection{NI PCI 5114 Digitizer}

NI PCI-5114 high-speed digitizer in Figure 4-14 simultaneously samples both input channels at $250 \mathrm{MS} / \mathrm{s}$ with 8 bit resolution. The digitizer has a bandwidth from $12 \mathrm{~Hz}$ to $125 \mathrm{MHz}$ and $2.8 \mathrm{~ns}$ rise time. There are two BNC connectors for the two inputs with impedances of $50 \Omega$ or $1 \mathrm{M} \Omega$ in parallel with $12 \mathrm{pF}$ capacitor software selectable input impedance. The full scale input voltage peak-to-peak is from 0.04 to $10 \mathrm{~V}$. The instrument's triggering capability allows isolating an event and capturing the signal before and after that event. It includes analog edge, digital and software triggering. Other triggering options include window, hysteresis and video triggering. Maximum number of records in onboard memory is $64 \mathrm{MB}$, but it can go up to $256 \mathrm{MB}$ with internal $250 \mathrm{MHz}$ clock or external clock from 50 to $250 \mathrm{MHz}$ [63]. The signal data is transferred from the digitizer to the PC for measurements and analysis. Although the card can sample at its 
maximum rate, the rate at which the data can be transferred to the $\mathrm{PC}$ is limited by bandwidth of the connecting bus such as PCI. At present, this bus is not able to sustain MS/s rates. If the interface bus cannot sustain continuous data transfer at the sample rate of the acquisition, onboard memory on the instrument provides the ability to acquire the signals at the maximum rate and later fetch the data to the PC for processing [63].
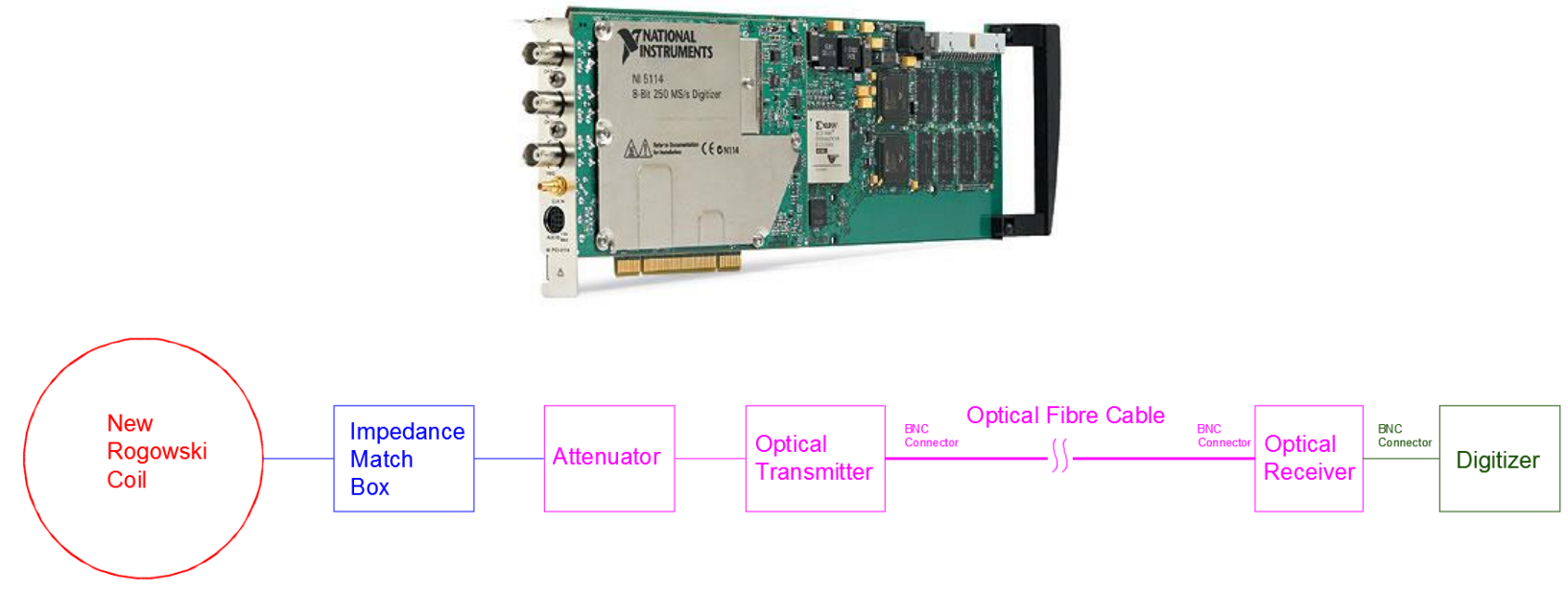

Figure 4-14 NI PCI 5114 digitizer connected to the new Rogowski coil

The driver software is NI SCOPE and the application software is LabVIEW. NI Measurements and Automation Explorer also provide interactive configuration and test tool for the digitizer.

\subsection{LeCroy LT342L WaveRunner}

LeCroy Waverunner digitizer in Figure 4-15 is used for data acquisition signals sensed by the Rogowski coils. The digitizer has a bandwidth from $25 \mathrm{~Hz}$ to $500 \mathrm{MHz}$ and $0.7 \mathrm{~ns}$ risetime. There are two BNC connectors for the two inputs with impedances of $50 \Omega$ or $1 \mathrm{M} \Omega$ in parallel with a $12 \mathrm{pF}$ capacitor front panel selectable. Maximum input voltage is 5VRMS for the $50 \Omega$ input impedance. The oscilloscope can acquire up to 500MS/s with an 8 bit vertical resolution. Although the oscilloscope can sample at its maximum rate, the rate which the data can be transferred to the PC is limited by bandwidth of the connecting bus such as GPIB. This bus is not able to sustain MS/s rates. If the interface bus cannot sustain continuous data transfer at the sample rate of the acquisition, the acquisition memory of $1 \mathrm{Mpt} / \mathrm{channel}$ provides the ability to 
acquire the signals at the maximum rate and later fetch the data to the $\mathrm{PC}$ for processing. The trigger could be set as bi slope, single, or DC [64].

ScopeExplorer is a highly practical PC-based connectivity tool that interfaces Waverunner to a PC that is running Microsoft Windows, via the rear panel GPIB (IEEE 488).
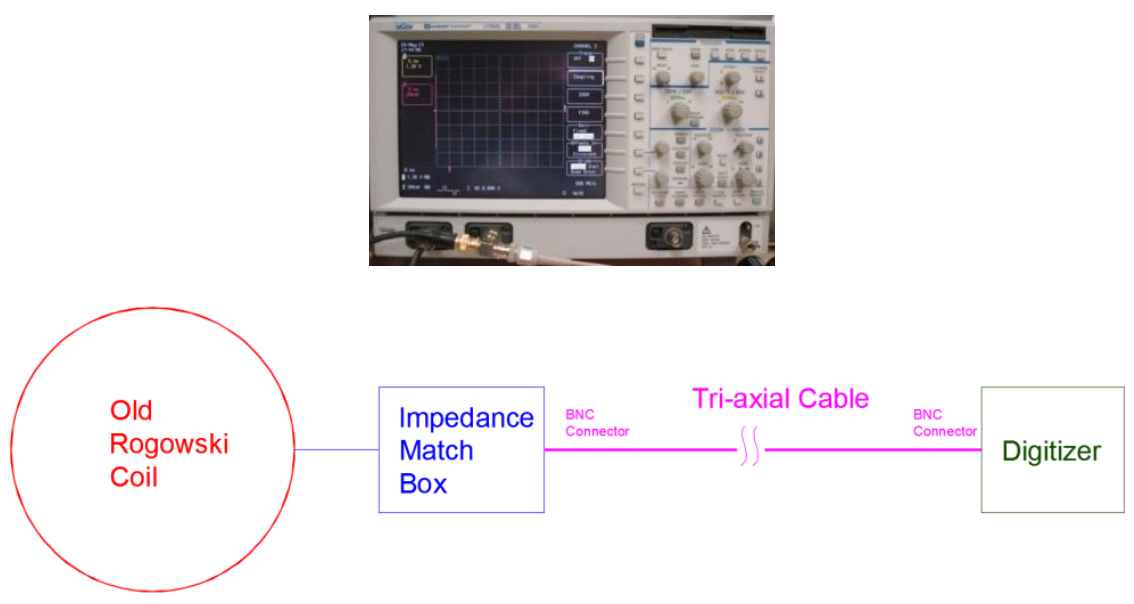

Figure 4-15 LeCroy LT342L Waverunner connected to the old Rogowski coil

The settings on the station are as below:

- $\quad$ CH1: Scale $=1.2 \mathrm{~V} ; 1.2 * 20 / 1.1985=20 \mathrm{kA} / \mu \mathrm{s}$

- $\quad$ Trigger on $\mathrm{CH} 1: \pm 200 \mathrm{mV}$ corresponding to $\pm 3.33 \mathrm{kA} / \mu \mathrm{s}$ (bi slope)

- $\quad$ Time resolution: 4 ns/pt, 50000 pts/segment, up to 20 segments, pre-trigger $=5000$ pts

\subsection{High Speed Camera}

A high speed camera, the Vision Research Phantom v.5.0, has been in use since 2006. It is located $4.73 \mathrm{~km}$ North-East of the CN Tower as shown in Figure 4-16. Digital data captured by the high-speed Phantom camera is being saved to PC via Fire Wire or RS 232 serial interface. It allows pre-trigger and post-trigger recording. The anti-blooming sensor is $1024 \mathrm{x} 1024$ pixels SR-CMOS (complementary metal-oxide semiconductor) color array that captures 1000 fps. Exposure time is $10 \mu \mathrm{s}$. It has IRIG-B timing capture \& standard time annotation. Unprocessed 
original ciné is saved as a separate file and it can be converted in a suitable format manageable in MatLAB. Phantom v.5.0 has a 1024MB internal image storage memory. It records 1024 images for one second of continuous recording at $1000 \mathrm{fps}$, full format [65].

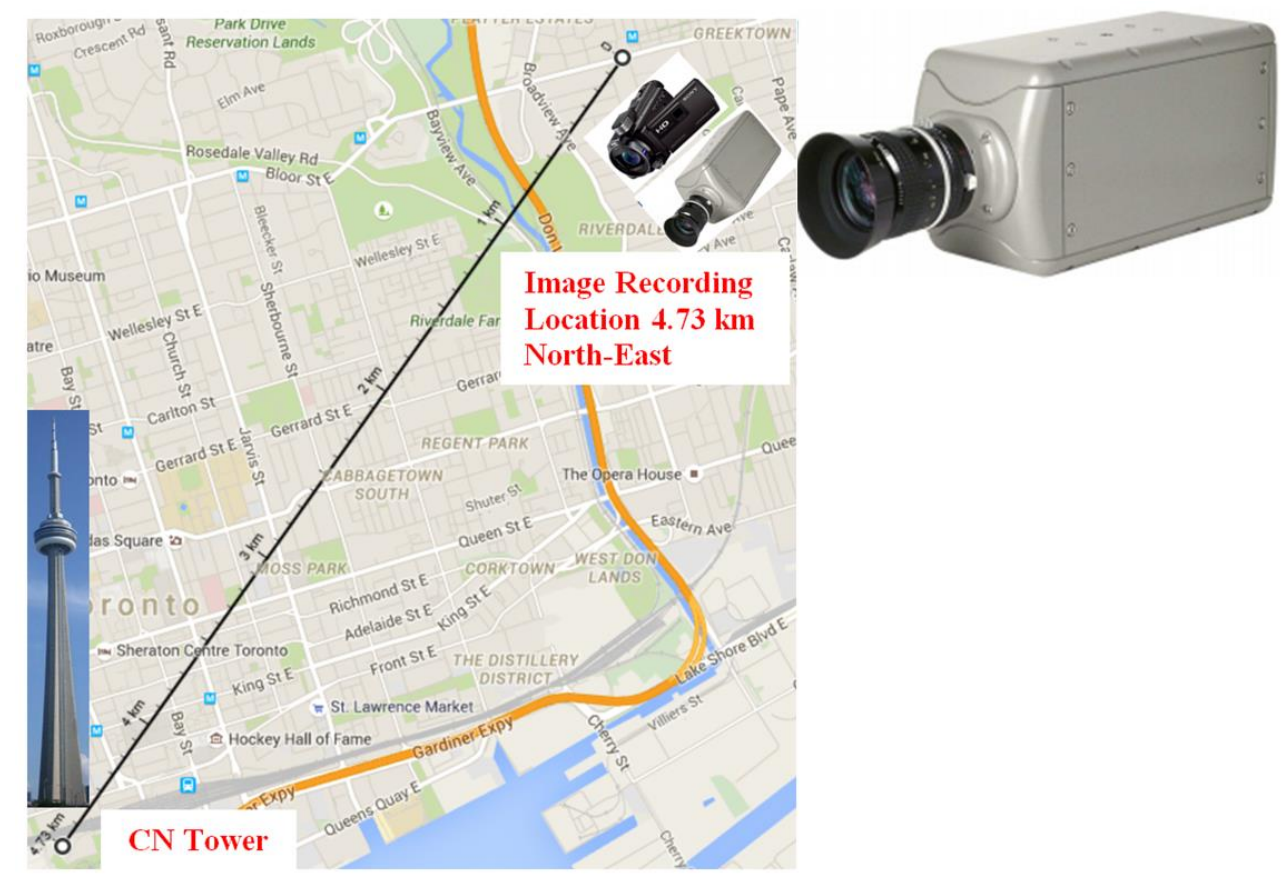

Figure 4-16 Phantom v5.0 high speed camera, present location

The Phantom v5.0 is rugged and can be mounted in any position. Flexible triggering and software features make it possible for the Phantom to run unattended waiting for one or multiple events for 24 hours a day. At present the camera is operating with a resolution of 512 x 512 for a recording time of $1.3 \mathrm{~s} ; 300 \mathrm{~ms}$ are pre-triggering time for initial stage current record and one second for return strokes.

The analysis of $\mathrm{CN}$ Tower lightning flashes is carried out by studying the lightning channel luminosity variation along successive frames within each flash [29]. Figure 4-17 shows one of the high speed camera frames to illustrate the $\mathrm{CN}$ Tower, a not-at-tower downward flash and an upward flash at the tower that did not contain any return stroke, but only the initial stage current. The upper subsection of Figure 4-18 displays time variation of the average luminosity across the width of the channel for a two-stroke flash on July 19, 2013. The channel luminosity time variation reveals the existence of the initial stage current and two return strokes which are confirmed from the corresponding time-matched current derivative, recorded by NI PCI 5114 
digitizer connected to the new coil, in the lower subsection of Figure 4-18. The existence of the initial stage currents corroborates that the flash was an upward one. The current derivative record also defines the stroke polarity.

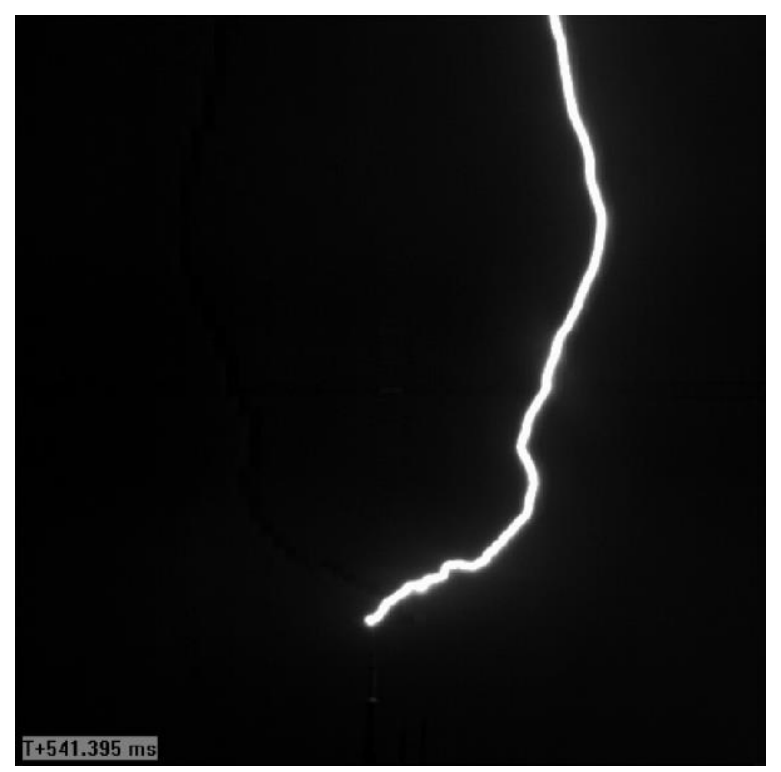

Figure 4-17 CN Tower lightning image recorded by the high speed camera on July 19, 2013
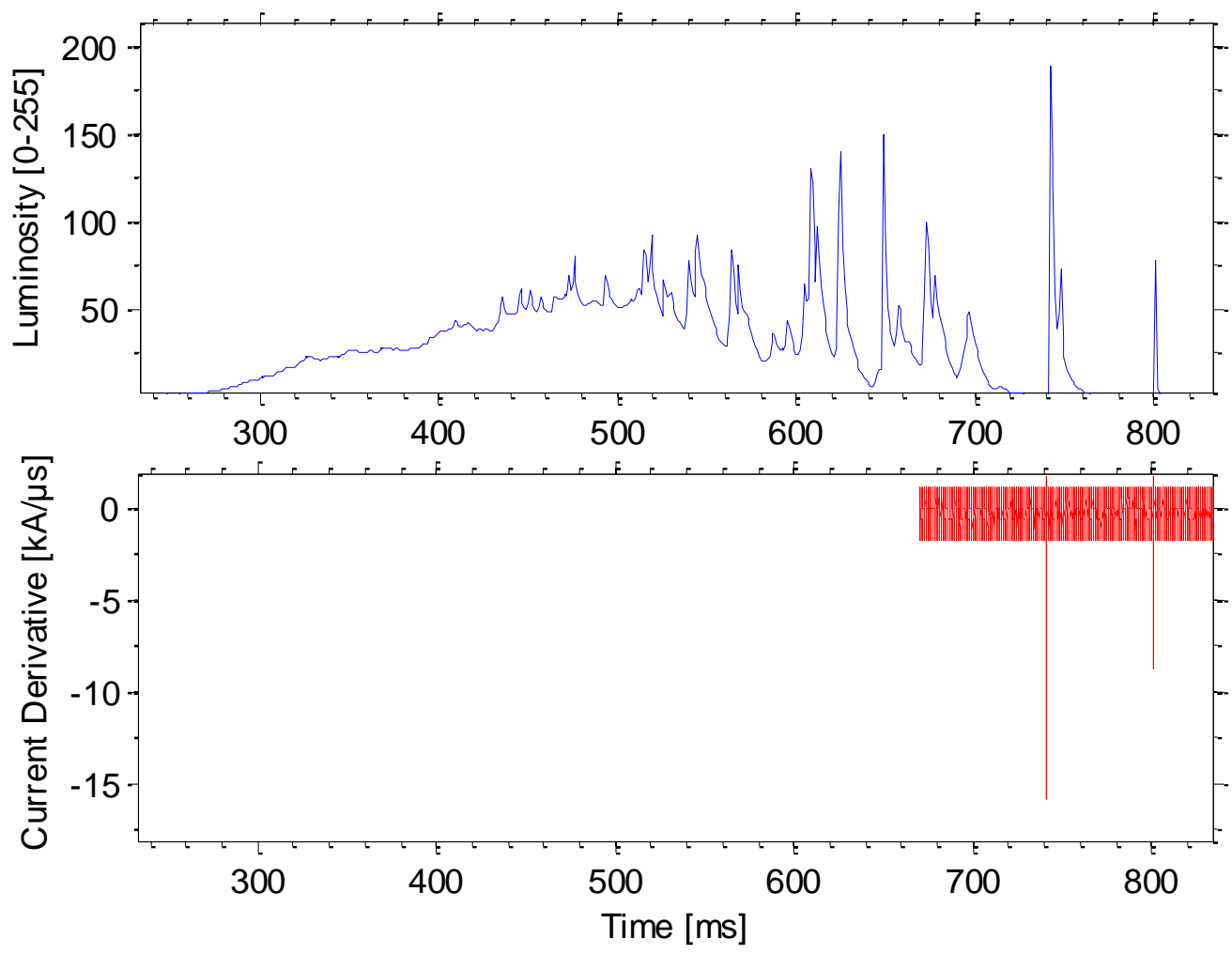

Figure 4-18 Current derivative vs luminosity of a CN Tower flash on July 19, 2013 


\subsection{Low Speed Camera}

The low speed Sony HDR PJ790VB camera in Figure 4-19 is positioned in the same location as the high speed camera.. It is compatible with Windows OS and uses the Play Memories software on a PC. Relevant features of the camera include 60fps, 1920x1080 frame resolution, 96GB of built-in flash memory (up to 38 hours), Exmor®R CMOS sensor, ability to record video to external hard drive, 17x extended zoom in conjunction to 10x optical zoom and shutter speed from $1 / 60$ to $1 / 10000$ of a second [66].

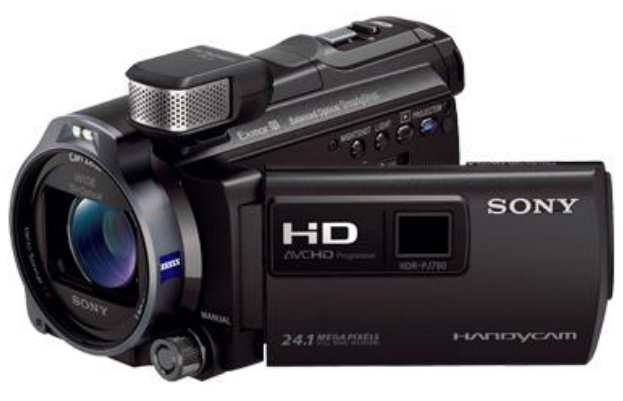

Figure 4-19 Sony camera

CMOS cameras convert the charge to voltage directly at each pixel and do not use shift registers to transfer data. It is convenient to avoid saturating regions from the field of view with a CMOS camera [66].

Figure 4-20 shows one of the low speed camera frames, taken during the 2014 storm. This flash did not contain any return strokes, but only initial stage current. Figure 4-21 shows a perfect time match between NI-PCI-5114 continuously current derivative and the corresponding LSC channel luminosity time variation for a three-stroke flash in September 2014. The channel luminosity time variation of the HSC, which triggered on initial stage current of the flash (it did not have enough recording time to record the return strokes), is shown in the upper subplot of the figure. The LSC has captured the return-stroke images because it is preset to record the entire storm. Also, because the inter-stroke intervals for this flash were greater than the $16.7 \mathrm{fps}$, it was possible to perfectly time match the current derivative recording with the LSC luminosity time variation. 


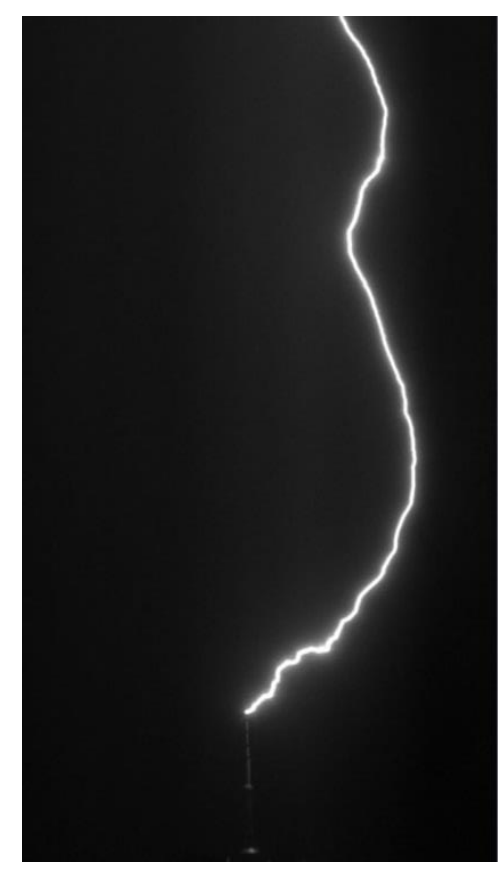

Figure 4-20 Image recorded by Sony camera, third CN Tower flash on September 5, 2014

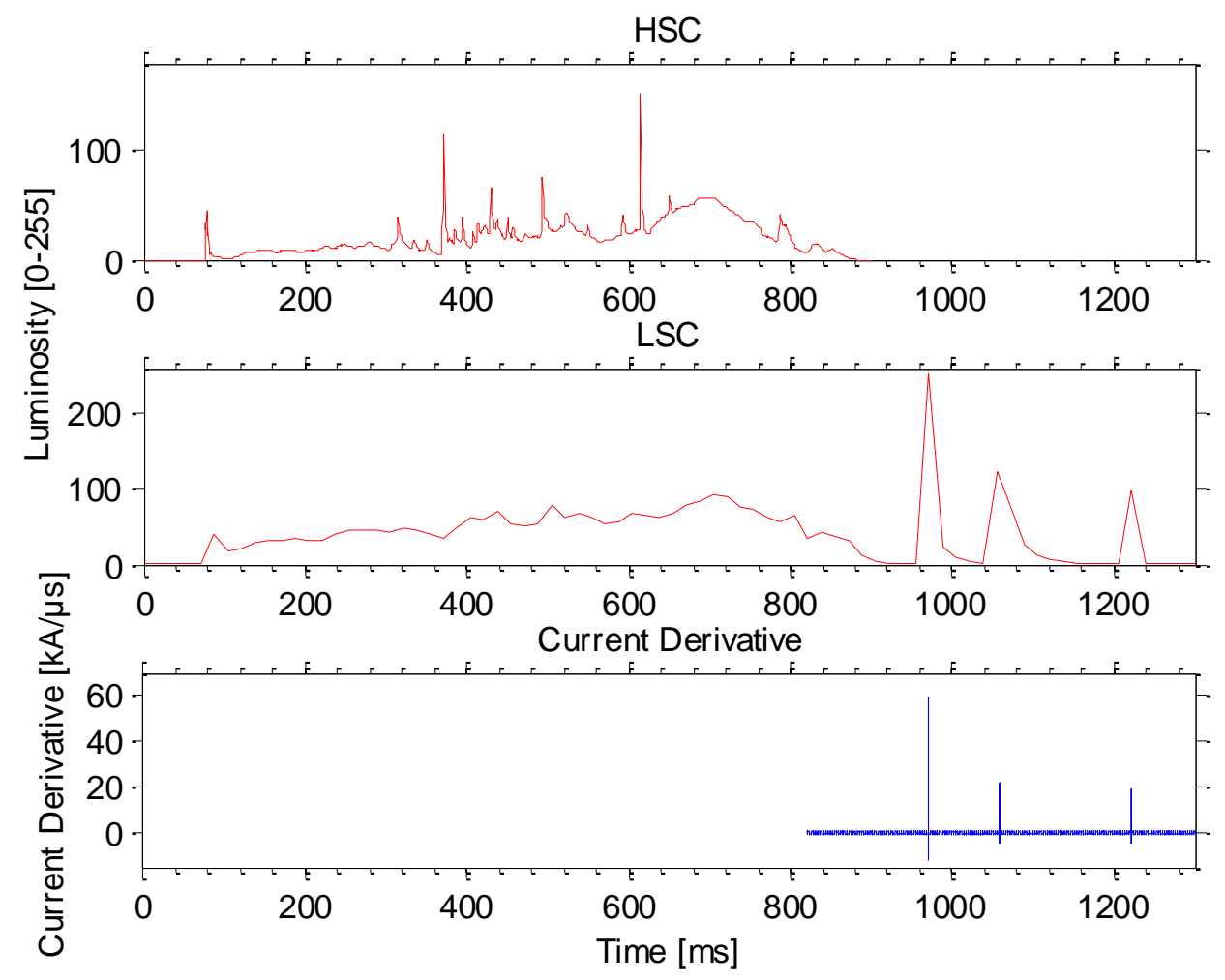

Figure 4-21 Current derivative vs luminosity of flash 19, September 5, 2014 


\subsection{NI - PXIe System}

One of the most important objectives of $\mathrm{CN}$ Tower lightning studies is the proper measurement of the current. In addition to NI PCI 5114 and LeCroy LT342L WaveRunner current recording systems, a NI PXIe system was acquired in 2015. It is programmed to continuously record the lightning current derivative signals for two full seconds with 250MS/s sampling rate. Based on lightning statistics at the tower, two seconds are sufficient to record any CN Tower flash [31]. With 4ns time resolution along with the 10bit signal-level resolution, PXIe system provides enough details to precisely record the lightning current derivative of every CN Tower flash. The main components of the PXIe system include: PXIe-1082 Chassis, NI PXIe-8135 Core i7 Controller, NI PXIE-5160 Digitizer, and NI PXI-6683H GPS Module [63].

\subsubsection{PXIe-1082, 8-Slot 3U PXI Express Chassis}

The PXIe-1082 chassis, shown in Figure 4-22, has eight slots for PXI and PXI express modules. One of the slots can be used as PXI Express system slot and the other slots can be utilized for PXI express compatible, PXI compatible and PXI express system timing compatible. The chassis allows $1 \mathrm{~GB} / \mathrm{s}$ per slot bandwidth with a total bandwidth of $7 \mathrm{~GB} / \mathrm{s}$ for the entire system.

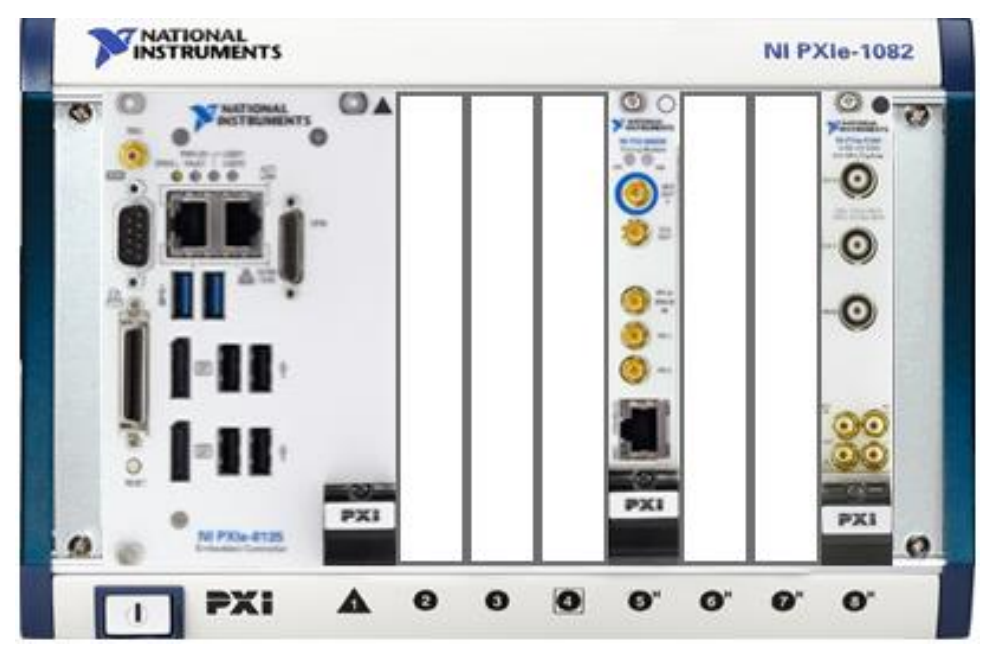

Figure 4-22 NI PXIe - 1082 chassis 


\subsubsection{NI PXIe-8135 Core i7-3610QE 2.3GHz Controller}

The processor of the PXIe system is shown in Figure 4-23. It is a $2.3 \mathrm{GHz}$ CPU clock frequency with PXI express bus type of up to 8GB/s bandwidth. The NI PXIe-8135 has a quad-core Intel Core $17-3610 \mathrm{QE}$ processor, dual channel DDR3 and an integrated hard drive. The system is upgraded with 500GB-2.5 in SATA hard drive compatible with PXI express windows controllers. Also, the system is upgraded with 4GB RAM for a total of 8GB RAM system.
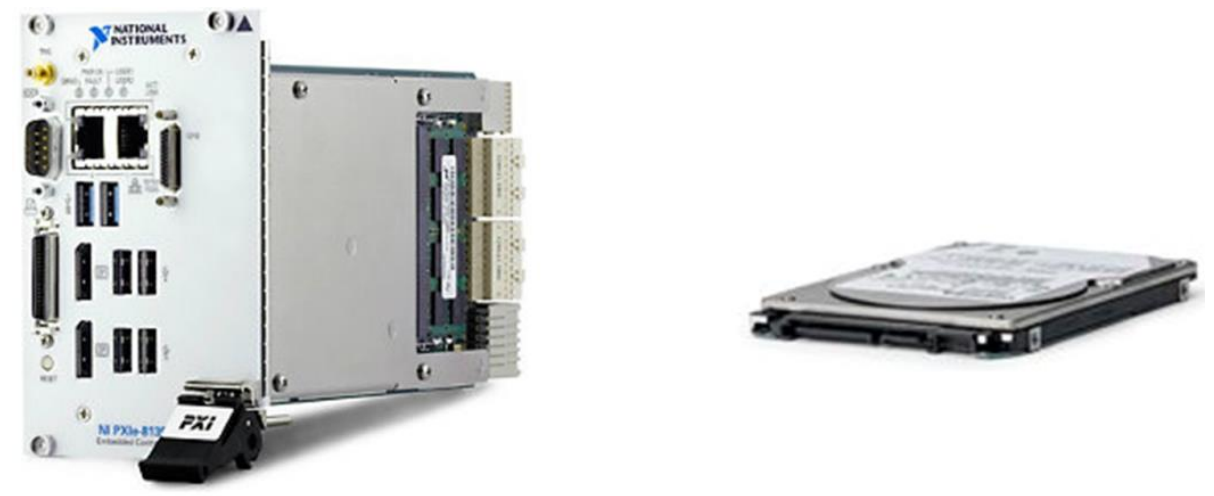

Figure 4-23 NI PXIe - 8135 controller with 500GB in SATA hard drive

\subsubsection{NI PXIe-5160, 2 CH, 2.5GS/S, 500MHz Digitizer with 2GB Onboard Memory}

The digitizer, the most important component of the system, is shown in Figure 4-24. The NI PXIe - 5160 digitizer has $500 \mathrm{MHz}$ bandwidth with $2.5 \mathrm{GS} / \mathrm{s}$ for each of the two channels. Each channel is configurable with $50 \Omega$ and $1 \mathrm{M} \Omega$ input impedance and has an onboard memory of 2GB. It has 10bit signal-level resolution accuracy. It allows an input range voltage of $V_{p k-p k}=$ $5 V$ for $50 \Omega$ input impedance.

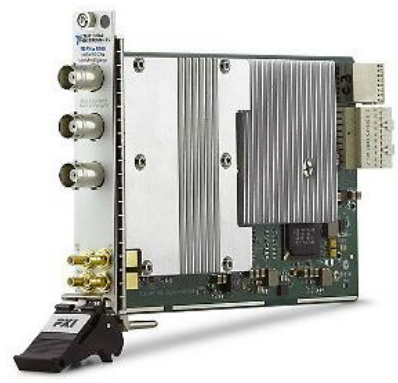

Figure 4-24 NI PXIe - 5160 digitizer 


\subsubsection{NI PXI-6683H GPS, IRIG-B, IEEE 1588 Sync and Time Module with TCXO}

The NI PXI 6683H module, presented in Figure 4-25, is used to synchronize PXI Express structure with GPS system by receiving the signal from GPS antenna. It allows the timestamping of events in PXI Express system.

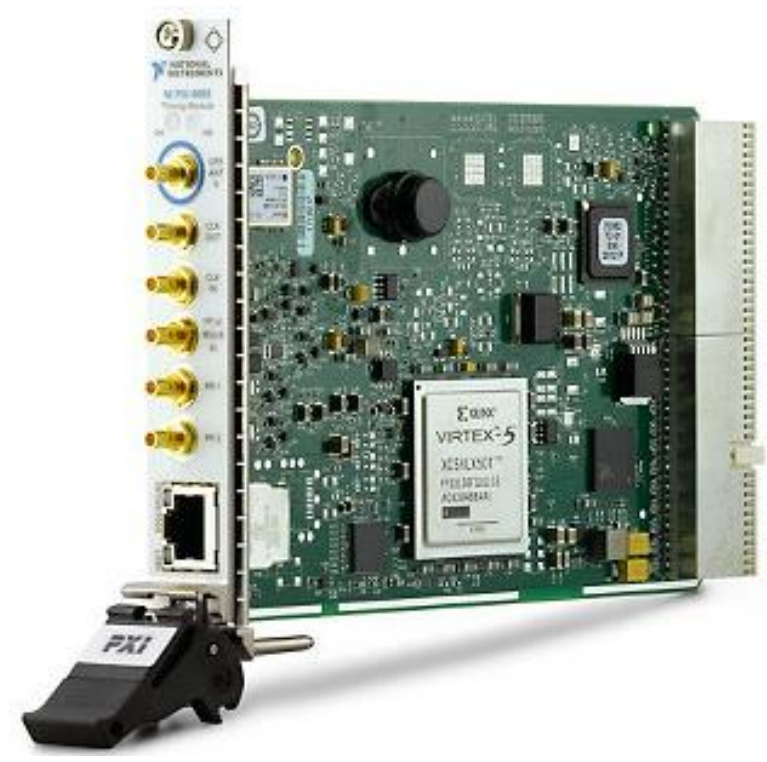

Figure 4-25 NI PXI - 6683H GPS module

The author acquired the new PXIe system through a Natural Sciences and Engineering Research Council (NSERC) grant in May 2015, and he programmed and installed it in October 2015 [26]. It was programmed to record the lightning current signal for two consecutive seconds (five segments of 400ms each) with 250 million points per second with a 10bit signal-level resolution. The first measured CN Tower flash, which took place on December 29, 2015, is shown in Figure 4-26. The PXIe was then connected to the new Rogowski coil. The figure shows a three-stroke flash with inter-stroke time intervals of $27.6 \mathrm{~ms}$ and $15.4 \mathrm{~ms}$. This flash was simultaneously recorded by NI-PCI-5114 digitizer, which was connected with the old Rogowski coil. It is shown in Figure 4-27. The inter-stroke time intervals from both systems are identical. Because of its high resolution and continuous recording, the new PXIe system has the advantage of providing more details of the pulses that are superimposed on slow time-varying initial-stage current (ISC). As Figure 4-26 shows, the new PXIe system did actually trigger on pulses superimposed on ISC. 


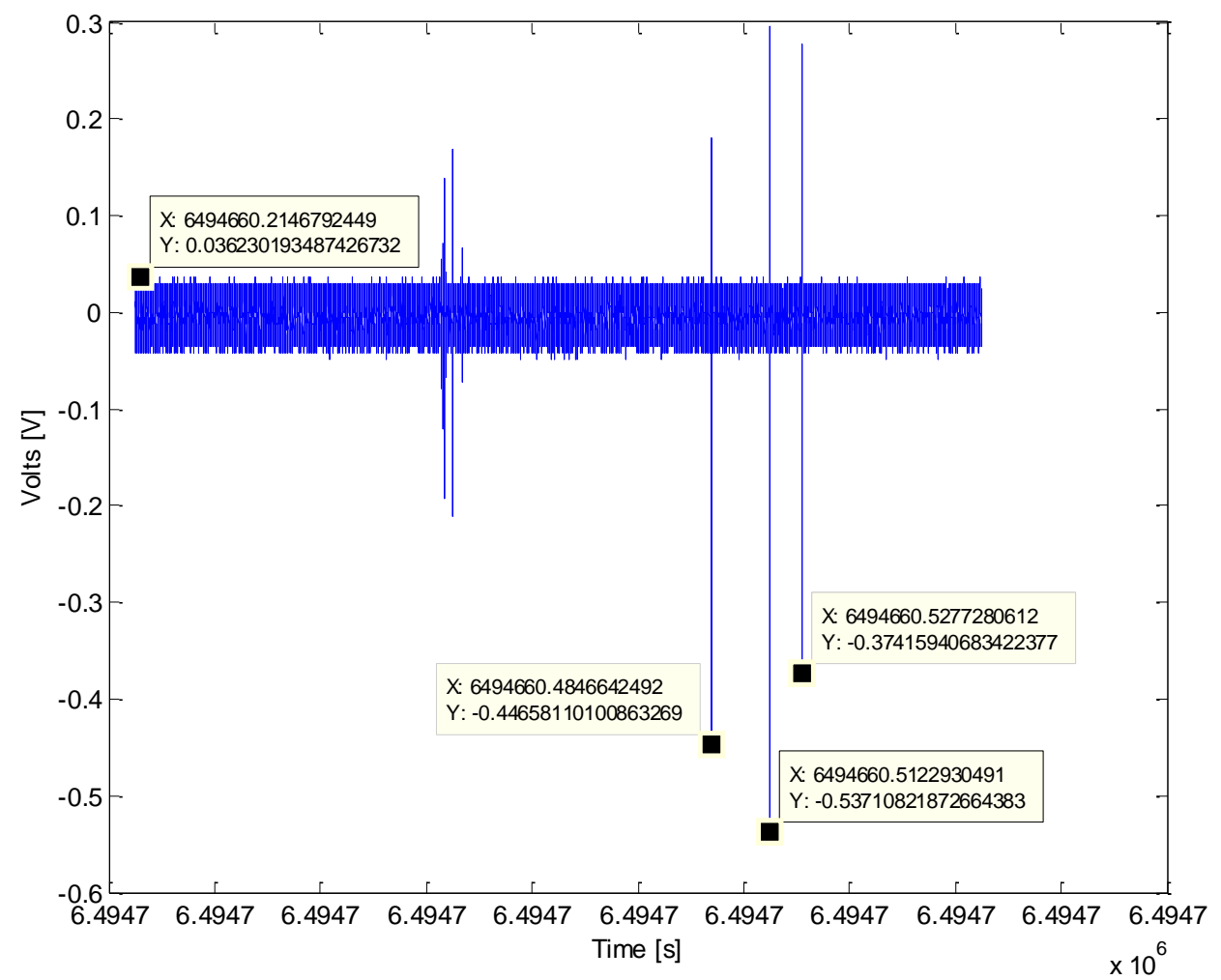

Figure 4-26 First CN Tower flash recorded by PXIe system, December 29, 2015

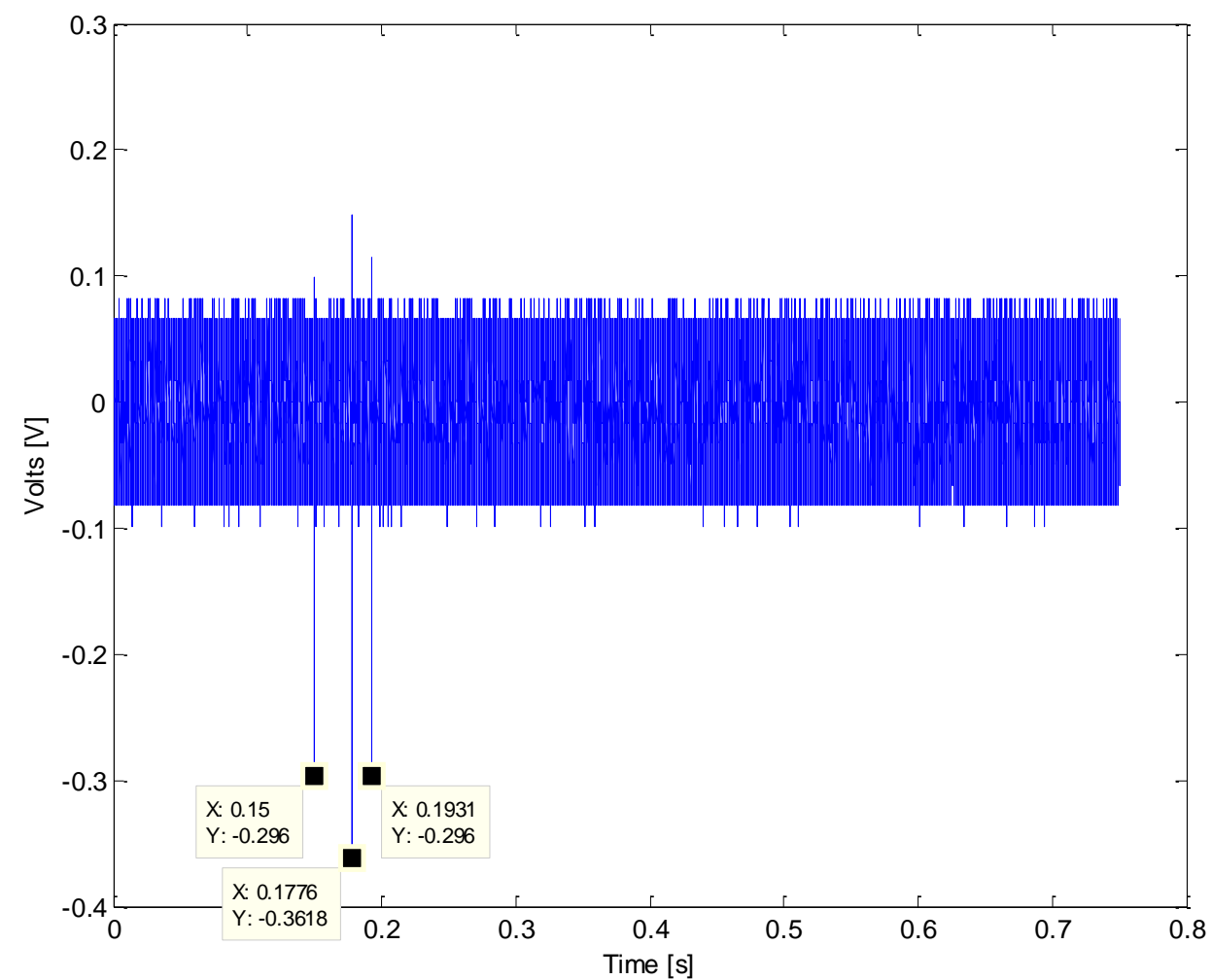

Figure 4-27 CN Tower flash, simultaneously recorded by NI-PCI-5114, December 29, 2015 


\subsection{Summary of Complimentary Nature of the Instruments}

All the equipment used for capturing the lightning current and image at the CN Tower has its own significance in the lightning research.

In order to fully understand a $\mathrm{CN}$ Tower lightning discharge, it is necessary to measure its current and record its trajectory images. Furthermore, it is important to study the lightning discharge macroscopically as well as microscopically. For example, Sony HDR PJ790VB low speed camera (LSC) is used for continuous recording of the lightning event at the tower. It can record continuously for 38 hours and provide all the information about the entire storm. It can help on verifying that the rest of the equipment is up and running and validate their efficiency on recording lightning at the tower. Also, LSC is crucial in determining inter-flash time intervals and the classification of the flashes into upward or downward. Apart from determining directions of flashes, the high speed camera (HSC), operating at 1ms resolution, is so valuable in providing details of return strokes, such as the number of return strokes, inter stroke intervals, the presence of initial stage current (ISC), continuing current (CC), M-components and ISC pulses. It also provides crucial information about ISC, $\mathrm{CC}$ and $\mathrm{M}$-component time durations, all very important in lightning protection standards.

The LeCroy digitizer, connected to either the new or the old Rogowski coils, is important in making available details about the return-stroke current polarity. Also, it gives the particulars about the risetime and decay time of return-stroke currents and its amplitude of the current. The NI PCI 5114 digitizer, connected either to the new or old Rogowski coils, provides continuous recording of the flash. It is essential for determining the number of strokes per flash, stroke polarity and inter-stroke intervals.

The new PXIe system has been designed (4ns time resolution, 10 bit resolution for two seconds of continuous recording, which is sufficient to record any flash at the tower) for the CN Tower current measuring system to provide a better insight of the ISC, CC and M-components as part of the complete flash characteristics at tall structures. 


\section{Performance Characteristics of NALDN based on CN Tower Lightning Data}

In this chapter, the performance characteristics of the North American Lightning Detection Network (NALDN) are investigated based on three distinctive CN Tower storms that took place in 2005, 2011 and 2014, each struck the tower at least several times. Also, the CN Tower lightning data and the network upgrades prior to each storm are included. The developmental stages of NALDN are presented in Appendix D. Furthermore, the characteristics of a flash recorded in 2015 by the newly designed current recording system are comprised.

Lightning flashes to tall objects together with rocket-triggered lightning are the direct ways to validate the performance characteristics of lightning locating systems (LLSs) [14]. Instrumented towers have provided lightning truth data for validating the performance of LLSs [20], [25]. The CN Tower is presently the second tallest structure that is instrumented for lightning studies. It is important to mention that downward-initiated lightning, representing the overwhelming majority of ground lightning, is rarely measured at very tall structures, such as the CN Tower. Therefore, the evaluation of the performance characteristics of LLSs based on the distinctively different first return stroke for ground lightning is difficult based on very tall structure lighting data.

The first storm, which took place on August 19, 2005 [57], is here analyzed for the evaluation of NALDN performance characteristics. Although this storm was previously utilized for evaluating the network performance characteristics [25], the obtained NALDN data then was based on $100 \mathrm{~m}$ stroke-location resolution. Recently, the 2005 NALDN data was obtained at a much better location resolution of $10 \mathrm{~m}$. Also, careful analysis of the 2005 storm data produced one more $\mathrm{CN}$ Tower stroke. Furthermore, in the new analysis, the NALDN estimated peak current is correlated to the first peak of the CN Tower measured current waveform, instead of the absolute peak used in earlier network's evaluation [25]. On August 19, 2005, two different storms occurred. Only the second storm is used in this analysis because it was more extensive. The objective of this research has been to evaluate the NALDN performance characteristics using a single storm after each of the three NALDN upgrades. The return-stroke current derivative signals of the selected 2005 storm were simultaneously measured via the old and new Rogowski 
coils at $8 \mathrm{~ns}$ resolution. The corresponding channel trajectory images were recorded by HSC (2ms resolution) and LSC (33ms resolution).

The second considered storm for the network evaluation is indeed the most severe lightning storm ever recorded at CN Tower. It took place on August 24, 2011 and it produced 52 flashes to the tower in about 84 minutes [29], [30], [67]. Out of the 52 video-recorded flashes, 32 were recorded by the $\mathrm{CN}$ Tower current measurement system, containing a total of 156 return strokes. During this storm, the current derivative of each $\mathrm{CN}$ Tower flash was measured via the old coil and was continuously recorded by the NI-PCI-5114 digitizer for two full seconds with 220ns time resolution.

The third selected storm, which took place on September 5, 2014, comprises lightning data simultaneously collected by two independent CN Tower current measurement systems. All flashes were optically recorded by HSC (1 ms resolution) and LSC (16.7ms resolution). Nine out of the storm's 24 optically-recorded flashes were recorded by the two current measurement systems (LeCroy LT342L, operating at 4ns resolution, and NI-PCI-5114, operating continuously at 100ns resolution) [31]. Evaluation of network's performance characteristics based on 2014 CN Tower lightning data has been completed [21], [68].

As part of this study, a new current recording PXIe system was installed and commissioned at the tower in 2015. The first flash was recorded on December 29, 2015, featuring 4ns resolution and 10-bit signal-level resolution with two seconds continuous recording. Evaluation of NALDN performance with these data forms a new contribution to this dissertation.

\subsection{Data}

During the considered 2005 storm, the CN Tower was struck with seven flashes, according to Phantom v-2 high-speed camera (HSC), operating at $2 \mathrm{~ms}$ resolution. The current derivative recording system, however, recorded only six flashes because the fourth of the seven flashes contained only an initial-stage current (ISC). The CN Tower current derivative recording systems are usually programmed to trigger on return stroke currents that feature much higher wavefront rise than that for low-varying ISCs. Figure 5-1 shows the relative times of occurrence 
of the storm's seven flashes that struck the tower within 90 minutes on August 19, 2005, based on optical and current records. The figure also displays the number of return strokes per flash for each of the six current-recorded flashes. The black dot in the figure refers to the fourth nonstroke flash that was only optically recorded.

The NALDN detected only six of the storm's seven flashes. Each of the NALDN flashes contains at least one return stroke as shown in Figure 5-1. Since the NALDN is not designed to detect tall-structure ISCs, the flash detection efficiency is defined based on flashes that contain at least one return stroke, as always the case of downward ground lightning. Therefore, the NALDN flash detection efficiency of the studied 2005 storm is $100 \%$. It is also noted that 21 out of $38 \mathrm{CN}$ Tower measured return strokes were detected by the network, resulting in $55.3 \%$ stroke detection efficiency.

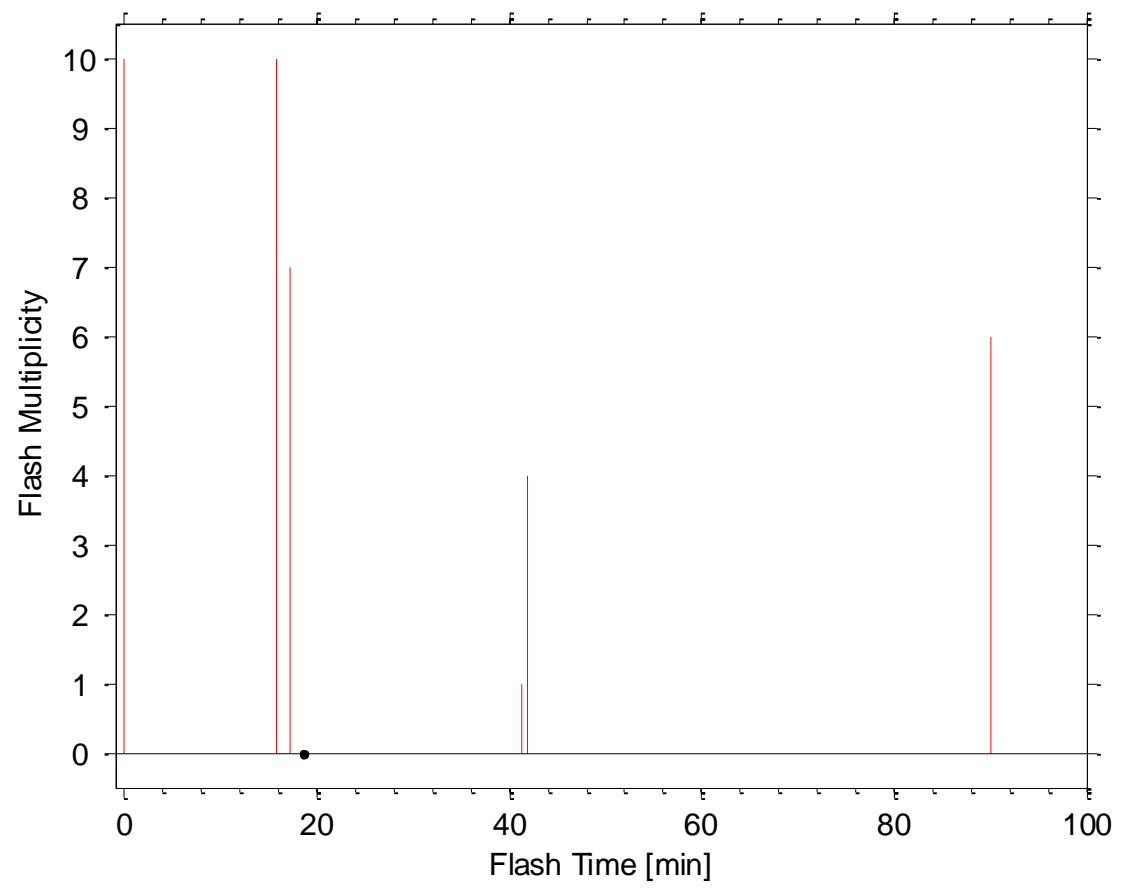

Figure 5-1 Relative times of occurrence of CN Tower flashes, 2005 selected storm

Figure 5-2 presents the luminosity analysis, based on HSC optical records, as well as the amplitude of the currents for the second flash of the selected 2005 storm that contains ten return strokes [57]. The perfect time match between luminosity peaks and independently recorded currents are clear. The duration of the current record of each return stroke is $200 \mu$ s, which basically explains the existence of vertical lines indicating current peaks. 
Figure 5-3 shows the frames of HSC recorded images for the second flash. The images were recorded at $2 \mathrm{~ms}$ resolution. In order to fit important flash frames in one page, some frames at the beginning, belonging to the initial-stage current, and some appeared after the last return stroke are not included in the figure. The frames indicating return strokes are clearly visible, they are also marked with red dots. It is noted that visible trajectories appeared after return strokes 2,3 and 10 , pointing out to the presence of continuing currents with duration exceeding $2 \mathrm{~ms}$.
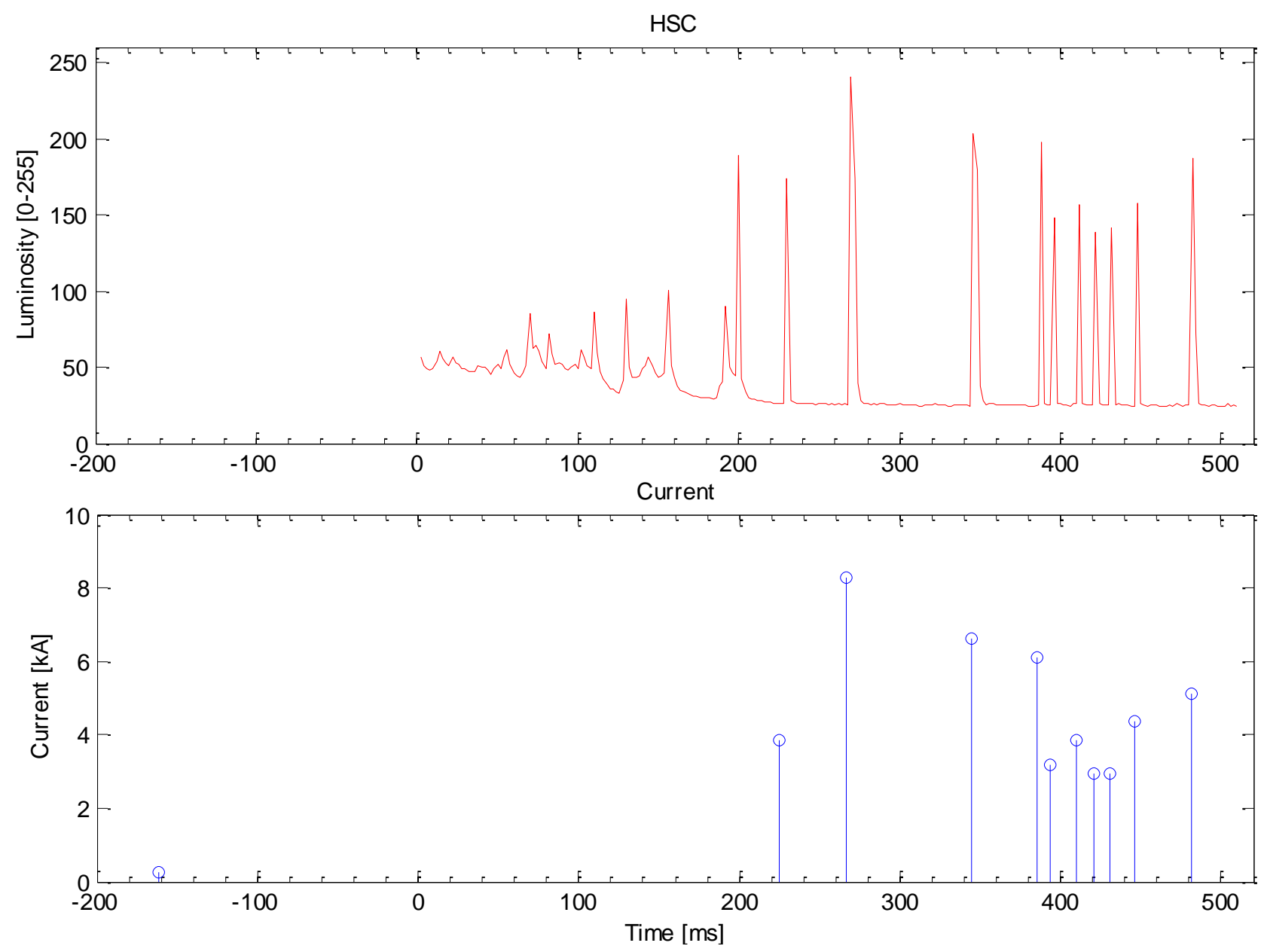

Figure 5-2 Current and channel luminosity of second flash, 2005 selected storm 


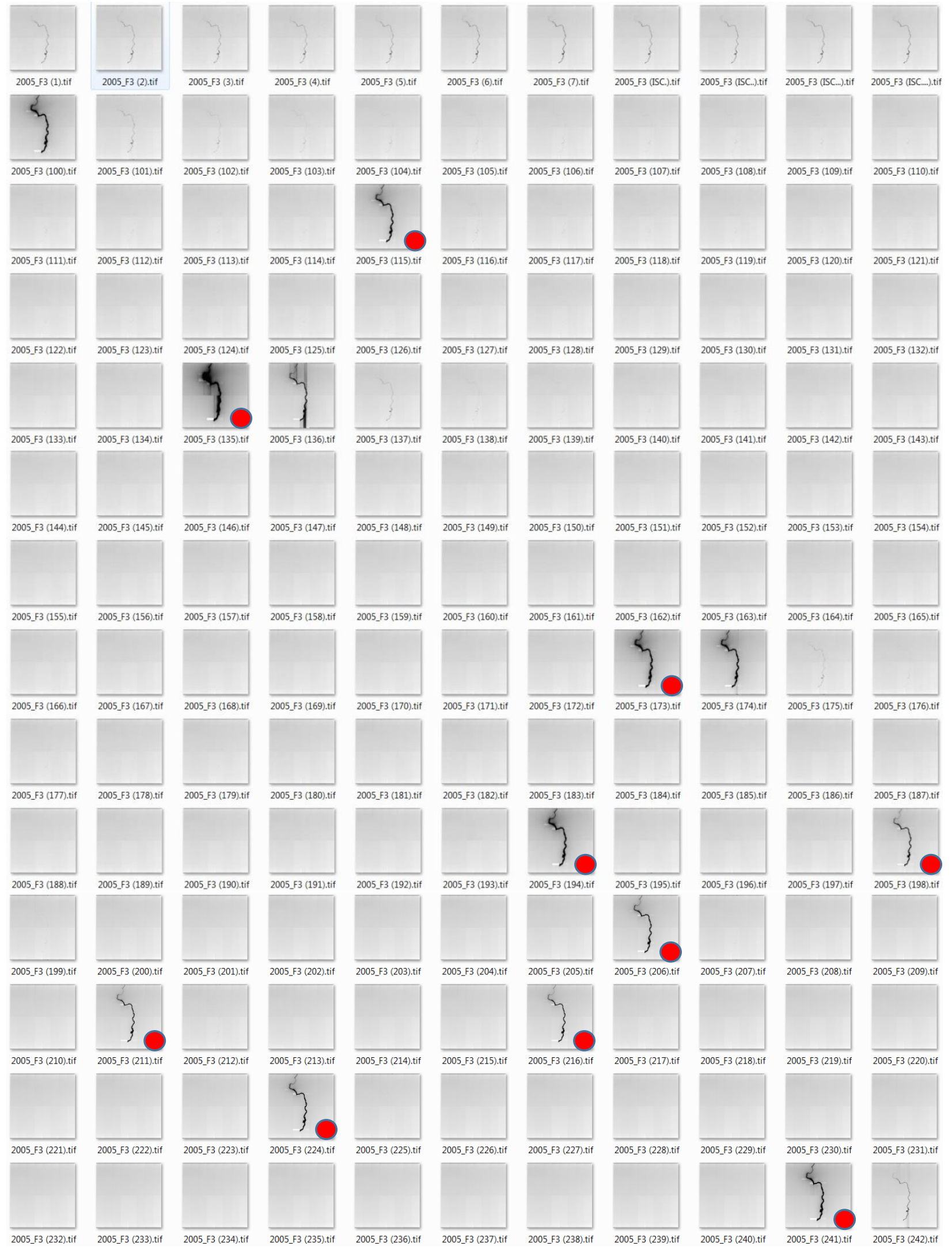

Figure 5-3 HSC video frames of the second flash, 2005 selected storm 


\subsubsection{Network Upgrades before the 2005 Storm}

The main network upgrade prior to August 19, 2005 was completed in 2003 when NLDN had 113 IMPACT-ESP sensors installed while CLDN had 32 IMPACT-ESP sensors and 51 LPATS IV sensors. The 2002-2003 upgrades replaced all time-of-arrival (only) LPATS III sensors with IMPACT-ESP sensors. The upgrade with IMPACT-ESP sensors allowed for the information from as few as two sensors to determine the striking location; improved the flash detection efficiency from $80-90 \%$ to $90-95 \%$, stroke detection efficiency from $50 \%$ to $60-80 \%$ and median location accuracy of 500m [48], [69]. The nominal time of arrival error of the network was $1.5 \mu$ s that caused a location error of 500m [69] - [71]. The time-of-arrival error depended on the landscape of the terrain and soil conductivity [48]. For the first time, sensors at baseline $300-350 \mathrm{~km}$ were modified to detect cloud flashes of high amplitude in VLF/LF bandwidth. Some limitations regarding the propagation of radiated fields over uneven terrain and soil conductivity were apparent after the upgrade [72] - [74]. The State University of New York at Albany (SUNYA) used GPS video cameras, electric field and optical recordings to validate the NLDN performance characteristics after the 2003-2004 upgrades in South Arizona and TexasOklahoma. For South Arizona, the flash detection efficiency was 93\%, stroke detection efficiency $76 \%$ and median location accuracy $424 \mathrm{~m}$. For Texas-Oklahoma, flash detection efficiency was $92 \%$, stroke detection efficiency $85 \%$ and median location accuracy $279 \mathrm{~m}$ [71]. NLDN performance using rocket-triggered lightning data, acquired at the International Center for Lightning Research and Testing (ICLRT) located in Camp Blanding National Guard, northcentral Florida, has been considered from 2004 to 2013 (except 2006). For 2005, flash detection efficiency was $63 \%$, stroke detection efficiency $62 \%$ and median location accuracy $242 \mathrm{~m}$ [75]. The first validation of the NALDN performance characteristics, using tall-structure (CN Tower) lightning data (revised in the following sections) was accomplished in [25], [76]. The results indicate $100 \%$ flash detection efficiency, 55\% stroke detection efficiency and 289m median location accuracy [25], [68]. During the 2002-2003 upgrades, the algorithm used to group individual strokes in a flash was modified. Strokes were added to a flash as long as they occurred within one second from the first stroke, $0.5 \mathrm{~s}$ time interval for other consecutive strokes, and at a location less than $10 \mathrm{~km}$ from that of the first stroke. If it happened that a stroke fits into two flashes, based on the above rules, it would be assigned to the flash that had the smallest distance from the first stroke [53]. 
Since the instrumented CN Tower lies on the border of the CLDN and the NLDN, it provides an excellent opportunity to evaluate the performance characteristics of the NALDN in the area around Toronto. Because of the close proximity of the tower to the U.S. border, two out of the three closest lightning detection sensors to the tower are actually NLDN sensors [76], shown in Figure 5-4. Table 5-1 provides a list of the types of sensors and their distance from the $\mathrm{CN}$ Tower, prior to the 2005 storm. The table also includes the ground conductivity over each path from the ITU World Atlas of Ground Conductivity.

Table 5-1 NALDN sensor locations around CN Tower in 2005 [25]

\begin{tabular}{|c|c|c|c|}
\hline Sensor Location & Sensor Type & $\begin{array}{c}\text { Sensor Distance to } \\
\text { CN Tower }[\mathrm{km}]\end{array}$ & $\begin{array}{c}\text { Ground Conductivity } \\
{[\mathrm{mS} / \mathrm{m}]}\end{array}$ \\
\hline Sanborn (U.S.) & IMPACT ESP & 66.8 & 10 \\
\hline Egbert (Canada) & LPATS IV & 73.1 & 10 \\
\hline Ubly (U.S.) & IMPACT ESP & 286.1 & 10 \\
\hline North Bay (Canada) & LPATS IV & 298.8 & 1 \\
\hline Petawawa (Canada) & LPATS IV & 304.9 & 1 \\
\hline
\end{tabular}

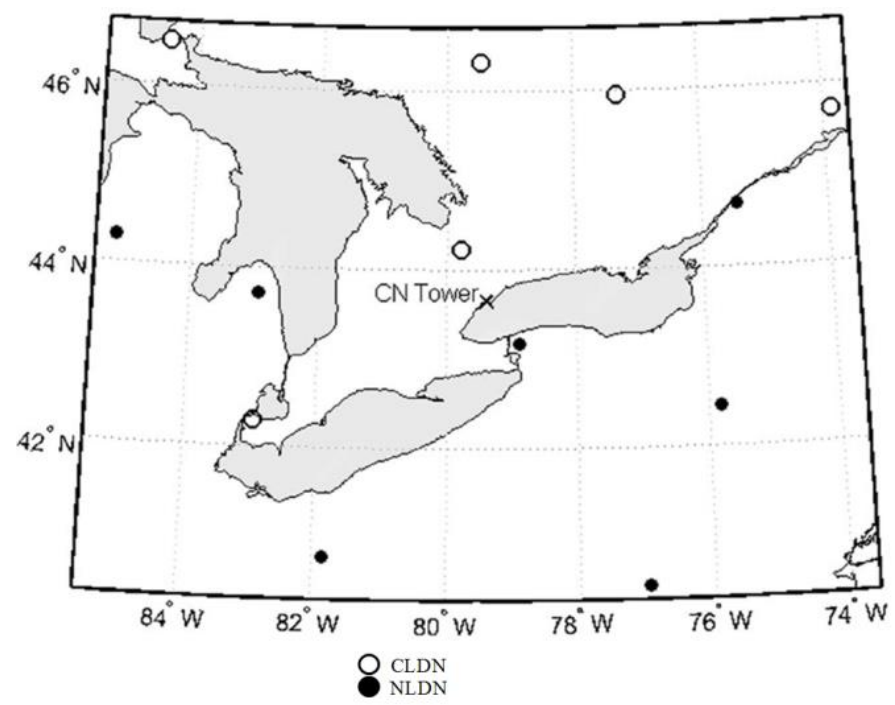

Figure 5-4 Locations of NLDN and CLDN sensors around the CN Tower [76] 


\subsection{Severe Storm}

A comprehensive investigation of the CN Tower lightning storm, which took place on August 24, 2011, shows that 52 flashes occurred within 84 minutes. This translates to an average inter-flash time of 1.6 minutes. The flash rate of this storm exceeds the severe storm of July 7, 1991 [77], where the tower was struck with 24 flashes within 100 minutes, implying an average inter-flash time of 3.3 minutes. Unfortunately, the high-speed digital imaging system (Phantom v5.0) was not operational during this important storm. The presented optical analysis was therefore built based on two digital cameras operated at 30fps. The locations of the CN Tower and the two digital cameras are shown in Figure 5-5.

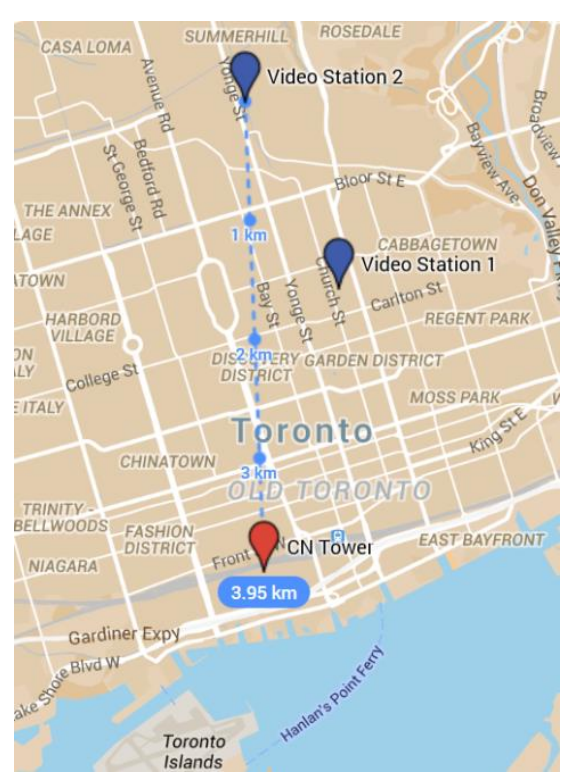

Figure 5-5 Locations of the CN Tower and two video cameras, August 24, 2011 Storm

The flashes containing return strokes are recorded by NI PCI-5114 digitizer connected to the old coil. Although video records show 52 flashes striking the tower, only the currents of 32 flashes were recorded because the current derivative measurement system was configured to trigger on flashes that had at least one return stroke. The recorded current signals were perfectly matched with their corresponding 32 video flash records. Through analyses of recoded images it was found that the 20 flashes that did not trigger the current derivative measurement system contained only initial stage currents (ISCs) and should not have been recorded either by NALDN or by $\mathrm{CN}$ Tower digitizers. Figure 56 shows the relative times of occurrence of the 52 flashes. 
The black dots indicate the flashes with only ISC and the length of red lines represent the number of return strokes per flash.

In this dissertation, the distinction between the ISC pulses and return strokes was made by analyzing video records, as well as the current derivative of each recorded impulse. Out of the 159 impulses, 156 proved to be return strokes beyond initial-stage currents. Detailed analysis of current records in association with corresponding video records proved that one of these impulses (the first impulse of flash 34 containing three impulses, triggered the current recording system) is actually an M-component superimposed on initial-stage current, because of its marked wave-front slowness. Also, two return-stroke-type impulses were found to be superimposed on the ISC of flash 23 that contains five return strokes beyond the ISC duration. Out of 156 return strokes recorded at the current measuring system, only 84 were reported by NALDN (53.8\%). Only one flash, containing one return stroke, was positive, but it was not detected by NALDN as a ground flash.

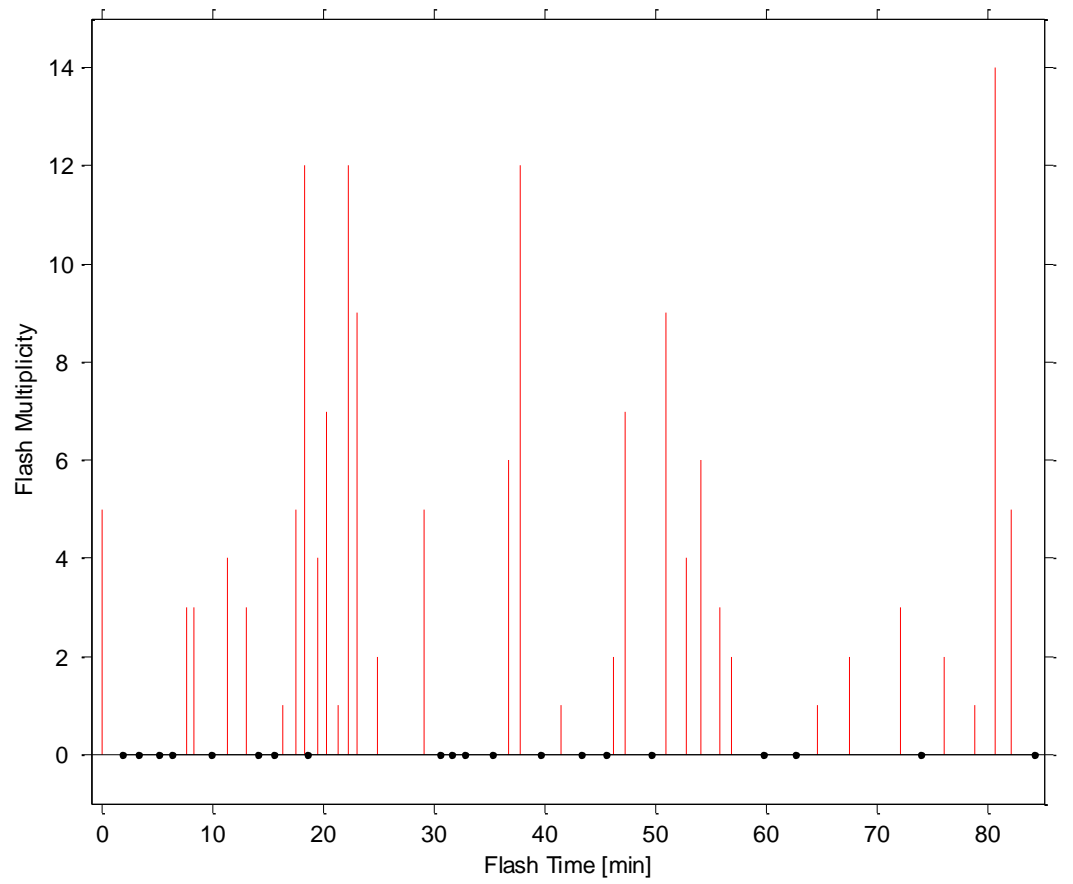

Figure 5-6 Relative times of occurrence of CN Tower flashes, August 24, 2011

Figure 5-7 shows the luminosity analysis of the first flash that contains five return strokes as well as the current derivative signal. The perfect time match between the luminosity analyses and the current recorded system has been achieved for all the records. Figure 5-8 shows the frames by the image recording system for flash one. The five return strokes can be noticed with the naked 
eye; the frames, displaying the return strokes, are signed with a red dot beside them. The return strokes 1, 2, 4 and 5 have channel luminous for more than one frame, indicating the continuing current component on them.

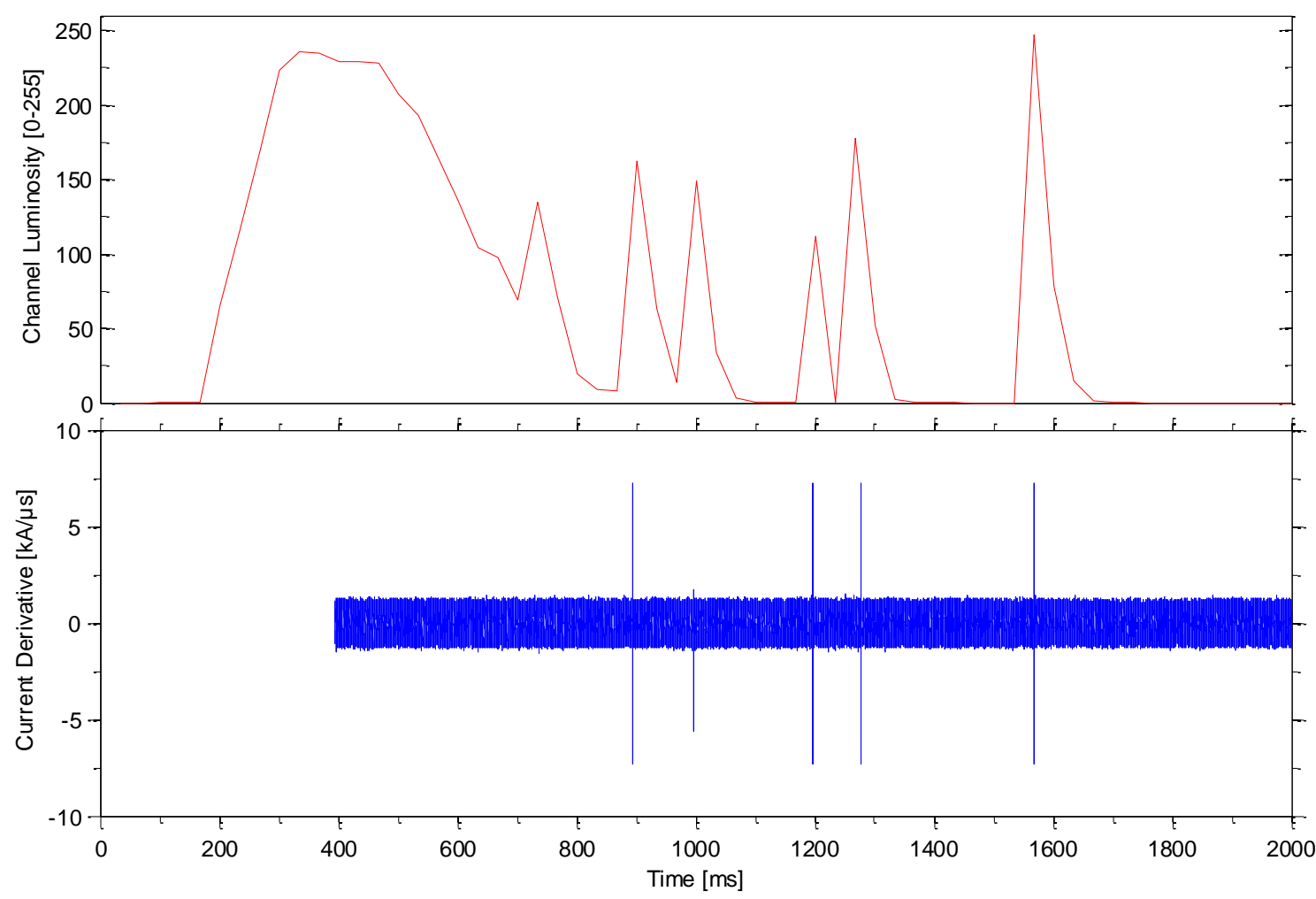

Figure 5-7 Current derivative of return-strokes time matched with channel luminosity, first flash

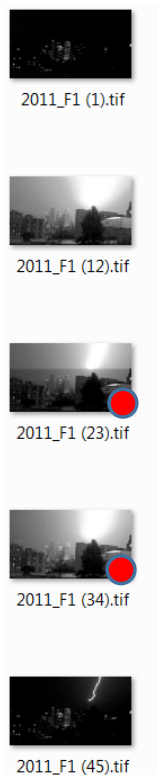

2011_F1 (45).tif

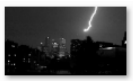

2011_F1 (2).tif

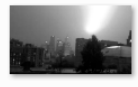

2011_F1 (13).tif

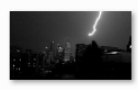

2011_F1 (24).tif

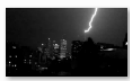

2011_F1 (35).tif

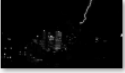

2011_F1 (46).tif

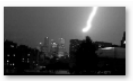

2011_F1 (3).tif

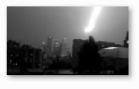

2011_F1 (14).tif

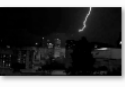

2011_F1 (25).tif

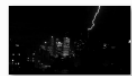

2011_F1 (36).tif

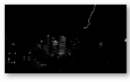

2011_F1 (47).tif

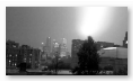

2011_F1 (4).tif

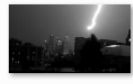

2011_F1 (15).tif

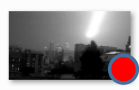

2011_F1 (26).tif

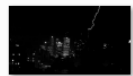

2011_F1 (37).tif

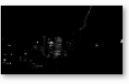

2011_F1 (48).tif

Figure 5-8

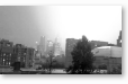

2011_F1 (5).tif

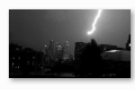

2011_F1 (16).tif

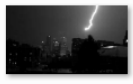

2011_F1 (17).tif

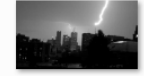

2011_F1 (18).tif
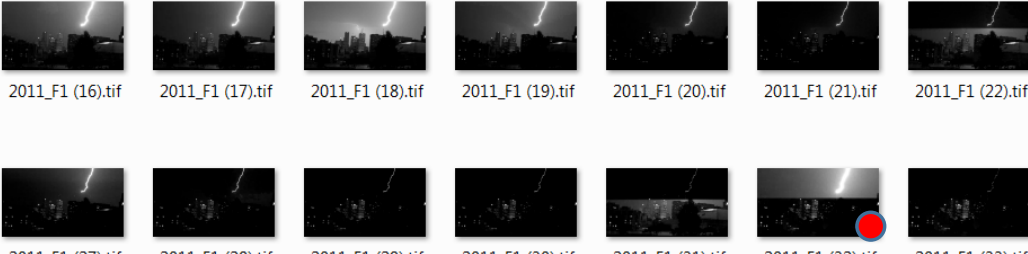

2011_F1 (28).tif
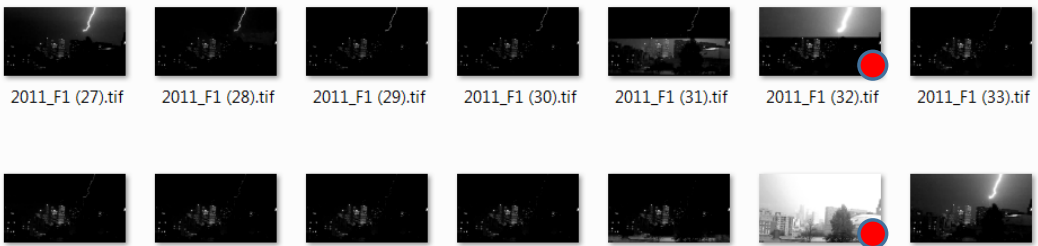

2011_F1 (38).tif
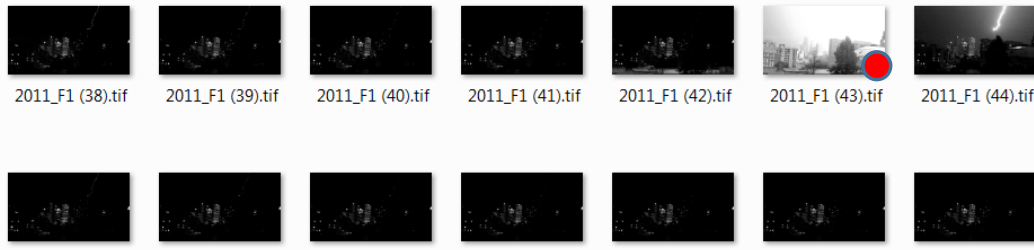

2011_F1 (49).tif

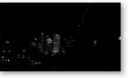

2011_F1 (50).tif
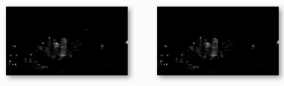

2011_F1 (52).tif

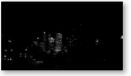

2011_F1 (53).tif

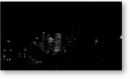

2011_F1 (54).tif

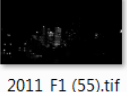

Images of the first flash, 2011 


\subsubsection{Network Upgrades before the August 24, 2011 Storm}

From 2005 until 2011, Environment Canada replaced the old LPATS-IV sensors with IMPACTESP and LS7000 sensors in Canadian territory as shown in Figure 5-9.

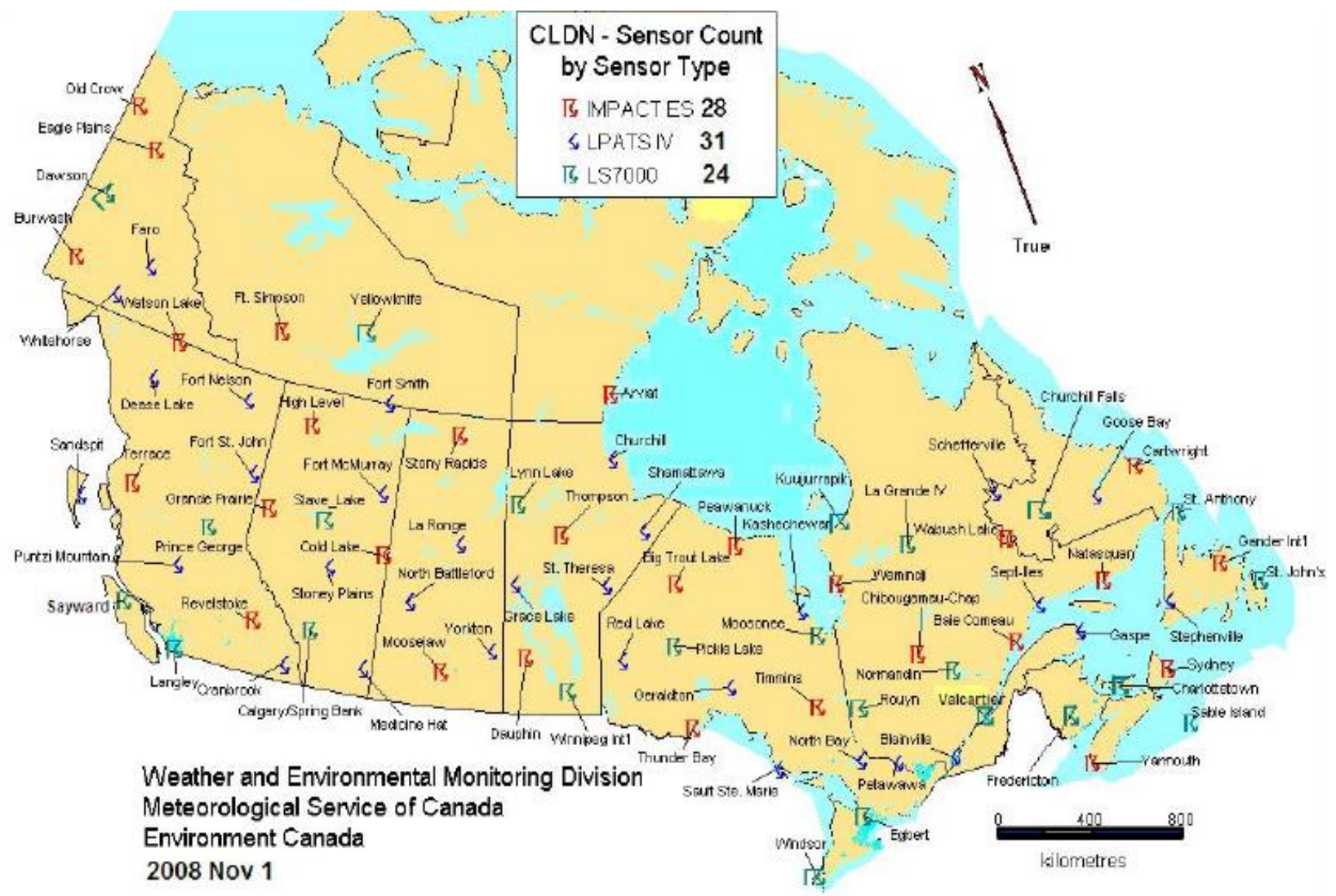

Figure 5-9 NALDN sensor types and locations, November 2008 [78]

Applications, such as detection of lightning-caused forest fires, power line fault location accuracy and aviation safety procedures have motivated Vaisala to enhance the hardware and software for better lightning location accuracy [69]. The location accuracy of a network depends on two main factors. First, the error caused by the delay on arrival time for the radiated field because of uneven terrain. Second, the time error and attenuation of radiation field is affected because of the finite ground conductivity [48]. For this reason, NLDN replaced IMPACT algorithm to a new one that would improve on accuracy of geo-location of return strokes. The key upgrade before August 24, 2011 has been done in 2010 when NLDN introduced Total Lightning Processor ${ }^{\mathrm{TM}}$ (TLPTM) algorithm, assumed to be used for IMPACT-ESP sensors, to make correction related to soil conductivity and landscape of terrain in the path from the point of 
stroke to the sensor location. At the same time, starting in 2010 and finishing in 2011, NLDN upgraded all 114 IMPACT-ESP sensors to LS7001 and TLS200 [15].

The TLP ${ }^{\mathrm{TM}}$ algorithm proved not well suitable for the latest LS7001 and TLS200 sensors [23]. The modifications to the software were made in 2012 [32]. In that period of time, the CLDN was replacing the LPATS IV with LS7000 sensors on a yearly basis. By the end of 2008, it had 31 of LPATS sensors and 52 of IMPACT-ESP and LS7000 sensors. The network was designed to provide $95 \%$ flash detection efficiency, about $80 \%$ stroke detection efficiency and median location accuracy of less than 200m [79]. NLDN performance using rocket-and-wire triggered lightning data, acquired at ICLRT, located in Camp Blanding, has been studied in 2011. The study found a flash detection efficiency of $100 \%$, stroke detection efficiency of $61 \%$ and median location accuracy 652m [32]. The validation results did not meet NALDN expectations for 2011 because of a lack of a smooth transition in the upgrades regarding the type of sensors and the software modifications to account for soil conductivity and terrain landscape.

\section{$5.3 \quad 2014$ Storm}

The special September 5th, 2014 storm has been simultaneously recorded by independent lightning recording systems, two current measurement systems and two image recording systems. The storm continued for 161.6 minutes. This storm comprises $24 \mathrm{CN}$ Tower flashes; on average, one flash every 6.73 minutes. Out of the 24 flashes, 15 contain only initial stage currents and 9 flashes (37\%) contain from one to ten return strokes each. Distributions of return strokes for the flashes with at least one return stroke are: four flashes contain only one stroke, one flash contains two strokes, two flashes contain three strokes, one flash contains eight strokes and another flash contains ten strokes. The use of Phantom v5 high speed camera and high sampling rate current recording systems has allowed current and channel luminosity correlation for flashes with return strokes. In this dissertation, lightning current and luminosity analyses suggest that initial stage current pulses can trigger the current measurement system connected to the new coil [31]. Figure 5-10 indicates that the HSC the NI PCI 5114 digitizer connected with the new coil has triggered on initial pulse of the initial stage current. LSC supports on identifying all 8 strokes for $22^{\text {nd }}$ flash. The full flash has been recorded by the Sony camera and 
the LeCroy digitizer connected with the old coil, which showed all eight recorded strokes. The recording time of the new coil-NI PCI-5114 current measuring system was not sufficient (750ms) to record the whole flash from the initial pulse of ISC to the last return stroke. The flash duration for this flash was $1468.5 \mathrm{~ms}$ based on LSC and $945.5 \mathrm{~ms}$ based on LeCroy digitizer (longest flash duration based on current signal recorded at CN Tower [31]).
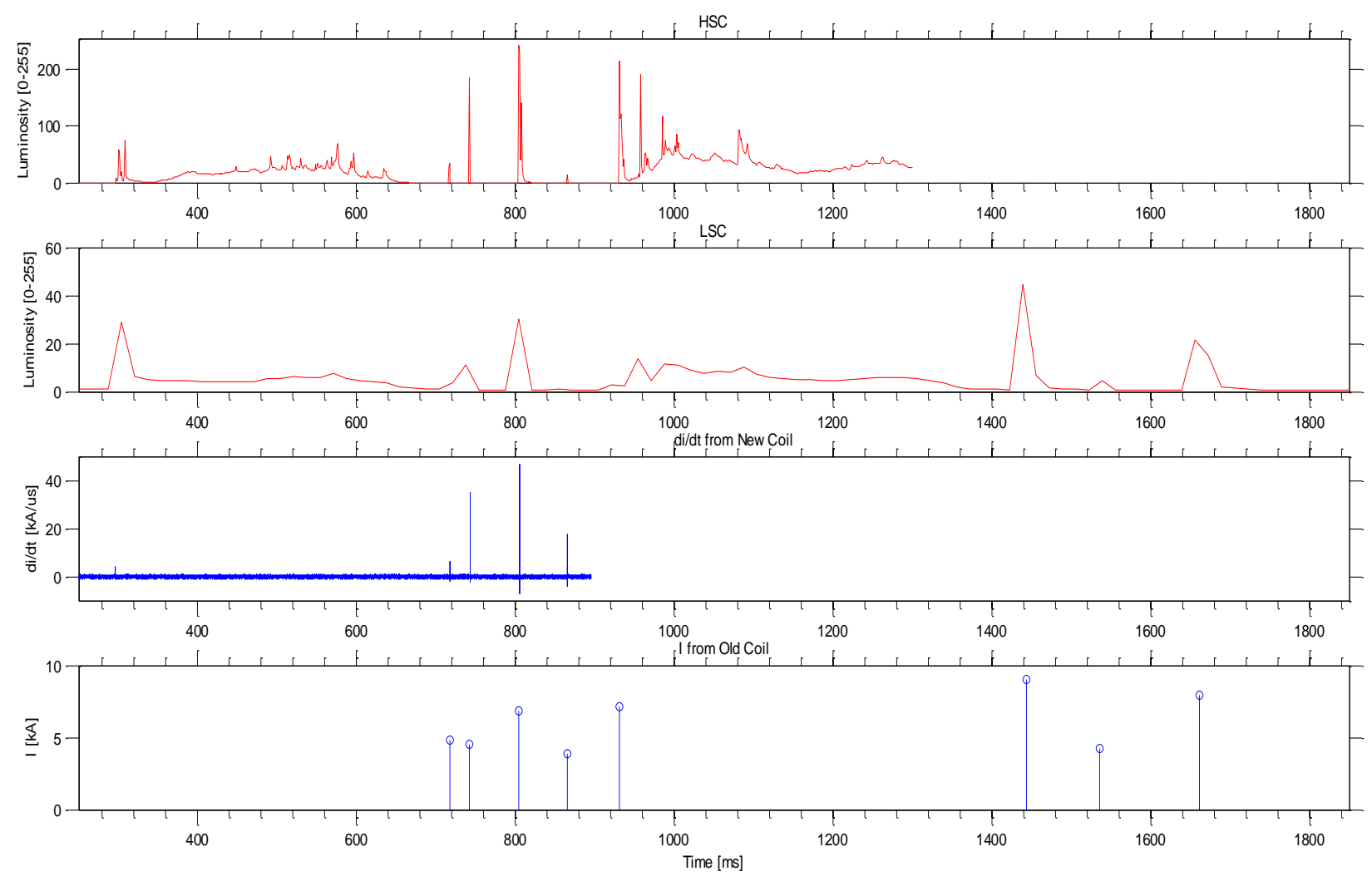

Figure 5-10 Luminosity, current derivative and current for flash 22, 2014

Two out of 24 flashes, both recorded only by LSC (flash 1 and 2 were not recorded by HSC), did not contain ISC component. By observation, one of them (flash 2) is so weak that it could be interpreted as just a leader going up without successful connection to the cloud. Its channel appears for only in one frame $(16.7 \mathrm{~ms}$ resolution for LSC). The connecting leader did not rise too high from the tower's tip and it did not trigger any of the current measuring systems. The other flash (flash 1) contained only one very bright frame $(16.7 \mathrm{~ms})$ that connected successfully to the cloud and it triggered both current measurement systems suggesting that the flash without ISC was a downward cloud to ground flash. This is uncommon occurrence in many years of 
observation of lightning at the $\mathrm{CN}$ Tower. The other 22 flashes had all ISC components designating upward initiating lightning.

Figure 5-11 shows the relative times of occurrence of the 24 flashes that hit the CN Tower on September 5, 2014. The figure also displays the number of return strokes per flash for the nine current-recorded flashes. The black dots indicate the flashes with only ISC and the red lines indicate the number of return strokes per flash.

Figure 5-12 shows the frames by the by the HSC for flash 8 . The recorded time length for the HSC was set 1300-ms with a 1-ms time resolution. In order to fit the flash frames in one page, some of the frames (30-495) of the flash that belong to the initial stage current and some of the frames (546-605) that belong to inter-flash time between the first and the second return strokes are not shown in the figure. The three return strokes can be noticed with the naked eye; the frames, displaying the return strokes, are marked with a red dot beside each of them. The first and third return strokes have luminous channel appearing for more than one frame, indicating the existence of continuing current. Figure 5-13 shows the luminosity analysis of the $8^{\text {th }}$ flash that contains three return strokes as well as the current derivative signal. The perfect time match between the luminosity analyses and the current recorded system has been achieved for all the records.

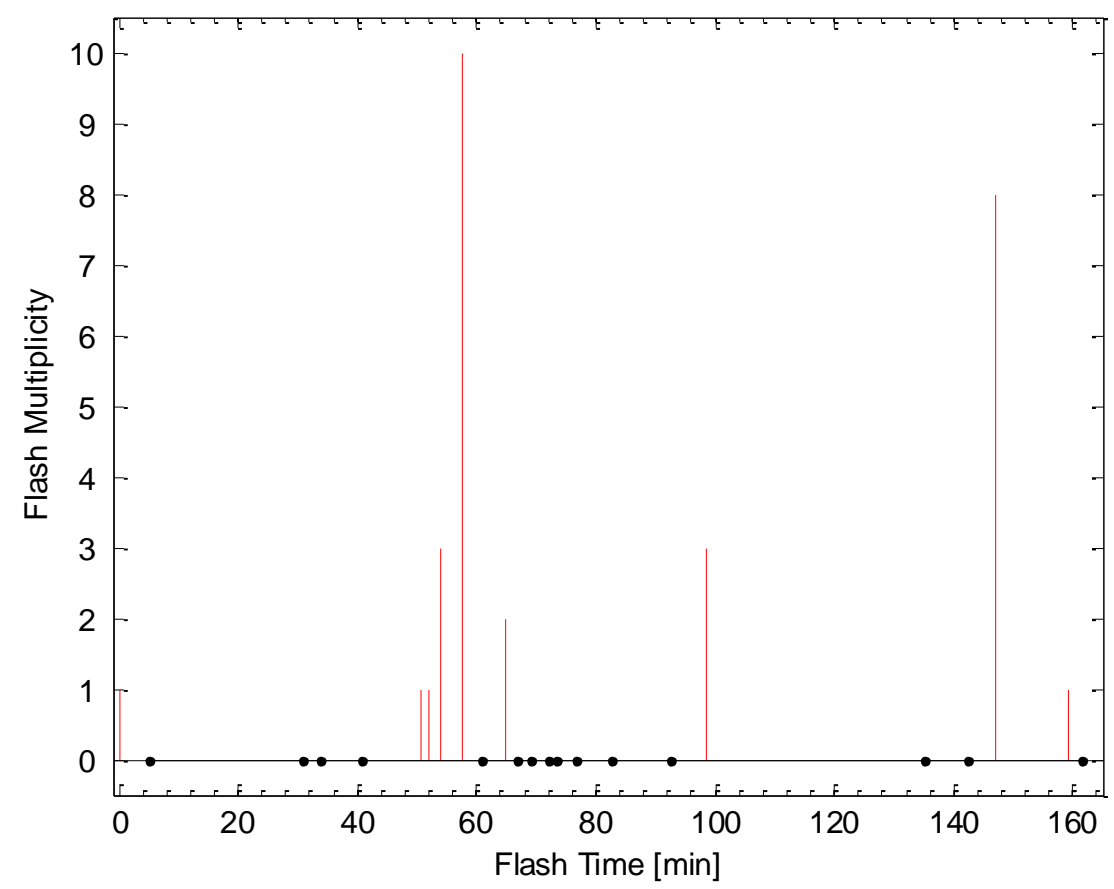

Figure 5-11 Relative times of occurrence of CN Tower flashes during the 2014 storm 
NALDN detected all nine flashes containing at least one return stroke (100\% flash detection accuracy) and 30 out of 30 return strokes (100\% stroke detection accuracy). Stroke polarity was found perfect, $100 \%$.

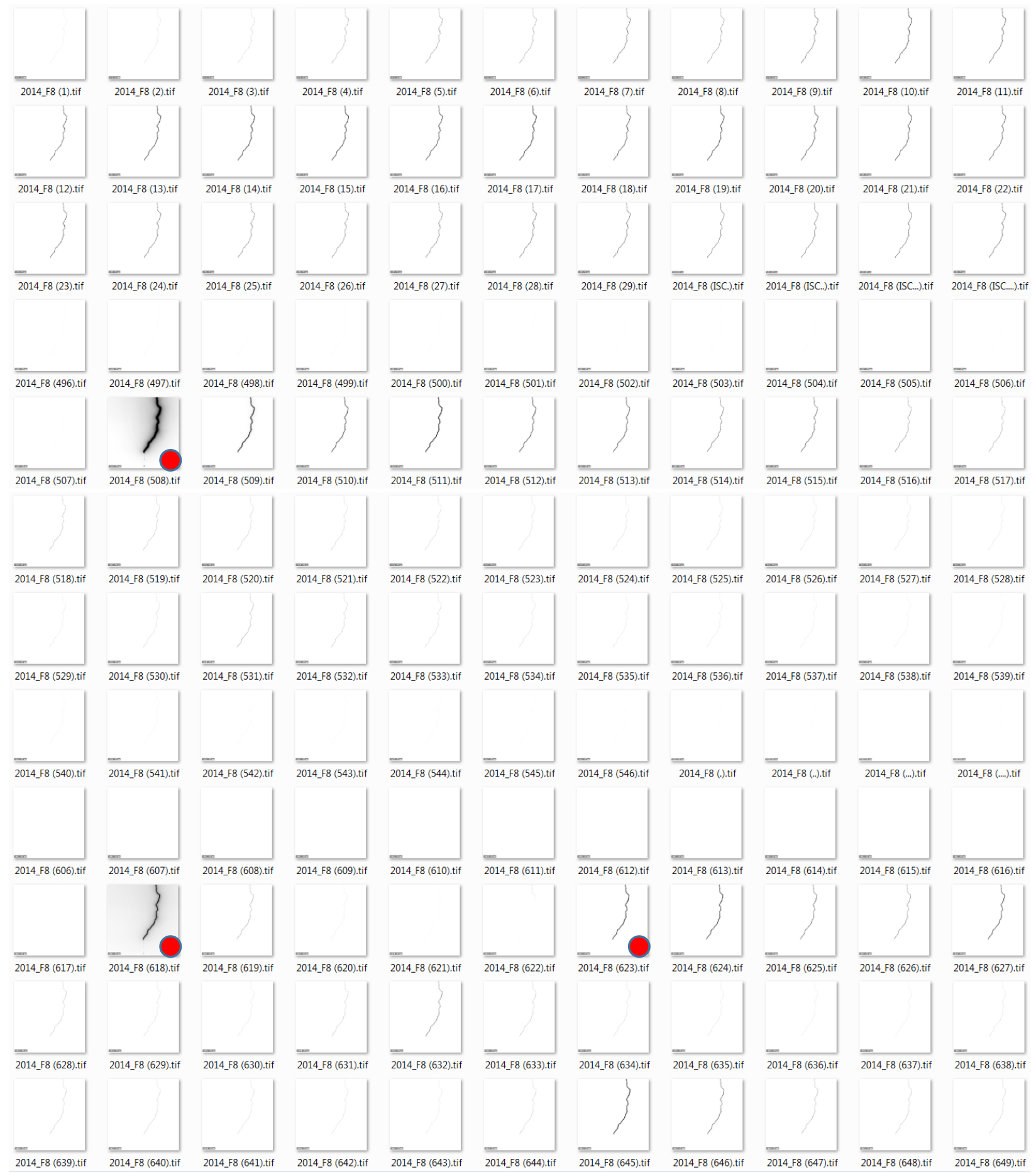

Figure 5-12 Video frames for flash 8 in 2014 

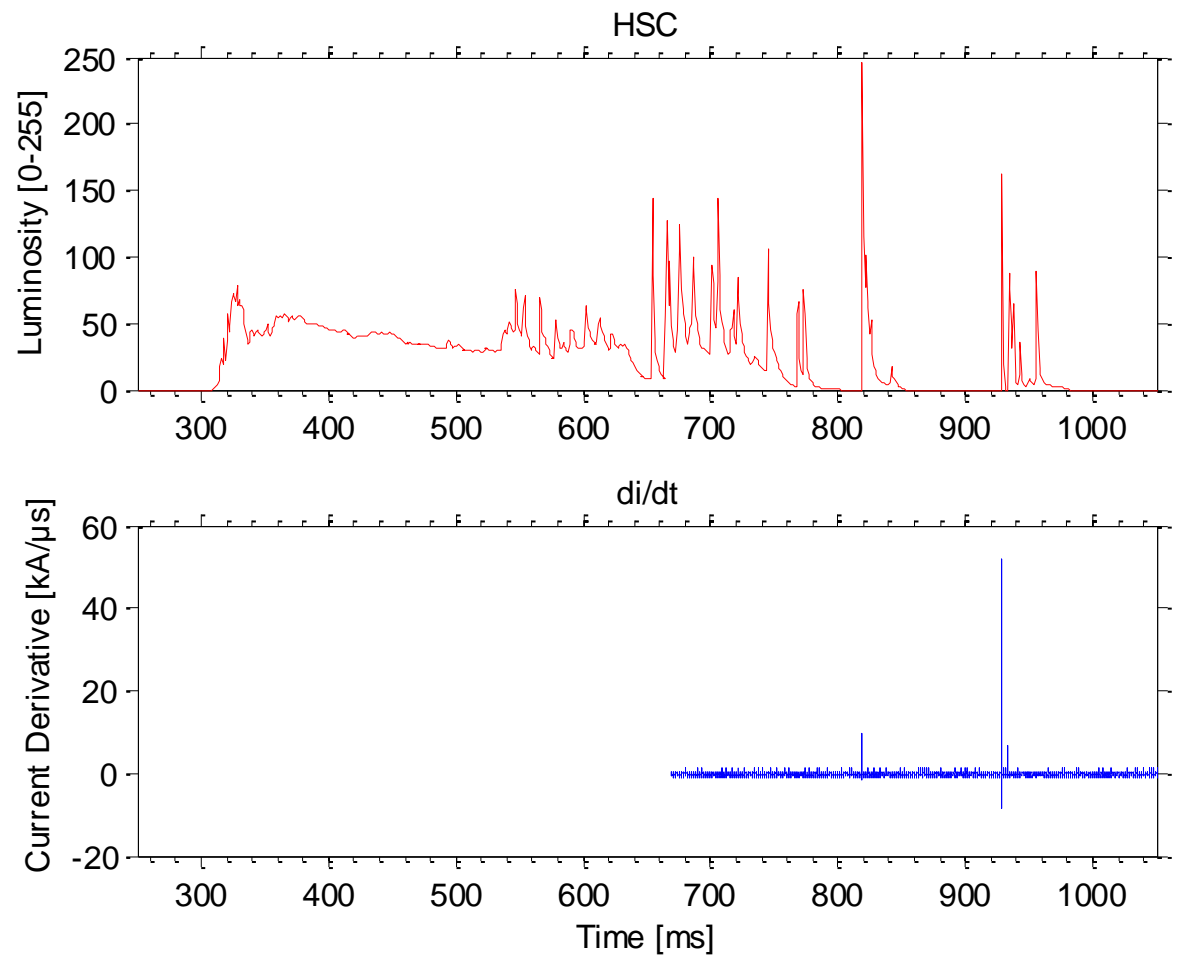

Figure 5-13 Current derivative of return-strokes time matched with channel luminosity, flash 8

\subsubsection{Network Upgrades before the September 05, 2014 Storm}

The main upgrade prior to the 2014 storm was completed in 2013 when Vaisala upgraded all its 114 sensors of NLDN digital LS7002 technology which is, like the predecessor, a combination measurement of MDF (angle or direction) and TOA (time difference) [15], [23], [80]. The expected location accuracy is shown in Figure 5-14 and the projected flash detection efficiency is shown in Figure 5-15. A review of the current literature suggests that this study is the first to validate the performance characteristics of the NALDN after the upgrade in 2013-2014. This patented combination MDF-TOA technique locates the striking point with as few as two sensors. LS7002 uses the waveform onset corrections to minimize the time error that allows improvement in location accuracy of striking points [81]. Additional features of these sensors are the simultaneous process of multiple pulses within in-cloud pulse trains and transmission of more waveform parameters of lightning radiated fields to the processor [15], [80]. LS7002 digital sensors detect low frequency (LF) lightning electromagnetic signals with an operating frequency range $1-350 \mathrm{kHz}$; they have sensitivity three times greater than IMPACT-ESP sensors regarding low amplitude radiation field signals [22], [23]. These sensors improve the signal-to-noise ratio 
by implementing digital filtering of noise sources maintaining the same $300-350 \mathrm{~km}$ distance between sensors [35].

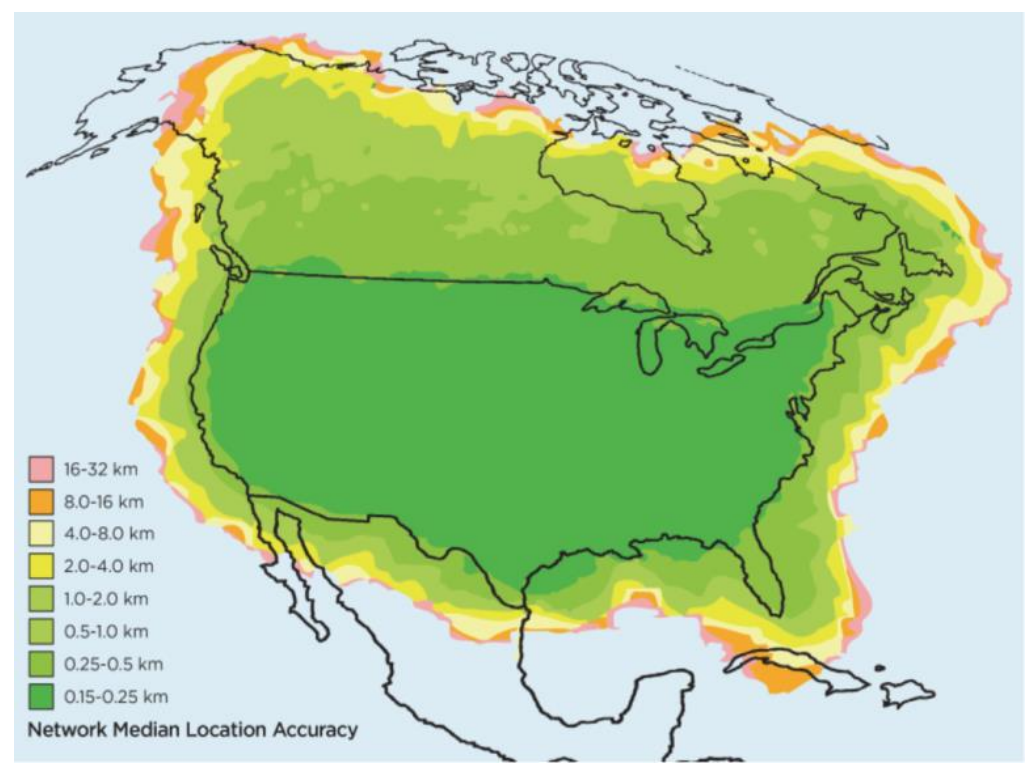

Figure 5-14 Network median location accuracy, 2014 [23]

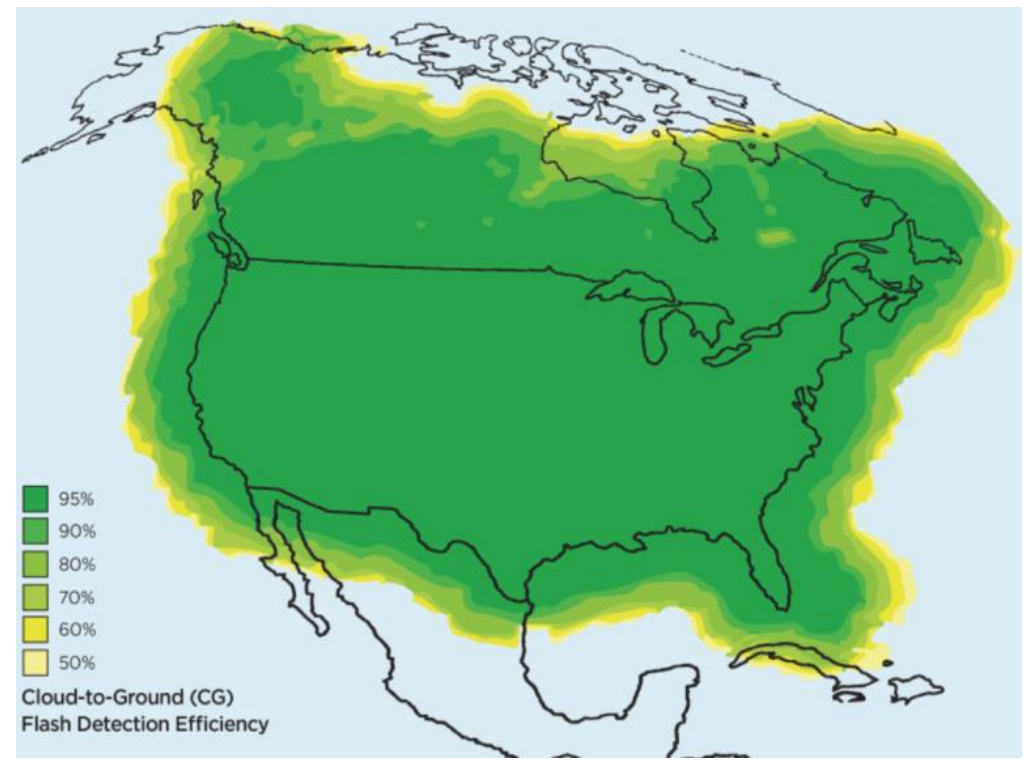

Figure 5-15 Cloud-to-ground flash detection efficiency, 2014 [23]

In order to sustain the improvements of the new sensors, Vaisala introduced TLP100 processor with new localization algorithms able to manage the pulse trains and determine their position [80]. This feature is expected to improve the cloud flash pulse detection efficiency from about $20 \%$ to $50 \%$ as well as to discriminate between cloud flashes and cloud to ground flashes with an 
accuracy of about 85\% [82], [83]. The processor, upgraded in the spring of 2014, classifies the lightning events (even for the positive lightning flashes) based on additional waveform parameters/characteristics received from LS7002 sensors. Before 2013, the network would classify all the positive flashes with peak current less than 15kA as cloud flashes [15]. Additional improvements to the software have been made to account for uneven terrain and soil conductivity. After the upgrades on the network, for the majority of USA and Canada, it is expected to have about $95 \%$ flash detection efficiency, 80-85\% stroke detection efficiency, 40$45 \%$ cloud flash detection efficiency, 150-250m median location accuracy and peak current estimation error for cloud to ground subsequent strokes at about 15\% [15] [23].

\subsection{Detection Efficiency}

Figures 5-16 - 5-17 show the frequency distribution of NALDN stroke detection efficiency as a function of current peak recorded by the $\mathrm{CN}$ Tower current measurement system for each of the 2005 and 2014 storms. The width of each bin is $1 \mathrm{kA}$ and the ratio inside the bin specifies the number of return strokes detected by the network versus the number of return strokes recorded by tower's current measuring system.

Only 33 out of 38 strokes have been considered for the storm of 2005; four current derivative signals exceeded the uppermost level, resulting in difficulties in recovering their peak currents peak, and one return-stroke current derivative signal was too low to be used. The network has detected all six flashes containing at least one stroke. For 2005, the stroke detection efficiency increased from $57 \%$ for $\mathrm{CN}$ Tower return strokes with current peaks between 5kA and 6kA to $100 \%$ for return strokes with current peaks greater than $7.2 \mathrm{kA}$. The lowest CN Tower current peak for strokes detected by the network is 5.3kA.

For the 2011 storm, the network has detected all 28 out of 32 flashes (87.5\%) containing at least one return stroke.

For the 2014 storm, 16 out of 30 strokes have been considered as 14 current derivative signals exceeded the upper most level. However, all 30 strokes were reported by NALDN, resulting in 
$100 \%$ flash and stroke detection efficiency. The lowest tower's current peak for strokes detected by the network is $2.08 \mathrm{kA}$.

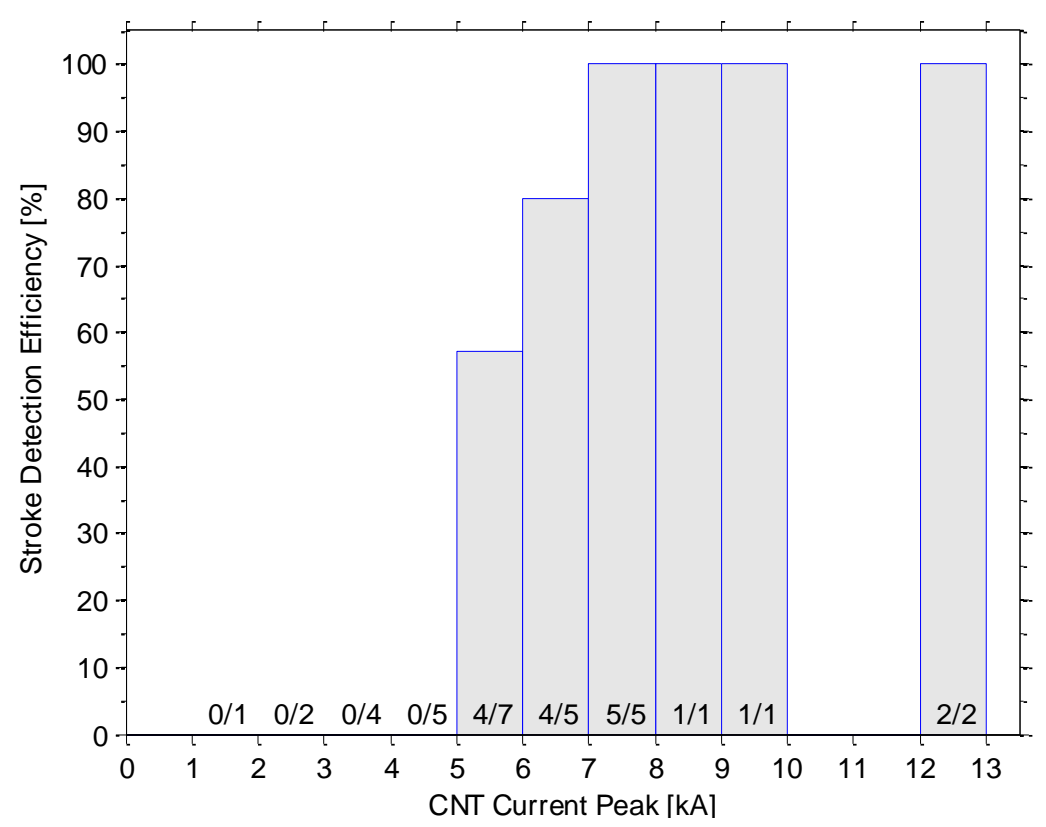

Figure 5-16 NALDN stroke detection efficiency versus CN Tower lightning current peak, 2005

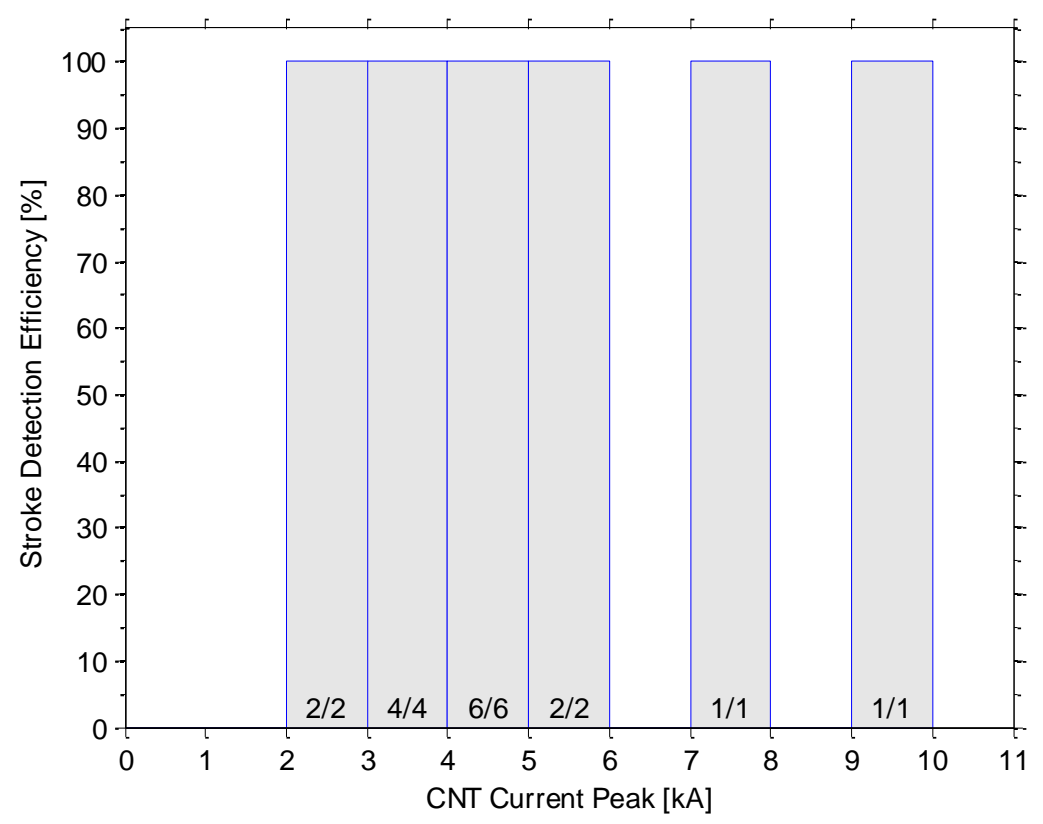

Figure 5-17 NALDN stroke detection efficiency versus CN Tower lightning current peak, 2014 


\subsection{Return Stroke Locations Predicted by NALDN}

Figures 5-18 - 5-20 display the NALDN estimated stroke location for the three storms. The WSG84 coordinates obtained from NALDN have been converted in Universal Transverse Mercator (UTM) system as shown in Appendix E. A North-South versus East-West distance plot of NALDN stroke location errors is shown in the figures, with the origin indicating the location of the tower. The horizontal and vertical axes correspond to the East-West (with east being positive) and North-South (with north being positive), respectively. Two return strokes were reported with the same location for three pairs of strokes in 2011 and one pair of strokes in 2014. The red dots depict the pair of strokes with the same predicted location. Table 5-2 presents the average and the median stroke location errors relative to the tower's location. The predicted return stroke locations have a bias towards north-east for the storm in 2005, a bias towards south-west in 2011 and a bias towards north-west in 2014.

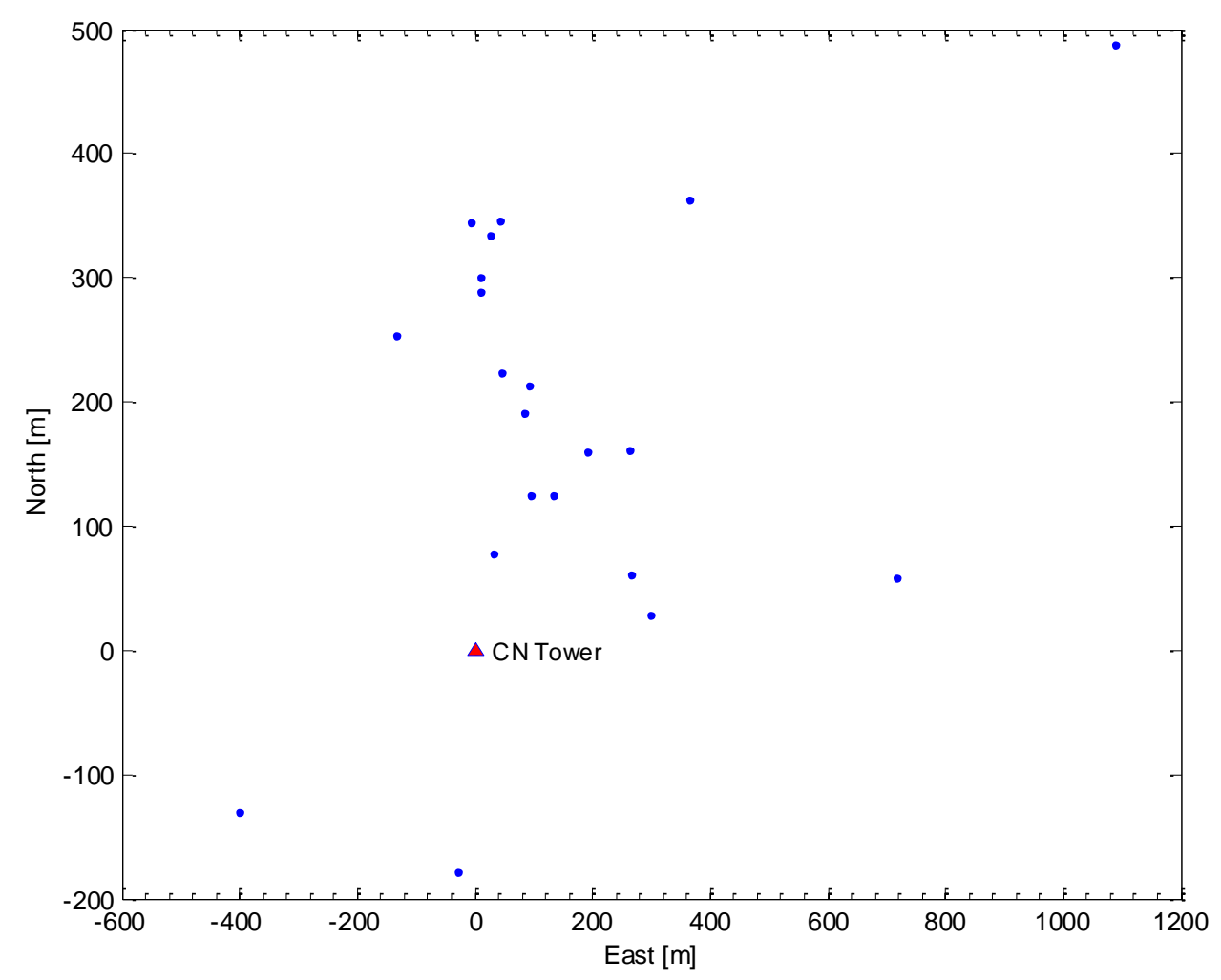

Figure 5-18 NALDN location error, 2005 


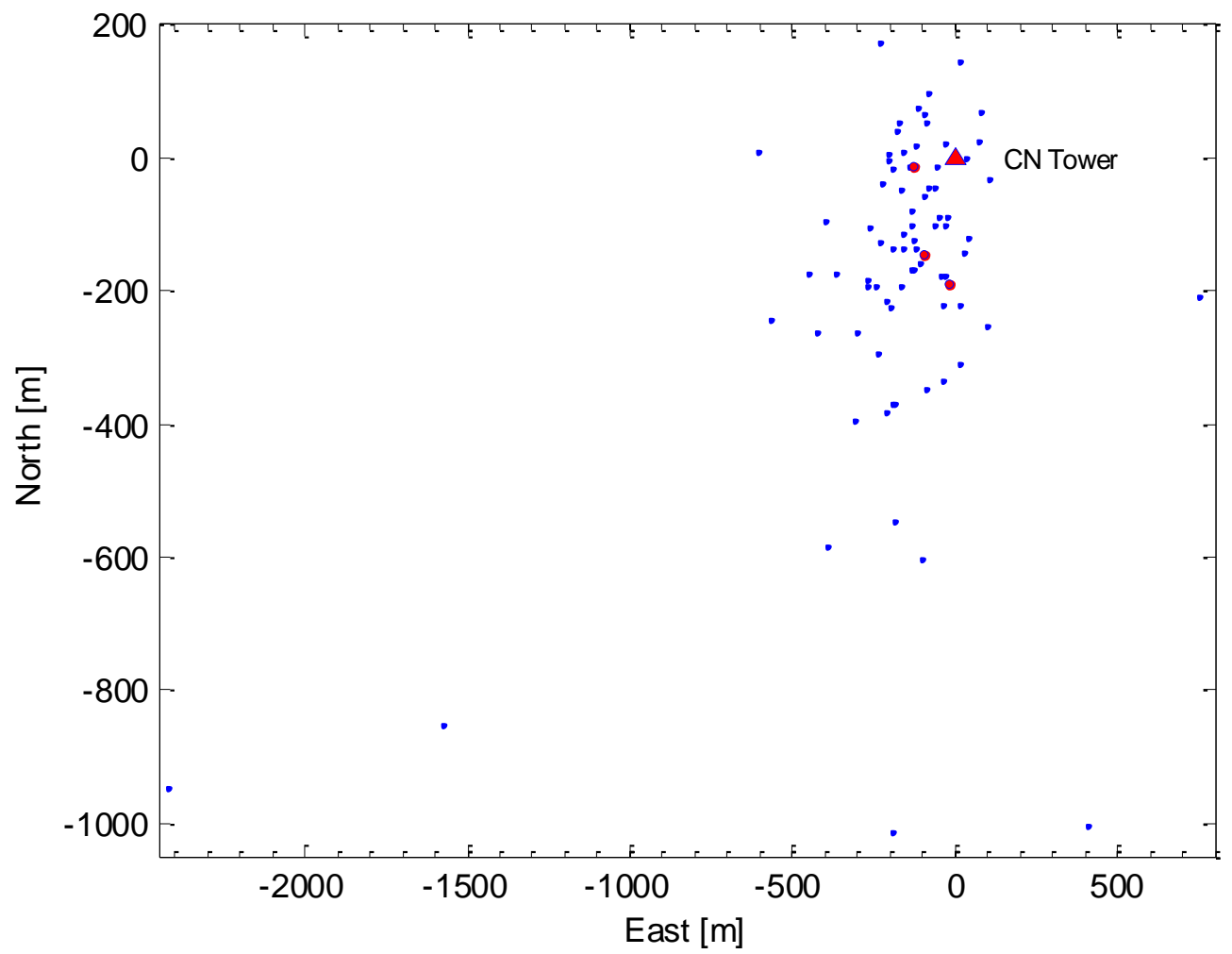

Figure 5-19 NALDN location error, 2011

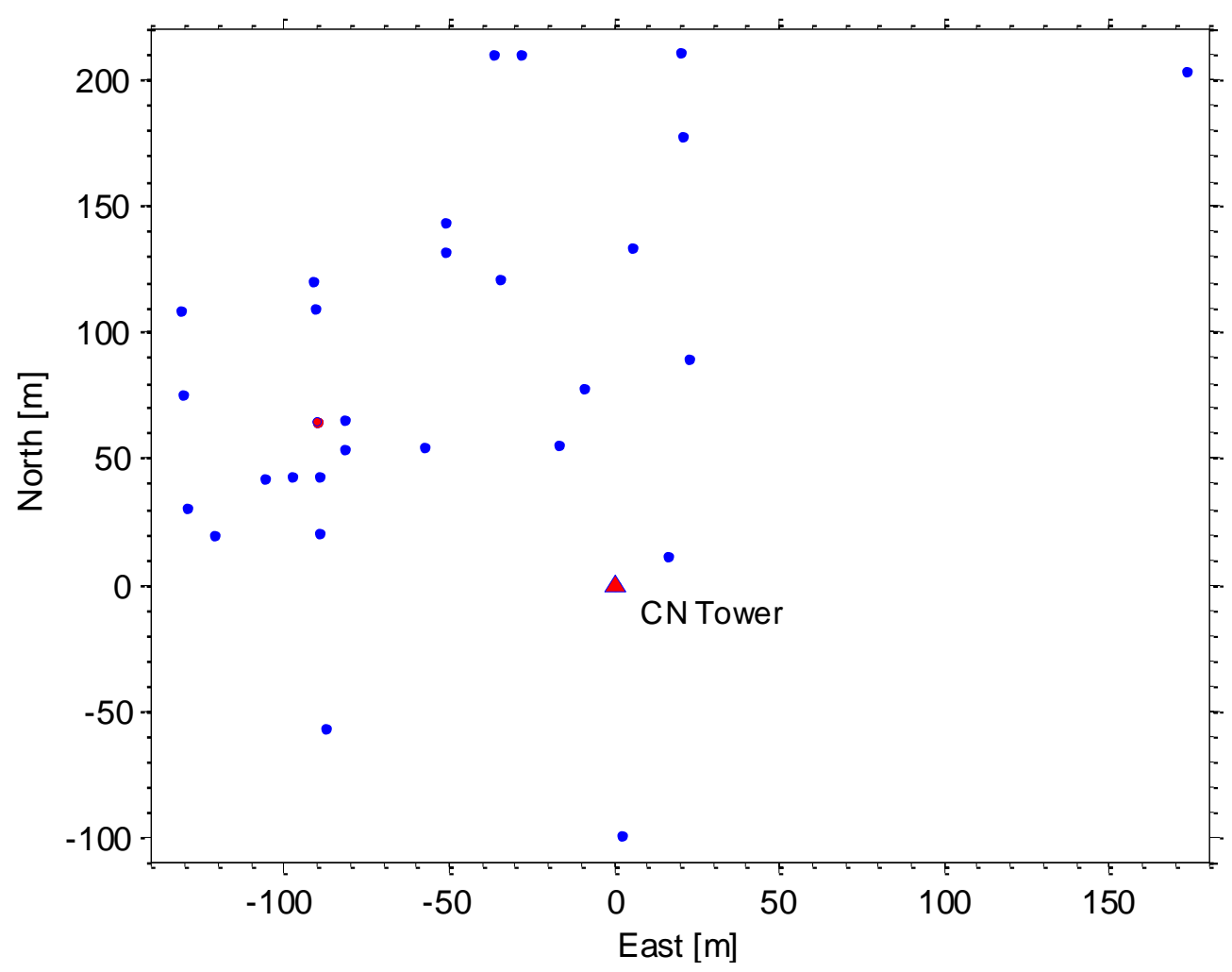

Figure 5-20 NALDN location error, 2014 
Table 5-2 Average and median location errors in 2005, 2011 and 2014

\begin{tabular}{|c|c|c|c|c|c|c|c|c|}
\hline & $\begin{array}{c}\text { North } \\
{[\mathrm{m}]}\end{array}$ & $\begin{array}{c}\text { South } \\
{[\mathrm{m}]}\end{array}$ & $\begin{array}{c}\text { West } \\
{[\mathrm{m}]}\end{array}$ & $\begin{array}{c}\text { East } \\
{[\mathrm{m}]}\end{array}$ & $\begin{array}{c}\text { N-W } \\
{[\mathrm{m}]}\end{array}$ & $\begin{array}{c}\text { N-E } \\
{[\mathrm{m}]}\end{array}$ & $\begin{array}{c}\text { S-W } \\
{[\mathrm{m}]}\end{array}$ & $\begin{array}{c}\text { S-E } \\
{[\mathrm{m}]}\end{array}$ \\
\hline $\begin{array}{c}2005 \\
\text { Average }\end{array}$ & 344.6 & 301.0 & 308.2 & 348.1 & 315.3 & 348.1 & 301.0 & - \\
\hline $\begin{array}{c}2005 \\
\text { Median }\end{array}$ & 289.3 & 301.0 & 315.3 & 289.3 & 315.3 & 289.3 & 301.0 & - \\
\hline $\begin{array}{c}2011 \\
\text { Average }\end{array}$ & 164.1 & 349.1 & 318.8 & 284.6 & 189.0 & 89.5 & 344.7 & 382.1 \\
\hline $\begin{array}{c}2011 \\
\text { Median }\end{array}$ & 132.8 & 224.1 & 201.8 & 145.9 & 149.4 & 90.3 & 220.8 & 247.8 \\
\hline $\begin{array}{c}2014 \\
\text { Average }\end{array}$ & 130.8 & 102.3 & 124.8 & 142.3 & 125.7 & 149.4 & 104.7 & 100.0 \\
\hline $\begin{array}{c}2014 \\
\text { Median }\end{array}$ & 124.7 & 102.3 & 113.9 & 133.5 & 118.5 & 156.5 & 104.7 & 100.0 \\
\hline
\end{tabular}

\subsection{Absolute Location Error Distribution}

Figures 5-21 - 5-23 present the frequency distributions of the NALDN absolute location error for the three storms. Each column represents the absolute location error within a bin size of $100 \mathrm{~m}$ for the storms in 2005 and 2011, but $20 \mathrm{~m}$ for the storm in 2014. For the storm of $2005,81 \%$ of the strokes (17 out of 21 RSs reported by NALDN) have absolute location errors in the range: $84.2 \mathrm{~m}$ to $347.7 \mathrm{~m}$. Only three strokes were predicted at a distance greater than the projected median accuracy of the network in $2005(500 \mathrm{~m})$. For the storm in 2011, 86.9\% (73 out of $84 \mathrm{RSs}$ reported by NALDN) of the strokes have absolute location errors in the range: $32.3 \mathrm{~m}$ to $498 \mathrm{~m}$. The number of return strokes, predicted at a distance greater than the projected median accuracy of the network in 2011 (200m), was 42 (50\%). For the storm of 2014, 80\% of the strokes (24 out of 30 RSs reported by NALDN) have absolute location errors in the range: $19.6 \mathrm{~m}$ to $179.4 \mathrm{~m}$. Only four strokes were predicted at a distance greater than the projected median accuracy of the network in $2014(200 \mathrm{~m})$.

Figures 5-24 - 5-26 present the cumulative probability distributions of the NALDN absolute location error for 21 return strokes in 2005, 84 strokes in 2011 and 30 return strokes in 2014 
detected by the network. Table 5-3 summarizes the statistical analyses of the NALDN absolute location error for the three storms.

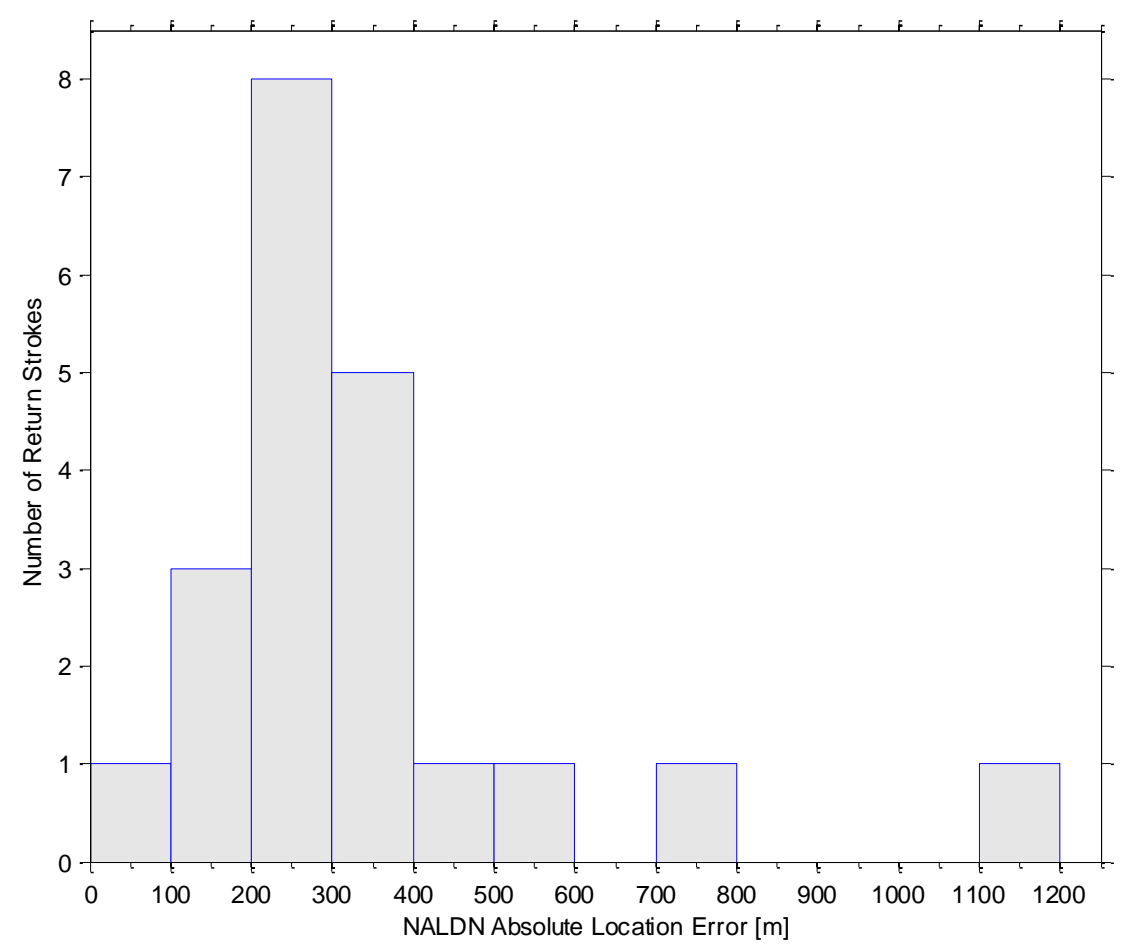

Figure 5-21 Frequency distribution of NALDN absolute location error, 2005

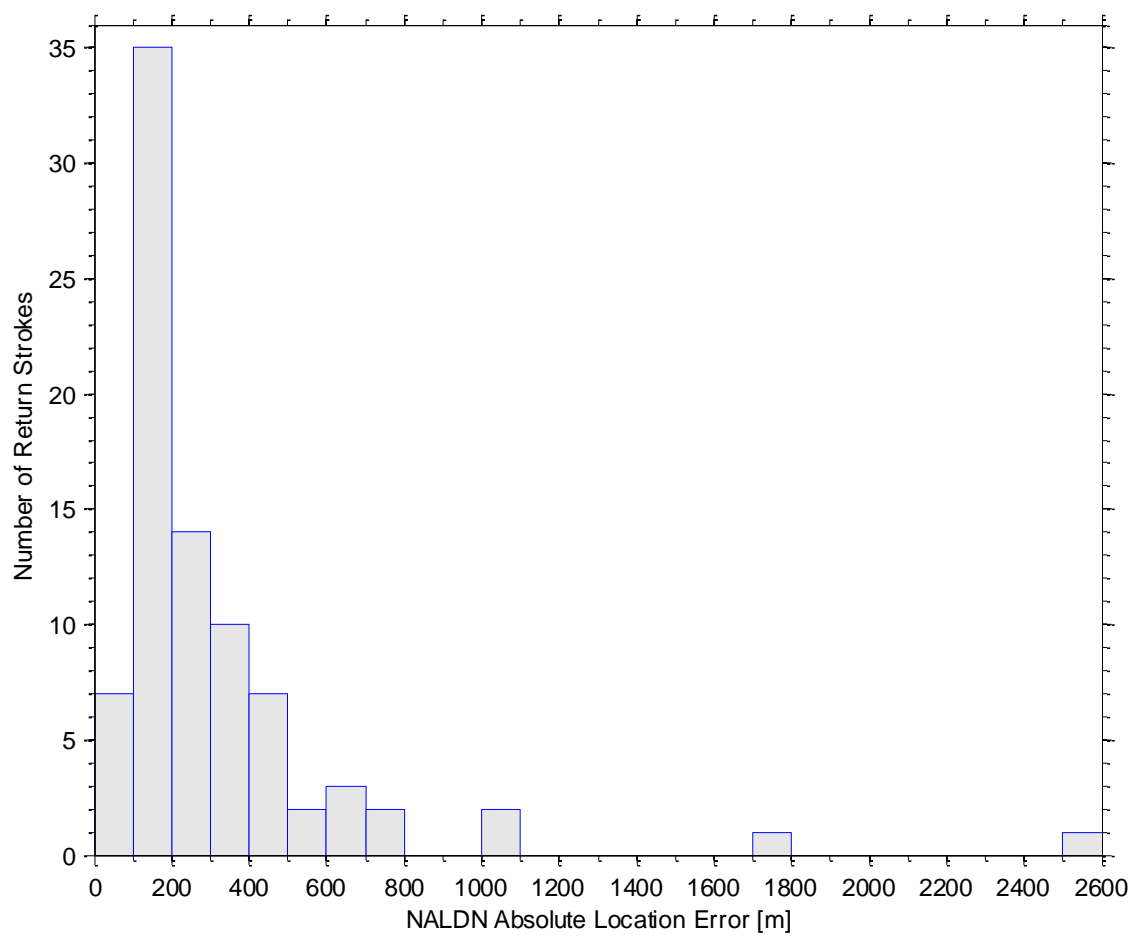

Figure 5-22 Frequency distribution of NALDN absolute location error, 2011 


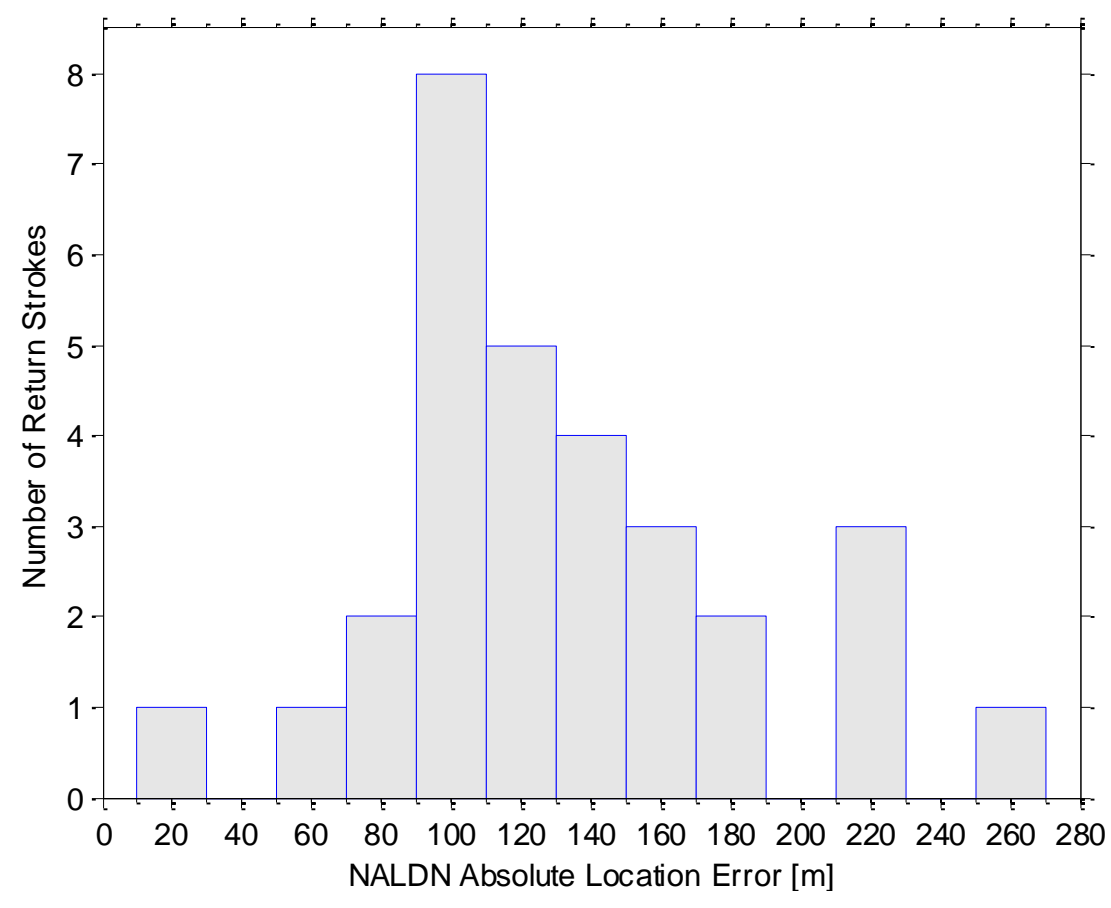

Figure 5-23 Frequency distribution of NALDN absolute location error, 2014

The median and the average absolute location errors were found to respectively be $289.3 \mathrm{~m}$ and $340.5 \mathrm{~m}$ in $2005,198.8 \mathrm{~m}$ and $313.9 \mathrm{~m}$ in 2011 and $118.5 \mathrm{~m}$ and $129.2 \mathrm{~m}$ in 2014 . The absolute location error at the $50 \%$ probability level is $294.6 \mathrm{~m}$ in $2005,201.7 \mathrm{~m}$ in 2011 and $126.4 \mathrm{~m}$ in 2014.

The analyses of this study find a lower value of median and mean absolute location error for the 2005 storm than the previous study [25]. The median and mean in [25] were $358 \mathrm{~m}$ and $395 \mathrm{~m}$ respectively. The location error improvement is attributed to the accuracy of the geographical coordinates obtained by NALDN. The absolute location error was found to vary between $84.2 \mathrm{~m}$ and $1192.7 \mathrm{~m}$ in 2005 . The median absolute location error for the 21 NALDN detected strokes $(289.3 \mathrm{~m})$ was markedly better than the projected $500 \mathrm{~m}$ median accuracy for the Toronto area after the major upgrades in 2003-2004.

The absolute location error was found to vary between $32.3 \mathrm{~m}$ and $2597.2 \mathrm{~m}$ in 2011 . The median absolute location error for the 84 detected strokes $(198.8 \mathrm{~m})$ was almost the same with the projected 200m median accuracy for the Toronto area in 2011. 
The absolute location error was found to vary between $19.6 \mathrm{~m}$ and $267.4 \mathrm{~m}$ in 2014 . The median absolute location error for the 30 NALDN detected strokes $(118.5 \mathrm{~m})$ was markedly better than the projected $200 \mathrm{~m}$ median accuracy for the Toronto area at the present.

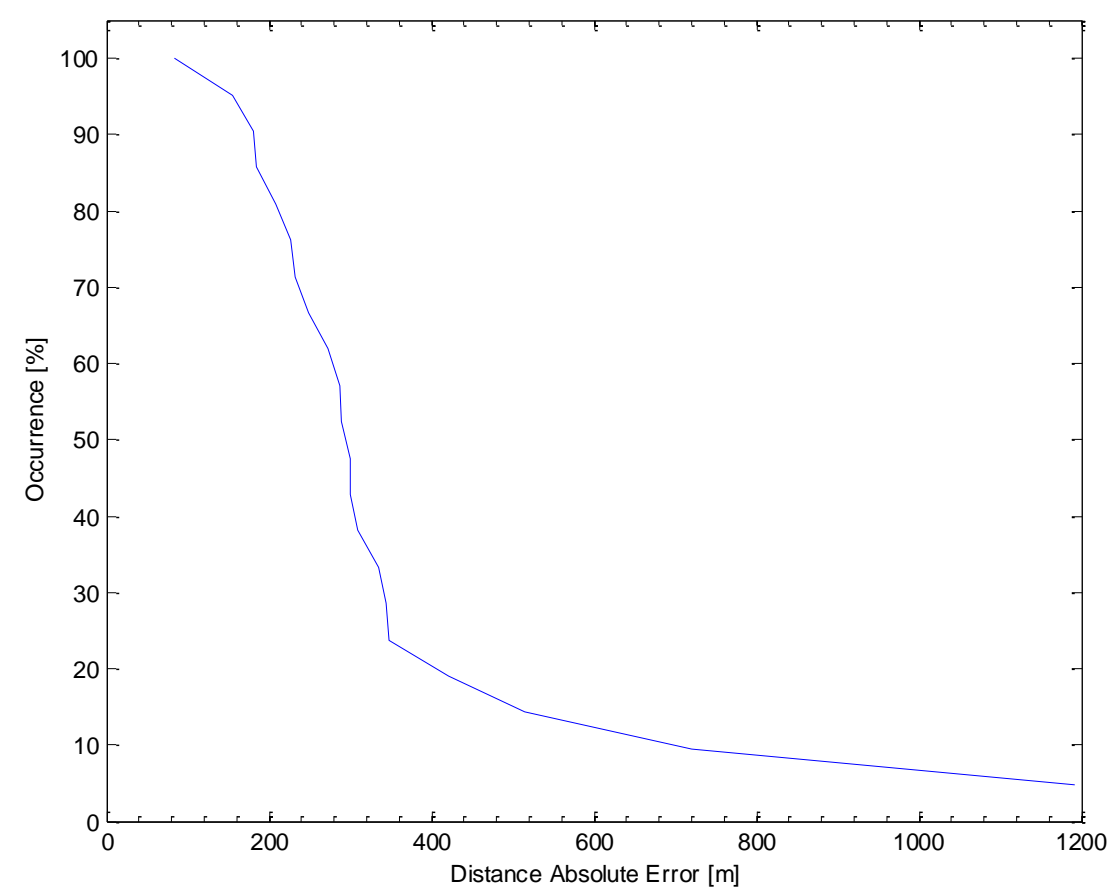

Figure 5-24 Cumulative probability distribution of absolute location error, 2005

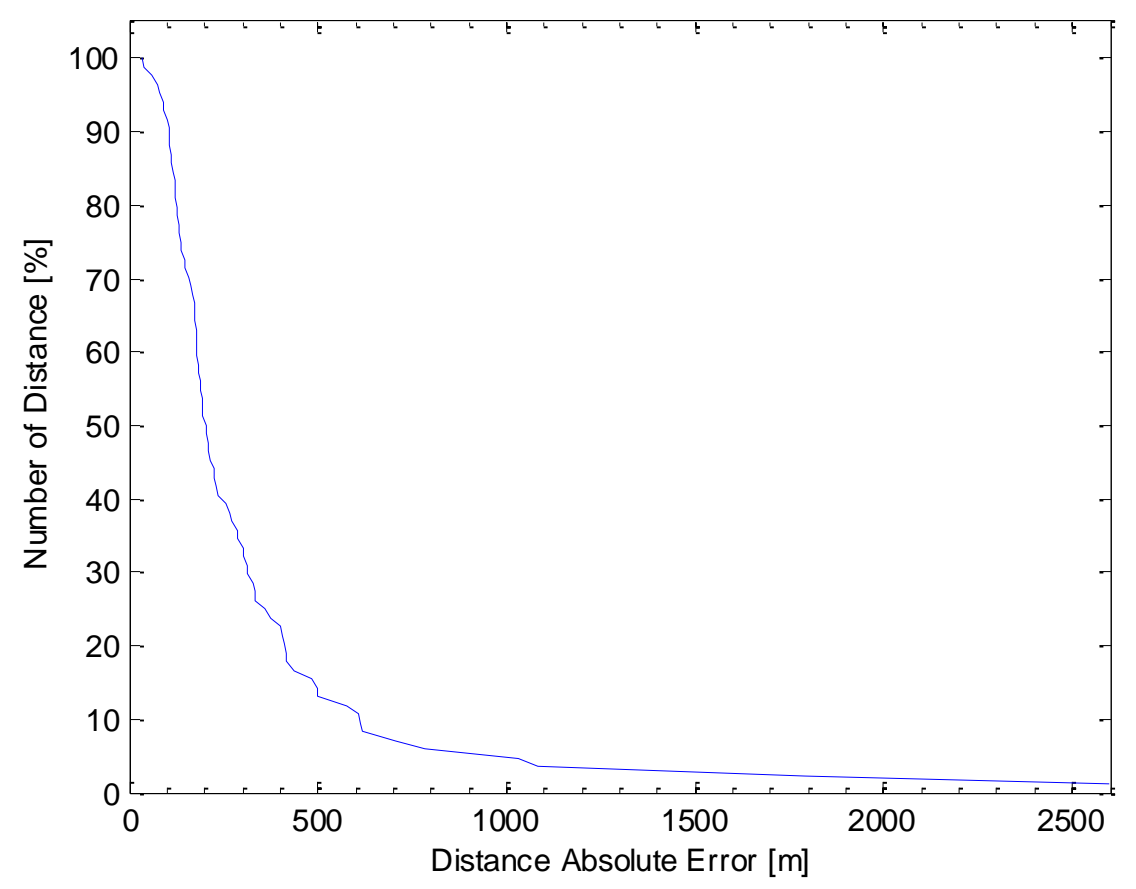

Figure 5-25 Cumulative probability distribution of absolute location error, 2011 


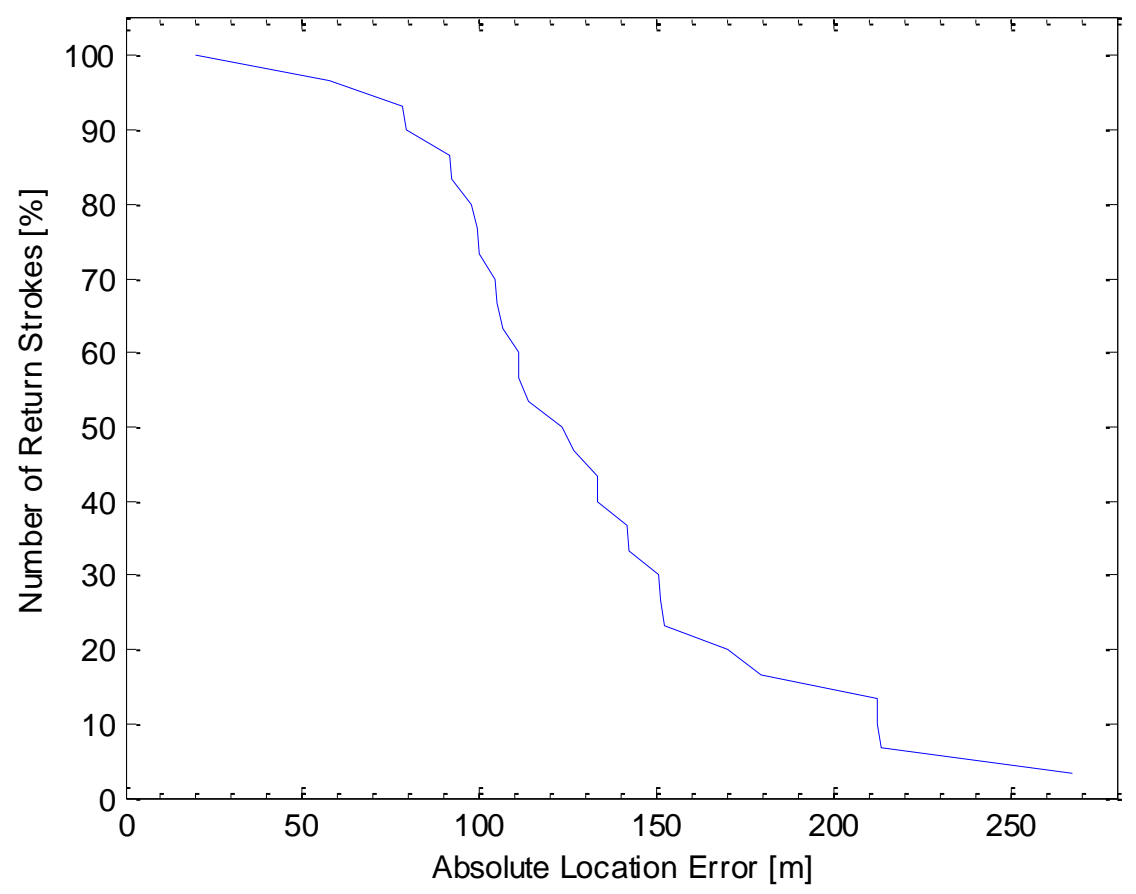

Figure 5-26 Cumulative probability distribution of absolute location error, 2014

Table 5-3 NALDN absolute location errors, statistics 2005, 2011 and 2014

\begin{tabular}{|c|c|c|c|}
\hline & $\begin{array}{c}\text { 2005 Absolute } \\
\text { Location Error } \\
{[\mathrm{m}]}\end{array}$ & $\begin{array}{c}\text { 2011 Absolute } \\
\text { Location Error } \\
{[\mathrm{m}]}\end{array}$ & $\begin{array}{c}\text { 2014 Absolute } \\
\text { Location Error } \\
{[\mathrm{m}]}\end{array}$ \\
\hline Data Size & 21 & 84 & 30 \\
\hline Minimum & 84.2 & 32.3 & 19.6 \\
\hline Maximum & 1192.7 & 2597.2 & 267.4 \\
\hline Mean & 340.5 & 313.9 & 129.2 \\
\hline Median & 289.3 & 198.8 & 118.5 \\
\hline 50\% Probability & 294.6 & 201.7 & 123.0 \\
\hline Standard Deviation & 236.7 & 361.9 & 51.4 \\
\hline
\end{tabular}




\subsection{Absolute Location Error vs NALDN and CNT Peak Currents}

The correlation between the location error, and the network estimated and the $\mathrm{CN}$ Tower recorded lightning currents, respectively, has been accomplished in this section.

\subsubsection{Absolute Location Error vs Estimated NALDN Peak Current}

Figures 5-27 - 5-29 display the relationship between the absolute location error $\left(\mathrm{E}_{\mathrm{A}}\right)$ and the corresponding NALDN estimated current peak $\left(\mathrm{I}_{\mathrm{NALDN}}\right)$ for each of the three storms. The absolute location error for each stroke is found as the distance from the NALDN predicted location to the $\mathrm{CN}$ Tower location (ground truth data). The absolute location error is shown to generally decrease as the NALDN peak current increases. This is because return strokes with high peak currents radiate high electromagnetic fields, resulting in better measurements by nearby sensors and have a higher probability to be detected by a larger number of sensors. An attempt has been made to define the location error $E_{A}$ as a rational function of $I_{N A L D N}$ :

$E_{A}=\frac{A}{I_{N A L D N}}$

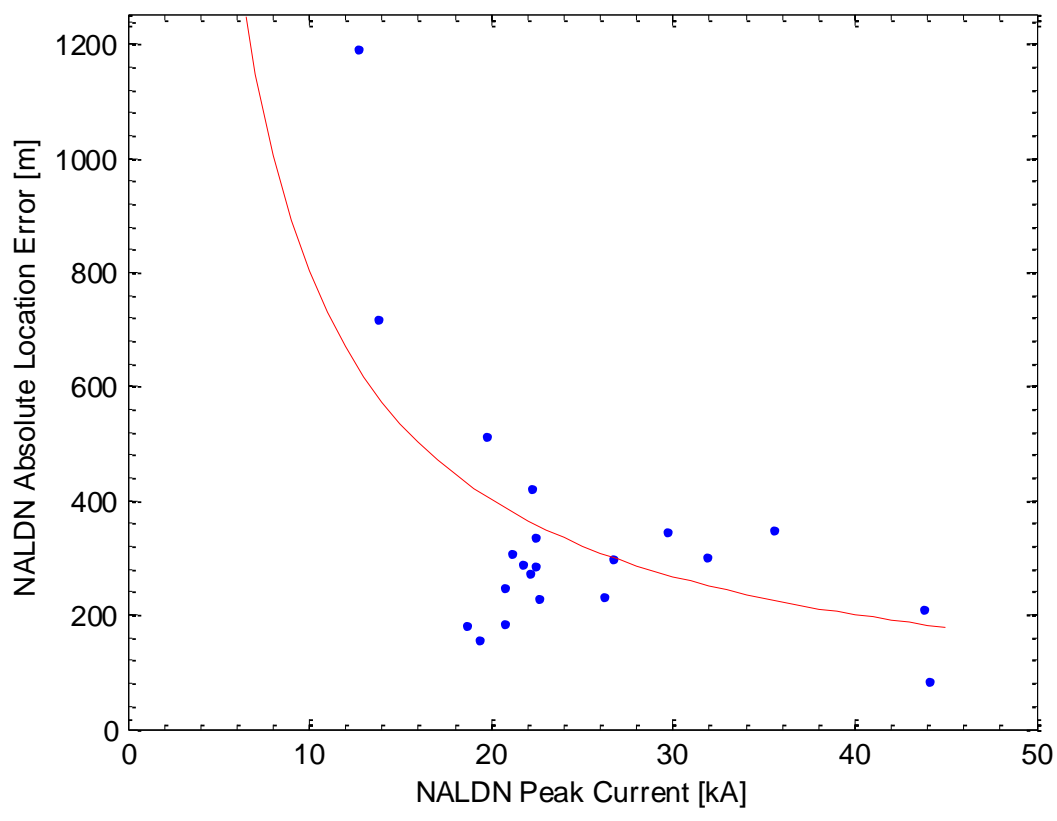

Figure 5-27 NALDN absolute location error versus NALDN peak current, 2005 


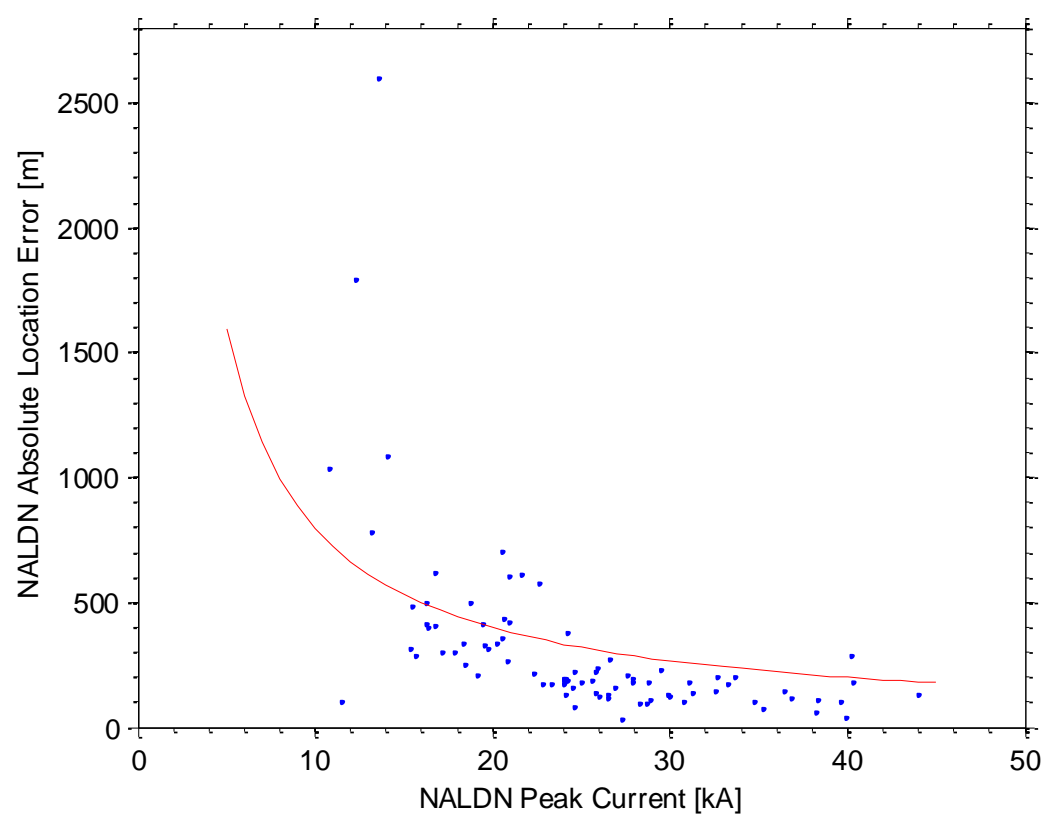

Figure 5-28 NALDN absolute location error versus NALDN peak current, 2011

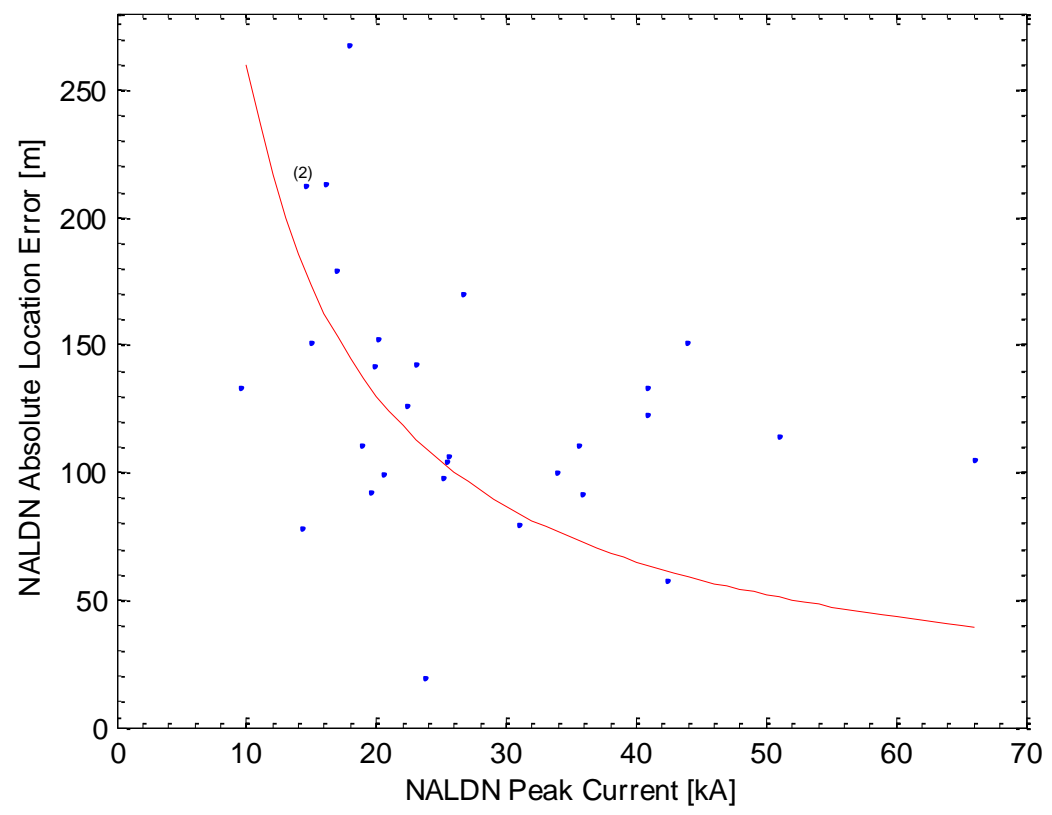

Figure 5-29 NALDN absolute location error versus NALDN peak current, 2014

Using Equation 5.1, and on the assumption that $I_{\mathrm{NALDN}}$ is in $\mathrm{kA}, A$ is constant in $\mathrm{kA}^{*} \mathrm{~m}$ and $E_{\mathrm{A}}$ is in meters, a data curve-fitting procedure was used. The curve fitting processes resulted in: $A=$ 8035 for 2005, $A=7973$ for 2011 and $A=2601$ for 2014. Although the curve-fitting processes did not produce strong correlation coefficients, the functional variations in Figures 5-27 - 5-29, show reasonable portrayal of the data. The NALDN has been able to detect only return strokes with estimated current peaks greater than $12.7 \mathrm{kA}$ in 2005 and 9.6kA in 2014. 


\subsubsection{Absolute Location Error vs CN Tower Peak Current}

Figures 5-30 - 5-31 display the relationship between the absolute location error $\left(\mathrm{E}_{\mathrm{A}}\right)$ and the corresponding $\mathrm{CN}$ Tower recorded current peak $\left(\mathrm{I}_{\mathrm{CNT}}\right)$ for each of the three storms. Out of the 21 return strokes reported by NALDN in 2005, three of the CN Tower current signals exceeded the upper most level (the fourth cut signal was not reported by the network) and one return-stroke current derivative signal was too low to be used. Out of 84 strokes reported by the network in 2011, only $15 \mathrm{CN}$ Tower current signals were not cut. Out of the 30 return strokes reported by NALDN in 2014, 14 strokes signals exceeded the upper most level. In 2005, the LeCroy digitizer was programmed to record current derivative signals of amplitude $\pm 2 \mathrm{~V}$ that corresponds to current derivative signals within the range of $\pm 27.86 \mathrm{kA} / \mu \mathrm{s}$. The NI PCI-5114 digitizer in 2011 was set to record current derivative signals of small amplitude that produced voltage signals within the range of $\pm 0.5 \mathrm{~V}$, which corresponds to current derivative signals within the range of $\pm 6.96 \mathrm{kA} / \mu \mathrm{s}$. In 2014, the LeCroy digitizer was programmed to record current derivative signals of amplitude $\pm 1.2 \mathrm{~V}$ that corresponds to current derivative signals within the range of $\pm 16.71 \mathrm{kA} / \mu \mathrm{s}$. It was noted that the recording digitizer exceeded the set range by $\pm 5 \%$ [67]. The absolute location error is shown to generally decrease as the $\mathrm{CN}$ Tower peak current increases. Using Equation 5.1, the curve fitting resulted in: $A=2570$ for 2005 and $A=573.5$ for 2014. Although the curve-fitting processes did not produce strong correlation coefficients, the functional variations included in Figures 5-30 - 5-31, show reasonable portrayal of the data. It is worth mentioning that NALDN has been able to detect only return strokes with CN Tower current peaks greater than $5.27 \mathrm{kA}$ in 2005 and $2.08 \mathrm{kA}$ in 2014.

NALDN has been able to detect return strokes with CN Tower current derivative signals greater than $9.47 \mathrm{kA} / \mu \mathrm{s}$ in 2005 and $3.26 \mathrm{kA} / \mu \mathrm{s}$ in 2014 . 


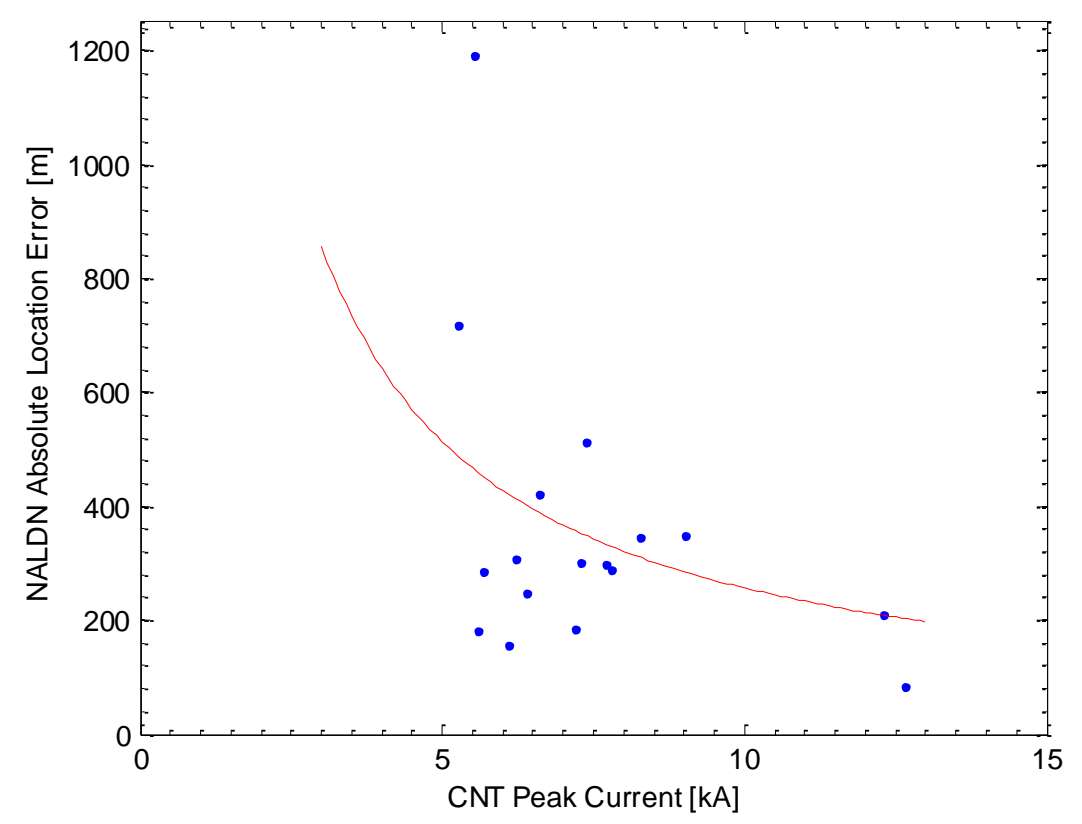

Figure 5-30 NALDN absolute location error versus measured peak current, 2005

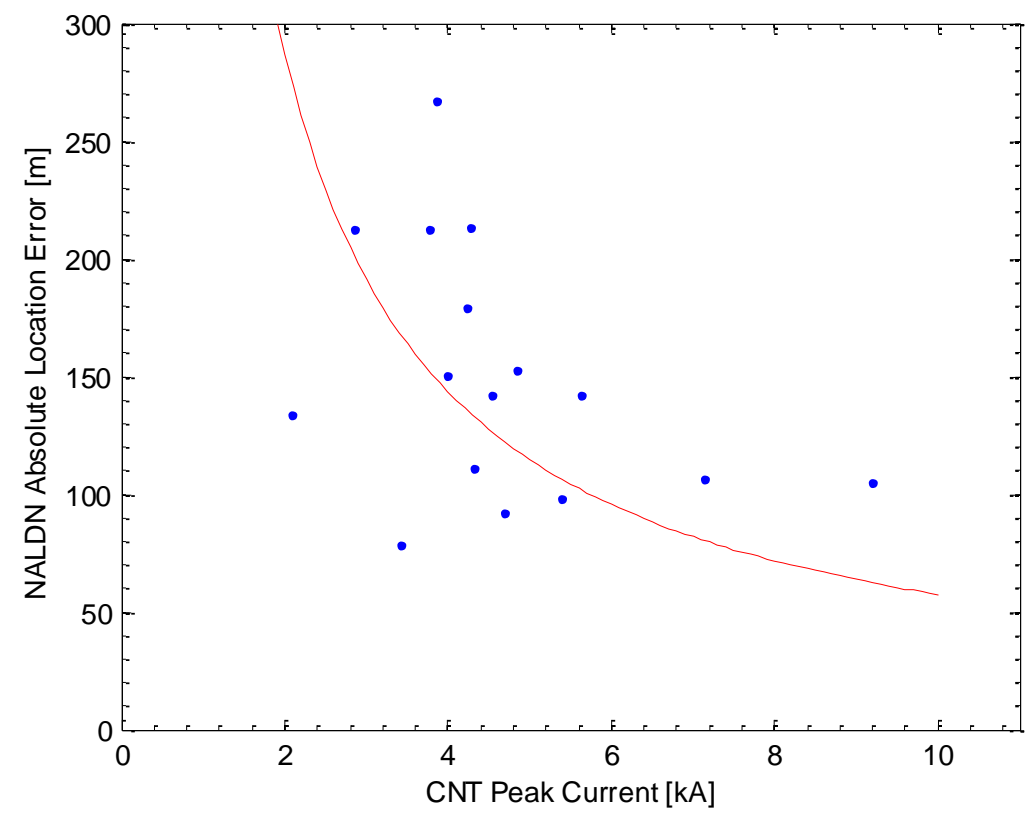

Figure 5-31 NALDN absolute location error versus measured peak current, 2014 


\subsection{NALDN vs CNT Peak Current Relation}

A correlation between the matched NALDN-estimated current peaks and the $\mathrm{CN}$ Tower measured current peaks is endeavored in this section for the unclipped return-stroke current derivative signals; 17 strokes in 2005 and 15 strokes in 2014. The first peak, not the maximum peak, of CN Tower measured current has been used for correlation with NALDN estimated peak current lightning data. The NALDN performance evaluation shows that NALDN have estimated peak currents in the range of $12.7-44.1 \mathrm{kA}$ in 2005 and $9.6-66.1 \mathrm{kA}$ in 2014 . The corresponding CN Tower measured absolute current peaks were found respectively to be in the range of 5.612.7kA for 2005 and 2.08-9.37kA in 2014. Figures 5-32 - 5-33 show the data points representing the relationship between NALDN estimated peak current $\left(I_{\text {NALDN }}\right)$ and the corresponding $\mathrm{CN}$ Tower measured absolute peak current $\left(I_{\mathrm{CNT}}\right)$ for the two storms. The estimated and measured peak currents are found to have a linear relationship, with a correlation coefficient (95\% confidence bounds) of 0.8607 in 2005 and 0.8542 in 2014. This relationship is shown in Table 5-4.

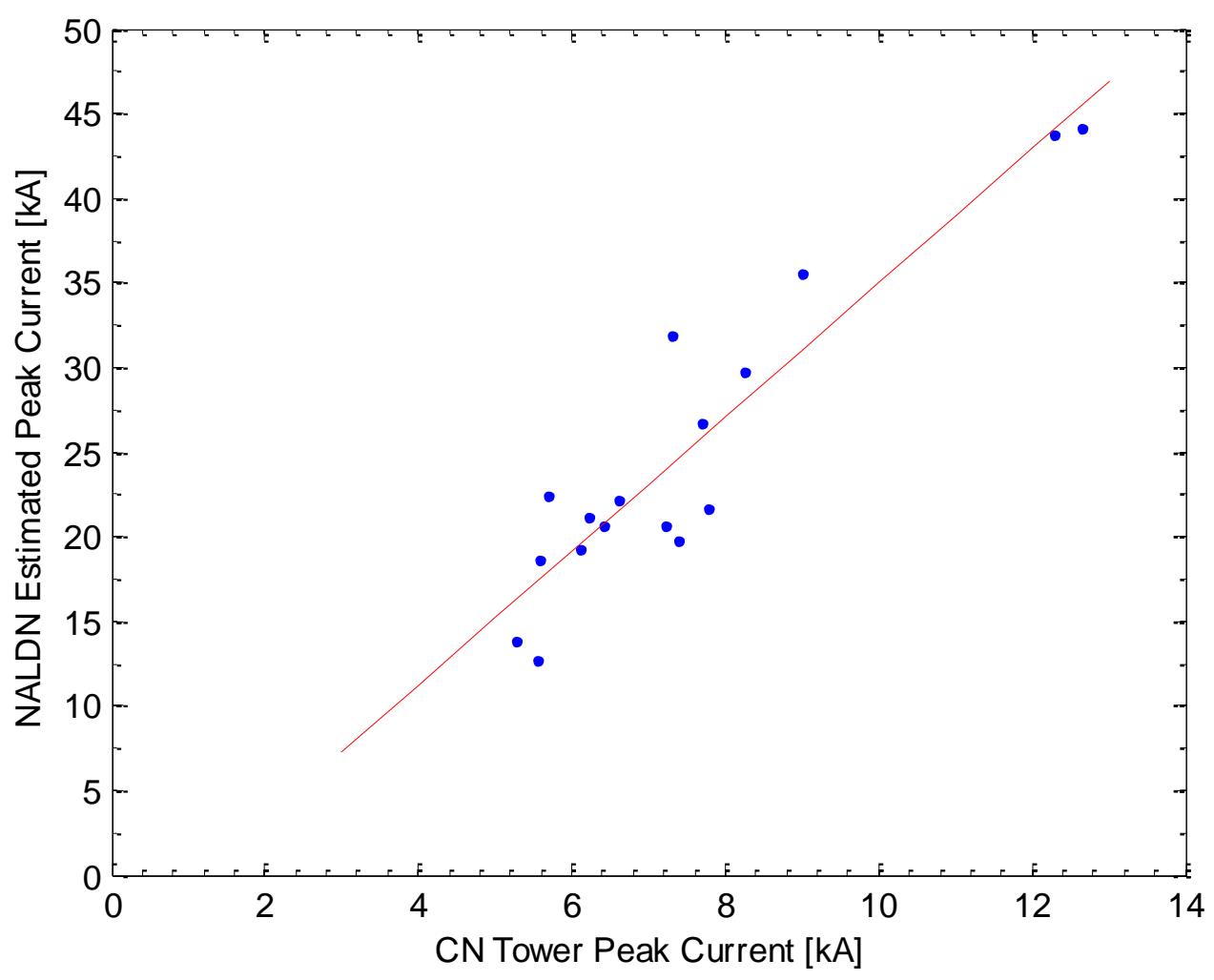

Figure 5-32 NALDN versus CN Tower peak current, 2005 


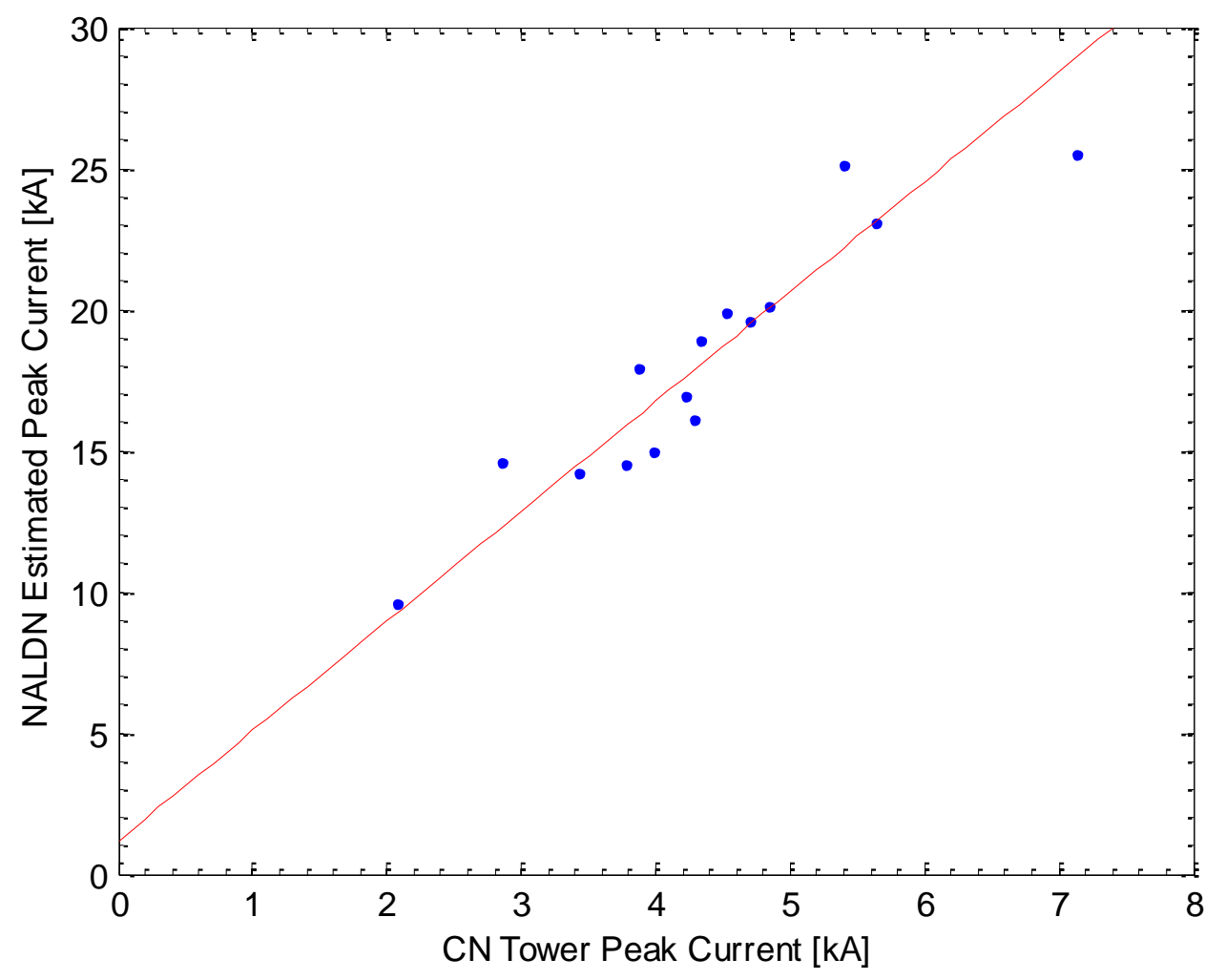

Figure 5-33 NALDN versus CN Tower peak current 2014

Table 5-4 NALDN vs CNT peak current relation in 2005 and 2014

\begin{tabular}{|c|c|c|}
\hline & $\begin{array}{c}\text { NALDN vs CNT Current } \\
2005\end{array}$ & $\begin{array}{c}\text { NALDN vs CNT Current } \\
2014\end{array}$ \\
\hline $\begin{array}{c}\text { Curve Fit } \\
\text { Expression }\end{array}$ & $\mathrm{I}_{\text {NALDN }}=\mathrm{P} 1 * \mathrm{I}_{\mathrm{CNT}}+\mathrm{P} 2$ & $\mathrm{I}_{\text {NALDN }}=\mathrm{P} 1 * \mathrm{I}_{\mathrm{CNT}}+\mathrm{P} 2$ \\
\hline $\mathrm{P} 1$ & 3.971 & 3.89 \\
\hline $\mathrm{P} 2$ & -4.701 & 1.189 \\
\hline R-square & 0.8607 & 0.8542 \\
\hline
\end{tabular}




\subsection{Flashes interpreted as multiple flashes by NALDN}

There have been instances that NALDN has grouped return strokes of different flashes incorrectly in the same flash or that strokes of the same flash have been grouped in different flashes during the three $\mathrm{CN}$ Tower lightning storms. The observed flash misinterpretations of the network are provided below for each storm in chronological order.

1. 2005 Storm

- Flash 6 contains 4 return strokes confirmed by both current and image measuring systems (between 18:37:52.5633923 and 18:37:53.2844420). NALDN has added an extra stroke at 18:37:52.543 (latitude 43.6369, longitude -79.3928, peak current-8.6kA) to the 4 strokes recorded at $\mathrm{CN}$ Tower. The network has combined strokes from different flashes and classified them as one flash. The NALDN predicted the location of the extra stroke within a range of $10 \mathrm{~km}$ from the other 4 return strokes; their flash duration was less than one second.

2. 2011 Storm

- Flash 1 displayed in Figures 5-7 - 5-8 had five strokes recorded by both current and image measuring systems (with the same channel trajectory). NALDN has detected the first two (classified as one flash) and the fifth return stroke (classified as another flash). The inter-stroke time between the second and the fifth return stroke was $572 \mathrm{~ms}$. All strokes were predicted at distances less than $200 \mathrm{~m}$ from each other and the flash duration was less than one second.

- Flash 37 had nine return strokes. The NALDN reported the first three strokes and the seventh one. The difference in time between the third and the seventh return strokes was $750 \mathrm{~ms}$. Even though all strokes have the same channel trajectory, the network grouped the first three strokes into one flash and the seventh stroke in a separate flash. All return strokes were predicted at distances less than $1000 \mathrm{~m}$ from each other and their flash duration was less than one second.

3. 2014 Storm

- Flash 8, also displayed in Figures 5-12 - 5-13, has three return strokes. A perfect time match was attained between the network-reported data, and both the $\mathrm{CN}$ Tower recorded current and recorded images. The trajectories of the three strokes 
are shown magnified in Figure 5-34 in order to display the similarity of channel trajectories of respective return strokes. Unfortunately, the network grouped the first two strokes in a separate flash from the third stroke. The difference in time between the second and the third return stroke was $5 \mathrm{~ms}$. All strokes were predicted at distances less than 200m from each other and their flash duration was less than one second.
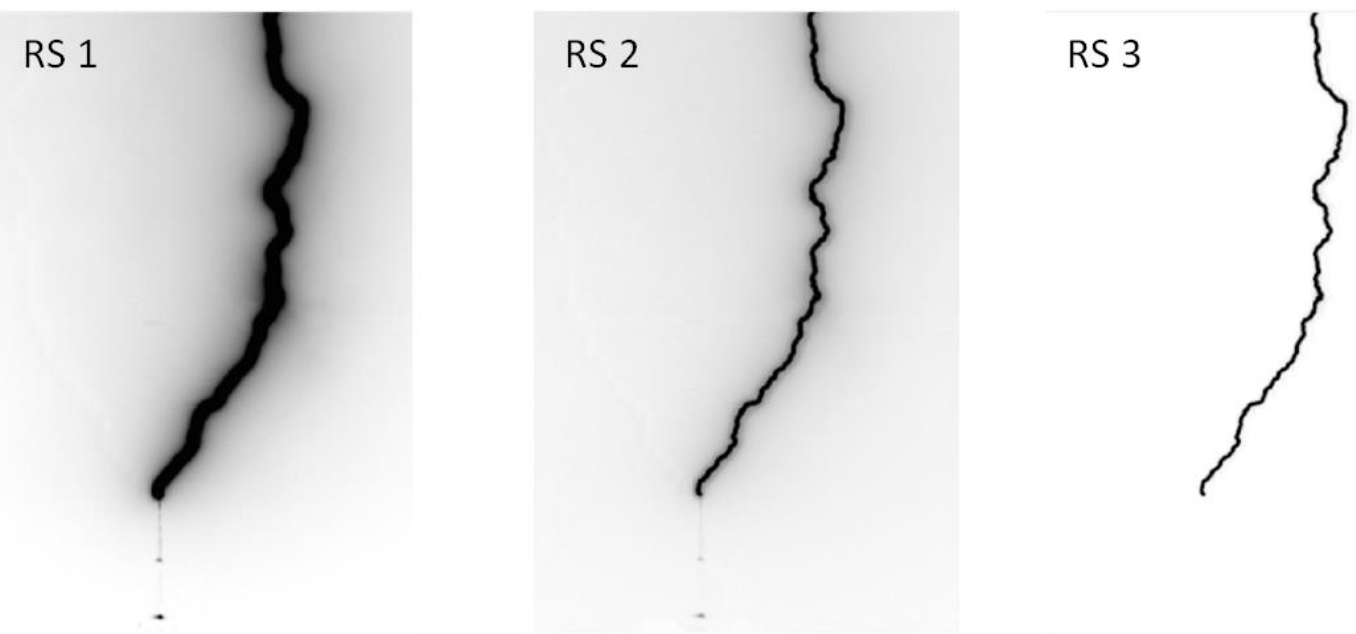

Figure 5-34 Trajectories of three return strokes of flash 8, 2014

- Flash 11 had two return strokes perfectly time matched between the network, CN Tower current and image recording systems. The time match between the luminosity analysis and current derivative signal for this flash is shown in Figure 5-35. The first stroke has been grouped in a separate flash from the second one. The difference in time between the first and the second return stroke was $5 \mathrm{~ms}$. Both strokes were predicted at distances less than $200 \mathrm{~m}$ from each other.

- Flash 19, displayed in Figure 4-21, has three return strokes, whose CN Tower recorded currents were time matched with three of the network reported strokes. The corresponding recorded images also time matched both the current records and the network reported strokes. The network, however, classified each of these strokes as a separate flash. The inter-stroke time between the first and the second stroke is $87.7 \mathrm{~ms}$. The time between the second and third stroke is found to be $163 \mathrm{~ms}$. All return strokes were predicted at distances less than $200 \mathrm{~m}$ from each other and their flash duration was less than one second. 
- Flash 22 displayed in Figure 5-10 had eight return strokes perfectly time matched to the network and $\mathrm{CN}$ Tower current and image recording systems. The first four strokes were grouped by the network as one flash; the fifth stroke was classified as a separate flash. The last three strokes were grouped in a third flash. The inter-stroke time between the fourth and the fifth return stroke was $66.8 \mathrm{~ms}$ whereas that between the fifth and sixth stroke it was $512.5 \mathrm{~ms}$. All strokes were predicted at distances less than $250 \mathrm{~m}$ from each other and their flash duration was less than one second.
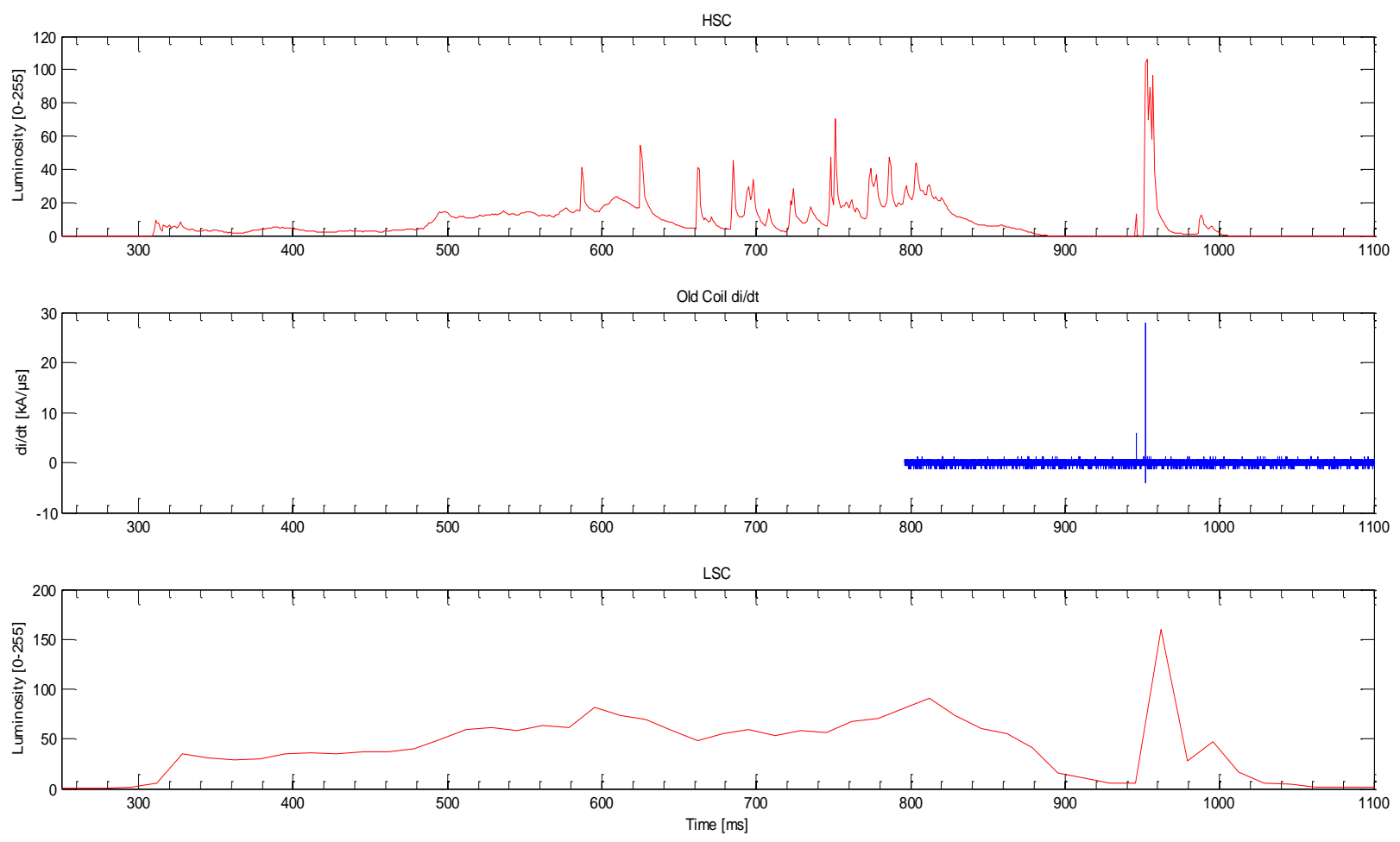

Figure 5-35 Two-return stroke flash (\# 11), 2014

\subsection{Flash Recorded by NI PXIe Current Measuring System in December 2015}

A flash recorded by both PXIe and PCI 5114 current measurement systems, as well as reported by NALDN, is discussed in this section. The high resolution and long duration of lightning current signals recorded by the new PXIe system contributes to the details of lightning flash components, very important in protection and electromagnetic compatibility of electrical equipment. 


\subsubsection{Flash Characteristics, 2015}

Figure 5-36 displays a perfect time match between the raw data recorded by the two current measurement systems. The NI PXIe-5160 system was connected to the new Rogowski coil via the optical fiber link and NI-PCI 5114 was connected to the old Rogowski coil via the tri-axial cable. The amplitudes of the two raw signals (Figure 5-36), which are obtained via the two independent measurement systems, are not identical because of their different current sensitivities, bandwidths and losses. It is worth mentioning that initial impulses superimposed on the initial continuous current have triggered the PXI Express system.
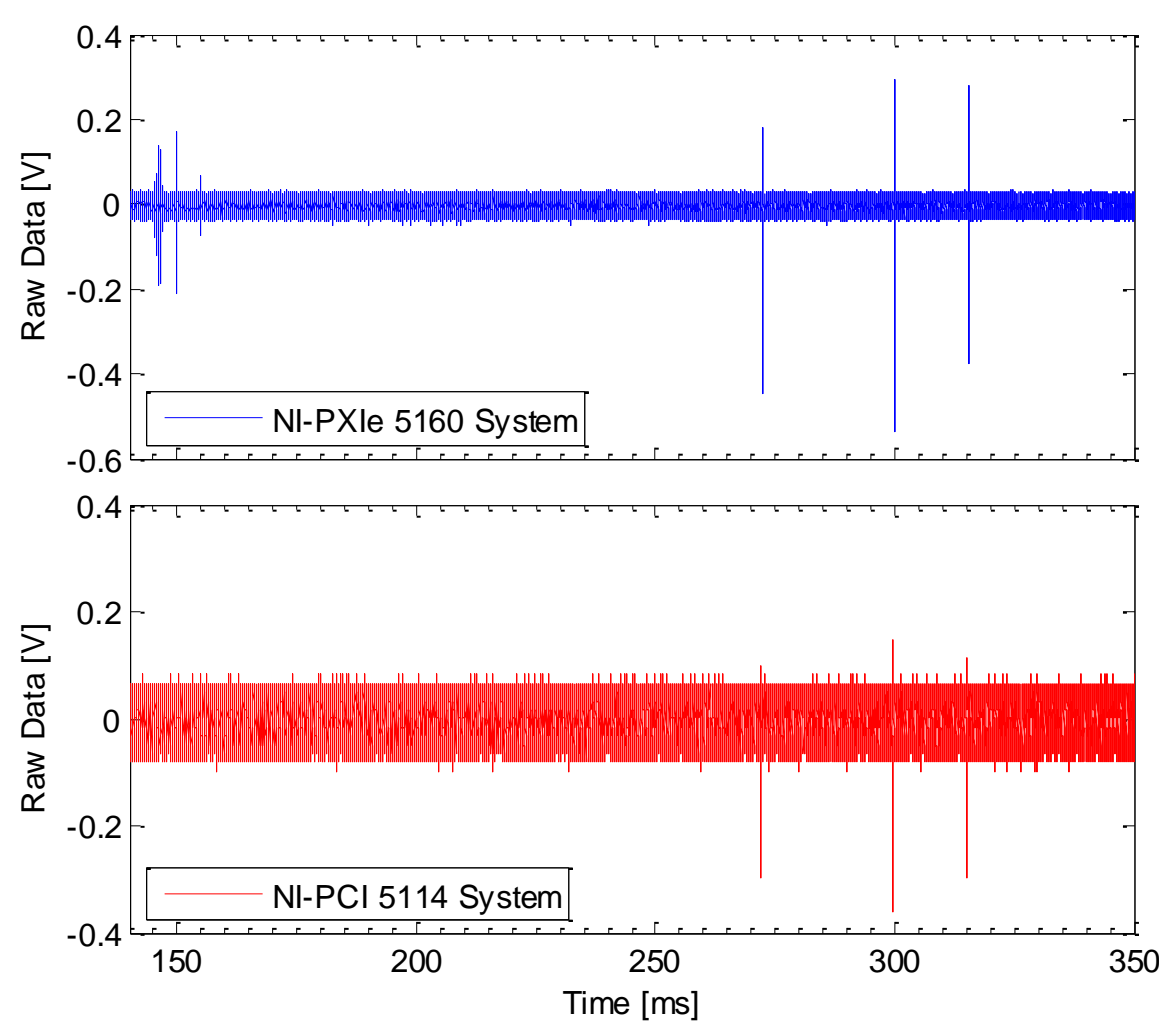

Figure 5-36 Current derivative of the 2015 CN Tower flash recorded by two independent current measurement systems

Figure 5-37 shows the current derivative signal of the full CN Tower flash, which was recorded by the PXIe system. Only a 400-ms time window of the two seconds record is displayed in the figure because of the non-existence of impulses in the remaining record. Although the $\mathrm{CN}$ Tower measured three return strokes are negative, they are displayed as if they were positive, for convenience. Figure 5-37 clearly points out to the existence of three return strokes that are preceded by several impulses, expectedly superimposed on a low time-varying initial stage 
current, which is apparently embedded in noise. The same flash was also recorded by the other NI PCI 5114 system programmed to record current derivative signals at 100-ns resolution. The existence of ISC proves that this flash is upward initiated as the case of most CN Tower flashes. The three return strokes of this flash were reported by NALDN. However, none of the eight ISC impulses was reported by the network.

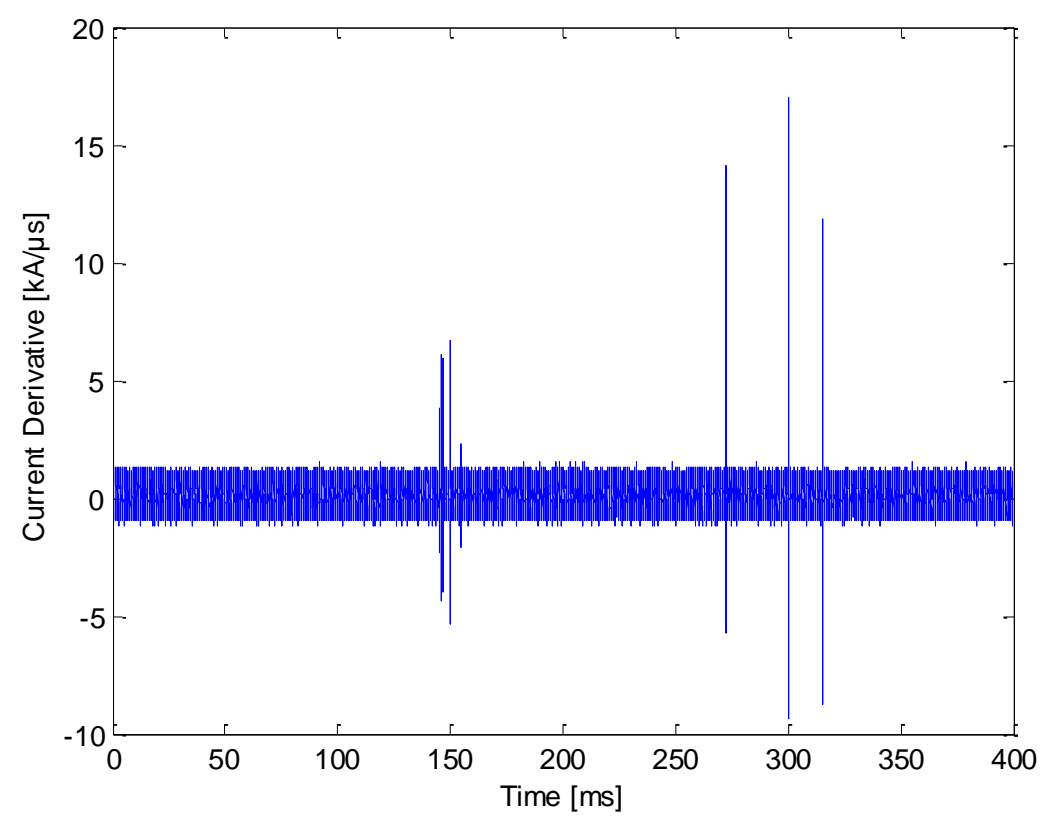

Figure 5-37 Current derivative of 2015 CN Tower flash recorded by NI PXIe system

The current derivative of the second return stroke, which exhibits the highest peak among the recorded impulses, is shown in Figure 5-38. Figure 5-39 shows the corresponding current obtained by numerically integrating the measured current derivative signal. Because of ground reflections, each current waveform displays an initial (first) peak and an absolute peak.

In an expanded scale, Figure 5-40 displays the current derivatives of the eight recorded ISC impulses. The current derivative of the seventh ISC impulse, which exhibits the highest peak among the recorded ISC impulses, is presented in Figure 5-41. It is noticed that the current derivative of this ISC impulse is quite different from that of a return stroke because of its fast pulsatory nature, which could represent luminosity perturbations in the leader. 


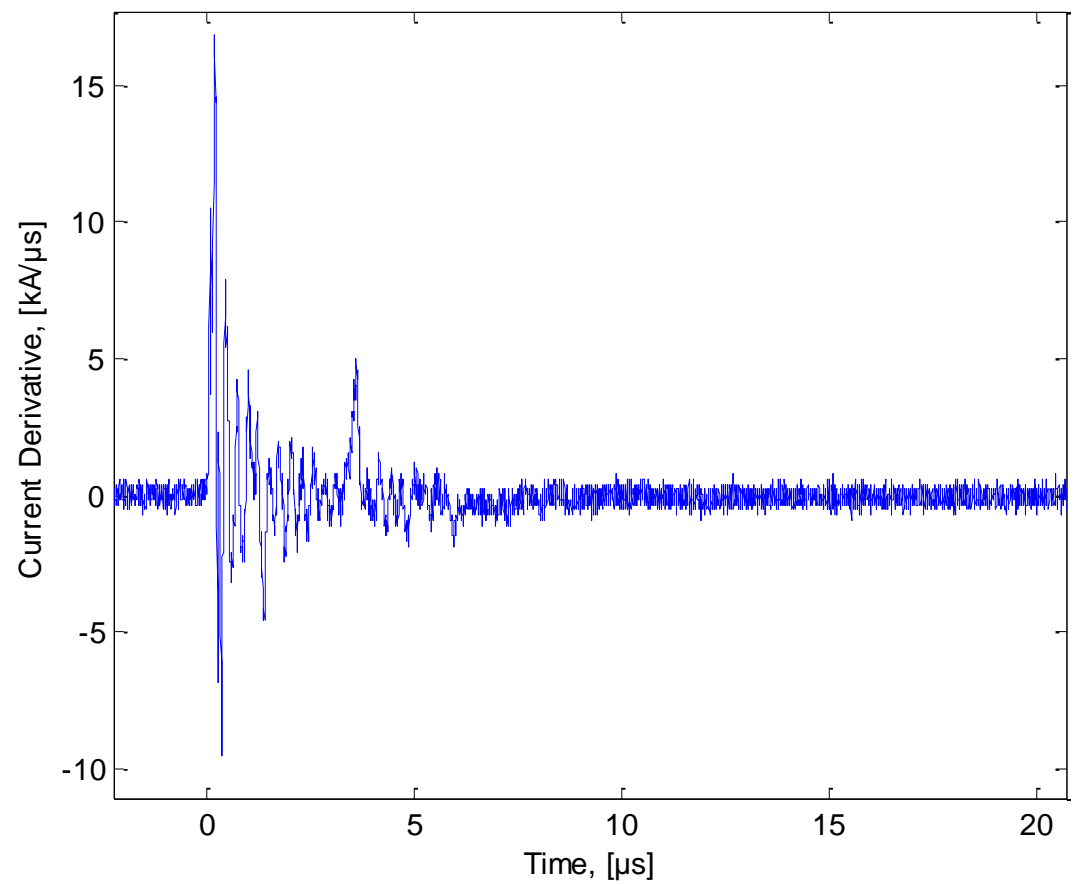

Figure 5-38 Current derivative of the second return stroke

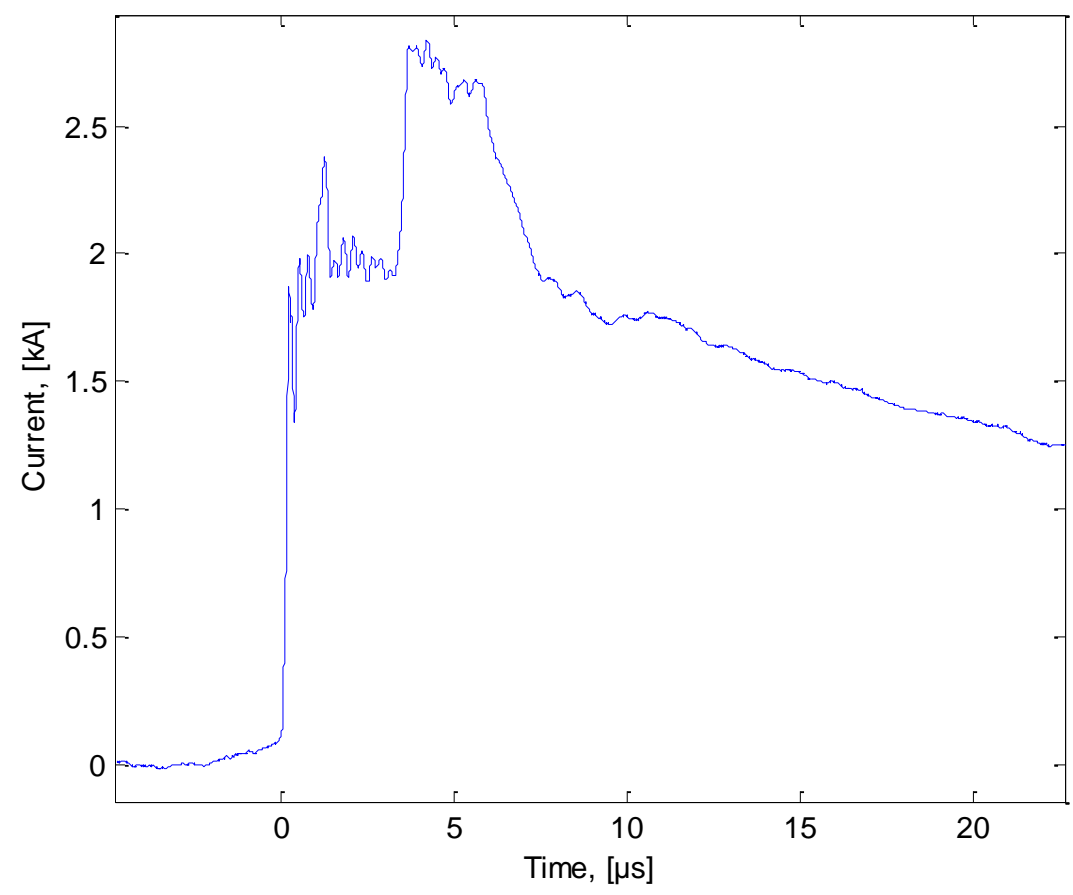

Figure 5-39 Current of the second return stroke 


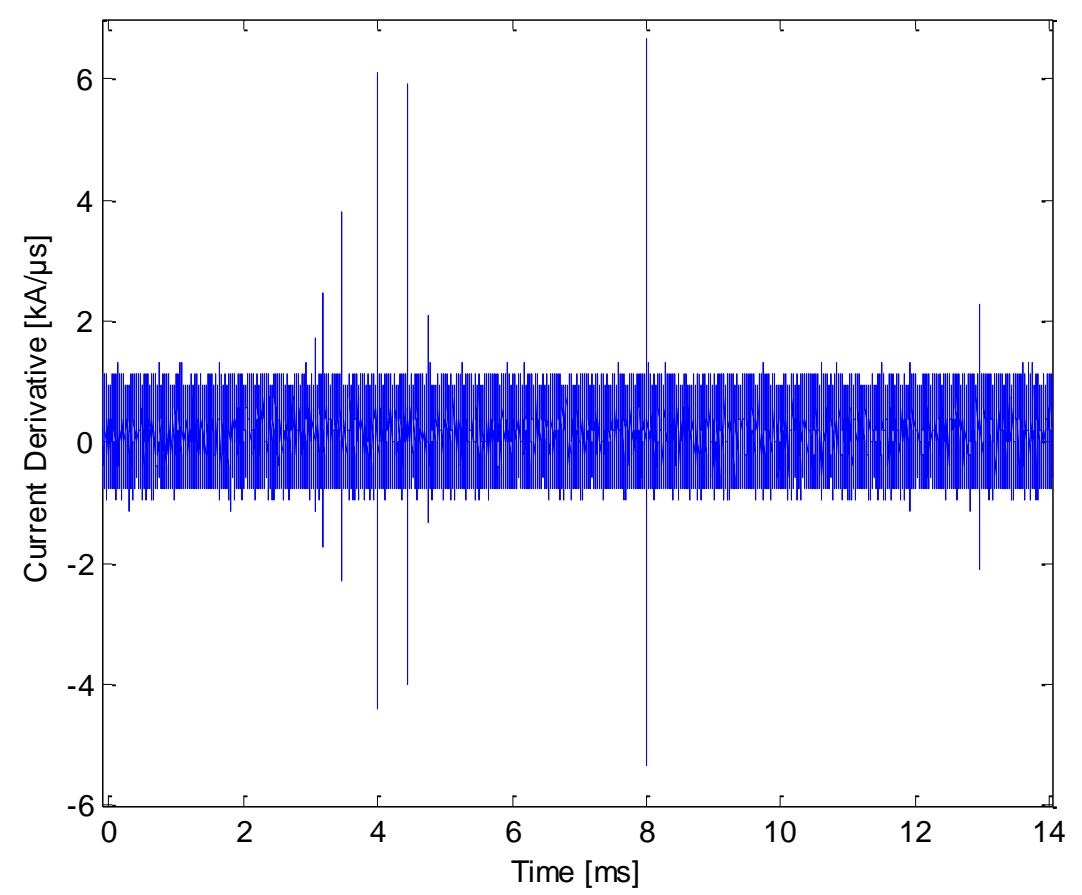

Figure 5-40 Current derivative of ISC impulses

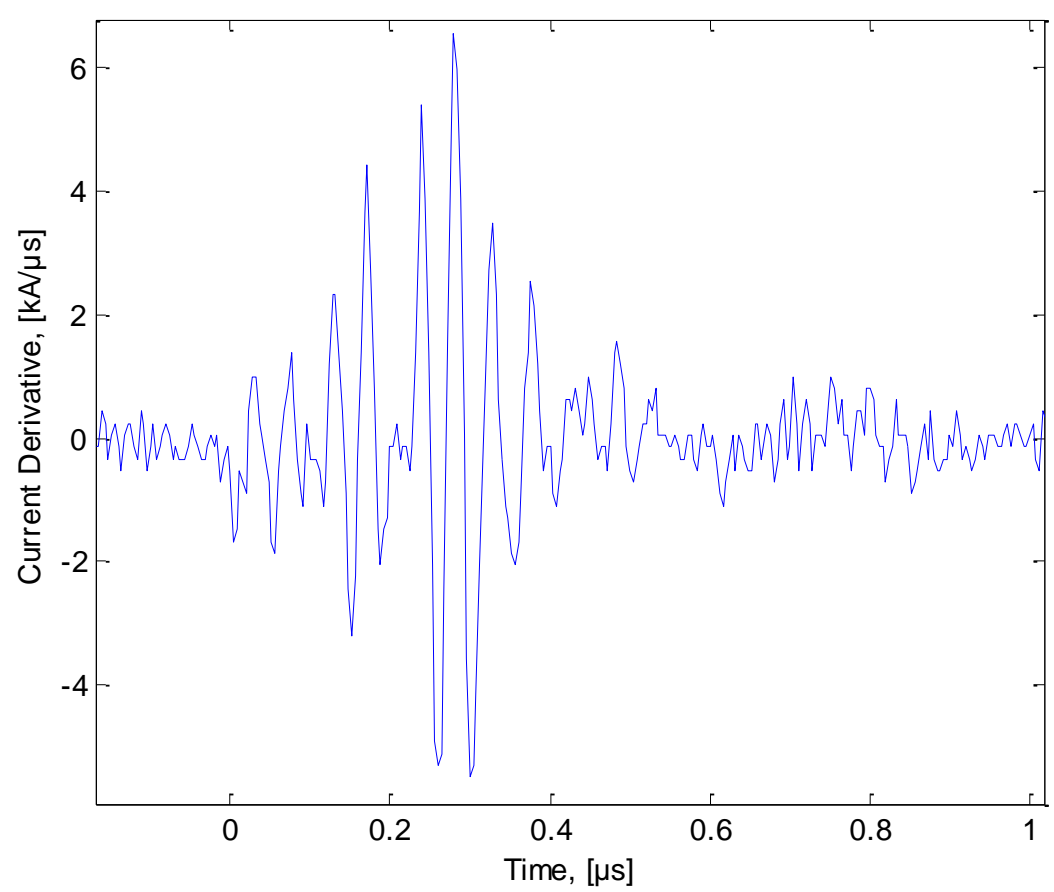

Figure 5-41 Current derivative of the seventh ISC impulse 


\subsubsection{NALDN Performance Characteristics, 2015}

Performance characteristics of NALDN for the 2015 CN Tower flash have been accomplished in this subsection. The flash's three current derivative signals, representing three $\mathrm{CN}$ Tower return strokes, were perfectly time matched with NALDN data. The two inter-stroke times of the three CN Tower recorded strokes, $27.629 \mathrm{~ms}$ and $15.434 \mathrm{~ms}$, are found to be identical to those reported by the network. Furthermore, the negative polarity of each of the measured return strokes matches that reported by the network.

Figure 5-42 shows the NALDN estimated locations of the three strokes. A North-South versus East-West distance plot of NALDN stroke location errors is shown with the origin indicating the location of the tower. The horizontal and vertical axes correspond to east-west (with west being positive) and north-south (with south being positive), respectively. Table 5-5 presents the current peaks estimated by the network with those measured at the tower. Also, the absolute location error for each stroke along with the bias in the south and west direction are provided in the table.

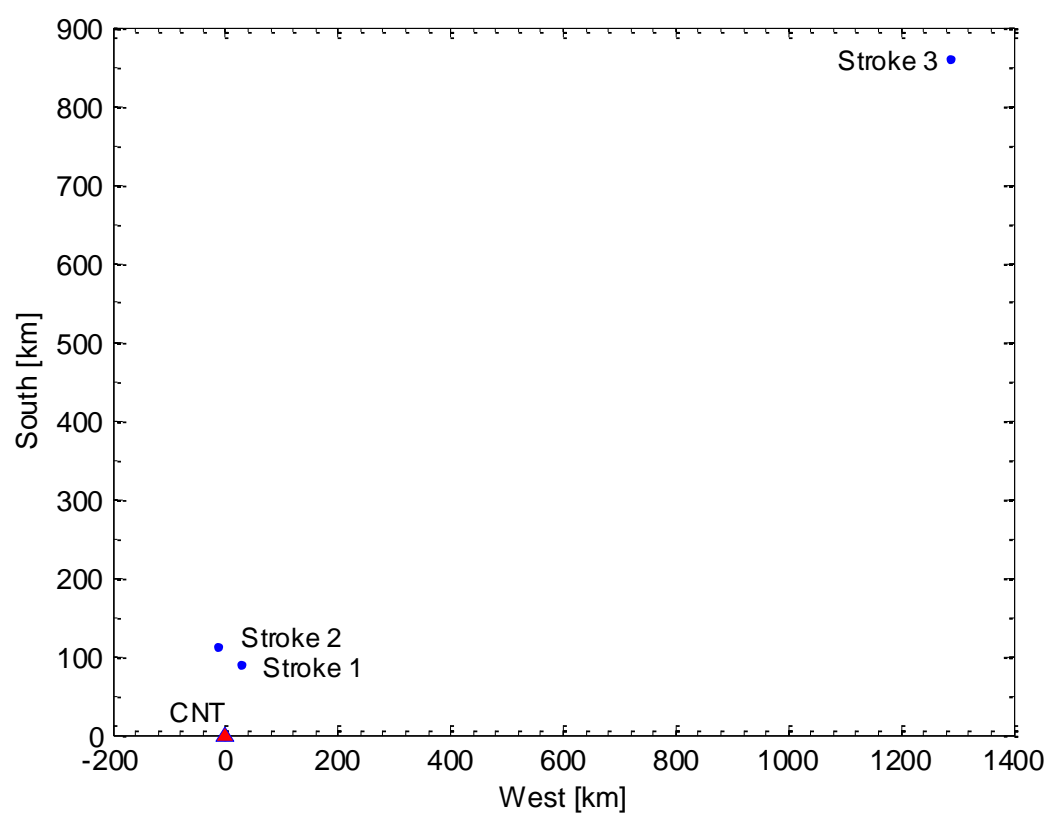

Figure 5-42 Location Error, 2015 flash

The absolute location errors for the first two return strokes $(94.6 \mathrm{~m}$ and $112.7 \mathrm{~m})$ are markedly better than the projected median location error in the Toronto area of $200 \mathrm{~m}$. The absolute 
location error for the third return stroke $(1547.9 \mathrm{~m})$ is many times larger than the network projected location error. This discrepancy is explained by the low network-estimated current of the third stroke (2.4kA); the lowest ever reported by NALDN for CN Tower strokes. While the network reporting of this low peak current demonstrates significant improvements in the detection efficiency of the network, the reported location error is definitely too high. The third return stroke was detected by only two NALDN sensors, while the other two return strokes were detected by four sensors, and this is the likely reason of the poor results for stroke 3 .

Table 5-5 CN Tower lightning data 2015

\begin{tabular}{|c|c|c|c|c|c|}
\hline 2015 & $\begin{array}{c}\text { NALDN } \\
\text { Current } \\
{[\mathrm{kA}]}\end{array}$ & $\begin{array}{c}\text { CNT } \\
\text { Current } \\
{[\mathrm{kA}]}\end{array}$ & $\begin{array}{c}\text { Distance } \\
{[\mathrm{m}]}\end{array}$ & $\begin{array}{c}\text { South } \\
{[\mathrm{m}]}\end{array}$ & $\begin{array}{c}\text { West } \\
{[\mathrm{m}]}\end{array}$ \\
\hline Stroke 1 & 7.1 & 1.229 & 94.6 & 90.5 & 27.4 \\
\hline Stroke 2 & 8.6 & 1.770 & 112.7 & 112.0 & -13.3 \\
\hline Stroke 3 & 2.4 & 1.120 & 1547.9 & 859.3 & 1287.5 \\
\hline
\end{tabular}

Figure 5-43 presents the absolute location error plotted versus the CN Tower NALDN estimated peak current, for the three detected strokes. The absolute location error is shown to generally decrease as the NALDN peak current increases. The following exponentially-decaying function is used for curve fitting the data:

$$
E_{A}=a * e^{-b * I_{N A L D N}}
$$

Where absolute location error, $\mathrm{E}_{\mathrm{A}}$, is in meters; estimated current peak, $\mathrm{I}_{\mathrm{NALDN}}$, is in $\mathrm{kA}$; $\mathrm{a}$ and $\mathrm{b}$ are constants. Using Equation 5.2, a data curve-fitting procedure resulted in: $a=5,536 \mathrm{~m}$ and $\mathrm{b}=$ $0.5311 / \mathrm{kA}$ with a correlation coefficient of R-square $=0.997$. Although the data size is small, the figure shows a reasonable relationship between the NALDN peak current and the corresponding absolute location error.

The NALDN estimated peak currents of the three return strokes of December 29, 2015, are respectively 7.1, 8.6 and $2.4 \mathrm{kA}$; all of them are below the previous network peak current estimation of the three storms in 2005, 2011 and 2014. The corresponding peak currents 
measured at the tower are: $1.229,1.77$ and 1.12kA, respectively. The NALDN was able to detect CN Tower return strokes with peak currents exceeding 9.6kA in the 2014 storm.

A correlation between the measured and estimated peak currents is not made because a lager data set is needed to better define that relationship.

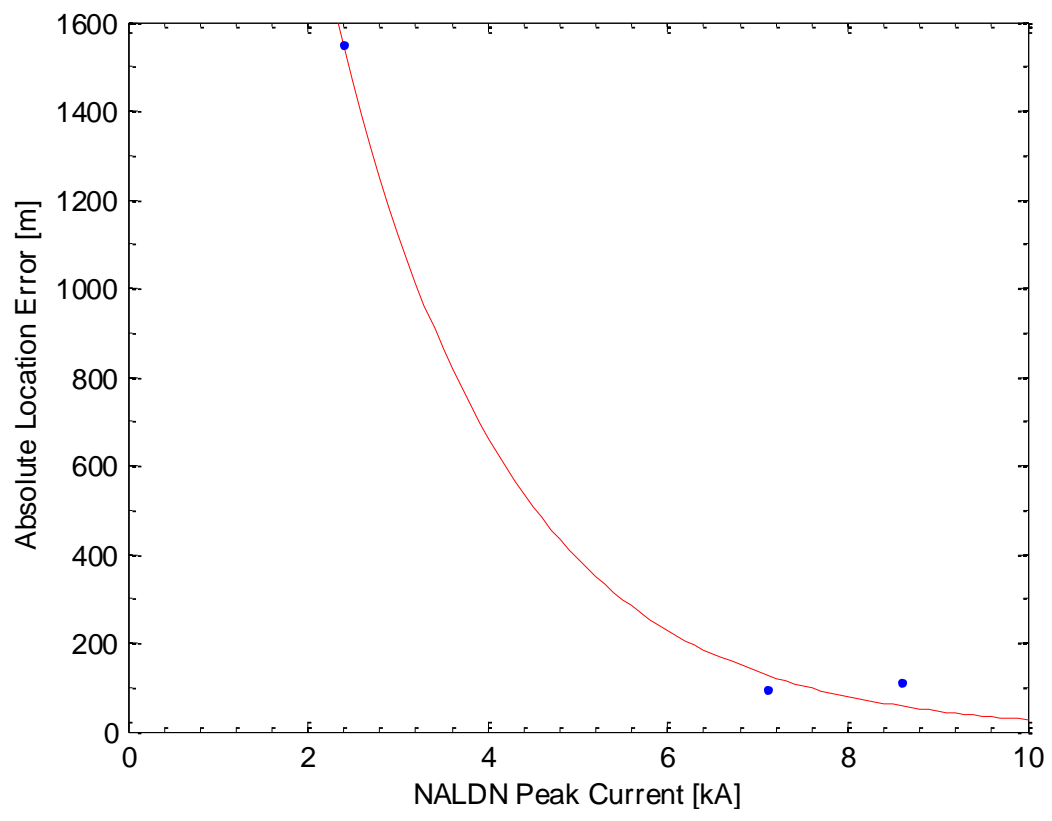

Figure 5-43 Absolute location error versus peak current estimate, 2015 flash

\subsection{Summary of NALDN Performance Evaluation}

The evaluation outcomes for the three storms of 2005, 2011 and 2014 have been compared in Table 5-6. The polarities of all NALDN-detected return strokes were perfectly matched with the polarities of the corresponding return-stroke currents measured at the tower. Flash detection efficiency was $100 \%$ in 2005 and 2014 whereas $87.5 \%$ in 2011 . Stroke detection efficiency was significantly higher in 2014 (100\%) than in 2005 (55.3\%) and in 2011 (53.8\%). The median location error has always been lower than the suggested values by NALDN. In 2005 the median location error was found $289.3 \mathrm{~m}$ lower than $500 \mathrm{~m}$ expected by the network. The median location error was found $198.8 \mathrm{~m}$ in 2011 and $118.5 \mathrm{~m}$ in 2014; in both years lower than $200 \mathrm{~m}$ suggested by NALDN. Also, the average location error has significantly improved from $340.5 \mathrm{~m}$ in 2005 and 
$313.9 \mathrm{~m}$ in 2011 to $129.2 \mathrm{~m}$ in 2014 . Figure 5-44 shows the cumulative distribution of the NALDN absolute location error for the CN Tower detected strokes in 2005, 2011 and 2014.

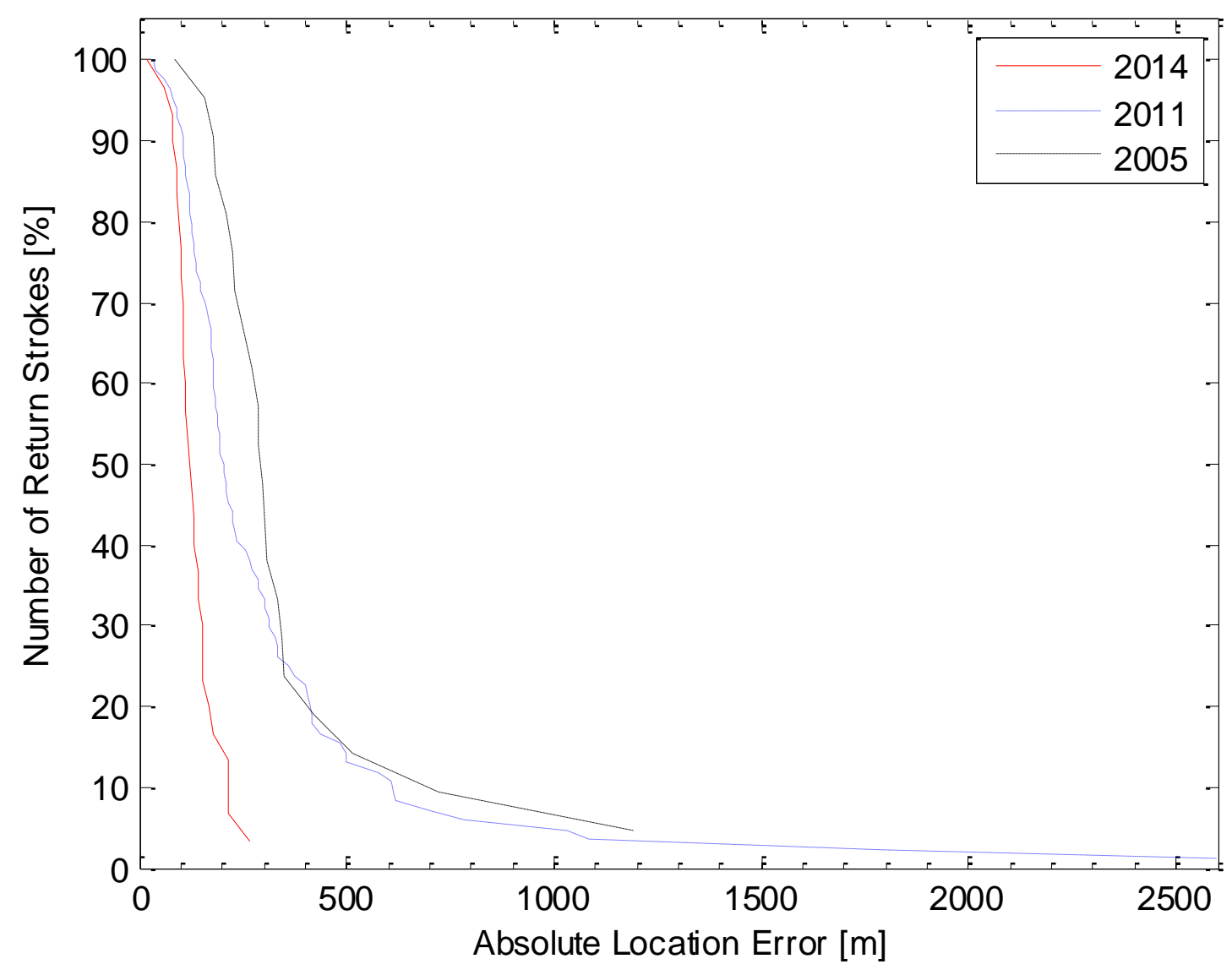

Figure 5-44 Cumulative probability distribution of absolute location error; 2005, 2011 and 2014

Figure 5-44 shows that location accuracy has significantly improved after the network upgrades in 2013-2014. A higher number of return strokes was detected, for smaller location errors, in 2014 as compared to 2005 and 2011. Based on the three storms (2005, 2011 and 2014), Figure 5-45 shows that the location error decreases as the network estimated peak current increases. The figure clearly shows that the network provided a much better location accuracy in 2014 in comparison with those provided in 2005 and 2011 for the same NALDN estimated peak currents. For a more detailed comparison, the absolute location error curve fittings are expanded in Figure 5-46. The figure displays the substantial improvement of the network absolute location error after the latest upgrade (2013-2014). The benefit of the 2013-2014 upgrades, as observed from Table 
$5-6$, is not only shown in the median and mean location error, but in the maximum and minimum location error as well. The maximum location error in 2014 is $267.4 \mathrm{~m}$, much lower than in 2005 $(1192.2 \mathrm{~m})$ and in $2011(2597.2 \mathrm{~m})$. The minimum location error in 2014 is $19.6 \mathrm{~m}$, lower than in 2005 (84.2m) and in 2011 (32.3m). The NALDN has detected strokes with lower estimated peak currents from the earlier to the later evaluation, confirming the progress of the network from one upgrade to the other.

Table 5-6 Important characteristics of the three storms; 2005, 2011 and 2014

\begin{tabular}{|c|c|c|c|c|}
\hline & Year & 2005 & 2011 & 2014 \\
\hline Number & flashes with RSs & 6 & 32 & 9 \\
\hline & ber of RSs & 38 & 156 & 30 \\
\hline $\begin{array}{r}\text { Ratio of } r \\
r e\end{array}$ & $\begin{array}{l}\text { cut RS signals vs } \\
\text { orted RSs }\end{array}$ & $17 / 21$ & $15 / 84$ & $16 / 30$ \\
\hline Strol & Polarity (\%) & 100 & 100 & 100 \\
\hline Flash dete & ion efficiency (\%) & 100 & 87.5 & 100 \\
\hline Stroke dete & ion efficiency $(\%)$ & 55.3 & 53.8 & 100 \\
\hline & Median & 289.3 & 198.8 & 118.5 \\
\hline Location & Mean & 340.5 & 313.9 & 129.2 \\
\hline Error (m) & Minimum & 84.2 & 32.3 & 19.6 \\
\hline & Maximum & 1192.2 & 2597.2 & 267.4 \\
\hline $\begin{array}{r}\text { Estimate } \\
\text { pea }\end{array}$ & $\begin{array}{l}\text { measured current } \\
\text { eelationship }\end{array}$ & $I_{\text {NALDN }}=3.971 * I_{\text {old }}-4.7$ & - & $I_{\text {NALDN }}=3.89 * I_{\text {old }}+1.189$ \\
\hline $\begin{array}{r}\text { Min } \\
\text { peal }\end{array}$ & $\begin{array}{l}\text { um reported } \\
\text { urrent }(\mathrm{kA})\end{array}$ & 12.7 & 10.8 & 9.6 \\
\hline $\begin{array}{r}\text { Minimu } \\
\text { dete }\end{array}$ & $\begin{array}{l}\text { current peak for } \\
\text { ed RSs (kA) }\end{array}$ & 5.27 & - & 2.08 \\
\hline $\begin{array}{r}\text { Minimu } \\
\mathrm{c}\end{array}$ & $\begin{array}{l}\text { measured peak } \\
\text { rent (kA) }\end{array}$ & 1.98 & - & 2.08 \\
\hline $\begin{array}{r}\text { Minimum } \\
\text { detect }\end{array}$ & $\begin{array}{l}\text { rrent derivative for } \\
\mathrm{RSs}(\mathrm{kA} / \mu \mathrm{s})\end{array}$ & 9.47 & - & 3.26 \\
\hline $\begin{array}{r}\text { Minimun } \\
\text { deri }\end{array}$ & $\begin{array}{l}\text { measured current } \\
\text { tive }(\mathrm{kA} / \mu \mathrm{s})\end{array}$ & 2.23 & - & 3.26 \\
\hline
\end{tabular}




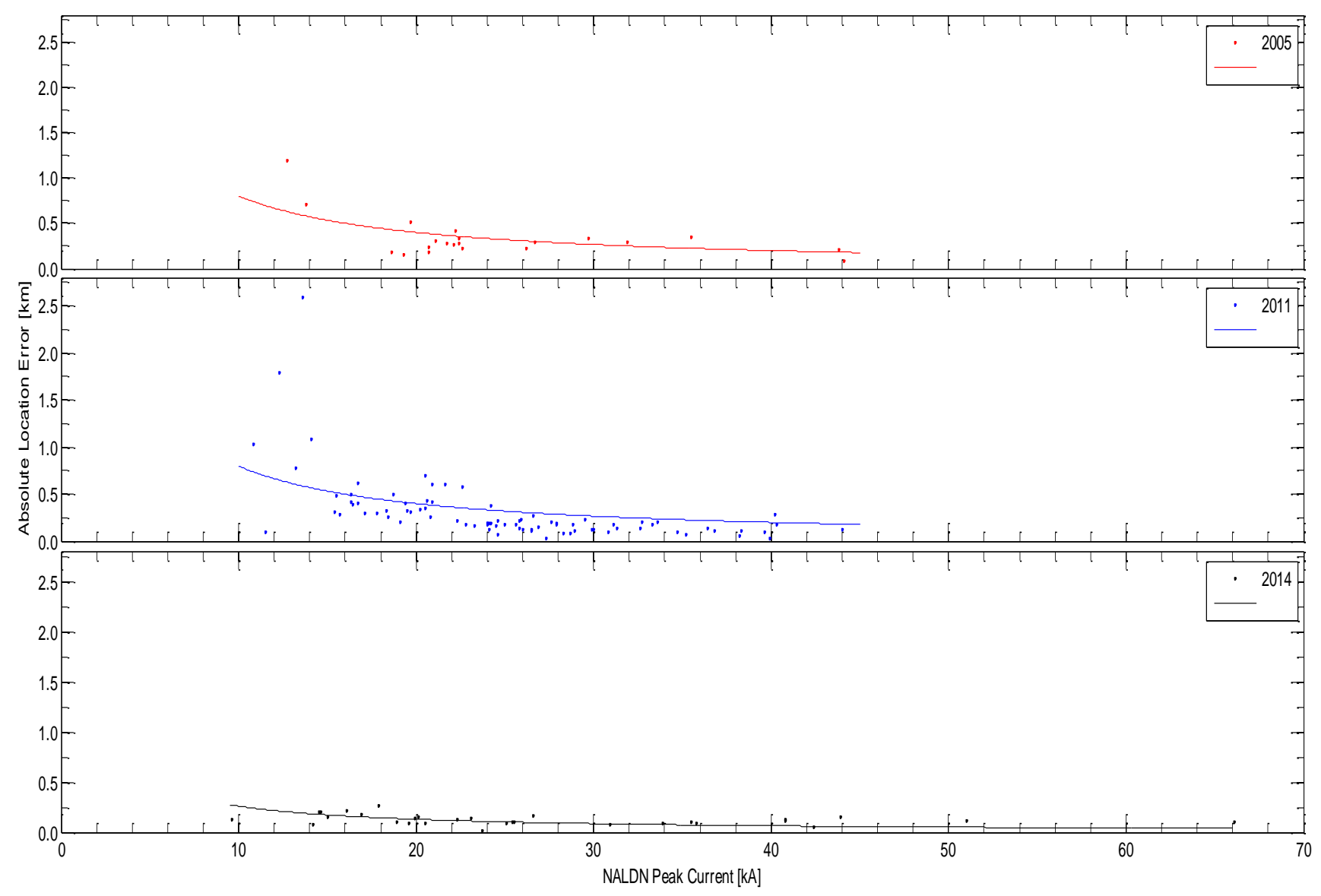

Figure 5-45 Absolute location error versus estimated peak current; 2005, 2011 and 2014

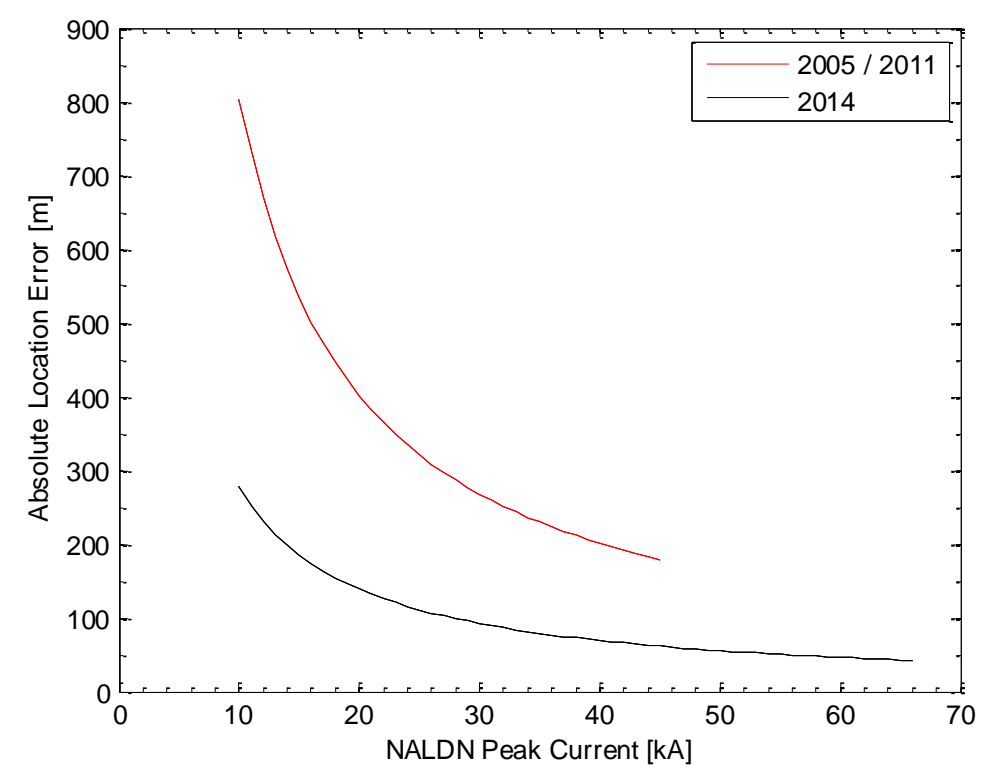

Figure 5-46 Absolute location versus estimated peak current curves; 2005, 2011 and 2014 
In 2005 and 2014 storms, the current peak estimated by the network was particularly larger than the peak currents measured at the CN Tower. The linear model found that the NALDN estimated peak current is 3.971 and 3.89 times greater than the CNT peak currents (first peak, not the absolute peak currents) for the 2005 and 2014 storms respectively. The correlation coefficient is almost the same for both storms ( 0.8607 and 0.8542 respectively). The regression line equations for the two storms are shown in Table 5-6 and the NALDN estimated peak current versus the CN Tower measured current peak for 2005 and 2014 are shown in Figure 5-47.

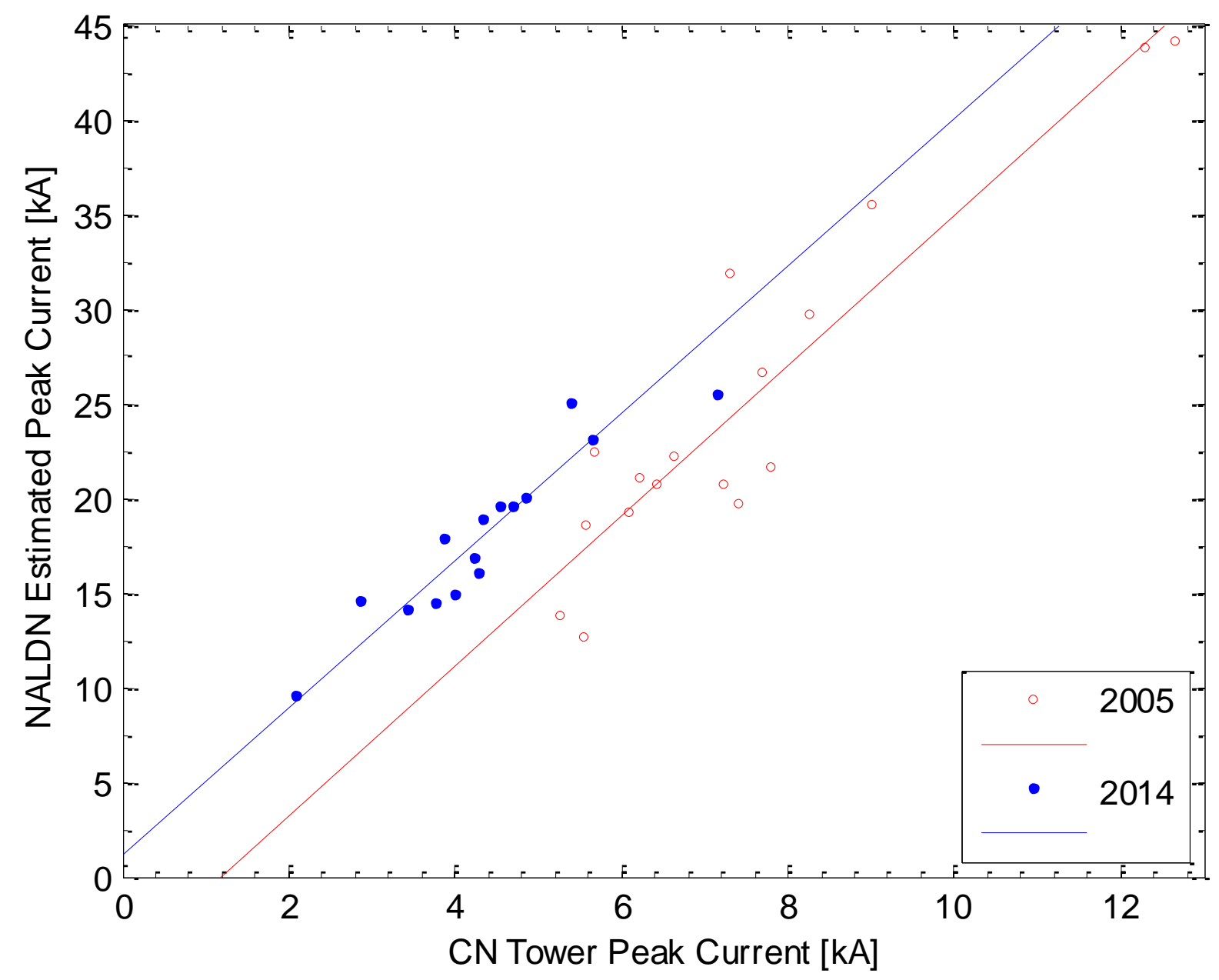

Figure 5-47 NALDN estimated peak current versus measured peak current, 2005 and 2014

Validation results based on the CN Tower 2005, 2011 and 2014 storms have been compared to the network performance characteristics in Florida region using rocket-triggered (RT) lightning in 2005, 2011 and 2013 [32]. The network applied the latest upgrade in 2013 (actually new 
geolocation algorithm, implemented to the NALDN central processor happened mid 2014 [23]). For the purpose of comparison, it should be noted that 2013 Florida evaluation occurred prior to or during the latest network upgrade. The $\mathrm{CN}$ Tower 2014 network validation is the only one assessing NALDN after the full 2013-2014 upgrades. Table 57 indicates that rocket-triggered study in 2005 found flash detection efficiency (63\%) lower than CN Tower evaluation (100\%), but (100\%) in 2011 compared to that of CN Tower (87.5\%). In 2014, both validation methods acknowledged perfect detection efficiencies for the network. The CN Tower evaluation in 2005 and 2011 found stroke detection efficiency (55.3\% and 53.8\% respectively) lower than the rocket-triggered lightning (62\% and 61\% respectively). However, the CN Tower study in 2014 found perfectly strong detection efficiency for the network. The CN Tower study in 2005 found a median location error $(289.3 \mathrm{~m})$ greater than the rocket-triggered $(242 \mathrm{~m})$, but significantly lower in 2011 and 2014 network evaluations (198.8m and 118.5m respectively from CN Tower compared to $652 \mathrm{~m}$ and $173 \mathrm{~m}$ from rocket-triggered).

Table 5-7 Network evaluation based on CN Tower and rocket-triggered (RT) lightning data [32]

\begin{tabular}{|c|c|c|c|c|c|c|c|}
\hline \multirow{3}{*}{\multicolumn{2}{|c|}{$\begin{array}{l}\text { Major network change } \\
\text { Method of evaluation }\end{array}$}} & \multicolumn{2}{|c|}{$2003-2004$} & \multicolumn{2}{|c|}{$2010-2011$} & \multicolumn{2}{|c|}{ 2013-2014 } \\
\hline & & $\mathrm{RT}$ & CNT & RT & CNT & RT & CNT \\
\hline & & 2005 & 2005 & 2011 & 2011 & 2013 & 2014 \\
\hline \multicolumn{2}{|c|}{ Number of flashes with RSs } & 8 & 6 & 11 & 32 & 12 & 9 \\
\hline \multicolumn{2}{|c|}{ Number of RSs } & 13 & 38 & 38 & 156 & 62 & 30 \\
\hline \multicolumn{2}{|c|}{$\begin{array}{l}\text { Flash detection efficiency } \\
\qquad(\%)\end{array}$} & 63 & 100 & 100 & 87.5 & 100 & 100 \\
\hline \multicolumn{2}{|c|}{$\begin{array}{l}\text { Stroke detection efficiency } \\
(\%)\end{array}$} & 62 & 55.3 & 61 & 53.8 & 76 & 100 \\
\hline \multirow{2}{*}{$\begin{array}{l}\text { Location Error } \\
\qquad(\mathrm{m})\end{array}$} & Median & 242 & 289.3 & 652 & 198.8 & 173 & 118.5 \\
\hline & Maximum & 416 & 1192.2 & 3481 & 2597.2 & 7458 & 267.4 \\
\hline
\end{tabular}




\section{Major Contributions}

Major contributions during the $\mathrm{PhD}$ tenure at Ryerson University are highlighted below:

1. The derivation of CN Tower lightning flash characteristics, based on current and optical lightning data since 2005. The investigated lightning flash characteristics include flash duration, flash multiplicity, inter-stroke time and return-stroke currents. Also, inter-flash time intervals are determined in successive multi-flash storms.

- The detailed analysis of the most intense lightning storm ever recorded at the CN Tower, which produced 52 flashes with about 84 minutes on August 24, 2011 [29], [30], [67].

- Extended lightning flash characteristics, based on current and video recordings of the major storm of 2011, were analyzed [67]. Findings are compared with those related to the 2005 storm.

- $\quad \mathrm{CN}$ Tower flash characteristics, based on current and video records of flashes that struck the tower in 2013, were investigated [56].

- Extended lightning flash analysis based on current and video recordings of a major storm in 2014 [31], was accomplished. Findings are compared with those determined based on 2011 and 2005 major CN Tower lightning storms.

2. Extended evaluation of NALDN performance characteristics based on three major CN Tower lightning storms. The performance characteristics of the network included flash and stroke detection efficiencies, location accuracy, polarity and peak current estimation [21], [68].

3. Designed, acquired and commissioned the new $\$ 37,000.00$ current recording system, featuring, for the first time, continuous recording at $4 \mathrm{~ns}$ resolution and 10bit signal-level resolution in 2015. The new high-resolution current recording system successfully recorded a CN Tower flash in 2015 [26].

4. Through analytical and computational analysis proved the necessity of utilizing the first peak of the CN Tower lightning current waveform, rather than the absolute peak, for correlation with NALDN estimated peak current [68]. 
5. Provided evidence that the NALDN needs to improve the grouping algorithm of return strokes within a flash, especially after the 2013-2014 NALDN upgrades [68].

6. Publication of findings in lightning conferences SIPDA 2013, CCECE 2014, ICLP 2014, APL 2015, SIPDA 2015, GROUND 2016 and in journal paper ATP 2016, EPSR 2016. 


\section{Conclusions and Recommendations}

An extensive evaluation of the performance characteristics of the North American Lightning Detection Network (NALDN) within an extended area around Toronto has been comprehensively accomplished based on CN Tower lighting data during three storms: 2005, 2011 and 2014. Each of the selected storms took place after one of the three recent major upgrades of the network: 2002-2003, 2010-2011 and 2013-2014. The hardware upgrades included LPATS and IMPACT (ESP) sensors in the first NALDN upgrade, LS7001 sensors in the second upgrade and LS7002 digital sensors in the third upgrade. The main algorithm and processor upgrades of the network consisted of the IMPACT algorithm in 1995, TLP ${ }^{\mathrm{TM}}$ in 2011 and TLP100 in 2014. The results of this study are also compared with similar studies performed at the rocket-triggered lightning facility at Camp Blanding, Florida, USA. Based on the current derivative signals and channel trajectory images every $\mathrm{CN}$ Tower flash was analyzed to determine its characteristics, including the initial-stage current (ISC), impulses super imposed on ISC, return strokes and continuing currents. The recorded return-stroke current derivative signals from the CN Tower were time-matched with the network detected strokes. Also, CN Tower initial peak currents were compared with the corresponding network-estimated peak currents.

During the 2005 selected storm, six flashes, containing 38 strokes, struck the tower. The network detected 21 out of the measured 38 strokes, resulting in $55.3 \%$ stroke-detection efficiency. On August 24, 2011, the CN Tower was struck with 52 flashes, only 32 of them contained at least one stroke each. The total number of strokes recorded at the tower were 156, but only 84 of them were detected by the network, resulting in $53.8 \%$ stroke detection efficiency. The storm of 2014 produced $24 \mathrm{CN}$ Tower flashes, only nine of them contained return strokes. These nine flashes included 30 strokes; all of them were detected by the network, resulting in $100 \%$ stroke detection efficiency. The evaluation of the performance characteristics of NALDN included stroke polarity, flash and stroke detection efficiencies, location accuracy, and peak current estimation.

Stroke Polarity. The polarities of NALDN-detected return strokes, for all three storms, were perfectly matched with the polarities of the corresponding return-stroke currents measured at the tower. All reported return strokes in 2005, 2011 and 2014 were of negative polarity. 
Flash and Stroke Detection Efficiency. The flash detection efficiency, for flashes that contain return strokes, was found to be $100 \%$ in $2005,87.5 \%$ in 2011 and $100 \%$ in 2014, which reasonably matched the network expected detection efficiency of $90-95 \%$ in 2005 and 2011 , and $95 \%$ in 2014 . Therefore, the flash detection efficiency was slightly lower than expectation in 2011. Stroke detection efficiency expectations from the network in 2005, 2011 and 2014 were $60-80 \%, 80 \%$ and $80-85 \%$, respectively. The findings of this study indicate that the stroke detection efficiency in 2005 and 2011 were well below expectations, $55.3 \%$ and 53.8\%, respectively. However, after the latest major upgrade in 2013-2014, the findings in 2014 results in $100 \%$ stroke detection efficiency, well above expectation.

Location Accuracy. The median location accuracy of this study matched or exceeded the network location accuracy expectations: a median in location accuracy of $289 \mathrm{~m}$ in 2005 (expectation was 500m), 199m in 2011 (expectation was 200m) and 118m in 2014 (expectation was $150-250 \mathrm{~m})$. Stroke location accuracy in 2014 was outstanding; it varied between $20 \mathrm{~m}$ and $267 \mathrm{~m}$, with an overall average of $129 \mathrm{~m}$. The absolute location error is shown to generally decrease as the NALDN-estimated peak current increases because strokes with higher peak currents radiate higher electromagnetic fields, resulting in better measurements at nearby sensors, and improve the probability of being detected by more sensors. A bias has been noticed regarding stroke locations for the 2005, 2011 and 2014 storms. The majority of strokes have been located north-east of the tower in 2005, south-west of the tower in 2011 and north-west of the tower in 2014. The bias may be related to the channel trajectory orientation that is expected to correlate with the direction of the storm movement in relation to the location of the tower.

Peak Current Estimation. Based on analytical investigations, the initial waveform peak, rather than the absolute peak, was considered. The NALDN estimated peak current is found to be larger than the peak current measured at the tower. Assuming a linear relationship between the current peak estimated by the network and that measured at the tower resulted in network overestimation of the measured current peak by a coefficient 3.89, based on 2014 data. This is indeed expected due to the relatively much higher speed of propagation of the current wave within the extremely tall tower, as compared to the assumed speed of propagation within the lightning channel in the NALDN field source inversion process. The close agreements between 
the 2005 and 2014 regression line equations, correlating the NALDN estimated current peaks to the measured current peaks, substantiate the validity and value of the two data sets.

The first flash of the 2014 storm is suspected to be a downward-initiated flash. Besides being a single stroke flash, the low speed camera (60 fps) recorded only one luminous frame of the channel trajectory suggesting that the flash did not contain initial-stage current, which is typical for upward-initiated lightning. Furthermore, the recorded current displayed a slower than usual rise-time. There is evidence that the new Rogowski coil recorded a pulse superimposed on an ISC because of the improved dynamic range of its fiber optical link. It demonstrates that ISC pulses may be fast enough to excite the Rogowski coils. With an integrator connected to the recently acquired NI-PXIe system ( 2 seconds of continuous recording at $250 \mathrm{mS} / \mathrm{s}$ ), it would be possible to record details of other such lightning flash components. A high-speed camera with at least 25,000 frames per second is required for the characterization ISC pulses.

A recent flash that struck the tower on December 29, 2015 comprises three return strokes and an ISC. The new current measurement system, featuring 10-bit and 4-ns resolutions, commissioned as part of this study, faithfully recorded all return strokes, as well as eight other impulses superimposed on ISC. This flash and its three return strokes were reported by NALDN, resulting in $100 \%$ stroke detection efficiency. Also, it was observed that the NALDN detected peak currents of these three strokes represent the network lowest ever detected peak currents for CN Tower lightning: $7.1 \mathrm{kA}, 8.6 \mathrm{kA}$ and $2.4 \mathrm{kA}$. Over the years, NALND has improved on detecting strokes with lower current peaks. There is no evidence in this study to suggest that ISC pulses were detected by NALDN.

This extensive evaluation indicates, beyond any doubt, that the most recent NALDN upgrade, (2013-2014), has substantially improved NALDN performance characteristics. 


\section{Appendix A. Lightning Electromagnetic Pulse}

A lightning discharge is a transient that generates an electromagnetic pulse (LEMP). This section provides the derivation of electromagnetic field associated with a lightning event using Maxwell's equations in free space.

$\nabla x \overrightarrow{\mathrm{E}}=-\frac{\partial \overrightarrow{\mathrm{B}}}{\partial t}$

$\nabla x \overrightarrow{\mathrm{H}}=\overrightarrow{\mathrm{J}}+\frac{\partial \overrightarrow{\mathrm{D}}}{\partial t}$

$\nabla \cdot \overrightarrow{\mathrm{D}}=\rho_{v}$

$\nabla \cdot \overrightarrow{\mathrm{B}}=0$

Constitutive relations:

$\overrightarrow{\mathrm{D}}=\varepsilon \overrightarrow{\mathrm{E}} \quad$ where $\varepsilon=\varepsilon_{0} \varepsilon_{r}$

$\overrightarrow{\mathrm{B}}=\mu \overrightarrow{\mathrm{H}} \quad$ where $\mu=\mu_{0} \mu_{r}$

Current densities:

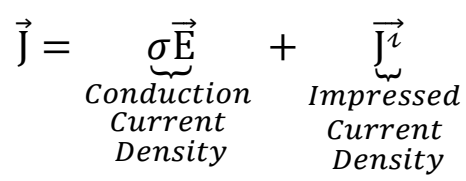

Field intensities, and charge and current densities are functions of the location of the point of observation and time, for example $\overrightarrow{\mathrm{E}}(\vec{r}, t), \rho_{v}(\vec{r}, t)$ and $\overrightarrow{\mathrm{J}}(\vec{r}, t)$, where $\vec{r}$ is the vector defining the point of observation in relation to the origin.

The electric and magnetic fields are determined based on vector and scalar potentials. The vector potential $\vec{A}$ is established using Equation A.4

$\nabla \cdot \overrightarrow{\mathrm{B}}=0 \Rightarrow \nabla \cdot(\nabla x \overrightarrow{\mathrm{A}})=0 \quad \therefore \quad \overrightarrow{\mathrm{B}}=\nabla x \overrightarrow{\mathrm{A}}$ 
The scalar potential $\mathrm{V}$ is defined as follows:

$\nabla x \overrightarrow{\mathrm{E}}=-\frac{\partial \overrightarrow{\mathrm{B}}}{\partial t}=-\frac{\partial}{\partial t}(\nabla x \overrightarrow{\mathrm{A}})=-\nabla x \frac{\partial \overrightarrow{\mathrm{A}}}{\partial t} \Rightarrow \nabla x\left(\overrightarrow{\mathrm{E}}+\frac{\partial \overrightarrow{\mathrm{A}}}{\partial t}\right)=0 \quad \therefore \quad \overrightarrow{\mathrm{E}}+\frac{\partial \overrightarrow{\mathrm{A}}}{\partial t}=-\nabla \mathrm{V}$

The wave equation in terms of $\overrightarrow{\mathrm{A}}$ is derived below using Equations A.2, A.8 and A.9:

$\nabla x \frac{1}{\mu}(\nabla x \overrightarrow{\mathrm{A}})=\overrightarrow{\mathrm{J}}+\varepsilon \frac{\partial}{\partial t}\left(-\nabla \mathrm{V}-\frac{\partial \overrightarrow{\mathrm{A}}}{\partial t}\right)$

$\nabla x \nabla x \overrightarrow{\mathrm{A}}=\mu \overrightarrow{\mathrm{J}}+\mu \varepsilon \frac{\partial}{\partial t}\left(-\nabla \mathrm{V}-\frac{\partial \overrightarrow{\mathrm{A}}}{\partial t}\right) \Rightarrow \nabla \nabla \cdot \overrightarrow{\mathrm{A}}-\nabla^{2} \overrightarrow{\mathrm{A}}=\mu \overrightarrow{\mathrm{J}}-\mu \varepsilon \frac{\partial}{\partial t} \nabla \mathrm{V}-\mu \varepsilon \frac{\partial^{2} \overrightarrow{\mathrm{A}}}{\partial t^{2}}$

$\nabla^{2} \overrightarrow{\mathrm{A}}-\mu \varepsilon \frac{\partial^{2} \overrightarrow{\mathrm{A}}}{\partial t^{2}}=-\mu \overrightarrow{\mathrm{J}}$ satisfying Lorent $z^{\prime}$ s condition $\nabla \cdot \overrightarrow{\mathrm{A}}+\mu \varepsilon \frac{\partial V}{\partial t}=0$

For wave propagation in free space, $\overrightarrow{\mathrm{J}}=\overrightarrow{\mathrm{J}^{1}}$.

For a volume current element $\overrightarrow{\mathrm{J}} d v$ placed at $\vec{r}^{\prime}$, as shown in Figure A-1, the solution of the wave equation (A.12) is given by [84]:

$\mathrm{A}(\vec{r}, t)=\frac{\mu_{0}}{4 \pi} \int_{v^{\prime}} \frac{\overrightarrow{\mathrm{J}^{1}}\left(\overrightarrow{r^{\prime}}, t-\frac{R}{c}\right)}{R} d v^{\prime}$

Where $R=\left|\vec{r}-\overrightarrow{r^{\prime}}\right|$ and $\mathrm{c}$ is the speed of propagation of electromagnetic wave in free space,

$c=\frac{1}{\sqrt{\varepsilon_{0} * \mu_{0}}}$

Figure A-2 presents the lightning channel as a vertical current-carrying line above a perfectly conducting flat ground.

$\vec{r}=\rho \widehat{a_{\rho}} ; \quad \overrightarrow{r^{\prime}}=z^{\prime} \widehat{a_{z}} ; \quad d \overrightarrow{L^{\prime}}=d z^{\prime} \widehat{a_{z}} ; \quad R=\sqrt{\rho^{2}+z^{\prime 2}}$ 


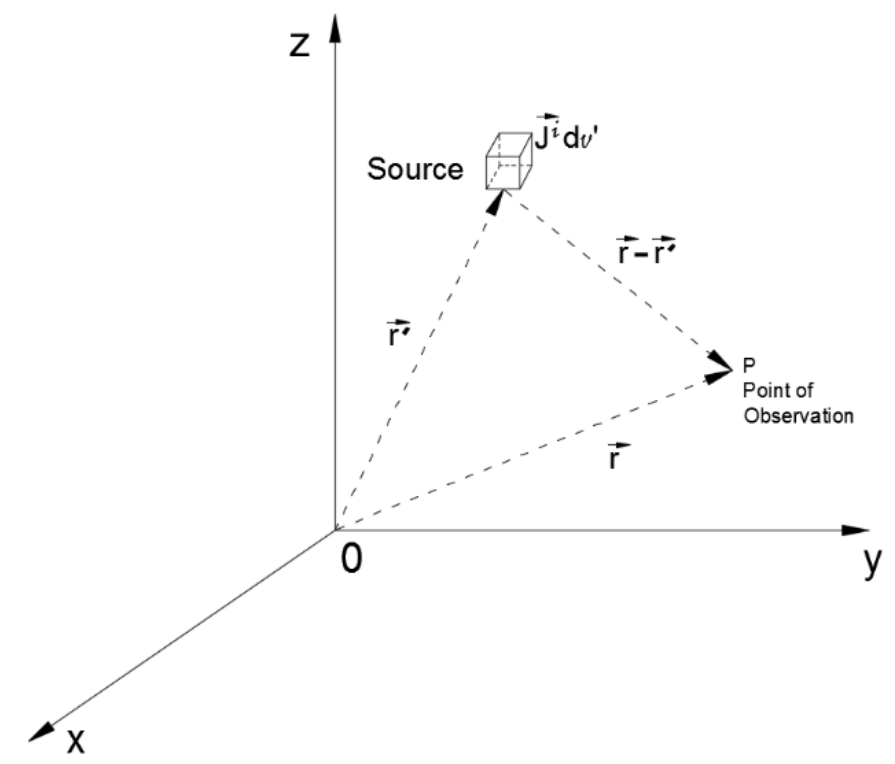

Figure A-1 The differential current element and the point of observation

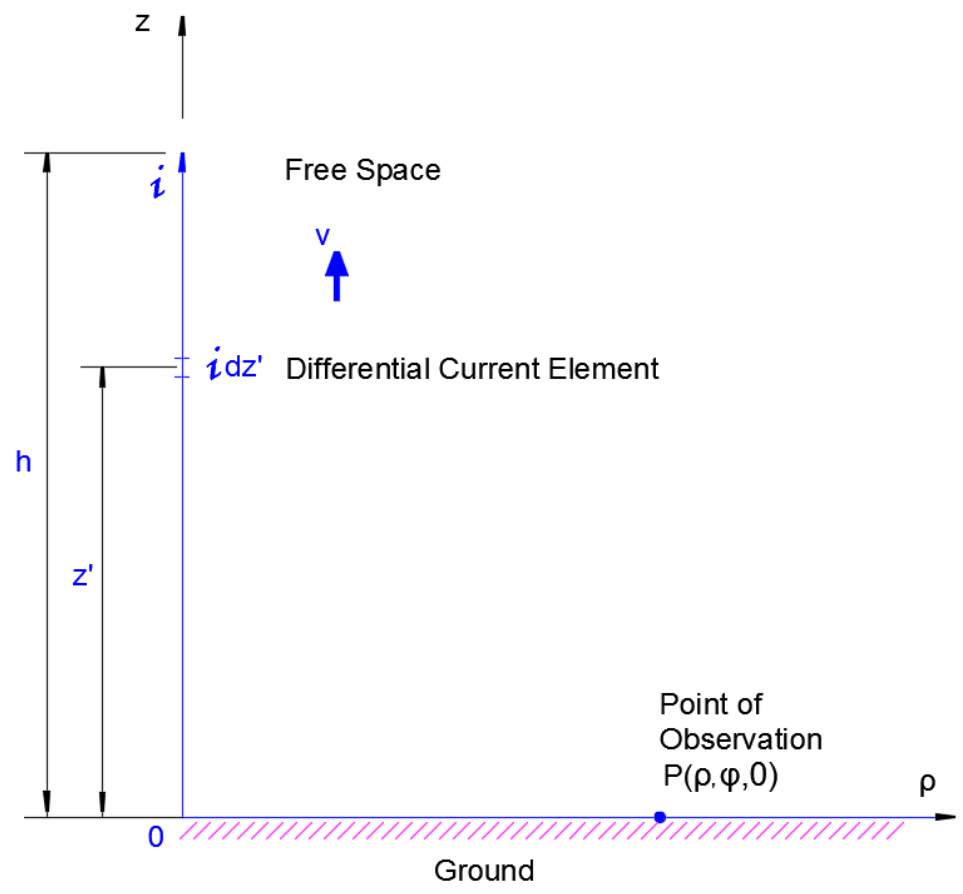

Figure A-2 Representation of a vertical lightning channel

Based on Equation A.13, the vector potential resulting from the differential current element (Figure A-2) is: 


$$
\begin{aligned}
& d \overrightarrow{\mathrm{A}}=\frac{\mu_{0}}{4 \pi} \frac{i\left(\overrightarrow{r^{\prime}}, t-\frac{R}{c}\right)}{R} d z^{\prime} \widehat{a_{z}} \\
& d \overrightarrow{\mathrm{H}}=\frac{1}{\mu_{0}} \nabla x d \overrightarrow{\mathrm{A}}=\frac{1}{\mu_{0} \rho}\left|\begin{array}{ccc}
\widehat{a_{\rho}} & \rho \widehat{a_{\varphi}} & \widehat{a_{z}} \\
\frac{\partial}{\partial \rho} & \frac{\partial}{\partial \varphi} & \frac{\partial}{\partial z} \\
0 & 0 & d \mathrm{~A}_{z}
\end{array}\right|=-\frac{1}{\mu_{0}} \frac{\partial}{\partial \rho}\left(d \mathrm{~A}_{\mathrm{z}}\right) \widehat{a_{\varphi}} \\
& d \overrightarrow{\mathrm{H}}=-\frac{1}{4 \pi} \frac{\partial}{\partial \rho}\left(\frac{i\left(\vec{r}, t-\frac{R}{c}\right)}{R} d z^{\prime}\right) \widehat{a_{\varphi}}=-\frac{d z^{\prime}}{4 \pi}\left[\frac{1}{R} \frac{\partial i\left(\vec{r}, t-\frac{R}{c}\right)}{\partial \rho}-\frac{i\left(\vec{r}, t-\frac{R}{c}\right)}{R^{2}} \frac{\partial R}{\partial \rho}\right] \widehat{a_{\varphi}}
\end{aligned}
$$

Simplifying,

$$
\begin{aligned}
& R^{2}=\rho^{2}+z^{2} \Rightarrow 2 R \frac{\partial R}{\partial \rho}=2 \rho \Rightarrow \frac{\partial R}{\partial \rho}=\frac{\rho}{R} \\
& \frac{\partial i\left(\vec{r}, t-\frac{R}{c}\right)}{\partial \rho}=\frac{\partial R}{\partial \rho} \frac{\partial i\left(\vec{r}, t-\frac{R}{c}\right)}{\partial R}=\frac{\rho}{R} \frac{\partial i\left(\vec{r}, t-\frac{R}{c}\right)}{\partial R} \\
& \frac{\partial i\left(\vec{r}, t-\frac{R}{c}\right)}{\partial R}=\frac{\partial i\left(\vec{r}, t-\frac{R}{c}\right)}{\partial\left(t-\frac{R}{c}\right)} \frac{\partial\left(t-\frac{R}{c}\right)}{\partial R}=-\frac{1}{c} \frac{\partial i\left(\vec{r}, t-\frac{R}{c}\right)}{\partial\left(t-\frac{R}{c}\right)} \\
& \frac{\partial i\left(\vec{r}, t-\frac{R}{c}\right)}{\partial t}=\frac{\partial i\left(\vec{r}, t-\frac{R}{c}\right)}{\partial\left(t-\frac{R}{c}\right)} \frac{\partial\left(t-\frac{R}{c}\right)}{\partial t}=\frac{\partial i\left(\vec{r}, t-\frac{R}{c}\right)}{\partial\left(t-\frac{R}{c}\right)} \\
& \frac{\partial i\left(\vec{r}, t-\frac{R}{c}\right)}{\partial R}=-\frac{1}{c} \frac{\partial i\left(\vec{r}, t-\frac{R}{c}\right)}{\partial t}
\end{aligned}
$$

So, Equation A.17 becomes:

$d \overrightarrow{\mathrm{H}}=\frac{d z^{\prime}}{4 \pi}\left[\frac{\rho}{c R^{2}} \frac{\partial i\left(\vec{r}, t-\frac{R}{c}\right)}{\partial t}+\frac{\rho}{R^{3}} i\left(\vec{r}, t-\frac{R}{c}\right)\right] \widehat{a_{\varphi}}$

Based on Equation A.2 and A.23, the electric field intensity can be put in the form: 


$$
\begin{aligned}
\frac{\partial d \overrightarrow{\mathrm{E}}}{\partial t}=\frac{d z^{\prime}}{4 \pi \varepsilon_{0}}\{ & -\frac{\rho^{2}}{c^{2} R^{3}} \frac{\partial^{2} i\left(\vec{r}, t-\frac{R}{c}\right)}{\partial t^{2}}+\frac{2 z^{\prime 2}-\rho^{2}}{c R^{4}} \frac{\partial i\left(\vec{r}, t-\frac{R}{c}\right)}{\partial t} \\
& \left.+\frac{2 z^{\prime 2}-\rho^{2}}{R^{5}} i\left(\vec{r}, t-\frac{R}{c}\right)\right\} \widehat{a_{z}}
\end{aligned}
$$

The time integration of both sides of Equation A.24 results in:

$$
\begin{aligned}
d \overrightarrow{\mathrm{E}}=-\frac{d z^{\prime}}{2 \pi \varepsilon_{0}} & \left\{\frac{\rho^{2}}{c^{2} R^{3}} \frac{\partial i\left(\vec{r}, t-\frac{R}{c}\right)}{\partial t}-\frac{2 R^{2}-3 \rho^{2}}{c R^{4}} i\left(\vec{r}, t-\frac{R}{c}\right)\right. \\
& \left.-\frac{2 R^{2}-3 \rho^{2}}{R^{5}} \int_{0}^{t} i\left(\vec{r}, t-\frac{R}{c}\right) d t\right\} \widehat{a_{z}}
\end{aligned}
$$

The total electric and magnetic field intensities are then obtained taking into consideration all current elements along the lightning channel shown in Figure A-2.

$$
\begin{aligned}
& \overrightarrow{\mathrm{H}}=\int_{0}^{h} d \overrightarrow{\mathrm{H}}=\frac{1}{2 \pi}[\underbrace{\int_{0}^{h} \frac{\rho / R}{R^{2}} i\left(z^{\prime}, t-\frac{R}{c}\right) d z^{\prime}}_{\text {Induction Term }}+\underbrace{\int_{0}^{h} \frac{\rho / R}{c R} \frac{\partial}{\partial t} i\left(z^{\prime}, t-\frac{R}{c}\right) d z^{\prime}}_{\text {Radiation Term }} \widehat{a_{\varphi}} \\
& \overrightarrow{\mathrm{E}}=-\frac{1}{2 \pi \varepsilon}\{\underbrace{\int_{0}^{\mathrm{h}}\left[\frac{2-3 \rho^{2} / \mathrm{R}^{2}}{\mathrm{R}^{3}} \int_{0}^{\mathrm{t}} \mathrm{i}\left(\mathrm{z}^{\prime}, \mathrm{t}-\frac{\mathrm{R}}{\mathrm{c}}\right) \mathrm{dt}\right] \mathrm{dz} \mathrm{z}^{\prime}}_{\text {Electrostatic Term }}+\underbrace{\int_{0}^{\mathrm{h}} \frac{2-3 \rho^{2} / \mathrm{R}^{2}}{\mathrm{cR}^{2}} \mathrm{i}\left(\mathrm{z}^{\prime}, \mathrm{t}-\frac{\mathrm{R}}{\mathrm{c}}\right) \mathrm{dz}}_{\text {Induction Term }} \\
& -\underbrace{\int_{0}^{\mathrm{h}} \frac{\left(\rho^{2} / \mathrm{R}^{2}\right)}{\mathrm{c}^{2} \mathrm{R}} \frac{\partial}{\partial \mathrm{t}} i\left(\mathrm{z}^{\prime}, \mathrm{t}-\frac{\mathrm{R}}{\mathrm{c}}\right) \mathrm{dz}}_{\text {Radiation Term }}\} \widehat{\mathrm{a}_{\mathrm{z}}}
\end{aligned}
$$

The two terms of Equation A.26 are respectively called the induction and the radiation terms of the magnetic field intensity. For the electric field intensity, an electrostatic term arises as indicated in Equation A.27.

In the far-field zone, $\rho>>\mathrm{h}, \mathrm{R} \sim \rho$, Equation A.26 becomes: 
$\overrightarrow{\mathrm{H}}=\frac{1}{2 \pi c \rho} \int_{0}^{h} \frac{\partial}{\partial t} i\left(z^{\prime}, t-\frac{\rho}{c}\right) d z^{\prime} \widehat{a_{\varphi}}$

Assuming the current pulse propagates along the lightning channel as it would in a lossless transmission line (neglecting corona-related losses) with a return-stroke velocity v.

$i\left(z^{\prime}, t-\frac{\rho}{c}\right)=i\left(0, t-\frac{z^{\prime}}{v}-\frac{\rho}{c}\right)=i(0, \tau) \quad$ where $\tau=t-\frac{z^{\prime}}{v}-\frac{\rho}{c}$

$\frac{\partial}{\partial z^{\prime}} i\left(0, t-\frac{z^{\prime}}{v}-\frac{\rho}{c}\right)=\frac{\partial i(0, \tau)}{\partial \tau} \frac{\partial \tau}{\partial z^{\prime}}=-\frac{1}{v} \frac{\partial i(0, \tau)}{\partial \tau}=-\frac{1}{v} \frac{\partial i(0, \tau)}{\partial t} \frac{\partial t}{\partial \tau}=-\frac{1}{v} \frac{\partial i(0, \tau)}{\partial t}$

Equation A.28 becomes,

$\overrightarrow{\mathrm{H}}=-\frac{v}{2 \pi c \rho} \int_{0}^{h} \frac{\partial i(0, \tau)}{\partial z^{\prime}} d z^{\prime} \widehat{a_{\varphi}}=\frac{v}{2 \pi c \rho}\left\{i\left(0, t-\frac{\rho}{c}\right)-i\left(0, t-\frac{h}{v}-\frac{\rho}{c}\right)\right\} \widehat{a_{\varphi}}$

Since $i\left(0, t-\frac{h}{v}-\frac{\rho}{c}\right)=0$ when $t<\frac{h}{v}+\frac{\rho}{c}$, therefore

$\overrightarrow{\mathrm{H}}=\frac{v}{2 \pi c \rho} i\left(0, t-\frac{\rho}{c}\right) \widehat{a_{\varphi}}, \quad \frac{\rho}{c}<t<\frac{h}{v}+\frac{\rho}{c}$

Similarly, in the far-field zone, the electric field intensity is:

$\overrightarrow{\mathrm{E}}=-\frac{v}{2 \pi c^{2} \varepsilon \rho} i\left(0, t-\frac{\rho}{c}\right) \widehat{a_{z}} \quad$ for $\quad \frac{\rho}{c}<t<\frac{h}{v}+\frac{\rho}{c}$

As expected, in the far-field zone (assuming propagation in free space), $\frac{E_{z}}{\mathrm{H}_{\varphi}}=-\sqrt{\frac{\mu_{0}}{\varepsilon_{0}}}=$ $-120 \pi[\Omega]$ 


\section{Lightning to Flat Ground}

For lightning strokes to a perfectly-conducting flat ground, on the assumption of a constant return stroke speed $v$ (Figure A-3), the relationship between the magnetic field intensity peak and the current peak are derived by considering a voltage source $\mathrm{V}_{0}$ at the base of the lightning channel. The current at $\mathrm{z}^{6}=0$ in the channel at any time is:

$$
\begin{gathered}
I_{c h}(0, t)=\frac{V_{0}(0, t)}{Z_{c h}+Z_{g r}}=\frac{Z_{c h}}{Z_{c h}+Z_{g r}} \frac{V_{0}(0, t)}{Z_{c h}}=\frac{1+\rho_{g r}}{2} I_{s c}(0, t) \\
I_{s c}(0, t)=\frac{V_{0}(0, t)}{Z_{c h}} \quad \text { and } \quad \rho_{g r}=\frac{Z_{c h}-Z_{g r}}{Z_{c h}+Z_{g r}}
\end{gathered}
$$

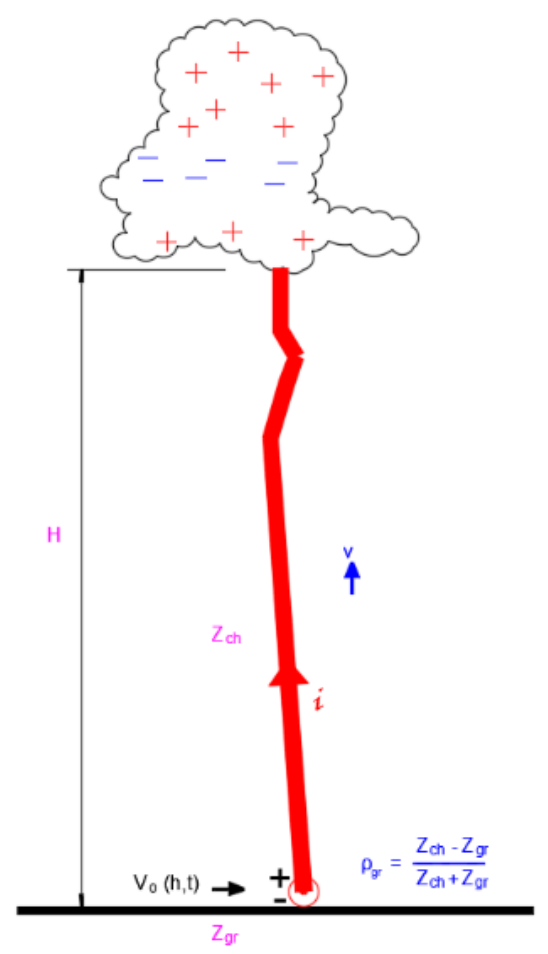

Figure A-3 Vertical lightning channel above flat ground

The far magnetic field peak for lightning to flat ground is found from Equation A.32:

$H_{\text {flat_peak }}=\frac{v}{2 \pi c \rho} I_{\text {base_peak }}=\frac{v}{2 \pi c \rho} \frac{1+\rho_{g r}}{2} I_{\text {sc_peak }}$ 


\section{Lightning to Tall Structure}

In order to formulate the electromagnetic field resulting from tall structure lightning, the currents along the tall structure and the lightning channel above it must be determined [27]. The configuration in Figure A-4 is the transmission line representation of the tower $\left(Z_{o b}\right)$, and lightning channel $\left(\mathrm{Z}_{\mathrm{ch}}\right)$. It is assumed that voltage source $\mathrm{V}_{\mathrm{o}}(\mathrm{h}, \mathrm{t})$ initially injects a current into the tower and lightning channel, $I(h, t)=V_{o}(h, t) /\left(Z_{c h}+Z_{o b)}\right.$. The reflection coefficients are shown in Figure A-4.

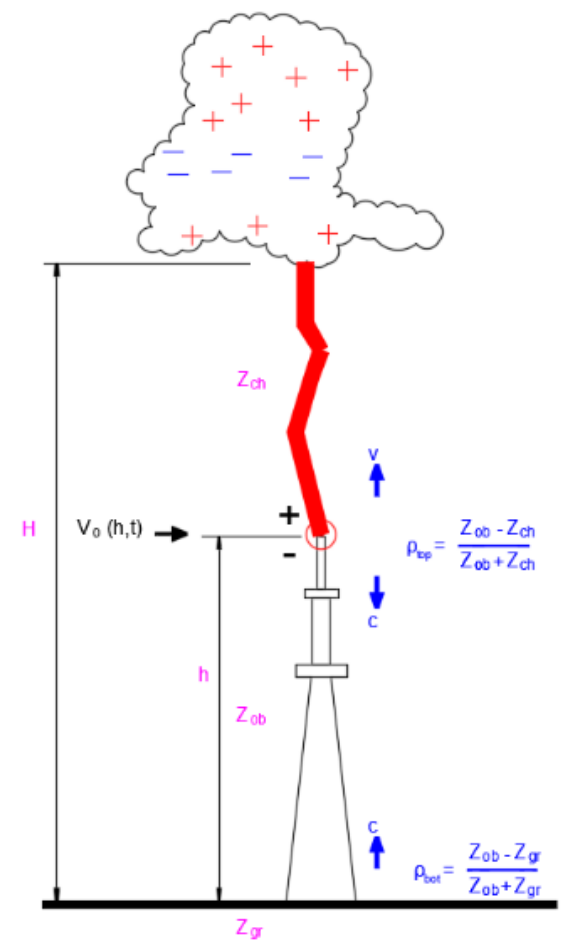

Figure A-4 Lightning to a tall structure

The current is assumed to be reflecting back and forth at the speed c. Therefore:

$$
\begin{aligned}
& I_{\text {tower }}\left(z^{\prime}, t\right)=\frac{1}{Z_{c h}+Z_{o b}} V_{o}\left(h, t-\frac{h-z^{\prime}}{c}\right)+\rho_{b o t} \frac{1}{Z_{c h}+Z_{o b}} V_{o}\left(h, t-\frac{h+z^{\prime}}{c}\right) \\
& +\rho_{\text {top }} \rho_{b o t} \frac{1}{Z_{c h}+Z_{o b}} V_{o}\left(h, t-\frac{h-z^{\prime}}{c}-\frac{2 h}{c}\right) \\
& +\rho_{b o t} \rho_{\text {top }} \rho_{b o t} \frac{1}{Z_{c h}+Z_{o b}} V_{o}\left(h, t-\frac{h+z^{\prime}}{c}-\frac{2 h}{c}\right)+\cdots
\end{aligned}
$$

for $0 \leq z^{\prime} \leq h$ 


$$
\begin{aligned}
I_{\text {tower }}\left(z^{\prime}, t\right)= & \sum_{n=0}^{\infty}\left[\rho_{\text {bot }}^{n} \rho_{\text {top }}^{n} \frac{1}{Z_{c h}+Z_{o b}} V_{o}\left(h, t-\frac{h-z^{\prime}}{c}-\frac{2 n h}{c}\right)\right. \\
& \left.+\rho_{\text {bot }}^{n+1} \rho_{\text {top }}^{n} \frac{1}{Z_{c h}+Z_{o b}} V_{o}\left(h, t-\frac{h+z^{\prime}}{c}-\frac{2 n h}{c}\right)\right] \\
I_{\text {tower }}\left(z^{\prime}, t\right)= & \frac{1-\rho_{\text {top }}}{2} \sum_{n=0}^{\infty}\left[\rho_{\text {bot }}^{n} \rho_{\text {top }}^{n} I_{s c}\left(h, t-\frac{h-z^{\prime}}{c}-\frac{2 n h}{c}\right)\right. \\
& \left.+\rho_{\text {bot }}^{n+1} \rho_{\text {top }}^{n} I_{s c}\left(h, t-\frac{h+z^{\prime}}{c}-\frac{2 n h}{c}\right)\right]
\end{aligned}
$$

where $\frac{1-\rho_{\text {top }}}{2} I_{s c}=\frac{Z_{c h}}{Z_{c h}+Z_{o b}} \frac{V_{o}}{Z_{c h}}=\frac{V_{o}}{Z_{c h}+Z_{o b}}, I_{s c}=\frac{V_{o}}{Z_{c h}}, \frac{1-\rho_{t o p}}{2}=\frac{Z_{c h}}{Z_{c h}+Z_{o b}}$

On the assumption that the speed of the current flow within the ionized portion of the channel is at speed c, the current along the lightning channel is given by:

$$
\begin{aligned}
I_{\text {channel }}\left(z^{\prime}, t\right) & =\frac{1}{Z_{c h}+Z_{o b}} V_{o}\left(h, t-\frac{z^{\prime}-h}{v}\right) \\
& +\left(1+\rho_{\text {top }}\right) \rho_{\text {bot }} \frac{1}{Z_{c h}+Z_{o b}} V_{o}\left(h, t-\frac{z^{\prime}-h}{c}-\frac{2 h}{c}\right) \\
& +\left(1+\rho_{\text {top }}\right) \rho_{\text {bot }} \rho_{\text {top }} \rho_{\text {bot }} \frac{1}{Z_{c h}+Z_{o b}} V_{o}\left(h, t-\frac{z^{\prime}-h}{c}-\frac{4 h}{c}\right) \\
& +\left(1+\rho_{\text {top }}\right) \rho_{\text {bot }} \rho_{\text {top }} \rho_{\text {bot }} \rho_{\text {top }} \rho_{b o t} \frac{1}{Z_{c h}+Z_{o b}} V_{o}\left(h, t-\frac{z^{\prime}-h}{c}-\frac{6 h}{c}\right) \\
& +\cdots \\
I_{\text {channel }}\left(z^{\prime}, t\right)= & \frac{1}{Z_{c h}+Z_{o b}} V_{o}\left(h, t-\frac{z^{\prime}-h}{v}\right) \\
& +\sum_{n=1}^{\infty} \rho_{b o t}^{n} \rho_{\text {top }}^{n-1}\left(1+\rho_{\text {top }}\right) \frac{1}{Z_{c h}+Z_{o b}} V_{o}\left(h, t-\frac{z^{\prime}-h}{c}-\frac{2 n h}{c}\right)
\end{aligned}
$$




$$
\begin{aligned}
I_{\text {channel }}\left(z^{\prime}, t\right) & =\frac{1-\rho_{\text {top }}}{2}\left[I_{s c}\left(h, t-\frac{z^{\prime}-h}{v}\right)\right. \\
& \left.+\sum_{n=1}^{\infty} \rho_{\text {bot }}^{n} \rho_{\text {top }}^{n-1}\left(1+\rho_{\text {top }}\right) I_{s c}\left(h, t-\frac{z^{\prime}-h}{c}-\frac{2 n h}{c}\right)\right] \\
I_{\text {channel }}\left(z^{\prime}, t\right) & =\frac{1}{2} I_{s c}\left(h, t-\frac{z^{\prime}-h}{v}\right)-\frac{1}{2} \rho_{\text {top }} I_{s c}\left(h, t-\frac{z^{\prime}-h}{v}\right) \\
& +\frac{1}{2}\left(1-\rho_{\text {top }}\right)\left(1+\rho_{\text {top }}\right) \sum_{n=1}^{\infty} \rho_{\text {bot }}^{n} \rho_{\text {top }}^{n-1} I_{s c}\left(h, t-\frac{z^{\prime}-h}{c}-\frac{2 n h}{c}\right)
\end{aligned}
$$

In the presence of a tall object of height $\mathrm{h}$, shown in Figure A-4, assuming that the lightning current wave-front risetime is smaller than $2 \mathrm{~h} / \mathrm{c}$, the terms (for $\mathrm{n}>0$ ) of Equation A.39 and A.44 are equal to zero [27], [85]. This assumption excludes any contribution from the reflection on the magnetic field peak at the far end. Equation A.39 and A.44 respectively become:

$$
\begin{aligned}
& I_{\text {tower }}\left(z^{\prime}, t\right)=\frac{1-\rho_{\text {top }}}{2} I_{s c}\left(h, t-\frac{h-z^{\prime}}{c}\right) \\
& I_{\text {channel }}\left(z^{\prime}, t\right)=\frac{1}{2} I_{s c}\left(h, t-\frac{z^{\prime}-h}{v}\right)-\frac{1}{2} \rho_{\text {top }} I_{s c}\left(h, t-\frac{z^{\prime}-h}{v}\right)
\end{aligned}
$$

For lightning to tall structures, the magnetic field peak in the far-field zone is obtained from Equation A.32:

$\mathrm{H}_{\text {tall_peak }}=\frac{v+c}{2 \pi c \rho} I_{\text {peak }}=\frac{v+c}{2 \pi c \rho} \frac{1-\rho_{\text {top }}}{2} \mathrm{I}_{s c_{-} \text {peak }}$

By comparing lightning to flat ground (Equation A.36) to the tall structure (Equation A.47), the relation between the two magnetic fields for the same lightning current $\mathrm{I}_{\mathrm{sc}}$ is given:

$\frac{\mathrm{H}_{\text {tall_peak }}}{\mathrm{H}_{\text {flat_peak }}}=\frac{v+c}{v} * \frac{1-\rho_{\text {top }}}{1+\rho_{g r}}$

For $v=1 / 3 \mathrm{c}, \rho_{\text {top }}=-0.351$ and $\rho_{\text {bot }}=0.462$ the ratio from Equation A.48 is (3.7) close to what is found by the analyses of three storm in this study. Figure A-5 shows the waveforms of current 
for a lightning stroke to flat ground and to a tower of height $533 \mathrm{~m}, \rho_{\text {top }}=-0.351$ and $\rho_{\text {bot }}=0.462$ [86]. Current waveforms at the tower are shown at the top and bottom of it. Heidler function represents the lightning current waveform.

$i_{\text {Heidler }}(t)=\frac{I_{0}}{\eta} * \frac{\left(\frac{t}{\tau_{1}}\right)^{n} * e^{\left(-t / \tau_{2}\right)}}{1+\left(\frac{t}{\tau_{1}}\right)^{n}}$

$\eta=e^{\left(-\tau_{1} / \tau_{2}\right) *\left(n * \frac{\tau_{2}}{\tau_{1}}\right)^{(1 /(n+1))}}$

Where $\mathrm{I}_{0}=10 \mathrm{kA} ; \tau_{1}=0.2 \mu \mathrm{s} ; \tau_{2}=50 \mu \mathrm{s} ; \mathrm{n}=7$;

Figure A-6 shows the waveforms of magnetic field on perfectly conducting ground at a distance $70 \mathrm{~km}$ for a stroke on a $533 \mathrm{~m}$ tall tower with the return stroke wave-front speed 1/3 speed of light.

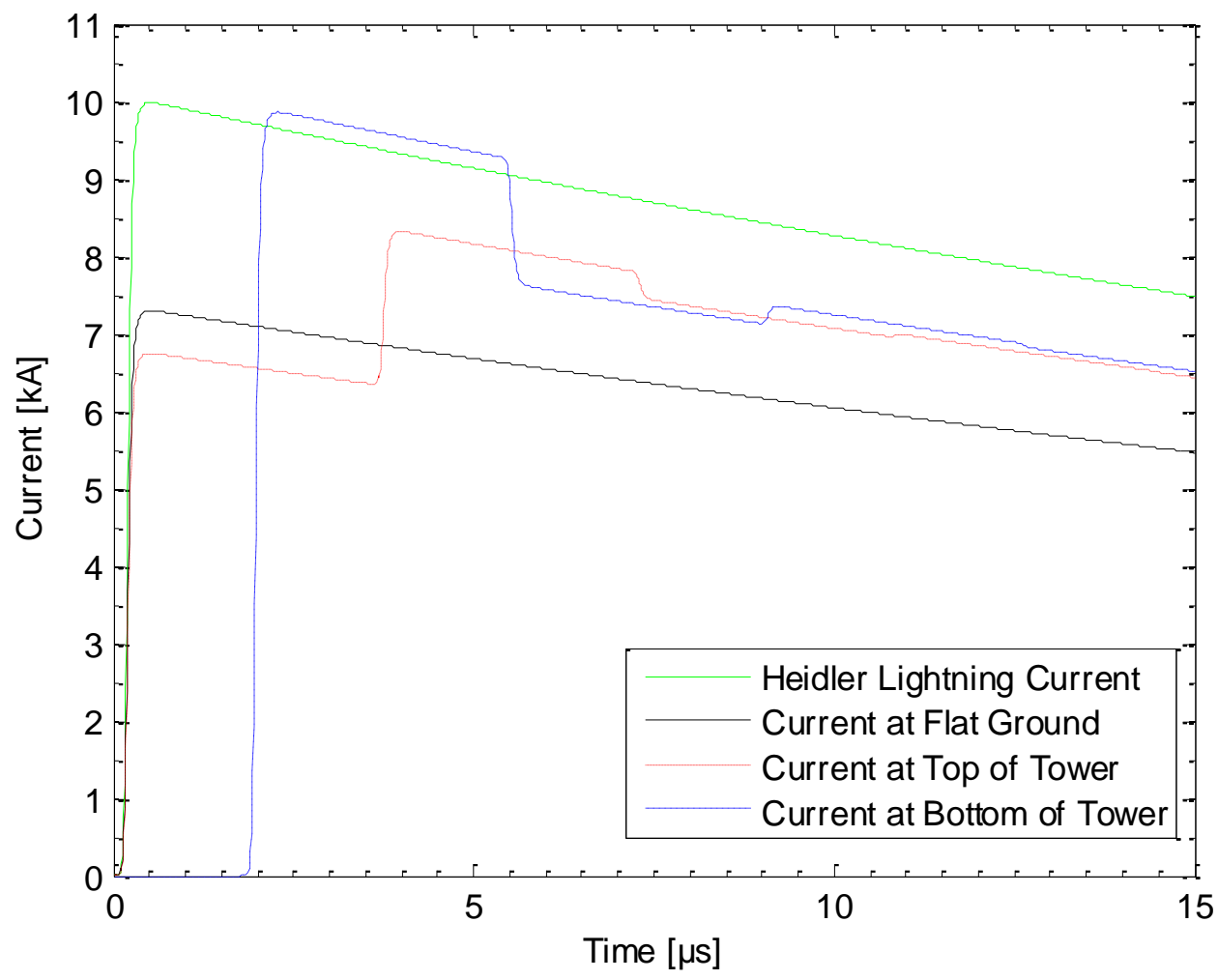

Figure A-5 Lightning current waveforms to flat ground and to a tower 


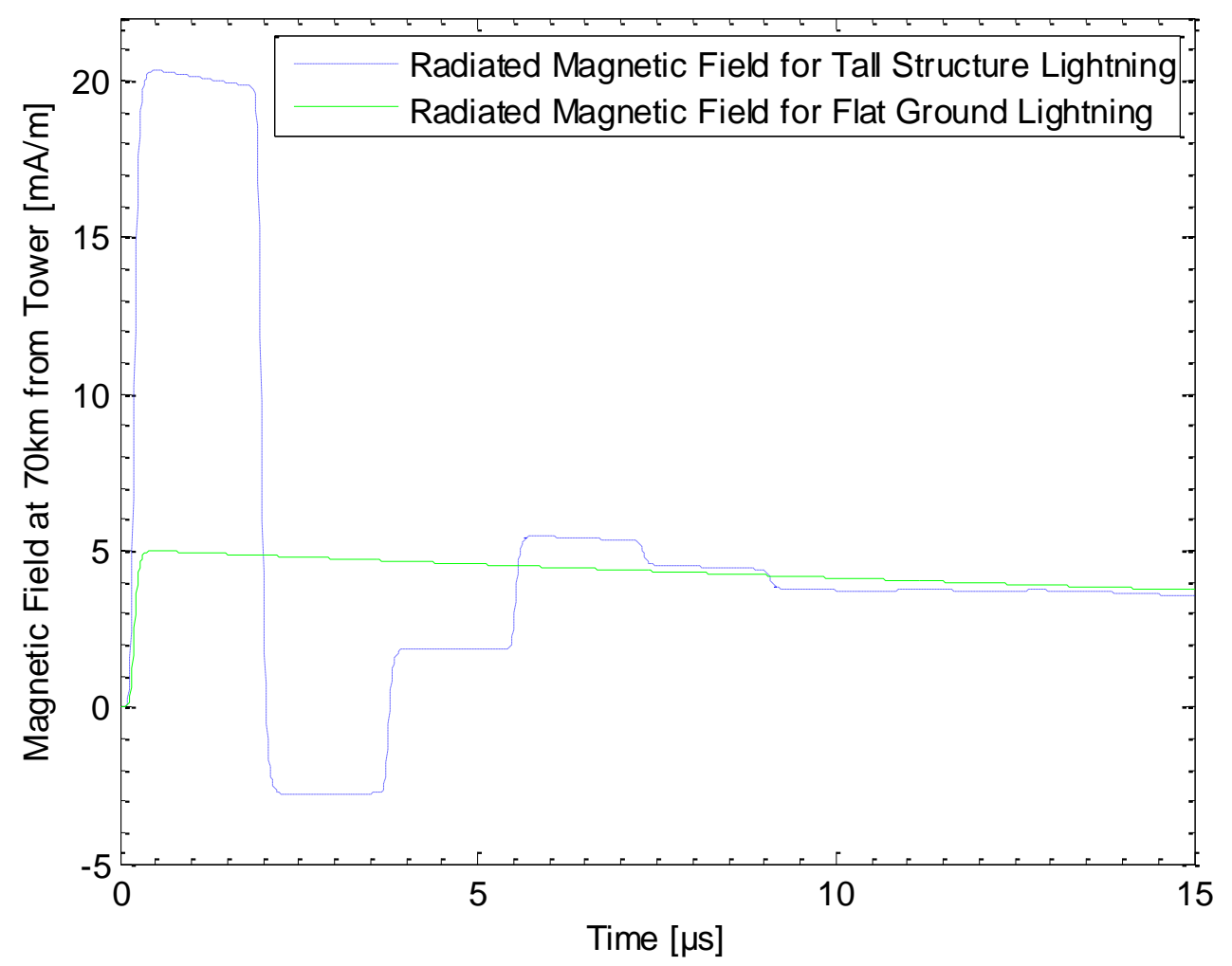

Figure A-6 Radiated magnetic field waveforms for flat-ground and tall-structure lightning

\section{Lightning Electromagnetic Fields Used to Locate Lightning Strokes}

Lightning discharge consists of different processes and development stages that emit electromagnetic radiation in the frequency range from a few hertz $(\mathrm{Hz})$ in case of continuing currents up to hundreds of $\mathrm{MHz}$ in case of breakdown and leader processes. Lightning locating systems provide electrical discharge characteristics based on the frequency of operation for specific lightning processes such as channel formation, return strokes, M-components, ISC pulses, and continuing currents [14], [15]. The best way to locate lightning is to use lightning locating systems that consist of a network of sensors/antennas and a processor. The sensors capture the lightning-generated electric and magnetic fields and send their waveform characteristics to the processor. The processor provides output results by executing the algorithm installed on it based on the input signals received from the sensors. An LLS sensor may operate at frequencies ranging from extremely low frequency (ELF) to ultra-high frequency (UHF). Also, one or more techniques can be used at the central processor to geo-locate the lightning event. 
The electric field has three components, electrostatic, induction and radiation (Equation A.26). When the distance from the point of stroke to the point of observation is small, the electrostatic component is dominant. When the distance becomes large, the radiation field becomes the main determining component. Out of the three components, only the radiation field maintains its field shape for long distances; but, the amplitude of the electric field will be inversely attenuated with the distance [1].

In the far-field zone when $\rho>>$, the radiation term is dominant.

$\lambda \ll \rho \Rightarrow \frac{c}{f} \ll \rho \Rightarrow \frac{1}{f} \ll \frac{\rho}{c} \Rightarrow \Delta t \ll \frac{\rho}{c}$

So, if the field reaches its peak in a very short time frame, then the distance from the point of observation may not have to be that far for the source to be considered a radiation field. For example, if the field impulse reaches the maximum in $2 \mu \mathrm{s}$, then a distance of $15 \mathrm{~km}$ can be considered enough to be in the radiation field zone. However, if the maximum is reached in 10 $\mu \mathrm{s}$, then it cannot be considered in the radiation field zone at $15 \mathrm{~km}$.

$2 * 10^{-6} \ll \frac{\rho}{c}=\frac{15 * 10^{3}}{3 * 10^{8}}=50 * 10^{-6}$

Lightning locating systems use methods based on the fact that the radiation field keeps its configuration as it propagates over long distances. The lightning peak radiated power is in the frequency range at about a few to $10 \mathrm{kHz}$ and decreases linearly with increasing frequency [9]. At a distance of $100 \mathrm{~km}$, radiated field amplitudes are estimated to attenuate by $12 \mathrm{~dB}$ per frequency up to $400 \mathrm{kHz}$; approximately double of that for frequency above $400 \mathrm{kHz}$. The ground-wave propagation with minimal attenuation and the lightning-radiated power peak both in the VLF-LF range makes this range of frequencies favorable for long and medium-range ground-based LLSs [15].

Main frequency ranges for lightning location systems are classified as following:

1. Very low frequencies (VLF) in the range $3 \mathrm{kHz}-30 \mathrm{kHz}$ or wavelength $100-10 \mathrm{~km}$

2. Low frequencies (LF) in the range $30 \mathrm{kHz}-300 \mathrm{kHz}$ or wavelength $10-1 \mathrm{~km}$

3. Very high frequencies (VHF) in the range $30 \mathrm{MHz}-300 \mathrm{MHz}$ or wavelength $10-1 \mathrm{~m}$ 
VHF radiation is related with physics of virgin air breakdown on channel formation processes. Strong emissions occur during the leader and streamer formation processes. LF waves are associated with the spatial and temporal development of discharges in and below the cloud used for three-dimensional mapping of lightning channels. VLF signals are related with return stroke currents in conducting lightning channels used to identify the ground striking point by lightning located systems [9], [14], [87]. As shown in Figure A-7, the sensors operating in the VHF range are located very close to the lightning channel to comply with the line-of-sight propagation requirements. Because the processes in the VHF range are of short duration, they can be displayed as point sources in two or three dimensions. The sensors operating in the LF/VLF range receive signals propagated along the Earth's surface and are mainly used by lightning locating systems to locate the lightning return strokes to ground. The sensors operating in the VLF range receive signals propagating between the ground and ionosphere (acting as a waveguide) for thousands of kilometers. In general, for distances between the lightning channel and the sensors less than $500 \mathrm{~km}$, the signals entirely propagate as ground waves in the LF range. For distances less than $1000 \mathrm{~km}$, the signals still can propagate as ground waves in LF/VLF range. For distances greater than $1000 \mathrm{~km}$, the signals propagate entirely in the groundionosphere waveguide in VLF range.

In the far-field zone, the amplitude of the lightning electromagnetic field decreases inversely with the distance (considering a perfectly conducting ground). The amplitude of the radiated field decreases further if the ground is not perfectly conducting because the ground absorbs energy from the radiated field [1]. The amount of this ground-absorbed energy is inversely proportional to the frequency of the radiated field. The Earth's conductivity in North America fluctuates between 1 and 30mS/m [14], [88], [89].

The lightning location systems have been devised according to three main technologies based on the frequency ranges of operation and distances between their sensors.

Short-range lightning locating systems have the distances between sensors designed within a few kilometers $(\mathrm{km})$ such as in Lightning Mapping Array (LMA $60 \mathrm{MHz}-66 \mathrm{MHz}$ ). They operate in narrow range VHF of the components of lightning signals that do not propagate as ground 
waves. Their sensors could be at base lines $10-40 \mathrm{~km}$ for time-of-arrival (TOA) technique or at about $100 \mathrm{~km}$ for interferometry [90], [91].

Medium-range locating systems have the distances between sensors designed between 50 and $400 \mathrm{~km}$. They operate in LF/VLF range of the components of lightning signals even though they will receive/process medium frequency to high frequency (MF/HF) components of the radiated field (major part of them will attenuate to low levels because of long distances) [41], [45]. The ground striking point of return stroke is determined with these systems by using magnetic direction finding (MDF), TOA, or combination thereof presented in the next chapter.

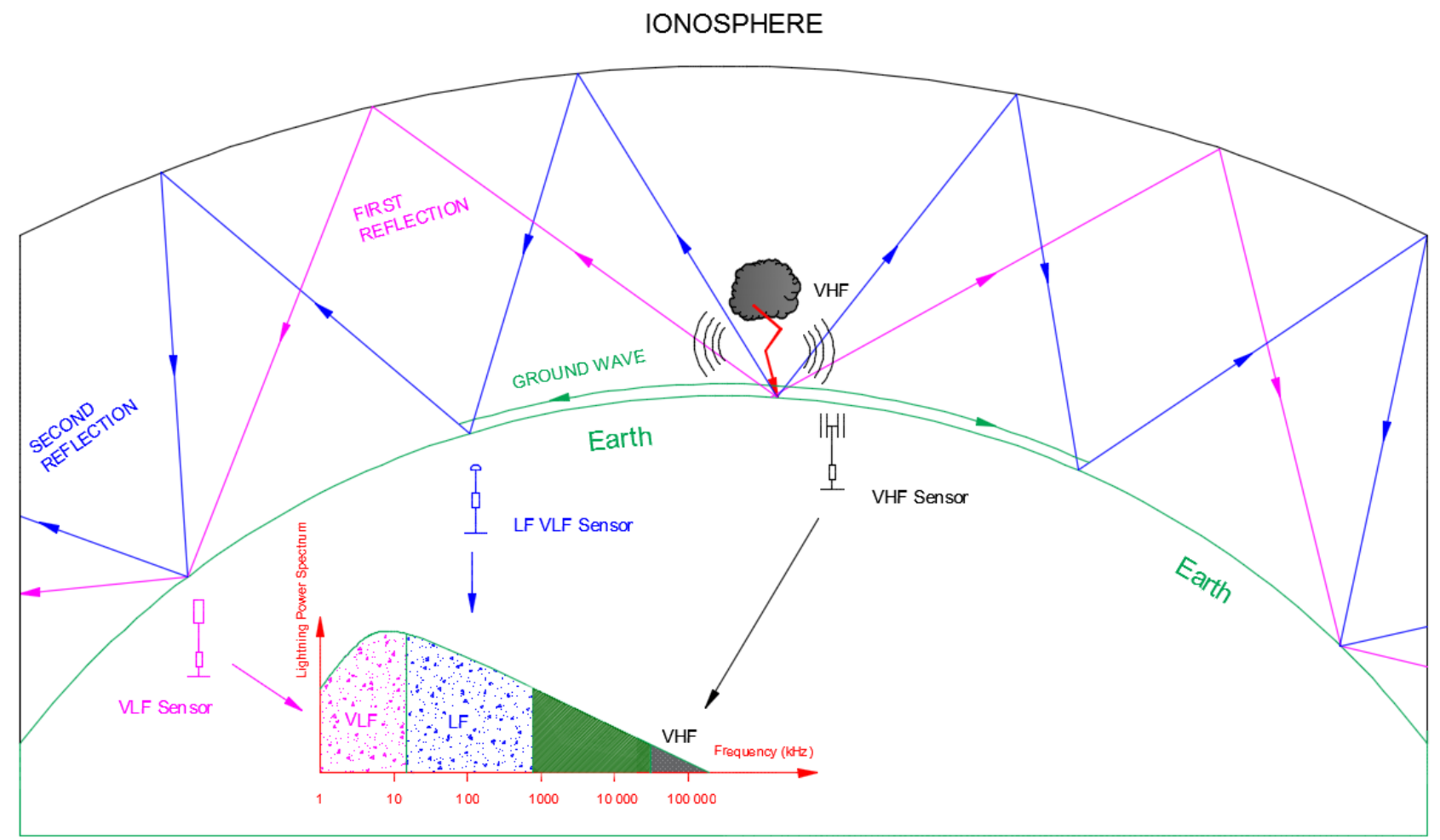

Figure A-7 Operating frequencies in lightning locating systems

Long-range locating systems have the distances between sensors designed to some thousands of kilometers. They operate in VLF range of components of lightning signals to provide lightning locating in global scale, such as Global Lightning Dataset (GLD360 3kHz - 30kHz) [92], [93]; World Wide Lightning Location Network (WWLLN 6kHz - 18kHz) [94], [95]; and Earth Networks Total Lightning Network (ENTLN 1Hz-12MHz) [96], [97]. 


\section{Appendix B. Interferometric Method}

The interferometric method is used to determine the source location of discharges for noise-like bursts electromagnetic radiation of duration from tens to hundreds microseconds. TOA systems have difficulty in identifying individual pulses. The interferometer measures the phase difference between noise-like bursts received by two or more very closely located antennas (A and B) shown in Figure B-1 [98]. For example, two antennas located at a distance d (few meters apart) from each other that receive the same signal generated by a source, but with a phase shift from each other, make an interferometer, Figure B-1. The distance $\mathrm{d}$ of the set of antennas will depend on the frequency of the signal of interest. The antennas are connected to a phase detector through a narrow band frequency filter. The phase detector generates a voltage proportional to the phase shift between the signals received by the two antennas. If the signals are considered sinusoidal with frequency $\omega$ and wavelength $\lambda$, and propagating with the speed of light $\mathrm{c}$, the time shift will translate in a phase shift $\Phi$ :

$$
\begin{aligned}
& t_{B}=\frac{r * \sin \theta * \sin \varphi}{c} \quad(B .1) \quad t_{A}=\frac{(r+d) * \sin \theta * \sin \varphi}{c} \\
& \Phi=\omega * t=2 * \pi * f * \Delta t=2 * \pi * \frac{c}{\lambda} *\left(t_{A}-t_{B}\right)=2 * \pi * \frac{c}{\lambda} * \frac{d * \sin \theta * \sin \varphi}{c} \\
& \Phi=\frac{2 * \pi * d * \sin \theta * \sin \varphi}{\lambda}
\end{aligned}
$$

Equation B.4 has two unknowns; elevation angle $\theta$ and azimuthal angle $\varphi$, which are to be determined. In order to solve the elevation angle $\theta$ and the azimuthal angle $\varphi$, another set of antennas is needed. The baselines of the two sets of antennas must be at $90^{\circ}$ apart. In this way, there would be two equations with two unknowns. The system consists of two sets of antennas in order to determine the elevation angle $\theta$ and the azimuthal angle $\varphi$.

$$
\begin{aligned}
& \Phi_{1}=\frac{2 * \pi * d * \sin \theta * \sin \varphi}{\lambda} \\
& \Phi_{2}=\frac{2 * \pi * d * \sin \theta * \cos \varphi}{\lambda}
\end{aligned}
$$


Two additional systems are needed to locate the source in three dimensional [14], [35].

Lightning is a challenging signal because of its wide range of frequencies and it may not be easy to retrieve from it the frequency of interest. The Fourier transformation of the signal is an alternative to narrow frequency band filter used to separate a particular frequency from the signal. For better results, the distance between the antennas of each set should be satisfying the equation:

$d \leq \frac{c}{\text { Bandwidth }}$

Several sources suggest that two sets of pairs of antennas located at $90^{\circ}$ to each other in distances of about $10 \mathrm{~km}$ with distance between antennas of each pair as $\lambda / 2$ and $4 \lambda$ respectively provide appropriate information about the cloud flashes [98] - [100].
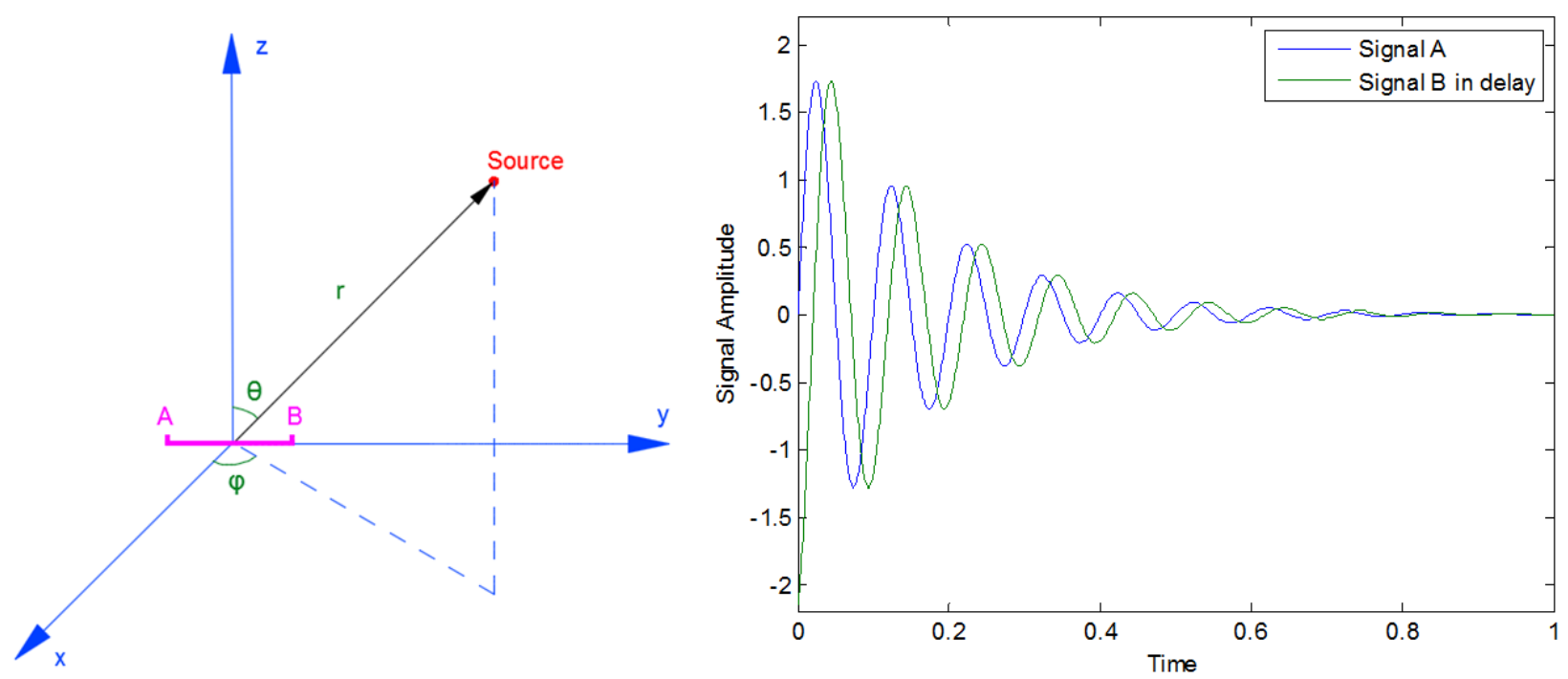

Figure B-1 Direction of arrival at two stations by interferometric method 


\section{Appendix C. Models of Lightning Locating Systems}

The lightning parameters are derived and assessed by LLSs based on the models for peak current estimation, location accuracy and detection efficiency. These models with the flash multiplicity algorithm, used by NALDN, are described below.

\section{Peak Current Estimation}

The NALDN estimates the lightning current peak using the peak of the detected magnetic field. The lightning-generated magnetic field is inversely proportional to the distance between the lightning channel and the sensor. Furthermore, the magnetic field is attenuated due to ground finite conductivity and ionosphere reflections. The magnitude of the radiated field must exceed the detection threshold of the sensor in order to have the event reported [50]. The transmission line model is used to find the relationship between the current peak and the far-field magnetic peak [36], [41], [101]. This model does not take into account the ground finite conductivity, reflections from the ionosphere and channel tortuosity [89], Appendix A.

$I_{\text {Peak }}=-\frac{2 * \pi * \varepsilon_{0} * c^{2} * \rho}{v} * E_{z-\text { Peak }} \quad$ and $\quad I_{\text {Peak }}=\frac{2 * \pi * c * \rho}{v} * H_{\varphi-\text { Peak }}$

$I_{\text {Peak }}, E_{z \text {-Peak }}$, and $H_{\varphi-P e a k}$ are the peaks of the lightning current, electric and magnetic fields, respectively. $\rho$ is the ground distance from the channel to the sensor, c is the speed of light, and $v$ is the return-stroke wave-front propagation speed. In Equation C.1, it is assumed that the ground is perfectly conducting, return-stroke speed is constant and the return-stroke front has not reached the top of the lightning channel (lower part of the thundercloud). For example, at a distance $\rho=100 \mathrm{~km}$ and $v=10^{8} \mathrm{~m} / \mathrm{s}$, Equation C.1 becomes:

$I_{\text {Peak }}=5000 * E_{z-\text { Peak }} \quad$ or $\quad I_{\text {Peak }}[k A]=5 * E_{z-\text { Peak }}\left[\frac{V}{m}\right]$

Equation C.2 is used by the network to calculate lightning current peak in kA when peak radiated field in $\mathrm{V} / \mathrm{m}$ is known. Each sensor of the network records and displays the peak field in lightning location and protection units (LLP - Units). The sensor records in LLP units should be 
correlated to the values of the magnetic field expressed in $\mathrm{V} / \mathrm{m}$. Vaisala provides the following relation between the sensor output signal in LLP-Units and field peak in V/m [41]:

$52\left[\frac{V}{m}\right]=1158[L L P-$ Units $] \quad \Rightarrow \quad 1[$ LLP - Units $]=\frac{52}{1158}\left[\frac{V}{m}\right]$

Substituting Equation C.3 into Equation C.2:

$I_{\text {Peak }}[k A]=5 * \frac{52}{1158}\left[\frac{V}{m}\right] * R N S S=S N F * R N S S$

Where $S N F$ is the signal normalization factor (for this example $S N F=0.225$ from Equation C.4) and RNSS is the sensor range normalization signal strength (normalized to a distance $100 \mathrm{~km}$ in this example) of the sensor that is contributing in the algorithm. RNSS of any sensor (x) is calculated using the model [36], [69], [88].

$R N S S_{X}=S S_{X} *\left(\frac{\rho_{X}}{100}\right)^{b} * e^{\left(\frac{\rho_{X}-100}{L}\right)}$

Where $S S_{X}$ is the raw signal strength normalized for distance of $100 \mathrm{~km}, \rho_{\mathrm{x}}$ is the distance from the sensor to the striking point, attenuation coefficient $b$ and e-folding length for attenuation $\mathrm{L}$ are coefficients that take into account soil conductivity. Different values of constants $b$ and $L$ have been proposed in [89], [102] - [104] to take into account the finite conductivity of soil. Vaisala uses Equation C.4 in the empirical form [53]:

$I_{P}[k A]=0.185 * R N S S$

It is not possible to calculate the peak current with very high accuracy from the measured lightning radiated fields because of propagation issues with radiated fields and the fact that the return stroke speed is not constant along the length of the lightning channel [105]. The average propagation speed of negative return stroke is in the range $\mathrm{c} / 3-\mathrm{c} / 2$ below the cloud and $(0.3-$ $0.7)^{*} \mathrm{c}$ in the bottom $100 \mathrm{~m}$ of the channel [106]. However, statistical estimation of current peak with the Equation C.6 is acceptable [107].

The peak currents calculated from Equation C.6 have been validated for negative subsequent strokes with true peak currents not more than 60kA because current measurement statistics at 
instrumented towers indicate a lightning current range from few kA up to 50kA. The complexity of the waveform for larger peak currents may affect the reliability of the sensor to generate the proper output for the software to accurately process the information [108].

Peak current estimation from a network is calibrated using the truth data from rocket triggered lightning or instrumented towers. There is an overestimation of peak current by NALDN from lightning to very tall towers; Equation C.6 is not valid for tall objects. In most of the cases, the zero-to-peak risetime of the lightning current on very tall towers is shorter than the round trip top to bottom wave propagation time $\left(2 *\right.$ height $\left._{\text {tower }} / \mathrm{c}\right)$. As a result, the current waveform contains both first peak and second - peak (includes the ground reflection) [61] and Appendix A. The lightning radiated fields from very tall structures are expected to be greater than the return strokes at ground level or short towers by a factor, $k_{\text {tall }}$, given in [85].

$$
\begin{aligned}
& I_{\text {Peak }}=-\frac{2 * \pi * \varepsilon_{0} * c^{2} * \rho}{v} * k_{\text {tall }} * E_{z-\text { Peak }} ; \\
& I_{\text {Peak }}=\frac{2 * \pi * c * \rho}{v} * k_{\text {tall }} * H_{\varphi-\text { Peak }} \\
& k_{\text {tall }}=\frac{1+\left(1-2 * \rho_{t}\right) * \frac{c}{v}}{1-\rho_{t}}
\end{aligned}
$$

Where the reflection coefficient at the top of the tower $\rho_{t}=\frac{Z_{t}-Z_{c h}}{Z_{t}+Z_{c h}}=-0.366$ [109] and $v=$ $1.2 * 10^{8} \mathrm{~m} / \mathrm{s}$ [110]. The factor of enhancement $k_{\text {tall }}=3.9$ is found by substituting the above coefficients in Equation C.7. Recent work found reflection coefficients at $\mathrm{CN}$ Tower to be $\rho_{t}=-0.345$ and average wave-front speed of propagation $v=93 \mathrm{~m} / \mu \mathrm{s}[86]$.

The enhancement factor of the radiated field for a very tall structure in [27] is found to be:

$k_{\text {tall }}=1+\frac{c}{v}=3.5$

The results from [27], [85] and Appendix A are in agreement. NALDN estimated peak current is plotted versus $\mathrm{CN}$ Tower peak current in [111]; it shows that the current predicted by the network is between 3.5 and 3.9 times greater than the real measured current at the tower. 
NALDN is assumed to provide the estimate of the initial peak current. It is proved in Appendix A and in [27] that the largest magnetic field peak corresponds to the initial (not the largest) current peak at the top of the object.

\section{Location Accuracy Model}

In addition to the detection efficiency, the location accuracy (LA) is quite fundamental for the performance characteristics of LLSs [55]. The information provided by the combined field sensors (MDF and TOA) is processed by an algorithm to optimize lightning location using the least squares method. This optimization technique minimizes the unconstrained error function that is the sum of the squares of the angle, time and field deviations. The optimized stroke location (latitude and longitude) and time of the event are determined by finding the stroke position along the surface of an oblate spheroidal earth (World Geodetic System, WGS84, used by GPS) in the direction of the gradient of the error until a minimum is found [2], [36].

$\chi^{2}=\sum_{i=1}^{N_{1}}\left(\frac{\theta_{m i}-\theta_{i}}{\sigma_{\theta_{i}}}\right)^{2}+\sum_{i=1}^{N_{1}}\left(\frac{t_{m i}-t_{0}}{\sigma_{t_{i}}}\right)^{2}+\sum_{i=1}^{N_{1}}\left(\frac{E_{m i}-E_{i}}{\sigma_{E_{i}}}\right)^{2}$

Where $\theta_{m i}, t_{m i}$ and $E_{m i}$ are the angle, time and measured electric field at station i respectively (the measured time is corrected to take into account the propagation time of the signal from the sensor location to the stroke location). Also, $\sigma_{\theta_{i}}, \sigma_{t_{i}}, \sigma_{E_{i}}$ are the expected errors in angle, time and field measurements used to operate with the normalized $\chi^{2}$ function. The unknowns are the true time of the stroke $t_{0}$, the angle $\theta_{i}$ (the angle from the sensor to the optimized stroke location) and the electric field $E_{i}$ (field amplitude for stroke at the optimized stroke location). $\mathrm{N}_{1}$ is the number of sensors that provide information about the stroke.

In the modern lightning locating systems, multiple sensors record and report the time and direction of occurrence of the radiated field by a lightning discharge channel. This information has accuracy limitations because of random and systematic errors, such as sensor design sensitivity, sensor location and the path from the sensor to the striking point. Assuming that the systematic errors have been corrected (no present systematic errors) and the random time and 
angle measurement errors are Gaussian and not correlated, the probability that a sensor will report an angle between $\theta+\psi$ and $\theta+\psi+\mathrm{d} \psi$ is given in [112]

$P(\psi) * d \psi=\frac{1}{\sigma_{\psi} * \sqrt{2 * \pi}} * e^{-\frac{\psi^{2}}{2 * \sigma_{\psi}^{2}}} * d \psi$

Where $\theta$ is the true angle, $\psi$ and $\sigma_{\psi}$ are the error and the standard deviation of the angle that the sensor reports, respectively.

Error ellipses are used to determine the location accuracy in NALDN location accuracy model. The ellipse shape develops from the outlines of constant differential in the cost function (Equation C.9) that is minimized in modelling the nonlinear process. The cost function takes the form of a sum of squares and follows a chi-square distribution [15]. Figure C-1 illustrates a twodimensional Gaussian distribution of location error model. The best stroke location is at the top of the error distribution. It shows the estimated stroke location at the least probable point that is the peak of the ellipsoid. The error ellipse defines the area of the striking point distribution at any probability between 0 and 100\%. The NALDN median location error is defined as the semimajor axis of the $50 \%$ probability ellipse (50\% probability that stroke occurs inside the ellipse) that expresses the median location accuracy. The $50^{\text {th }}$ percentile error ellipse is derived by cutting the distribution at a probability level of 0.5 .

If the striking point is outside the area covered by the reporting sensors, the ellipse will be very elongated. If the striking point is inside the area covered by the reporting sensors, the ellipse will be very close to a circle. The confidence ellipse can be calculated for any probability other than $50 \%$. The scaling factor for semi-major and semi-minor axis of the confidence ellipse other than $50 \%$ is given in [112]:

$S c F=\frac{\sqrt{-2 * \ln (1-P)}}{1.177}$

where $P$ is the preferred probability. For more commonly required probabilities of $90 \%$ and $99 \%$, the scaling factor is 1.82 and 2.57 , respectively. 
There are situations where the upward initiated lightning flashes from tall structures contain horizontal channel branches. Return strokes joining these horizontal branches are intercepted by the network as return strokes and are considered by the instrumentation of tall structures as superimposed ISC pulses with very fast risetimes [81], [113]. In these situations, the lightning detection system may locate the attachment point rather than the tower, resulting in poor location accuracy.

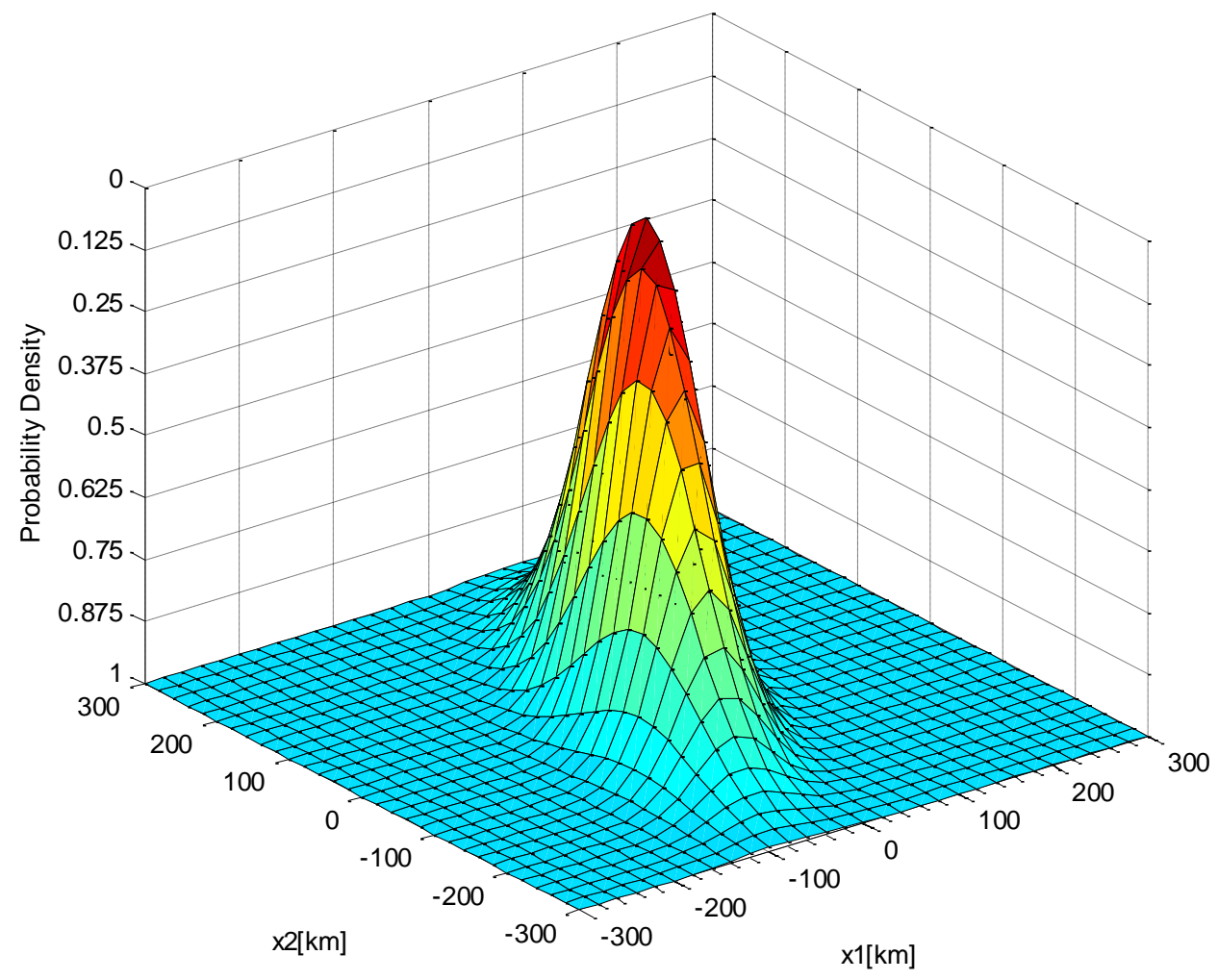

Figure C-1 Two-dimensional Gaussian distributions of location accuracy

\section{Detection Efficiency Model}

The ratio of flashes or strokes detected by a network to the total number of true flashes or strokes respectively, is called detection efficiency [114]. The detection efficiency has an effect on all lightning parameters predicted by lightning locating systems. The strokes that the network misses are those with low peak currents because their radiated field peaks are below the sensor's threshold, which results in larger mean and median values of peak currents, and lower mean and median values of flash multiplicity [115]. 
The peak of the lightning radiated field is proportional to the peak current of the return stroke. The strength of this field should be at the proper level to trigger the sensor. The signal strength should be within a certain range, as shown in Figure C-2, in order to be detected. If it is under or over the range, the detection efficiency for the signal will drop drastically and the output of the sensor will not be reliable [41]. It is important to take into account the field reduction due to normal propagation, soil conductivity and other losses, to ensure that the field reaching the sensor is above the trigger level.

The probability that a stroke is detected by at least two stations in a network consisting of three sensors is given in [41]. By assuming that the signal strength at the location of sensor $\left(\mathrm{S}_{\mathrm{i}}\right)$ is a function of the current peak $\left(I_{p}\right)$ and distance from the striking point $\left(\rho_{\mathrm{i}}\right)$, it has a probability $D E_{i}$ to be detected and a probability $Q_{i}=1-D E_{i}$ not to be detected by that sensor (for $\mathrm{i}=1,2,3$ ).

$\left[D E_{1}\left(I_{p}, \rho_{1}\right) * D E_{2}\left(I_{p}, \rho_{2}\right) * Q_{3}\left(I_{p}, \rho_{3}\right)\right]+$

$\left[D E_{1}\left(I_{p}, \rho_{1}\right) * D E_{3}\left(I_{p}, \rho_{3}\right) * Q_{2}\left(I_{p}, \rho_{2}\right)\right]+$

$\left[D E_{2}\left(I_{p}, \rho_{2}\right) * D E_{3}\left(I_{p}, \rho_{3}\right) * Q_{1}\left(I_{p}, \rho_{1}\right)\right]+$

$\left[D E_{1}\left(I_{p}, \rho_{1}\right) * D E_{2}\left(I_{p}, \rho_{2}\right) * D E_{3}\left(I_{p}, \rho_{3}\right)\right]$ only sensors $S_{1}$ and $S_{2}$ have triggered

only sensors $S_{1}$ and $S_{3}$ have triggered only sensors $S_{2}$ and $S_{3}$ have triggered all sensors $S_{1}, S_{2}$ and $S_{3}$ have triggered

The probability of a combination of sensors detecting the stroke in Equation C.12 is found by the product of $D E_{i}$ and $Q_{i}$ for all the sensors. The sum of all combinations will provide the probability for that stroke to be detected by the entire network. Equation C.12 assumes that each sensor operates and triggers independently from other sensors.

To generate a model for overall detection efficiency of a region, the region is divided into a grid of cells with imaginary current peaks at the center of each cell. The imaginary current peaks are taken from the peak current distribution data. Based on the generated peak current from the peak current distribution data, the model estimates the signal strength when it reaches each sensor (find RNSS from Equation C.6 and then SS from Equation C.5). The model uses the look up table to compare the signal strength calculated with the trigger level of the sensor to determine the probability that the sensor will detect that signal. This routine is performed for each sensor of the grid. To determine the detection efficiency of the entire network for a specific stroke, the 
sum of the probabilities for all sensors detecting that stroke is executed as shown in Equation C.12. For networks using combination TOA+MDF the minimum number of sensors is two, for networks using only MDF the minimum number of sensors is two to three (it depends on the location of striking points in relation to the sensor), for networks using only TOA the number of sensor is three to four [53]. The detection efficiency for the entire region is found by the sum of DE values for each simulated peak current that depends on the probability of incidence taken by peak current distribution.

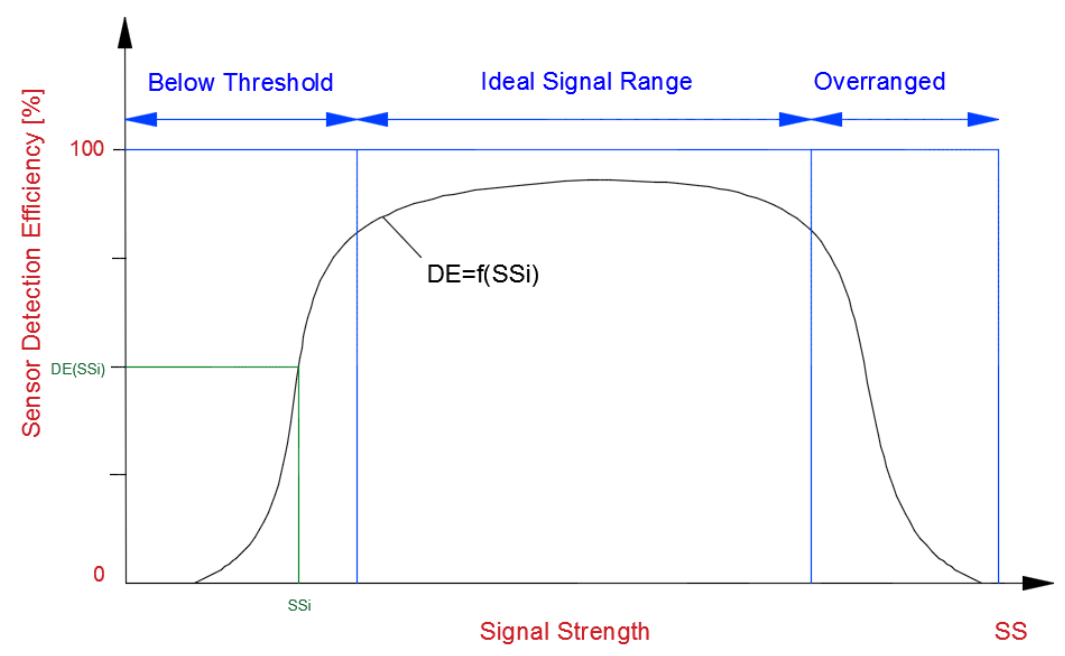

Figure C-2 Sensor detection efficiency versus signal strength relationship

In conclusion, the truthfulness of the model of detection efficiency depends on peak current distribution, trigger level of the sensors, saturation limit, soil conductivity, number of sensors to determine the location and waveform discrimination algorithm [116], [117].

\section{Flash Multiplicity and Misinterpretation of Noise}

Classification of lightning electromagnetic pulses is convoluted as the sensors are wide-open to several processes associated with the flash as well as with unrelated environment noise. The main reason for false detection is noise. Noise could be the radio and television broadcast frequencies that lie in the frequency bandwidth of the sensors. Also, noise could be the operation of powerful motors and electric power lines [15]. To improve on false detection, the sensor is designed to reject the non-lightning signals by comparing particular features of the received 
radiated field to the lightning stroke waveform. Often the sensors are equipped with filters against the noise. In addition, the processor could be programmed to reject the outliners after receiving the signal from multiple sensors [118], [119].

NALDN applies a method to group individual strokes into a flash. Prior to 1995, the network classified strokes in a group by adding all the stroke signals that occurred within $2.5^{\circ}$-range from the receiving sensor and within one second from the first return-stroke signal. Flash multiplicity was determined by the highest number of strokes received by any of the sensors processing the particular flash [36]. This method overestimated the flash multiplicity in case of simultaneous flashes that could be detected within $2.5^{\circ}$-range by more than one sensor and missed the possibility of multiple ground terminations [106]. Later, NALDN used both spatial and temporal algorithms to classify the strokes within a flash. Return strokes are grouped in the same flash if they occur within 1 second and are in range of $10 \mathrm{~km}$ from the first stroke [41]. Also, subsequent strokes should have inter-stroke time less than 500ms [41]. If there are more than 15 return strokes that satisfy the above restrictions, the exceeding ones are classified as a new flash [15]. 


\section{Appendix D. Developmental Stages of NALDN}

A series of the network hardware and software upgrades, during the last 33 years, is presented in this chapter. There are many large operating networks in the world that accurately locate cloud to ground lightning using LF/VLF technology. The main North American networks include: National Lightning Detection Network (NLDN), 400Hz - 400kHz [120], U.S. Precision Lightning Network (USPLN), $1.5 \mathrm{kHz}-400 \mathrm{kHz}$ [9] and Canadian Lightning Detection Network $(\mathrm{CLDN}), 400 \mathrm{~Hz}-400 \mathrm{kHz}$ [78]. The Lightning Detection Network (LINET), 5kHz - 100kHz, covers part of Europe, South America, Australia and Africa [121], [122]. The European network is comprised of European Cooperation for Lightning Detection (EUCLID), [112], [123] and the Austrian Lightning Detection Network (ALDIS), $1 \mathrm{kHz}-350 \mathrm{kHz}$ [112], [122], which also contributes to the EUCLID network and portions of the LINET network in Europe [121], [124]. Other primary networks include Japan Lightning Detection Network (JLDN) [125], the Brazilian National Network (BrasilDAT) [126] - [128] and the South African national network [129].

The development stages of lightning locating systems that led to the NALDN as one of the most modern and reliable networks to geo-locate the cloud to ground flashes are chronologically described as follows. At present, NALDN is operated by Vaisala, with headquarters in Helsinki, Finland. The name is derived from the company's founder, inventor and director, Professor Vilho Vaisala. The company's lightning detection sensors operate in more than 50 countries [3] as shown in Figure D-1. As of 2014, the NLDN uses 114 LS7002 sensors and EUCLID uses 146 sensors, 8 LPATS, 16 IMPACT, 33 IMPACT ES/ESP and 89 LS7000 [23], [55], [130].

On June $3^{\text {rd }}, 2013$, Vaisala posted the five greatest moments in the network's history: the first lightning data was recorded and archived on June $1^{\text {st }}, 1983$; the full coverage of the U.S. territory by the network was celebrated in 1989; the combination of magnetic direction finding and time of arrival technology in one sensor was achieved in 1992; in 1998, the CLDN was united with NLDN to create NALDN that covers the whole continent. The CLDN and NLDN are completely interconnected with all data processing being performed at Vaisala Network Control Centre in Tucson, Arizona. The fifth success occurred in 2013-the new digital technology sensors with enhanced software designed to improve the distinction between cloud and cloud to ground lightning [131]. 


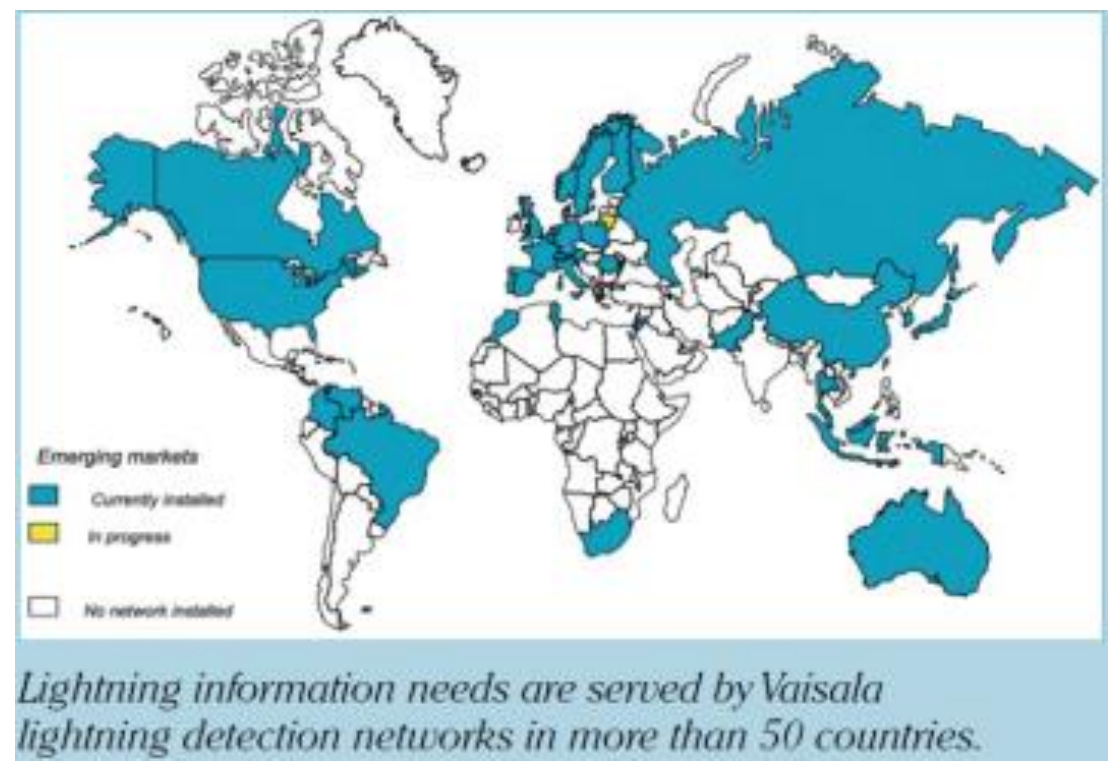

Figure D-1 Map of countries using Vaisala technology [131]

The main events in the network's 33 years of activity, shown below, include a series of improvements on the sensor technology and processor design as well as better-quality location algorithms as indicated in [79]. The continuous improvements over the years in NALDN have been motivated by competition and requirements of the lightning data applications.

1983-1989 Three isolated networks covering a major part of the American territory. First, Lightning Location and Protection (LLP) network covered 11 states (Western States plus Alaska). Second, US National Severe Storm Laboratory (NSSL) magnetic detection finding (MDF) network covered Oklahoma and part of the adjacent states. Third, State University of New York of Albany (SUNYA) MDF network covered the East Coast. The networks used magnetic direction finding sensors commercially made available by Lightning Location and Protection in 1980 [132]. A 16-station network, cooperatively operated by Ontario Ministry of Natural Resources and Ontario Hydro was used for 1986 and 1989 lightning seasons [88], [89].

1989 Regional networks share data to create a real time operation national network, NLDN. The national project is funded by the Electric Power Research Institute (EPRI) and is operated by State University of New York at Albany. Live lightning data feeds are turned on for users across the country. The Time-of-Arrival technique was implemented 
in Lightning Position and Tracking System (LPATS) sensors, made commercially available by Atmospheric Research Systems, Inc. (ARSI) in 1989 [76].

1991 Real-time and historic lightning information becomes commercially available.

1993 NLDN Network Control Center (NCC) is relocated in Tucson, Arizona.

1995 First major network-wide upgrade is completed with project partner EPRI. The upgrade added sensors that combined time-of-arrival and magnetic direction finding, Improved Accuracy and Combined Technology (IMPACT). There were 59 LPATS III and 47 IMPACT sensors installed for a total of 106 sensors in the network with sensor baselines values between 275 and $325 \mathrm{~km}$ [36]. The IMPACT location algorithm was used for time-of-arrival information from LPATS sensors and combined time-of-arrival plus direction finding information from IMPACT sensors. The NLDN began reporting flashes and individual strokes within a flash. Flash detection efficiency increased to 80-90\% with median stroke location accuracy of 500m [9].

1996-1999 Commercial uses of historic lightning data increased in electric power, insurance and other industries with improved location accuracy and application-specific software developments.

1998 Canadian Lightning Detection Network, owned by Environment Canada, was completed and joined NLDN; CLDN operated as part of NALDN with control centre in Tucson, Arizona. The network consisted of 30 Improved Accuracy from Combined Technology Enhanced Sensitivity and Performance (IMPACT-ESP) sensors and 51 LPATS IV sensors with two additional IMPACT-ESP sensors installed in Yukon for a total of 83 sensors [5]. Flash detection efficiency was $80-90 \%$ across most of Canada with median stroke location accuracy of 500m for cloud-to-ground strokes [133].

2000 NLDN real-time and historic data is available on the internet in several application specific formats.

2003 Second major upgrade of NLDN completed with installation of next generation sensors, all IMPACT-ESP sensors for a total of 113. These sensors have improved analog 
circuitry to reduce noise, to allow better detection of small amplitude signals and to reduce processing time [69]. CLDN maintained the same type of sensors at that time [13], [134]. The Improved Accuracy through Combined Technology (IMPACT) algorithm is used for locating striking points [48].

2005 Survey level cloud detection available. CLDN initiated a plan to upgrade incrementally each year the older LPATS IV sensors with IMPACT and LS7000 sensors [5].

2010 Complete communications upgrade to new Very Small Aperture Terminal (VSAT) technology for higher bandwidth capabilities and speed. Latency improved to 15 seconds or less. Introduction of Total Lightning Processor ${ }^{\mathrm{TM}}$ (TLPTM) algorithm operating in $\mathrm{NLDN} \circledast$ with propagation corrections to account for ground conductivity and topography of terrain over which the lightning electromagnetic waves propagate for IMPACT-ESP sensors. It is designed for $200 \mathrm{~m}$ or better location accuracy [32].

2011 Network fully upgraded to latest technology with LS7001 and TLS200 sensors for improved location accuracy and detection efficiency. The TLPTM algorithm with propagation corrections designed for IMPACT - ESP sensors, the year before, were not appropriate for the newly installed LS7001 sensors. The adjustments were made in February 2012 [32].

2013-2014 Third major upgrades completed the network with digital sensor technology, LS7002, and improved embedded software with enhanced features along with TLP100 processor [48], [49], [135]. The upgrade improves the sensitivity of the sensor to low amplitude lightning-generated signals and a better distinction of cloud flashes from cloud to ground flashes [15]. The algorithm of TLP100 processor is updated to classify lightning flashes using several waveform parameters, to locate pulses (before, during and after the lightning flash by using "burst processing" algorithm) and to have smaller arrival time errors as a result of improved evaluation technique of radiation field propagation [15]. 


\section{Appendix E. The Universal Transverse Mercator Coordinates}

The NALDN provides the latitude and longitude of the stroke location by the use of world geodetic system (WGS84) in locating system algorithm. WGS 84 is the reference coordinate system used by the Global Positioning System (GPS). It is the ellipsoid model of Earth (datum).

The Earth in Figure E-1 is approximated to an ellipsoid with major axis a, flattening factor $\mathrm{f}$ and minor axis b defined below:

$a=6378137 m$

$f=\frac{1}{298.257223563}$

$b=a *(1-f)=6356752.3142 m$

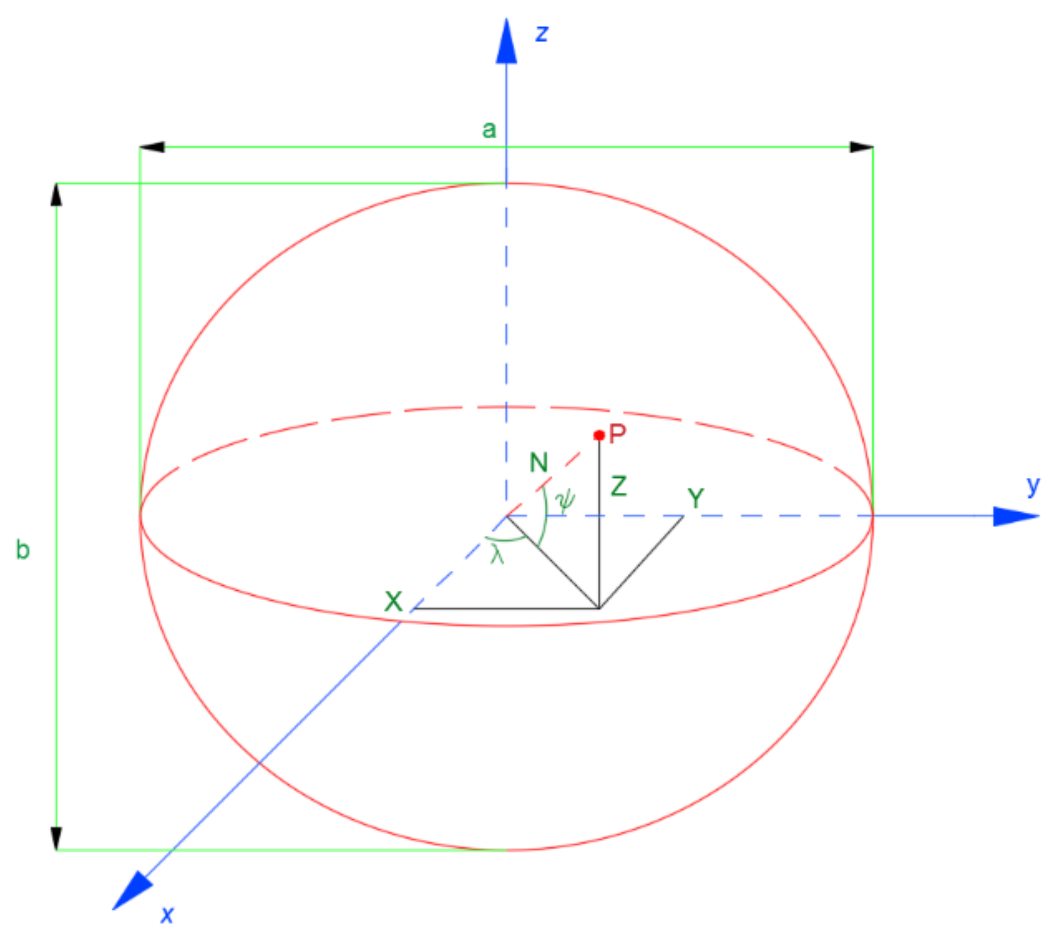

Figure E-1 Ellipsoid Model of Earth

The origin of WSG84 system is the center of mass of Earth with an error less than $2 \mathrm{~cm}$. The meridian zero longitude of the system is 5.32 seconds (102.5m) east of Greenwich [44]. 
For any point $\mathrm{P}$ on ellipsoid in Figure E-1, the Cartesian coordinates will be defined as shown below:

$$
\begin{aligned}
& X=N * \cos \psi * \cos \lambda \\
& Y=N * \cos \psi * \sin \lambda \\
& Z=N *\left(1-e^{2}\right) * \sin \psi \\
& N=\frac{a^{2}}{\sqrt{a^{2} * \cos ^{2} \psi+b^{2} * \sin ^{2} \psi}}=\frac{a}{\sqrt{1-e^{2} * \sin ^{2} \psi}}
\end{aligned}
$$

Eccentricity of the ellipsoid, e, and small expansion parameter, $\mathrm{n}$, are found:

$$
\begin{aligned}
& e=\sqrt{\frac{a^{2}-b^{2}}{a^{2}}} \\
& n=\frac{a-b}{a+b}=\frac{f}{2-f}
\end{aligned}
$$

The Universal Transversal Mercator (UTM) is the flat model of Earth by conformal projection of the ellipsoid into a two-dimensional map. It divides Earth, between the latitudes $80^{\circ}$ South and $84^{0}$ North, into 60 zones; it uses secant transverse Mercator projection in each zone. Each zone is wide $6^{0}$ of longitude $(800 \mathrm{~km})$ as shown in Figure E-2. The range of UTM eastings changes from $167 \mathrm{~km}$ at the poles to $833 \mathrm{~km}$ at the equator. Each zone is segmented into 20 latitude bands. Each latitude band is 8 degrees high, and is lettered starting from " $\mathrm{C}$ " at $80^{\circ} \mathrm{S}$, increasing up the English alphabet until "X", omitting the letters "I" and "O" (because of their similarity to the numerals one and zero). The last latitude band, " $\mathrm{X}$ ", is extended an extra 4 degrees, so it ends at $84^{\circ} \mathrm{N}$ latitude, thus covering the northernmost land on Earth. Latitude bands "A" and "B" do exist, as do bands "Y" and "Z".

The point of intersection of the equator and the central meridian of the zone defines the point of origin of that UTM zone. To avoid negative easting values, the central meridian of each zone is set at $500 \mathrm{~km}$ east. If easting location is less than $500 \mathrm{~km}$, the point of interest is west of the central meridian. If easting location is greater than $500 \mathrm{~km}$, the point of interest is east of central 
meridian. Northing locations for the northern hemisphere increase from zero in equator to $9324 \mathrm{~km}$ at latitude $84^{0}$ north. Northing locations for the southern hemisphere decrease from $10000 \mathrm{~km}$ in equator to the $1100 \mathrm{~km}$ at $80^{\circ}$ south. To avoid negative northing values, the northing at the equator is set at $10000 \mathrm{~km}$. So, when operating in the Southern hemisphere, the calculated northing is subtracted from $10000 \mathrm{~km}$.

The CN Tower is at $43^{\circ} 38^{\prime} 33.24^{\prime \prime} \mathrm{N}, 79^{\circ} 23^{\prime} 13.7^{\prime \prime} \mathrm{W}\left(43.6425667^{\circ} \mathrm{N}, 79.387139^{\circ} \mathrm{W}\right)$, which is in UTM zone 17, and the grid position is $630084 \mathrm{~m}$ east, $4833438 \mathrm{~m}$ north. Two points in Zone 17 have these coordinates, one in the northern hemisphere and one in the south. The letter $\mathrm{T}$ is used to distinguish between the two points.

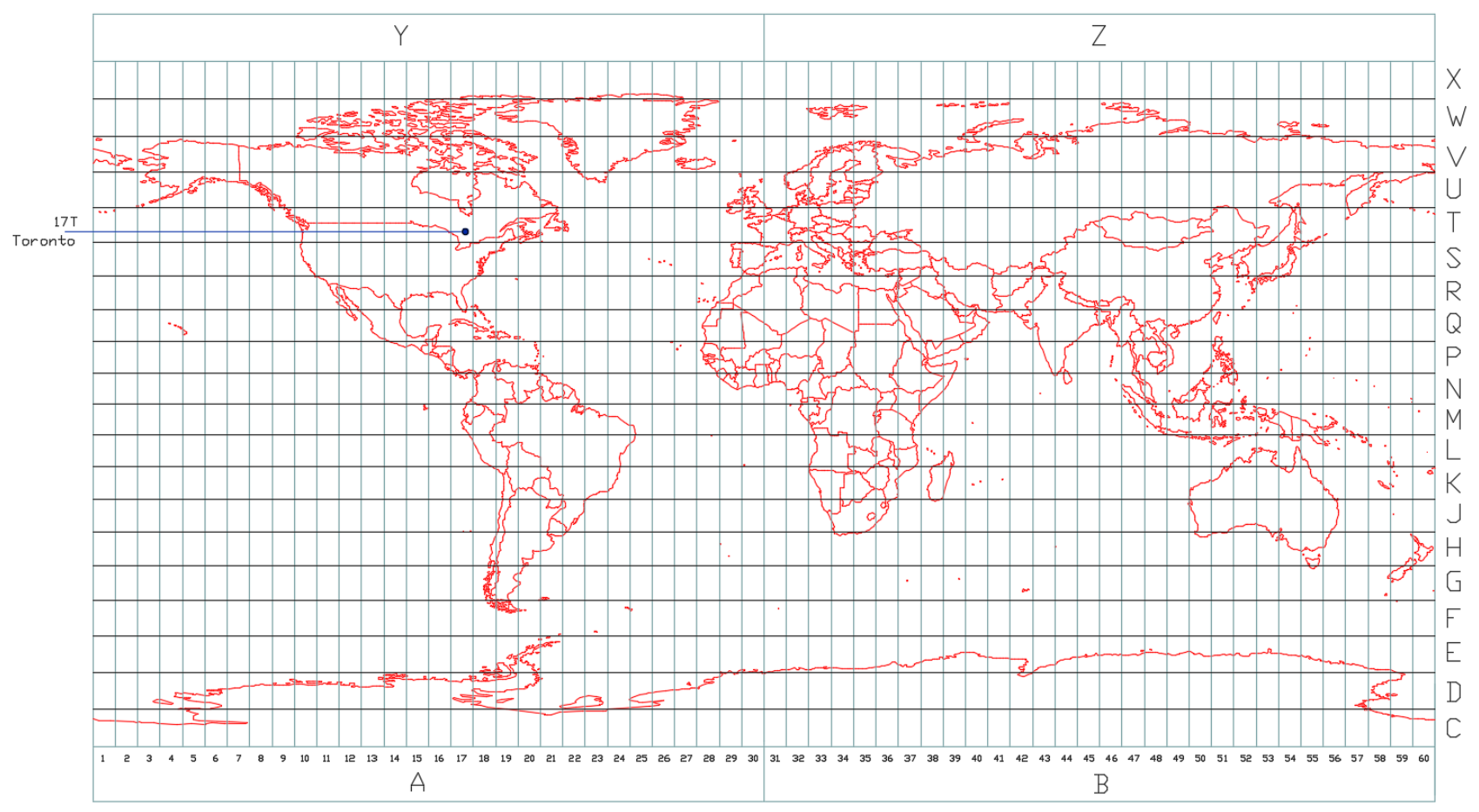

Figure E-2 Latitude bands

The conformal mapping formulas below were originally derived by Kruger for accuracy to around a millimeter within $6,000 \mathrm{~km}$ of the central meridian. A projection is conformal when angular relationships and accurate shapes are maintained. Transverse Mercator projection was revised by Karney in 2011 as shown in the following formulas [136]. 
For a point with latitude $\varphi$, and longitude $\lambda$ of ellipsoid model, the isometric latitude, $\psi$, of ellipsoid is found to be:

$\psi=g d^{-1} \varphi-e * \tanh ^{-1}(e * \sin \varphi)$

Where: $g d^{-1} \varphi=\tanh ^{-1}(\sin \varphi)$

The conformal Mercator projection for the ellipsoid is given by:

$\chi=\psi+i \lambda$

The corresponding spherical latitude $\varphi$ ' is found by making the conformal latitudes for the ellipsoid, $\psi$, and for the sphere, $\psi$, equal to each other. It maps a point on the ellipsoid with latitude $\varphi$ to a point on the sphere with latitude $\varphi$ '.

$\varphi^{\prime}=g d(\psi)=g d\left[g d^{-1} \varphi-e * \tanh ^{-1}(e * \sin \varphi)\right]$

The Mercator projection for the sphere is given by:

$\chi^{\prime}=\psi^{\prime}+i \lambda$

The transverse Mercator projection of the sphere is given by:

$\zeta^{\prime}=g d\left(\chi^{\prime}\right)=g d\left(\psi^{\prime}+i \lambda\right)$

Gauss-Kruger mapping is applied to make the scale constant:

$$
\begin{aligned}
& \zeta=\zeta^{\prime}+\sum_{j=1}^{\infty} \alpha_{j} * \sin \left(2 j \zeta^{\prime}\right) \\
& \alpha_{1}=\frac{1}{2} * n-\frac{2}{3} * n^{2}+\frac{5}{16} * n^{3}+\frac{41}{180} * n^{4}-\frac{127}{288} * n^{5}+\frac{7891}{37800} * n^{6}+\frac{72161}{387072} * n^{7}+\cdots \\
& \alpha_{2}=\frac{12}{48} * n^{2}-\frac{3}{5} * n^{3}+\frac{557}{1440} * n^{4}+\frac{281}{630} * n^{5}-\frac{1983433}{1935360} * n^{6}+\frac{13769}{28800} * n^{7}+\cdots \\
& \alpha_{3}=\frac{61}{240} * n^{3}-\frac{103}{540} * n^{4}+\frac{15061}{26880} * n^{5}+\frac{167603}{181440} * n^{6}-\frac{67102379}{29030400} * n^{7}+\cdots
\end{aligned}
$$




$$
\begin{aligned}
& \alpha_{4}=\frac{49561}{161280} * n^{4}-\frac{179}{168} * n^{5}+\frac{660661}{7257600} * n^{6}+\frac{97445}{49896} * n^{7}+\cdots \\
& \alpha_{5}=\frac{34729}{80640} * n^{5}-\frac{3418889}{1995840} * n^{6}+\frac{14644087}{9123840} * n^{7}+\cdots \\
& \alpha_{6}=\frac{212378941}{319334400} * n^{6}-\frac{30705481}{10378368} * n^{7}+\cdots \\
& \alpha_{7}=\frac{1522256789}{1383782400} * n^{7}+\cdots
\end{aligned}
$$

Karney suggested using $\tau$ and $\tau^{\prime}$ instead of $\varphi^{\prime}$ and $\psi$ in order to maintain accuracy near $\varphi= \pm \pi / 2$

$$
\begin{aligned}
& \tau=\tan \varphi \\
& \tau^{\prime}=\tau \sqrt{1+\sigma^{2}}-\sigma \sqrt{1+\tau^{2}}
\end{aligned}
$$

Where:

$$
\sigma=\sinh \left[e * \tanh ^{-1}\left(\frac{e * \tau}{\sqrt{1+\tau^{2}}}\right)\right]
$$

Also, it was suggested writing $\zeta^{\prime}$ for numerical accuracy as shown below:

$$
\zeta^{\prime}=\xi^{\prime}+i \eta^{\prime}
$$

Where:

$$
\begin{aligned}
& \xi^{\prime}=\tan ^{-1}\left(\frac{\tau^{\prime}}{\cos \lambda}\right) \\
& \eta^{\prime}=\sinh ^{-1}\left(\frac{\sin \lambda}{\sqrt{\tau^{\prime 2}+\cos ^{2} \lambda}}\right)
\end{aligned}
$$

So, the real and imaginary parts of Equation E.14 become:

$$
\xi=\xi^{\prime}+\sum_{j=1}^{\infty} \alpha_{j} * \sin \left(2 j \xi^{\prime}\right) * \cosh \left(2 j \eta^{\prime}\right)
$$


$\eta=\eta^{\prime}+\sum_{j=1}^{\infty} \alpha_{j} * \cos \left(2 j \eta^{\prime}\right) * \sinh \left(2 j \eta^{\prime}\right)$

To get the transverse Mercator easting $\mathrm{x}$ and northing $\mathrm{y}, \xi$ and $\eta$ found from Equations E.22 and E.23 are scaled below:

$x=k_{0} * A * \eta$

$y=k_{0} * A * \xi$

Where:

$A=\frac{a}{1+n}\left(1+\frac{n^{2}}{4}+\frac{n^{4}}{64}+\frac{n^{6}}{256}+\frac{n^{8}}{16384}+\frac{n^{10}}{65536}+\cdots\right)$

$k_{0}=0.9996$

The amount of distortion is held below one part in 1000 inside each zone by reducing the scale factor $\mathrm{k}_{0}$ along the central meridian to 0.9996 . 


\section{Bibliography}

[1] V. Cooray, An Introduction to Lightning, Dordrecht: Springer, 2015.

[2] V. A. Rakov and M. A. Uman, Lightning: Physics and Effects, New York: Cambridge University Press, 2003.

[3] N. Hembury and R. Holle, "Flash of Inspiration. Latest Innovation in Worldwide Lightning Detection," Meteorological Technology International, pp. 49-50, May 2011.

[4] N. Demetriades, "Strike in Action. Advanced Lightning Warning Systems Are Now Available Worldwide," Meteorological Technology International, pp. 46-48, May 2012.

[5] K. Spring, "The Canadian Lightning Detection Network Web Portal based Products, Services \& Indicators of Real Time Performance Measurement," in 19th International Lightning Detection Conference \& 1st International Lightning Meteorology Conference, Tuscon, Arizona, USA, 2006.

[6] B. Mills, D. Unrau, L. Pentelow and a. K. Spring, "Assessment of lightning related damage and disruption in Canada," Journal of the International Society for the Prevention and Mitigation of Natural Hazards, vol. 52, no. 2, pp. 481-499, 2010.

[7] E. B. Curran, R. L. Holle and a. R. E. Lopez, "Lightning Casualties and Damages in the United States from 1959 to 1194," Journal of Climate, vol. 13, no. 19, pp. 3448 - 3464, 2000.

[8] K. L. Cummins, E. P. Krider and M. D. Malone, "The U.S National Lightning Detection Network ${ }^{\mathrm{TM}}$ and Applications of Cloud-to-Ground Lightning Data by Electric Power Utilities," IEEE Transactions on Electromagnetic Compatibility, vol. 40, no. 4, pp. 465 - 480, November 1998.

[9] K. L. Cummins and M. J. Murphy, "An Overview of Lightning Locating Systems: History, Techniques, and Data Uses, With an In-Depth Look at the U.S. NLDN," IEEE Transactions on Eelectromagnetic Compatibility, vol. 51, no. 3, pp. 499 - 518, August 2009.

[10] B. Stocks, J. Mason, J. Todd, E. Bosch, B. Wotton, B. Amiro, M. Flannigan, K. Hirsch, K. Logan, D. Martell and W. Skinner, "Large Forest Fires in Canada, 1959 - 1997," Journal of Geophysical Research, vol. 107, no. D1, pp. FFR 5-1-FFR 5-12, 2002.

[11] R. L. Holle, R. E. López, L. J. Arnold and J. Endres, "Insured Lightning-Caused Property Damage in Three Western States," Journal of Applied Meteorology, vol. 35, no. 8, pp. 1344 - 1351, August 1996.

[12] B. Mills, D. Unrau, C. Parkinson, B. Jones, J. Yessis, K. Spring and L. Pentelow, "Assessment of lightningrelated fatality and injury risk in Canada," Journal of the International Society for the Prevention and Mitigation of Natural Hazards, vol. 47, no. 2, pp. 157 -183, November 2008.

[13] B. Kochtubajda, W. Burrows and B. Power, "Large Current Lightning Flashes in Canada: 1999 - 2006," in 20th International Lightning Detection Conference \& 2nd International Lightning Meteorology Conference, Tuscon, Arizona, USA, April 2008.

[14] A. Nag, M. J. Murphy, W. Schulz and K. L. Cummins, "Lightning Locating Systems: Insights on Characteristics and Validation Techniques," Earth and Space Science, vol. 2, no. 4, pp. 65-93, 2015.

[15] A. Nag, M. Murphy, K. Cummins, A. Pifer and J. Cramer, "Recent evolution of the U.S. National Lightning Detection Network," in 23rd International Lightning Detection Conference \& 5th International Lightning Meteorology Conference, Tuscon, Arizona, March, 2014.

[16] J. H. Christian, R. J. Blakeslee and S. J. Goodman, "The Detection of Lightning from Geostationary Orbit," Journal of Geophysical Research: Atmospheres, vol. 94, no. D11, pp. 13329 - 13337, 1989.

[17] T. Morimoto, H. Kikuchi, M. Sato, T. Ushio, A. Yamazaki, M. Suzuki and Z.-I. Kawasaki, "VHF Lightning Observations by Digital Interferometry from ISS / JEM - GLIMS," in XV International Conference on Atmospheric Electricity, Norman, Oklahoma, USA, June 2014.

[18] T. Morimoto, H. Kikuchi, M. Sato, M. Suzuki, A. Yamazaki and T. Ushio, "VHF Lightning Observations on JEM-GLIMS Mission - Gradual Approach to Realize Space - born VHF Broadband Digital Interferometer," 
IEEJ Transactions on Fundamentals and Materials, vol. 131, no. 12, pp. 977 - 982, 2011.

[19] C. Bouquegneau, "The Need for an International Standard on Lightning Location Systems," in 23rd International Lightning Detection Conference \& 5th International Lightning Meteorology Conference, Tuscon, Arizona, USA, March 2014.

[20] G. Diendorfer, "LLS Performance Validation Using Lightning to Towers," in 21 st International Lightning Detection Conference \& 3rd International Lightning Meteorology Conference, Tuscon, Arizona, USA, April 2010.

[21] S. Kazazi, A. M. Hussein and P. Liatos, "Evaluation of the Performance Characteristics of the North American Lightning Detection Network Based on Recent CN Tower Lightning Data," in XIII International Symposium on Lightning Protection, Balenario Camboriu, Brazil, pp. 447-453, 2015.

[22] Vaisala, "Vaisala Thunderstorm, Advanced Total LightningTM Sensor LS7002," Ref. B211284EN-A, Helsinki, Finland, 2013.

[23] T. L. Buck, A. Nag and M. J. Murphy, "Improved Cloud-to-Ground and Intracloud Lightning Detection with the LS7002 Advanced Total Lightning Sensor," in World Meteorological Organization Technical Conference on Meteorological and Environmental Instruments, Saint Petersburg, Russian Federation, July 2014.

[24] A. Nag, M. J. Murphy, W. Schulz and K. L. Cummins, "Lightning Locating Systems: Characteristics and Validation Techniques," in 32nd International Conference on Lightning Protection, Shanghai, China, 2014.

[25] A. Lafkovici, A. M. Hussein, W. Janischewskyj and K. L. Cummins, "Evaluation of the Performance Characteristics of the North American Lightning Detection Network Based on Tall-Structure Lightning," IEEE Transactions on Electromagnetic Compatibility, vol. 50, no. 3, pp. 630 - 641, 2008.

[26] S. Kazazi, A. M. Hussein and J. MacPherson, "Continuous recording of CN Tower lightning current flashes at high resolutiions," in 12th International Conference on Ground and 5th Lightning Physics and Effects, Porto de Galinhas (Pernambuco), Brazil, pp. 64-69, 2016.

[27] Y. Baba and V. A. Rakov, "Lightning Strikes to Tall Objects: Currents Inferred from Far Electromagnetic Fields Versus Directly Measured Currents," Geophysical Research Letters, vol. 34, no. 19, pp. L19810 (1 - 5), 2007.

[28] G. Diendorfer and W. Schulz, "Lightning Incidence to Elevated Objects on Mountains," in 24th International Conference on Lightning Protection, Birmingham, UK, 1998.

[29] A. M. Hussein and S. Kazazi, "Characteristics of a Tall-Structure Severe Lightning Storm," in XII International Symposium on Lightning Protection, Belo Horizonte, Brazil, pp. 146-151, 2013.

[30] A. M. Hussein, S. Kazazi, M. Anwar, M. Yusouf and P. Liatos, "CN Tower Lightning Characteristics Based on Current-Recorded Flashes," in 32nd International Conference on Lightning Protection, Shanghai, China, pp. 2028-2034, 2014.

[31] S. Kazazi, A. M. Hussein and P. Liatos, "CN Tower Lightning Characteristics Based on Current and Video Records," in 9th Asia-Pacific International Conference on Lightning, Nagoya, Aichi; Japan, pp. 465-474, 2015.

[32] S. Mallick, V. Rakov, T. Ngin, W. Gamerota, J.T.Pilkey, J.D.Hill, M.A.Uman, D. Jordan, J. Cramer and A. Nag, "An Update on the Performance Characteristics of the NLDN," in 23rd International Lightning Detection Conference \& 5th International Lightning Meteorology Conference, Tuscon, Arizona, USA, 2014.

[33] M. A. Uman, The Lightning Discharge, Mineola, New York: Dover, 2001.

[34] M. A. Uman, Lightning, Pittsburgh, PA: McGraw Hill, 1969.

[35] V. Rakov, "Electromagnetic Methods of Lightning Detection," Surveys in Geophysics, vol. 34, no. 6, pp. 731 753, November 2013.

[36] K. L. Cummins, M. J. Murphy, E. A. Bardo, W. L. Hiscox, R. B. Pyle and A. E. Pifer, "A combined TOA/MDF Technology Upgrade of the U.S. National Lightning Detection Network," Journal of Geophysical Research: Atmospheres, vol. 103, no. D8, pp. 9035 - 9044, 1998. 
[37] E. P. Krider, R. C. Noggle and M. A. Uman, "A Gated, Wideband Magnetic Direction Finder for Lightning Return Strokes," Journal of Applied Meteorology and Climatology, vol. 15, no. 3, pp. 301 - 306, March 1976.

[38] M. A. Uman, Y. T. Lin and E. P. Krider, "Errors in Magnetic Direction Finding Due to Nonvertical Lightning Channels," Radio Science, vol. 15, no. 1, pp. 35 - 39, 1980.

[39] F. Rachidi and M. Rubinsein, "Time reversal of electromagnetic fields and its application to lightning location," in XII International Symposium on Lightning Protection, Belo Horizonte, Brazil, 2013.

[40] R. Orville Jr., "An Analytical Solution to Obtain the Optimum Source Location using Multiple Direction Finders on a Spherical Surface," Journal of Geographical Research, vol. 92, no. D9, pp. 10877-10886, 1987.

[41] G. Diendorfer, "Lightning Location Systems (LLS)," in IX International Symposium on Lightning Protection, Foz do Iguacu, Brazil, November 2007.

[42] R. M. Passi and R. E. Lopez, "A Parametric Estimation of Systematic Errors in Networks of Magnetic Direction Finders," Journal of Geophysical Research: Atmospheres, vol. 94, no. D11, pp. 13319 - 13328 , September 1989.

[43] M. W. Maier and M. B. Wilson, "Accuracy of the NLDN real-time data service at Cape Canaveral, Florida," in XIV International Lightning Detection Conference, Global Atmospherics, Tuscon, Arizona, USA, November 1996.

[44] S. J. Bugayevskiy L. M., Map Projections: A Reference Manual, London: Taylor \& Francis, 1995.

[45] K. L. Cummins, M. J. Murphy and J. V. Tuel, "Lightning Detection Methods and Meteorological," in IV International Symposium on Military Meteorology, Malbork, Poland, September 2000.

[46] P. W. Casper and R. B. Bent, "Results from the LPATS USA National Lightning Detection and Tracking System for the 1991 Lightning Season," in 21st International Conference on Lightning Protections, Berlin, 1992.

[47] R. S. Bent and W. A. Lyons, "Theoretical Evaluations and Initial Operational Experiences of LPATS (Lightning Position and Tracking System) to Monitor Lightning Ground Strikes Using a Time-of-Arrival (TOA) Technique," in 7th International Conference on Atmospheric Electricity, Albany, New York, USA, 1984.

[48] K. L. Cummins, M. J. Murphy, J. A. Cramer, W. Scheftic, N. Demetriades and A. Nag, "Location Acuracy Improvements Using Propagation Corrections: A Case Study of the U.S. National Lightning Detection Network," in 21st International Lightning Detection Conference \& 3rd International Lightning Meteorology Conference, Orlando, Florida, USA, 2010.

[49] N. Honma, K. L. Cummins, M. J. Murphy, A. E. Pifer and T. S. Rogers, "Improved Lightning Locations in the Tohoku Region of Japan Using Propagation and Waveform Onset Corrections," IEEJ Transactions on Power and Energy, vol. 133, no. 2, pp. 195 - 202, 2013.

[50] K. L. Cummins, M. Murphy, N. Demetriades, B. Pifer, A. Pessi and S. Businger, "Modeling and Calibration of Vaisala's Operational Long Range Lightning Detection Network," in 20th International Lightning Detection Conference \& 2nd International Lightning Meteorology Conference, Tuscon, Arizona, USA, 2008.

[51] R. L. Holle and R. E. Lopez, "Overview of Real-Time Lightning Detection Systems and Their Meteorological Uses", Norman, Oklahoma, USA: U.S. Dept. of Commerce, National Oceanic and Atmospheric Administration, Environmental Research Laboratories, National Severe Storm Laboratory NSSL-102, 1993, p. 68.

[52] R. Bernstein, R. Samm, K. Cummins, R. Pyle and J. Tuel, "Lightning Detection Network Averts Damage and Speeds Restoration," IEEE, Computer Application in Power, vol. 9, no. 2, pp. 12 - 17, 1996.

[53] G. Diendorfer, M. Bernardi, K. Cummins, F. D. L. Rosa, B. Hermoso, A. Hussein, T. Kawamura, F. Rachidi, V. Rakov, W. Schulz and H. Torres, "Cloud-to-Ground Lightning Parameters Derived from Lightning Location Systems. The Effects of System Performance," CIGRE. Working Group C4.404, 2009.

[54] K. L. Cummins and M. J. Murphy, "Overview of Lightning Detection in the VLF, LF, and VHF Frequency 
Ranges," in 16th International Lightning Detection Conference, Tucson, Arizona, USA, 2000.

[55] W. Schulz, "Location Accuracy Improvements of the Austrian Lightning Location System During the Last 10 Years," in 9th Asia - Pacific International Conference on Lightning, Nagoya, Japan, 2015.

[56] S. Kazazi, P. Liatos and A. M. Hussein, "Simultaneous Recording of CN Tower Lightning Current and Channel Luminosity," in 27th Canadian Conference on Electrical and Computer Engineering, Toronto, ON, Canada, pp. 699-704, 2014.

[57] A. M. Hussein, M. Milewski and W. Janischewskyj, "Characterization of CN Tower Lightning Flash Components," in International Conference on Grounding and Eathing (ground) \& 4th Inetrnational Conference on Lightning Physics and Effects, Salvador, Brazil, 2010.

[58] A. M. Hussein, M. Milewski, E. Burnazovic and W. Janischewskyj, "Current Waveform Characteristics of CN Tower Negative and Positive Lightning," in X International Symposium on Lightning Protection, Curitiba, Brazil, 2009.

[59] M. Milewski, Lightning Return-Stroke Transmission Line Modelling Based on the Derivative of Heidler Function and CN Tower Data, Toronto: PhD Ryerson University, Toronto, ON, Canada, 2009.

[60] P. Liatos and A. M. Hussein, "Characterization of 100-kHz Noise in the Lightning Current Derivative Signals Measured at the CN Tower," IEEE Transactions on Electromagnetic Compatibility, vol. 47, no. 4, pp. 986 997, November 2005.

[61] A. M. Hussein, M. Milewski and W. Janischewskyj, "Correlating the Characteristics of the CN Tower Lightning Return-Stroke Current with Those of Its Generated Electromagnetic Pulse," IEEE Transactions on Electromagnetic Compatibility, vol. 50, no. 3, pp. 642 - 650, 2008.

[62] Manual Fiber Link Instructions, "OP 2000A Optical Transmission System," NANOFAST Inc., Chicago, Illinois, USA, 1996.

[63] NI Digitizer Specifications, "NI PCI 5114 Specifications," National Instruments, http://ni.com/manuals, Accessed on Aug. 25, 2015.

[64] LeCroy Operator's Manual, "LeCroy Waverunner," LeCroy Corporation, Chestnut Ridge, New York, USA, 2001.

[65] Phantom Technical Specifications, "Phantom v5.0," Vision Research Inc., Wayne, New Jersey, USA, 2000.

[66] Sony Camera Instructions, "Sony Handycam Camera HDR PJ790VB," Sony Corporate, Toronto, ON, Canada, 2013.

[67] A. Hussein, S. Kazazi, M. Anwar, M. Yusouf and P. Liatos, "Characteristics of CN Tower Most Intense Lightning Storm," Journal of Atmospheric Solar-terrestrial Physics, vol. 1, no. May 4, 2016, pp. 1-44, 2016.

[68] S. Kazazi, A. M. Hussein and P. Liatos, "Extensive Evaluation of NALDN Performance Characteristics Based on CN Tower Lightning Data," Journal of Electric Power System Research, Vols. submitted on April 30, 2016, pp. 1-22, 2016.

[69] K. L. Cummins, J. A. Cramer, C. Biagi, E. P. Krider, J. Jerauld, M. A. Uman and V. A. Rakov, "The U.S. National Lightning Detection Network: Post-Upgrade Status," in 2nd Conference on Meteorological Applications of Lightnig Data, Atlanta, Georgia, USA, 2006.

[70] A. Nag, J. Jerauld, V. Rakov, M. Uman, K. Rambo, D. M. Jordan, B. A. DeCarlo, J. Howard, K. L. Cummins and J. A. Cramer, "NLDN Responses to Rocket-Triggered Lightning at Camp Blanding," in 29th International Conference on Lightning Protection, Uppsala, Sweden, 2008.

[71] C. J. Biagi, K. Cummins, K. Kehoe and E. Krider, "National Lightning Detection Network (NLDN) Performance in Southern Arizona, Texas, and Oklahoma in 2003-2004," Journal of Geophysical Research: Atmospheres, vol. 112, no. D5, pp. D05208 (1 - 17), 2007.

[72] N. Honma, F. Suzuki, Y. Miyake, M. Ishii and S. Hidayat, "Propagation Effect on Field Waveforms in Relation to Time-of-Arrival Technique in Lightning Location," Journal of Geophysical Research, vol. 103, no. D12, pp. 14141 - 14145, 1998. 
[73] M. Murphy and A. E. Pifer, "Network Performance Improvements using Propagation Path Corrections," in 15th International Lightning Detection Conference, Tuscon, Arizona, USA, 1998.

[74] G. Diendorfer, W. Schulz and F. Fuchs, "Comparison of Correlated Data from the Austrian Lightning Location System and Measured Lightning Currents at the Peissenberg Tower," in 24th Conference on Lightning Protection, Birmingham, UK, 1998.

[75] S. Mallick, V. A. Rakov, J. D. Hill, T. Ngin, W. R. Gamerota, D. M. Jordan, R. C. O. III, M. A. Uman and L. A. Cramer, "The NLDN Performance Characteristics: An Update," in 22nd International Lightning Detection Conference \& 4th International Lightning Meteorology Conference, Broomfield, Colorado, USA, 2012.

[76] A. Lafkovici, A Performance Analysis of the North American Lightning Detection Network Using CN Tower Lightning Data, Toronto: M. A. Sc. Ryerson University, Toronto, ON, Canada, 2005.

[77] A. M. Hussein, "CN Tower Lightning Parameters," in X International Symposium on Lightning Protection, Curitiba, Brazil, 2009.

[78] W. R. Burrows and B. Kochtubajda, "Cloud to Ground Lightning in Canada," in 21st International Lightning Detection Conference \& 3rd International Lightning Meteorology Conference, Orlando, Florida, USA, 2010.

[79] Vaisala, "Vaisala's NLDN. U.S. National Lightning Detection Network," Ref. B210412EN-F, Tucson, Arizona, USA, 2011.

[80] M. J. Murphy, A. Nag, J. A. Cramer and A. E. Pifer, "Enhanced Cloud Lightning Performance of the U.S.

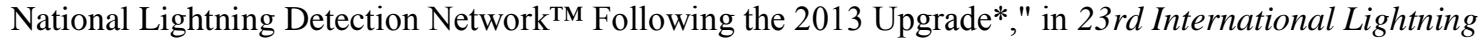
Detection Conference \& 5th International Lightning Meteorology Conference, Tucson, Arizona, USA, 2014.

[81] G. Diendorfer, H. Pichler and W. Schulz, "EUCLID Located Strokes to the Gaisberg Tower - Accuracy of Location and Its Assigned Confidence Ellipse," in 23rd International Lightning Detection Conference \& 5th International Lightning Meteorology Conference, Tuscon, Arizona, USA, March 2014.

[82] R. L. Holle, N. W. S. Demetriades and A. Nag, "Lightning Warnings with NLDN Cloud and Cloud-to-Ground Lightning Data," in 23rd International Lightning Detection Conference and 5th International Lightning Meteorology Conference, Tucson, Arizona, USA, 2014.

[83] A. Nag, M. J. Murphy, K. L. Cummins, A. E. Pifer and J. A. Cramer, "Upgrade of the U.S. National Lightning Detection Network in 2013," in XII International Symposium on Lightning Protection, Belo Horizonte, 2013.

[84] M. N. Sadiku, Elements of Electromagnetics, Philadelphia: Oxford University Press, 2014.

[85] J. L. Bermudez, F. Rachidi, M. Rubinstein, W. Janischewskyj, V. O. Shostak, D. Pavanello, J. S. Chang, A. M. Hussein, C. A. Nucci and M. Paolone, "Far-Field-Current Relationship Based on the TL Model for Lightning Return Strokes to Elevated Strike Objects," IEEE Transactions on Electromagnetic Compatibility, vol. 47, no. 1, pp. 146 - 159, 2005.

[86] M. S. Rahimian and A. M. Hussein, "ATP Modeling of Tall-Structure Lightning Current: Estimation of Return-Stroke Velocity Variation and Upward-Connecting Leader Length," IEEE Transactions on Electromagnetic Compatibility, vol. 57, no. 6, pp. 1576 - 1592, 2015.

[87] D. Malan, Physics of Lightning, London: The English Universities Press, 1963.

[88] N. Herodotou, Study of Peak Currents Due to Lightning in Ontario Using an LLP System, Toronto: M. A. Sc. Thesis, University of Toronto, ON, Canada, 1990.

[89] N. Herodotou, W. A. Chisholm and W. Janischewskyj, "Distribution of Lightning Peak Stroke Currents in Ontario Using an LLP System," IEEE Transactions on Power Delivery, vol. 8, no. 3, pp. 1331 - 1340, 1993.

[90] R. J. Thomas, P. R. Krehbiel, W. Rison, S. J. Junyady, W. P. Winn, T. Hamlin and J. Harlin, "Accuracy of the Lightning Mapping Array," Journal of Geophysical Research: Atmospheres, vol. 109, no. D14207, pp. 1 - 34, July 2004.

[91] D. Sills, H. Yang and P. Joe, "A Lightning Mapping Array in Southern Ontario, Canada, and Uses for Severe Weather Nowcasting," in 27th Conference on Severe Local Storms, Madison, Wiscosin, USA, 2014. 
[92] R. K. Said, M. B. Cohen and U. Inan, "Highly Intense Lightning over the Oceans: Estimated Peak Currents from Global GLD360 Observations," Journal of Geophysical Research: Atmospheres, vol. 118, no. 13, pp. 6905 - 6915, July 2013.

[93] S. Mallick, V. Rakov, T. Ngin, W. Gamerota, J. Pilkey, J. Hill, M. Uman, D. Jordan, A. Nag and R. Said, "Evaluation of GLD360 Performance Characteristics Using Rocket-and-Wire Triggered Lightning Data," Geophysical Research Letters, vol. 41, no. 10, pp. 3636 - 3642, May 2014.

[94] M. L. Hutchins, R. H. Holzworth, C. J. Rodger and J. B. Brundell, "Far-Field Power of Lightning Strokes as Measured by the World Wide Lightnig Location Network," Journal of Atmospheric and Oceanic Technology, vol. 29, no. 8, pp. 1102 - 1110, 2012.

[95] S. Mallick, V. Rakov, T. Ngin, W. Gamerota, J. Pilkey, J. Hill, M. Uman, D. Hordan, M. Hutchins and R. Holzworth, "Evaluation of the WWLLN performance characteristics using rocket-triggered lightning data," in International Conference on Grounding and Earthing (GROUND) \& 6th International Conference on Lightning Phyics and Effects, Manaus, Brazil, May 2014.

[96] S. Mallick, V. A. Rakov, J. D. Hill, T. Ngin, W. R. Gamerota, J. T. Pilkey, D. M. Jordan, M. A. Uman, S. Heckman, C. D. Sloop and C. Liu, "Performance characteristics of the ENTLN evaluated using rockettriggered lightning data," Electrical Power Systems Research, vol. 118, pp. 15 - 28, 2014.

[97] S. Mallick, V. A. Rakov, T. Ngin, W. R. Gamerota, J. T. Pilkey, J. D. Hill, M. A. Uman, D. M. Jordan, S. Heckman, C. D. Sloop and C. Liu, "An Update on Testing the Performance Characteristics of the ENTLN," in XV International Conference on Atmospheric Electricity, Norman, Oklahoma, USA, June 2014.

[98] X. M. Shao, P. R. Krehbiel, R. J. Thomas and W. Rison, "Radio Interferometric Observations of Cloud-toGround Lightning Phenomena in Florida," Journal of Geophysical Research: Atmospheres, vol. 100, no. D2, pp. 2749 - 2783, 1995.

[99] C. T. Rhodes, X. M. Shao, P. R. Krehbiel, R. J. Thomas and C. O. Hayenga, "Observation of Lightning Phenomena Using Radio Interferometry," Journal of Geophysical Research: Atmospheres, vol. 99, no. D6, pp. 13059 - 13082, 1994.

[100] X. M. Shao and P. R. Krehbiel, "The Spatial and Temporal Development of Intracloud Lightning," Journal of Geophysical Research: Atmospheres, vol. 101, no. D21, pp. 26641 - 26668, 1996.

[101] M. A. Uman, D. K. McLain and E. P. Krider, "The Electromagnetic Radiation from a Finite Antenna," American Journal of Physics, vol. 43, no. 1, pp. 33 - 38, 1975.

[102] R. E. Orville, "Calibration of a Magnetic Direction Finding Network Using Measured Triggered Lightning Return Stroke Peak Currents," Journal of Geophysical Research: Atmospheres, vol. 96, no. D9, pp. 17135 17142, September 1991.

[103] V. P. Idone, A. B. Saljoughy, R. W. Henderson, P. K. Moore and R. B. Pyle, "A Reexamination of the Peak Current Calibration of the National Lightning Detection Network," Journal of Geophysical Research: Atmospheres, vol. 98, no. D10, pp. 18323 - 18332, October 1993.

[104] J. A. Cramer, K. L. Cummins, A. Morris, R. Smith and T. R. Turner, "Recent Upgrades to the U.S. National Lightning Detection Network," in 18th International Lightning Detection Conference, Helsinki, Finland, 2004.

[105] V. A. Rakov, "Lightning Return Stroke Speed," Journal of Lightning Research, vol. 1, no. 1, pp. 80 - 89 , 2006.

[106] V. Rakov, A. Borghetti, C. Bouquegneau, W. Chisholm, V. Cooray, K. Cummins, G. Diendorfer, F. Heidler, A. Hussein, M. Ishii, C. Nucci, A. Piantini, O. P. Jr., X. Qie, F. Rachidi, M. Saba, T. Shindo, W. Schulz, R.Thottappillil and S. Visacro, "CIGRE Technical Brochure on Lightning Parameters for Engineering Applications," in XII International Symposium on Lightning Protection, Belo Horizonte, Brazil, 2013.

[107] F. Rachidi, J. L. Bermudez, M. Rubinstein and V. A. Rakov, "On the Estimation of Lightning Peak Currents from Measured Fields Using Lightning Location Systems," Journal of Electrostatics, vol. 60, no. 2 - 4, pp. $121-129,2004$. 
[108] G. Diendorfer and W. Schulz, "Critical Analyses of LLS Detected Very Large Peak Current Lightning Strokes," in 20th International Lightning Detection Conference \& 2nd International Lightning Meteorology Conference, Tucson, Arizona, USA, April 2008.

[109] W. Janischewskyj, V. Shostak, J. Barratt, A. M. Hussein, I. Russan and J. S. Chang, "Collection and Use of Lightning Return Stroke Parameters Taking into Account Characteristics of the Struck Object," in 23rd International Conference on Lightning Protection, Florence, Italy, 1996.

[110] D. Wang, Z. I. Kawasaki, K. Yamamoto, K. Matsuura, J.-S. Chang and W. Janischewskyj, "Luminous Propagation of Lightning Attachment to CN Tower," Journal of Geophysical Research: Atmospheres, vol. 100, no. D6, pp. 11661 - 11667, June 1995.

[111] D. Pavanello, F. Rachidi, W. Janischewskyj, M. Rubinstein, V. O. Shostak, C. A. Nucci, K. L. Cummins, A. M. Hussein and J.-S. Chang, "On the Current Peak Estimates Provided by Lightning Detection Networks for Lightning Return Strokes to Tall Towers," IEEE Transactions on Electromagnetic Compatibility, vol. 51, no. 3, pp. 453 - 458, 2009.

[112] G. Diendorfer, "EUCLID - Technical Structure and Performance of the European Wide Lightning Location System," in International Conference on Grounding and Earthing (GROUND) \& 3rd Brazilian Workshop on Atmospheric Electricity, Rio de Janeiro, Brazil, 2002.

[113] D. Flache, V. A. Rakov, F. Heidler, W. Zischank and R. Thottappillil, "Initial-Stage Pulses in Upward Lightning: Leader/Return Stroke Versus M-Component Mode of Charge Transfer to Ground," Geophysical Research Letters, vol. 35, no. 13, pp. L13812 (1 - 5), 2008.

[114] M. Rubinstein, "On the Determination of the Flash Detection Efficiency of Lightning Location Systems Given Their Stroke Detection Efficiency," in 11th International Zurich Symposium on Electromagnetic Compatibility, Zurich, Switzerland, 1995.

[115] R. L. Holle, N. W. S. Demetriades and A. Nag, "Lightning Warnings with NLDN Cloud and Cloud-to-Ground Lightning Data," in 32nd International Conference on Lightning Protection, Shanghai, China, 2014.

[116] W. Schulz and G. Diendorfer, "Detection Efficiency and Site Errors of Lightning Location Systems," in 14th International Lightning Detection Conference, Tucson, Arizona, USA, 1996.

[117] W. Schulz, R. Iorio, F. Hofbauer and A. Stimmer, "Correction of Lightning Density and Lightning Current Distribution of Detection Efficiency," in 23rd International Conference on Lightning Protection, Firenze, Italy, September 1996.

[118] D. Boccippio, W. Koshak, R. Blakeslee, K. Driscoll, D. Mach, D. Buechler, W. Boeck, H. Christian and S. Goodman, "The Optical Transient Detector (OTD): Instrument Characteristics and Cross-Sensor Validation," Journal of Atmospheric and Oceanic Technology, vol. 17, no. 4, pp. 441 - 458, 2000.

[119] M. J. Murphy, A. Nag, J.-Y. Lojou and R. K. Said, "Preliminary Analysis of the Vaisala TLS200 Network Deployed During the CHUVA Campaign," in Sixth Conference on the Meteorological Applications of Lightning Data. American Meteorological Society, Austin, Texas, USA, 2013.

[120] K. Cummins, D. Zhang, M. Quick, A. Garolera and J. Myers, "Performance of the U.S. NLDN during the Kansas Windfarm2012 and 2013 Field Programs," in 23rd International Lightning Detection Conference \& 5th International Lightning Meteorology Conference, Tuscon, Arizona, USA, 2014.

[121] H. D. Betz, K. Schmidt and W. P. Oettinger, "LINET - An International VLF/LF Lightning Detection Network in Europe," in Lightning: Principles, Instruments and Applications. Review of Modern Lightning Research, U. S. a. P. L. H. D. Betz, Ed., Dordrecht, Netherland, Springer, 2008, pp. Chapter 5 (115 - 140).

[122] E. Defer, J. P. Pinty, S. Coquillat, J. M. Martin, S. Prieur, S. Soula, E. Richard, W. Rison, P. Krehbiel, R. Thomas, D. Rodeheffer, C. Vergeiner, F. Malaterre, S. Pedeboy, W. Schulz, T. Farges, L.-J. Gallin, P. Ortéga, J. F. Ribaud, G.Anderson and e. al., "An Overview of the Lightning and Atmospheric Electricity Observations Collected in Southern France During the HYdrological Cycle in Mediterranean EXperiment (HyMeX), Special Observation Period 1," Atmospheric Measurment Techniques, vol. 8, no. 2, pp. 649 - 669, 2015.

[123] W. Schulz, K. Cummins, G. Diendorfer and M. Dorninger, "Cloud-to-Ground Lightning in Austria: A 10 Year Study Using Data from a Lightning Location System," Journal of Geophysical Research, vol. 110, no. 
D9, pp. D09101 (1 - 20), 2005.

[124] H. D. Betz, K. Schmidt, B. Fuchs, W. P. Oettinger and H. Holler, "Cloud Lightning: Detection and Utilization for total Lightning Measured in the VLF/LF Regime," Journal of Lightning Research, vol. 2, pp. 1 - 17, 2007.

[125] A. Sugita and M. Matsui, "The Frequency of Lightning Activity in Hokkaido as Observed by the JLDN from 2000 to the Present," in 23rd Internal Lightning Detection Conference \& 5th International Lightning Meteorology Conference, Tucson, Arizona, USA, 2014.

[126] O. Pinto Jr., I. R. C. A. Pinto and K. P. Naccarato, "Maximum Cloud-to-Ground Lightning Flash Densities Observed by Lightning Location Systems in the Tropical Region: A Review," Atmospheric Research, vol. 84, no. 3, pp. 189 - 200, 2007.

[127] O. Pinto Jr. and I. R. C. A. Pinto, "On the Sensitivity of Cloud-to-Ground Lightning Activity to Surface Air Temperature Changes at Different Timescales in Sao Paolo, Brazil," Journal of Geophysical Research, vol. 113, no. D20, pp. D20123 (1 - 9), 2008.

[128] K. P. Naccarato and O. Pinto Jr., "The Third Generation Relative Detection Efficiency Model for the Brazilian Lightning Detection Network (BRASILDAT)," in 20th International Lightning Detection Conference \& $2 n d$ International Lightning Meteorology Conference, Tuscon, Arizona, USA, 2008.

[129] T. Gill, "A Lightning Climatology of South Africa for the First Two Years of Operation of the South African Weather Service Lightning Detection Network: 2006 - 2007," in 20th International Lightning Detection Conference \& 2nd International Lightning Meteorlogy Conference, Tuscon, Arizona, USA, 2008.

[130] W. Schulz and S. Pedeboy, "Validation of the EUCLID LLS During HyMeX SOP1," in 23rd International Lightning Detection Conference \& 5th International Lightning Meteorology Conference, Tuscon, Arizona, USA, 2014.

[131] Vaisala Press, "Top Five Greatest Moments in National Lightning Detection Network® (NLDN) 30-Year History," http://www.vaisala.com/en/press/news/2013/Pages/Page_20130606112746.aspx, Helsinki, Finland, June 2013.

[132] M. A. Uman, The Art and Science of Lightning Protection, New York: Cambridge University Press, 2008.

[133] Vaisala, "Environment Canada's CLDN, Canadian Lightning Detection Network," Ref. B210413EN-B, Tuscon, Arizona, USA, 2011.

[134] A. Nag, S. Mallick, V. A. Rakov, J. S. Howard, C. J. Biagi, J. D. Hill and M. A. Uman, "Evaluation of U.S. National Lightning Detection Network Performance Characteristics Using Rocket-Triggered Lightning Data Acquired in 2004 - 2009," Journal of Geophysical Research, vol. 116, no. D2, pp. D02123 (1 - 8), 2011.

[135] K. L. Cummins, N. Honma, A. E. Pifer, T. Rogers and M. Tatsumi, "Improved Detection of Winter Lightning in the Tohoku Region of Japan using Vaisala's LS700x Technology," IEEJ Transactions on Power and Energy, vol. 132, no. 6, pp. 529 - 535, 2012.

[136] C. F. F. Karney, "Transverse Mercator with an accuracy of a few nanometers," Journal of Geodesy, vol. 85, no. 8, pp. 475-485, 2011. 